\title{
QUEER SPIRITUAL SPACES
}

This volume defines a compelling new agenda for queer scholarship, moving into the much neglected area of spiritual and religious experience. Its emphasis on crossing cultural borders, on addressing both mainstream religious institutions and seemingly marginal spiritual movements, and its insistence on establishing empirical foundations for future studies, all signal a meaningful shift in the field.

Ellen Lewin, University of Iowa, USA

A multivocal, multi-centred exploration of queer spirituality and place. Queer Spiritual Spaces makes a significant contribution to the field through its investigation of queer spiritualities outside of mainstream religions: Quakers, Muslims, Buddhists, feminist spiritualities, New Age communities, and even virtual spiritual realities all play a role in this important book. A must-read for students of contemporary religions, sexualities, and geographies.

Melissa M. Wilcox, Whitman College, USA 
This book is dedicated to

Donna, Mum and Dad

(Kath)

Dora, companion and familiar, 1990-2009

(Sally)

The boy from Greeba

(Andrew) 


\title{
Queer Spiritual Spaces
}

Sexuality and Sacred Places

\author{
KATH BROWNE \\ University of Brighton, UK \\ SALLY R. MUNT \\ University of Sussex, UK \\ ANDREW K.T. YIP \\ University of Nottingham, UK
}


First published 2010 by Ashgate Publishing

Published 2016 by Routledge

2 Park Square, Milton Park, Abingdon, Oxon OX14 4RN

711 Third Avenue, New York, NY 10017, USA

Routledge is an imprint of the Taylor \& Francis Group, an informa business

Copyright (C) 2010 Kath Browne, Sally R. Munt and Andrew K.T. Yip

Kath Browne, Sally R. Munt and Andrew K.T. Yip have asserted their rights under the Copyright, Designs and Patents Act, 1988, to be identified as the authors of this work.

The Open Access version of this book, available at www.taylorfrancis.com, has been made available under a Creative Commons Attribution-Non Commercial-No

Derivatives 4.0 license

Notice:

Product or corporate names may be trademarks or registered trademarks, and are used only for identification and explanation without intent to infringe.

\section{British Library Cataloguing in Publication Data}

Queer spiritual spaces : sexuality and sacred places.

1. Sexual minorities--Religious life--Great Britain.

2. Sexual minorities--Religious life--Canada. 3. Sexual minorities--Religious life--United States.

I. Munt, Sally. II. Browne, Kath. III. Yip, Andrew K. T., $1963-$

200.8'66-dc22

\section{Library of Congress Cataloging-in-Publication Data}

Browne, Kath.

Queer spiritual spaces : sexuality and sacred places / by Kath Browne, Sally R. Munt, and Andrew K.T. Yip.

$$
\text { p. cm. }
$$

Includes bibliographical references and index.

ISBN 978-0-7546-7527-3 (hbk.) 1. Homosexuality--

Religious aspects 2. Sexual minorities--Religious life. 3. Sexual minorities--Identity. 4. Spiritual life. I. Munt, Sally. II. Yip, Andrew K. T., 1963- III. Title.

BL65.H64B76 2009

204.086'64--dc22 


\section{Contents}

List of Figures

vii

List of Tables

ix

Notes on Contributors

$x i$

Acknowledgements

1 Queer Spiritual Spaces

Sally R. Munt

2 Coming Home from the Wilderness: An Overview of Recent Scholarly Research on LGBTQI Religiosity/Spirituality in the West

Andrew K.T. Yip

3 Quakers: Post-Christian Selfhoods within the Liberal Sphere Sally R. Munt

$4 \quad$ Looking for Allab: Spiritual Quests of Queer Muslims Andrew K.T. Yip with Amna Khalid

5 Queerness and Sangha: Exploring Buddhist Lives Andrew K.T. Yip with Sharon Smith

6 Dyke Spiritualities at Michigan Womyn's Music Festival Kath Browne

$7 \quad$ New Age Spiritualities: Findhorn and the Sexual Self Kath Browne with Elizabeth Dinnie

8 Virtual Believers: Queer Spiritual Practice Online Kate O'Riordan with Heather White

9 Queer Spiritual Spaces: Conclusion 


\section{QUEER SPIRITUAL SPACES}

Appendix

Bibliograpby

265

Index 


\section{List of Figures}

1.1 Sally discovers the sublime 4

1.2 Shrimp goby and shrimp 5

1.3 The pushmi-pullyu 24

1.4 'Limpid Pool' looks toward the University of Sussex

1.5 'Limpid Pool' standing outside of the Queer Spiritual Spaces Building, New Brighton, in Second Life 30

1.6 'Limpid Pool' with Bernard (site owner) and 'Only Messing' (Patrick) in the Queer Spiritual Spaces Building in Second Life (interior: on the third floor, the contemplation room)

3.1 'Thou shalt decide for yourself'. Quaker web page banner

3.2 Quaker Witness: Gathering together for Brighton Pride, August 2008

3.3 Outside the local Meeting House. Individuals carry banners and doves of peace, made especially by Quaker children

3.4 In front of Brighton Pier. Waiting in the pouring rain for the parade to start $\quad 71$

3.5 The Quaker Witness: Brighton Pride, August 2008

4.1 'Allab loves us all' 106

$\begin{array}{ll}\text { 5.1 SGI-UK's presence in Gay Pride } & 127\end{array}$

5.2 The Three Jewels 128

6.1 Scout following our interview 143

6.2 Tree altar at Michigan Womyn's Music Festival 149

6.3 Running order for the Shabbat on Friday night 160

7.1 The entrance of Findhorn Foundation 170

$\begin{array}{lll}7.2 & \text { Ecohousing at Findhorn } & 172\end{array}$

7.3 Map of the park outside the Phoenix shop 173 


\section{QUEER SPIRITUAL SPACES}

8.1 The Mediation Room in the Queer Spiritual Spaces Meeting House in Second Life

8.2 Second Life research interview

8.3 Second Life image of Jubilant 


\section{List of Tables}

1.1 Visits to www.queerspiritualspaces.com over 12 months (May 2008-April 2009)

\section{Appendix}

A.1 Chapter 3: Quakers

A.2 Chapter 4: Queer Muslim

A.3 Chapter 5: Queer Buddhists

A.4 Chapter 6: Michigan Womyn's Music Festival

256

A.5 Chapter 7: Findhorn

260

A.6 Chapter 8: Queer Spiritual Seekers 



\section{Notes on Contributors}

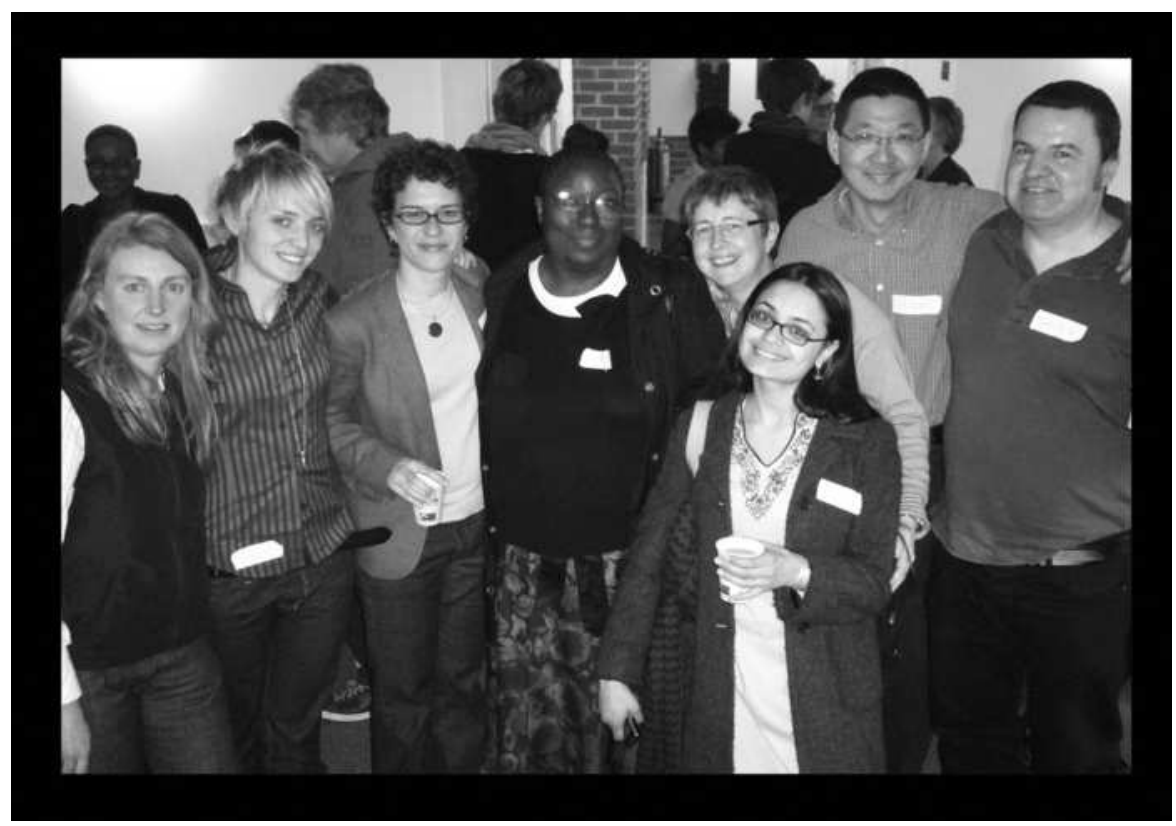

\section{Contributors group photo}

From left: Elizabeth, Kath, Heather, Sharon, Sally, Amna, Andrew, Patrick.

Kath Browne is a senior lecturer in the School of Environment at the University of Brighton. In 2007 Kath was awarded the coveted Gill Memorial Award from the Royal Geographical Society/Institute of British Geographers recognising young researchers who have shown great potential. Prior to this research, she used British Academy funding to explore the 31st Michigan Womyn's Music Festival as an example of contemporary womyn's separatist space. Kath coedited the key text, Geographies of Sexualities: Theory, Practices and Politics (Ashgate, 2007), and has written over 40 publications across a range of disciplines using diverse formats.

Elizabeth Dinnie was awarded her PhD from the University of Aberdeen in 2008 for her ethnographic study of the Findhorn community, one of Europe's oldest and most well known intentional communities. Her thesis investigated 
the relationship between individualistic beliefs and creating a shared way of life. Her research interests are in the sociology of religion and spirituality, and alternative ways of life with a particular focus on the role of individualism and authority as they affect social order. She is also interested in how beliefs affect attitudes towards issues such as identity, sexuality and the environment.

Patrick James was a Research Assistant for the Queer Spiritual Spaces project. $\mathrm{He}$ created and managed the project's digital media components. To date, he has never actually worked in digital media professionally, but rather he has a fascination for all things Internet. In fact Patrick's background is in production for television and radio. He was born in Belfast in Ireland and one of his early projects was a documentary on the history of the LGBT community in Northern Ireland for BBC Radio Ulster; he has always liked its name - Queer and Here. Patrick now lives in Hove on the south coast of England.

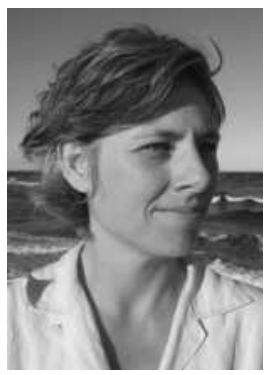

Olu Jenzen teaches English Literature and Cultural Studies at the University of Sussex where she completed her $\mathrm{PhD}$ thesis in 2009 on the literary fantastic and dissident sexuality and gender in the works of Jeanette Winterson. She organised the 'Queer Spiritualities' conference, and functioned as research assistant on the Queer Spiritual Spaces project.

Amna Khalid completed her DPhil in History of Medicine at the University of Oxford in 2009. She is now a Senior Lecturer in South Asian History at the University of Cape Town, South Africa. Her research interests lie at the intersection of South Asian history, the history of medicine and British colonial history in nineteenth and early twentieth centuries. She is particularly interested in studying sacred spaces as foci of epidemics and sites of worship and healing. She is currently developing her own research project on Sufi shrines in India, Pakistan and South Africa to explore their link with health and healing.

Sally R. Munt is Professor and Director of the Sussex Centre for Cultural Studies. She has written widely on culture, class, sexuality and space, and most recently on shame, in Queer Attachments: The Cultural Politics of Shame (Ashgate, 2007), in which she discusses the transformative quality, and even spiritual potential, of shame. Sally recently returned to her Mother's tradition of Unitarian Universalism, finding within their open and creedless spiritual inquiry a sacred space; since 2007 she has trained as a PADI Rescue Diver and a Cognitive Behavioural Therapist. Sally finds unpredictable connections between estranged species particularly enchanting. 


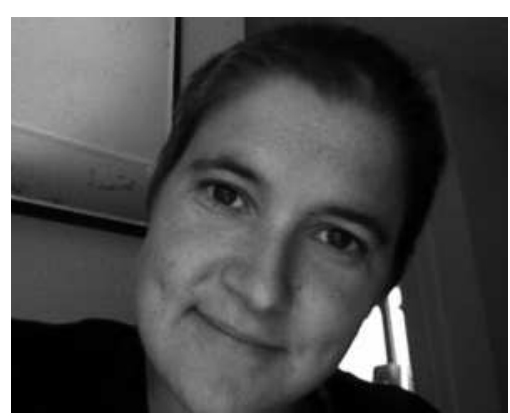

Kate O'Riordan is a senior lecturer in Media at the University of Sussex, codirector of the Centre for Material Digital Culture, and an affiliate of the Centre for the Economic and Social Aspects of Genomics (CESAGen) at Lancaster University. Her work is a cultural studies of science and technology. Publications include Queer Online: Media Technology and Sexuality (Peter Lang, 2007), Human Cloning and the Media: From Science Fiction to Science Practice (Routledge, 2008).

Sharon Smith is a sociologist of religion whose interests are in the ways religious/spiritual spaces and identities are taken up and further inscribed by other axes of 'difference' (particularly 'race', class, gender and sexuality), and in notions of diversity held by faith communities/practitioners of spiritualities. Her PhD from Goldsmiths, University of London, was a feminist ethnographic study of Western convert Buddhist movements and their interactions with those minoritised due to being people of colour and/or working class. For the Queer Spiritual Spaces project she researched LGBTQI Buddhists in London.

Heather White is a Visiting Assistant Professor of Religion at the New College of Florida. She received her $\mathrm{PhD}$ in Religion from Princeton University. She is an historian of American religions by training, and has overlapping interests in gender, sexuality, and LGBT studies. Her current book project, titled American Churches and the Rise of Gay Rights, examines Christians' involvements on various sides of the emerging gay rights politics in the US from the postwar era to the 1980s.

Andrew Kam-Tuck Yip is Associate Professor and Reader in Sociology at the University of Nottingham. He has published extensively in the areas of LGB Christian and Muslim identities and relationships. His writings have appeared in journals such as British Journal of Sociology, Sociology of Religion, Theology and Sexuality, Sexualities, and Contemporary Islam. He is the author of Gay Male Christian Couples: Life Stories (Praeger, 1997) and co-author of Lesbian and Gay Lives Over 50 (York House Publishing, 2003). He is currently involved in two research projects; Citizens in Diversity: A Four-nation Study on Homophobia and Fundamental Rights and Religion, Youth, and Sexuality: A Multi-faith Exploration (www.nottingham.ac.uk/ sociology/rys). 



\section{Acknowledgements}

Grateful thanks are due to: those who gave their time, thoughts and tears by participating in this research, making it possible, including: Quakers - Becky, Berta, Dominic, Jamie Crofts, Gerry, Harvey, Kaki, Kristin, Nancy, Nancy, O, Sarah, Susan, Rachel; Muslim - Adnan, Al, Aly, Anjam, Ashir, Asif, Ratih, Haleh, Suhail, Fazal, El-Farouk, Asif, Muzzam, Juned, Hany, Ibrahim, Rashida; Buddhist-Ajamu, Akasavajri, Anthony, Dharma, Det, Du, Ella, Jayamitra, Jo, Karunamati, Kieran, Mia, Phillip, Subha, Rebecca; Findhorn - Camilla, Dewi, Holly, Jason, Karen, Lianne, Massimiliano; Michigan Womyn's Music Festival - Amber, Amy, Alethea, April, Ashley, Bonnie, Chelsea, Ellen, Elizabeth, Jeanne, Lisa, Marcy, Mary, Musawa, Patty, Roddy, Sally, Shari, Scout, Yvette; Spiritual Seekers Online: Christopher, Jubilant, Mary-Anne, Rusty, Rivka, Simon Mark, Zander.

The authors want to thank the postdoctoral fellows Drs Elizabeth Dinnie, Amna Khalid, Sharon Smith and Heather White; and to Kate O'Riordan, Patrick James and Olu Jenzen, of the University of Sussex, without all of whom this book would not be possible.

Significant thanks are also due to university administrators Peta Ainsworth and Paul Grant, programme staff at the Arts and Humanities Research Council UK, and many others: Ahavia, Jenny Alexander, Gavin Brown, Harvey Gilman, Rev. Jeffrey Lane Gould, Trevor Jones, Professor Linda Woodhead, Bernard from Second Life, the University of Sussex Department of Media and Film for sabbatical leave, the School of Environment and Technology at the University of Brighton for financial support for the Michigan Womyn's Music Festival Case Study, the Arts and Humanities Research Council and the Economic and Social Research Council Religion and Society Programme for the funding for the primary research, which was also enhanced by the generous support of the Universities of Brighton, Nottingham and Sussex, the home institutions of the co-investigating team.

Thanks to Linden Labs for permission to reproduce images from Second Life. Second Life is a trademark of Linden Research Inc. Certain materials have been reproduced with the permission of Linden Research Inc.

Thank you to Hal Everett for reproduction of the photograph of the shrimp goby, taken in Raja Ampat, Indonesia.

Grateful thanks to Clara Teresa Montoya, artist, for reproduction of her painting of the 'Rainbow Tree', and to her partner Gary Button for arranging 


\section{QUEER SPIRITUAL SPACES}

a copy of this painting to be made for the book, and for their generosity of spirit in support of the project. We are also grateful for the help of Sarah Norman and Sharon Smith, who assisted us in our efforts to locate the owner of Figure 5.1. 


\title{
Chapter 1 \\ Queer Spiritual Spaces
}

\author{
Sally R. Munt
}

\section{Introduction}

Where are queer spiritual spaces and what happens in them? This book doesn't provide a definitive answer to that question - so, reader, if you are an aspiring logical positivist, put it down now before you get disappointed or enraged. ${ }^{1}$ Our book is the culmination and review of a research project conducted during 2008-2009, which involved a group of academics talking to about 150 Lesbian, Gay, Bisexual, Trans, Queer and Intersex [LGBTQ1] ${ }^{2}$ peoples involved in several religious/spiritual traditions. The institutional and non-institutional case studies chosen were, namely: the predominantly Christian Quakers, Muslims, and Buddhists, together with those 'non-aligned' more place-based faith activities: the New Age community at Findhorn in Scotland, spirituality at the Michigan Womyn's Music Festival in the US and the 'spiritually curious online' on the (global) Internet. The following chapters are arranged in this order. Our intention in the project was to 'go fishing' - to ask open questions, to see what we could find, and to be as curious and receptive as possible to what our participants said.

What brought us to thinking about queer spiritual spaces? All of the researchers on this project have their own narratives to tell. Because the field

1 Logical positivism is a philosophical approach based on empirical, rational principles that rely upon scientific, observational methods.

2 We use the acronym LGBTQI to represent lesbian, gay, bisexual, trans and intersex people, however we also understand that these are contingent, overlapping and interrelated categories. LGBTQI is used here as an overarching category, recognising that this is flawed but expedient for our purposes of discussing gender and sexual differences and how they have been addressed in relation to the literature on religion/spirituality. We recognise and explore diversity between this category throughout the chapters, but also note how commonality and collectivity under banners such as 'gay and lesbian', LGBT and LGBTQI can be used to create belonging, agitate around inequities, and be used to find safe, welcoming spiritual spaces. We do not, in the main, use 'queer' much as an overarching category for two reasons: firstly those in our research largely tended to problematise or reject this label, and secondly, as the conclusion explores, we seek to question the academic baggage associated with this term (although also see Chapter 8 for an alternative view). 
was so vast (and relatively unexplored by academics, see Chapter 2), I likened the project to a giant jellyfish, which are by nature what biologists call 'bloomy'. So the direction of the project took a spidergraph form, dictated in part by the personal histories of the researchers, who each brought their own distinctive familiarity to a chosen case study. Most of our team was personally involved in one way or another with the spiritualities and spiritual spaces they researched, although this connection varied in intensity from individual to individual. We hoped that we could bring our comparative knowledge and insight together, so enriching our collective effort. We were committed to diversity in its many shapes, in approach, content, and selection. Queer spiritual spaces are emergent; we were asking, what is the role of this space/these spaces in contemporary religious and spiritual cultures, as both 'knowledge and action' (Lefebvre 1994 [1974])? We were exploring spaces as dynamic, produced, contested and temporal. Our team was informed by geographies, and I am particularly interested in spatial theory expanded over the past thirty years, but pioneered by French Marxist philosopher Henri Lefebvre. Spatial theory has now developed with an interdisciplinary richness too broad to specify, but coalescing fruitfully within the sub-discipline of Cultural Geography. This field has been closely allied with social geographies and, therefore is sensitive to the complex intersectionality that infuses social categories such as race/ethnicity, sexuality, gender, class, age and so on. ${ }^{3}$ Social sensitivities informed by social and cultural geographies were hugely useful to us as we sought to build in ethical approaches to our understanding of queer spiritual spaces. Within this system of thought, space is seen less as a blank to be filled, and more as constituted through the elements within it emerging according to what occurs. Hence, spaces are political, multi-faceted and continually being re-created. How does the presence of LGBTQI people and communities re-work the meaning of iconic religious/spiritual spaces, and how are LGBTQI people in turn affected by their attendance in a sacred venue? Much use of the concept of performativity (Austin 1962, Butler 1997) has been made, drawing on the idea that space can 'perform us' as social actors, and that space in turn will modify or transform due to these enactments. ${ }^{4}$

3 Intersectionality is the exploration of how different social categories such as sexuality, gender and ethnicity, operate together to produce inequalities within society, functioning systematically in order to ensure multiple forms of discrimination, within a 'matrix' of oppression. Intersectionalities, although structural entities within societies, result in producing separate, discrete subjectivities, thus individuals find themselves enmired by a host of troubles and need complex strategies to 'escape'. The work of Black Feminist cultural critic Patricia Hill Collins $(2000,2007)$ is useful here.

4 See Austin (1962), Butler (1997) for uses of the performative. See Gregson and Rose (2000) for a discussion of the performative constitution of space. 


\section{Queer underwater}

Queer peoples - which can encompass those who identify as Lesbian, Gay, Bisexual, Transgendered, Intersex, or 'other' - each have a personal narrative that can emphasise a trajectory of realisation and acceptance concerning their sexual/gender identities. ${ }^{5}$ Coming out stories were a staple of Anglo-American Lesbian and Gay Literature in the 1970s-1990s, and the 'coming out story' remains an enduring trope of queer existence into the twenty-first century. Selfnarratives are intrinsic to late modernity, evidenced by the 'biographical turn', but have been particularly prevalent in the subcultures of sexual and gender difference. They can be less concerned with myths of origins (What made me gay') than critical autobiographies or reflexive accounts reliant on epistemologies ('How I learned to live a lesbian life'). For example, (it's all about me!): although baptised as a Unitarian Universalist, I grew up in a predominantly socialist and atheistic family. I eagerly converted to Evangelical Christianity aged 13, joined a religious community aged 19 , became influenced by Liberation Theology there, and got chucked out aged 22 for having a same-sex relationship. I then spent many years adopting the religious cult of Lesbian Feminism, only to hit upon in my forties a smidgen of disenchantment with sexual identity politics and activisms, needing an ineffable 'more'. As I now approach my fifties I've been returning to my Unitarian 'roots', but I have encountered the queer sublime most utterly by going underwater.

On my 47th birthday I tried scuba diving (Figure 1.1); it was astonishing. A coral reef is a stupendous example of the unfathomable Other, not least because in many places of the world 'air-side' is a barren desert, often suggesting no clue to the cacophony and visual opulence of the sea-life lurking below. At the risk of 'going Cousteau' on you, I would like to draw your attention to the incredible, weird and wonderful ecologies of ocean animals. We have much to learn about natural diversity, here is one example: young reef fish can choose when they mature and which sex they want to be when they grow up. Most reef fish change sex within their individual life cycle, indeed, fish that remain as the same sex for their life span (gonochoristic) are in the minority. J.P. Hobbs notes:

We already know that lots of adult fish change sex. Now we've discovered that juvenile fish also possess this flexible sexual development. With juvenile coral gobies this flexible sexual development is influenced by social conditions. (cited in Byrne 2003)

5 Of course we recognise that we are working in a particular cultural context in which these labels and identities are made meaningful and associated with specific practices. We also note that queer is not necessarily related to LGBTI and vice versa, this will become apparent throughout the text. 


\section{QUEER SPIRITUAL SPACES}

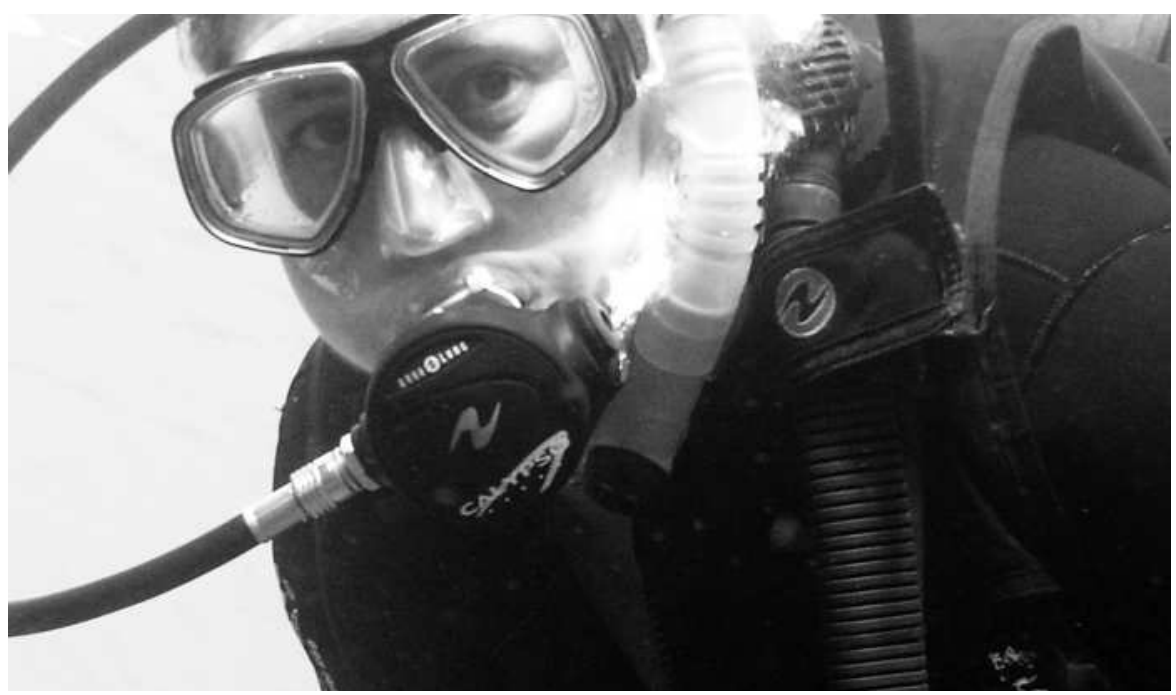

Figure 1.1 Sally discovers the sublime

J.P. Hobbs found that juveniles only mature when they meet an adult fish. If they meet a male fish they mature as females and vice versa,

It all relates back to a coral goby's lifestyle, the big adult gobies muscle their way into the larger corals where they form a breeding pair. Juveniles are not allowed to live with the adults and are forced to live by themselves in corals too small to support a breeding pair. Here they eagerly await the disappearance of an adult so that they can enter the larger coral and pair up with the remaining adult. With all the larger corals occupied by breeding pairs, there are very few opportunities for a juvenile to 'get lucky'. So it makes sense for a juvenile to delay maturing until it finds a partner and then to mature into the opposite sex of the newfound adult. We suspect this flexibility in juvenile sexual development also happens in many other reef fish. (cited in Byrne 2003)

In discovering scuba diving, I have belatedly become an anorak, a hobbyist, an amateur marine biologist, an enthusiast, a fan, and therefore (no doubt) every so often, a bore. On each short trip to the Red Sea I return with typically over 600 underwater photos - yes I'm a submerged voyeur, and no doubt a pain to my longsuffering friends. But immersion into someone else's world allows an encounter with the deeply strange, the spaces you drift into are unaccountably aberrant to human notions of organisation, they are deviant, eccentric, peculiar, odd and inevitably queer (Giffney and Hird 2008). Take the shrimp goby for example (see Figure 1.2): the shrimp goby is a species of fish that sets up monogamous domestic relationships with shrimps (prawns). 


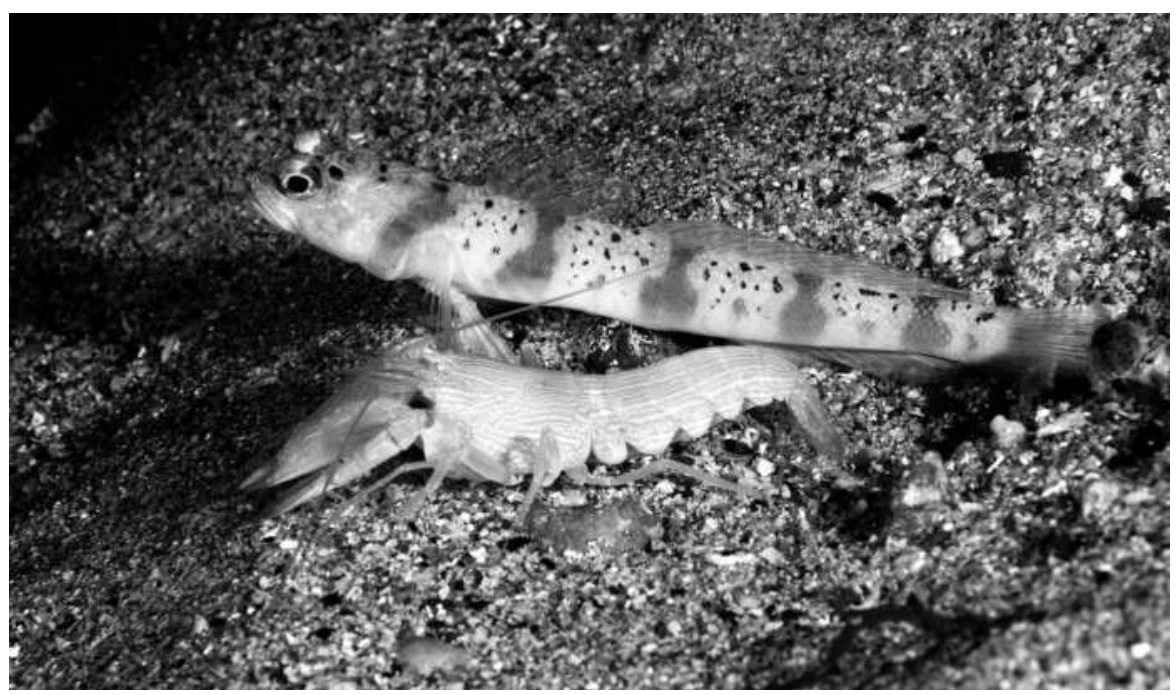

\section{Figure 1.2 Shrimp goby and shrimp}

Marine researcher Rob Nelson states 'there is a strong attraction for both shrimp and goby to their particular partner' (Nelson 2004). ${ }^{6}$ Lynn Moehring observed that there is a complex warning communication between the two animals, enacted via touch. The goby is essentially the 'guardian of the hole' as the shrimp has very limited visual abilities. Because of this, the shrimp while resting or digging outside the burrow, always holds one antennae on the goby. If the goby sees a potential threat, it will give a slight tail flick to warn the shrimp who consequently darts safely into the hole. If the danger approaches further, the goby will shoot into the hole and enter the burrow too (Moehring 1972 cited in Nelson 2004).

Other fishy tales include Philip Munday's, who explains that 'Tblue head wrasse] are very sensitive to their social surroundings, which ultimately determine whether they will become male or female. It turns out that social effects are really important [as] to whether a blue head wrasse becomes a male or a female when it is young. This shows that sex is not genetically predetermined' (quoted in Cox 2008). Ashley Cox explains how in species such as parrot fish and wrasses, the sexual change is also accompanied by altered colouration. Species in which this occurs are classified by the term 'dichromatic'. Other factors leading to sex change include chemical pollution in the waters. Cox continues:

6 For further fascinating insights on the queer life of the shrimp goby, see http://www. explorebiodiversity.com/Hawaii/Shrimp-goby/general/index.htm. 
The ability to change gender has been an incredible survival tool for many fishes. When the only sexed fish in the community dies off, another can take his or her place easily. This is very beneficial for species of fish that live in pairs. When one dies, the other does not have to risk leaving the security of the reef and travel in open waters to find a mate, but only has to wait for another fish of the species to come along. If they are the same sex, one will change gender, and they will continue their lives as a pair. (Cox 2008)

There are many different patterns for sex-change. Some species will begin life as males and switch to females (protandry), and others switch from female to male (protogyny). Further still, some will change sex in both directions, and others will be both sexes at the same time (see Rice 1999). In the film Finding Nemo (2003) the clownfish protagonist appears as a boy, but his character could logically become Nema, and most of his friends could change sex too. (This movie is also a gay shark coming out story, but I digress further.) Knowing these fantastic facts about fish enhances my dive, but the sheer exhilaration of experiencing the totality of underwater immersion - the 'deep blue' takes me into a spiritual place, for me a very queer spiritual space.

\section{The sodomitical sublime}

In the eighteenth century the spiritual was developed through the concept of the sublime. What Edmund Burke described as the 'sublime' in A Philosophical Inquiry into the Origin of Our Ideas of the Sublime and Beautiful (2005 [1756]), is the unrecognisable, for it 'goes beyond' perception. ${ }^{7}$ The imagination is moved to awe and instilled even with some degree of horror by what is 'dark, uncertain, and confused'. The sublime inspires anxious pleasure; the sublime has the capacity to instil feelings of intense emotion hence in diving this can descend suddenly as a panic, a momentary confusion of the elements because one's environment is just too strange to be borne. In his Critique of Judgment (1987[1790]), Immanuel Kant also investigated the sublime, stating that 'we call that sublime which is absolutely great', distinguishing between the 'remarkable differences' of the Beautiful and the Sublime, noting that beauty 'is connected with the form of the object', having 'boundaries', while the sublime 'is to be found in a formless object', represented by a 'boundlessness' - a concept that resonates with the sensation of hovering motionless at 100 feet deep, held still by the breath, unable to see the surface of the sea, only the endlessly varying

7 In my previous book Queer Attachments (2007) I introduced the idea of the sodomitical sublime. 
blue, knowing that the body itself is 60 percent water. ${ }^{8}$ Kant considers the Sublime 'indefinite', one's inability to grasp the enormity of a sublime event reveals the inadequacy of one's rational perception, moving one into the realm of the uncanny.

For Jean-François Lyotard (1994), the sublime's significance is located in the way it points to an aporia in human reason; it expresses a puzzle or an impasse, bringing us to the periphery of our conceptual powers. Lodged in the experience of the sublime is a consciousness that provokes a crisis in representation, but crucially we have some sense of it, we know there is something more to be sought. For me, this is always present in a dive, the compelling urge to swim off into the deeper ocean, into the disappearing miasma of marine. For Lyotard in Lessons on the Analytic of the Sublime this is ethical, what one witnesses in the sublime is the differend - the straining of the mind at the edges of itself. This is the most accurate description of scuba diving, and even surface snorkelling can provide this peripheral 'aerial' glimpse of the incomprehensible, the perplexingly beautiful, the perception of space unreliable and distorted by refraction. The sea can make the scuba diver go mad, such is its otherness, stealthily filling one's blood with nitrogen, dizzying the consciousness and fooling us into believing we can breathe. 'Narked' divers frequently pull off their regulator and mask, deluded that they can blend into the sea. When this happens to a diver (as it did to me), its most unerring feeling is how utterly right this merging feels: taking yourself into the beyond, letting go, becoming one - these moments are experienced as spiritual, contemplative, as reaching in entirety for something compelling, somewhere distinctly 'else', but uncannily, home.

So, a queer spiritual space, for me, is a scuba dive. All the rigorous preparatory rituals are important too (squeezing into a neoprene costume, priming, cleaning and double checking equipment, bonding with one's diving buddy, putting one's faith blindly into the instructor or dive master to keep us safe). Am I being unethically anthropomorphic about the sea here? - Probably. Perhaps I have just got wealthy and this mere consumerist exercise to enrich my 'self' through expensive leisure activities masquerades as culturally meaningful. For you, it could be golf, or gardening, or drugs. Certainly Maslow's Hierarchy of Needs (1943) could suggest that acquiring a spiritual life through self-actualisation comes well after survival issues, and scuba is indeed expensive. You decide.

Our respondents were also asked 'where' they would find a queer spiritual space. Their answers varied, with some citing everywhere as sacred (see Chapters $4,7,8$ ), although frequently they also described sacred buildings and places as a spiritual space, going on to describe and explain how they could be temporarily 'queered' (see, for example, Chapters 3, 7). But their answers

8 Sixty percent is the average/mean for a lean adult male. Actually between 45 percent and 75 percent of the human body is water, depending on how much fat the body is carrying. 
did vary from the 'natural', such as storms, mountains, specific trees, stones or woods, to cultural practices such as going on public transport (bus journeys), dancing at nightclubs, being in the audience at musical gigs, singing, cooking and so on, to participating in political events such as Pride and having sex. There is lots more detail in what follows, however I want to suggest that there is a way of conceptualising queer spiritual spaces as the sodomitical sublime (Munt 2007). Sodomitical here is referring to more than just anal sex, as it has come to mean in the modern world; it is a bigger category of transgressive, non-normative behaviour, it is the sense of the strange, the different, a certain type of transportation past conventional categories. The sodomitical sublime is a symbol of diffuse desires, mysterious delight and inchoate feelings, with a potential for uncanniness, and a counter-normative capacity to transgress and subvert. Historically, 'sodomy' was a crime that could not be fully defined, but that was associated with foreigners, strangers, with treason and corruption, as a crime: 'sodomy was less about desiring men than about desiring everything', 'like a quark, sodomy was known primarily by its effusions' (Herrup 1999: 33, 37). The sodomitical sublime could be described as a realm of potential enjambment for conflicting desires. This concept may help some, but not others, to express what is meant by a 'queer spiritual space', but I raise it here as one propositional model for embracing what follows in our case studies.

\section{Unleashing terms such as religion, spirituality, secularism and the self}

Thrashing about between these exceptionally complex concepts, we had to start somewhere: spirituality can be associated with a movement, a journey, or even a pilgrimage. Spirituality, like the current approaches to understanding space, is seen as dynamic and interactive, often perceived as an ultimate entity venerated by a 'seeker', but also as organic, as a substance that one can grow. The idea of a soul is associated with spirituality, this is at one and the same time conceived as a core essence and an internal property (all humans 'have' one, and plausibly non-human animals do too), and a potential matter, because it can change, go on a 'journey' and in Christianity, even be 'won'. Already we have entered the uncertain, the contradictory, the speculative and maybe even the supernatural. We cannot provide anything but belief and conjecture in these matters, as they are profoundly cultural. All human societies have a role for this spiritual 'stuff', yet can remain stubbornly differentiated in specifically how it is interpreted, organised and deployed as religion, varying what place it occupies in the principal worldview of any particular civilisation. Spirituality, like religious belief, seems to be a property that can be acquired, and perhaps that it is inevitable within Western capitalist economies, but as to agreement on a definition of the spiritual, and an agreed designation for what it is for, we 
are at a loss. Critical analysis breaks down at this point: we do not know, and perchance we cannot know, except to put side by side all views from the cynical - following Marx's comments on religion as the 'opiate of the people', and 'the heart of a heartless world', to the celebratory or proselytising. Are we dangling ignorantly in the realm of the magical, the enchanting, the transcendent, the numinous and irrational? Or are we scientifically assessing the ideology of morality, the materiality of belief, the susceptibility of the masses to myth, superstition and manipulation? As the Ancient Greek philosopher and critic Xenophanes famously commented:

Men make gods in their own image; those of the Ethiopians are black and snubnosed, those of the Thracians have blue eyes and red hair.

In relation to current trends toward religious disbelief, atheism and secularism, there has been a flood of popular sceptical treatises of late such as The God Delusion (Dawkins 2006), The End of Faith (Harris 2004) and God is not Great: How Religion Poisons Everything (Hitchens 2007) - all bestsellers. Religion, understood sociologically, usually operating through the prism of theism or approved deities, proscribes morality and a way of life, imposes cultural norms and traditions and even ethnic identity. Religion is habitually understood as the outward, organised expression of an inner spirituality, but it can also be read as opposed to spirituality and criticised for being obdurate, institutionalised and chiefly archived in ritual customs preserved inside archaic, designated and patriarchal sacred spaces.

'Post-Christian' describes contemporary cultural attitudes, personal worldviews, ideologies, religious movements or societies that are no longer rooted in the language and assumptions of Christianity, though previously suffused by an environment of ubiquitous Western Christianity. A post-Christian worldview is one in which Christianity is no longer the dominant civil religion, but one that has gradually included varieties of schema from secular and non-Western beliefs. Since the nineteenth century, Western countries generally have largely become societies no longer willing to profess submission to a transcendent, monotheistically-conceived deity. Following on from Friedrich Nietzsche, in his landmark treatise The Death of God (1961), the French theologian Gabriel Vahanian argued that modern secular culture in most of Western civilisation had lost all sense of the sacred, and lacked any sacramental meaning. He was disdainful, citing that religion now lacked any transcendental purpose, bringing him to the totemic conclusion that for the modern mind, 'God is dead'. It encapsulated a growing trend in modern societies away from an obligatory nominally Christian past and toward a social arrangement increasingly based foundationally upon 'the self', privileging individualism and a proliferating diversity of elective spiritualities that are invested in the idea of fashioning and developing individual consciousness, or a personal 'inner journey'. The 
diminishing master-narrative of a 'Godly life', planned out for you by a higher power and mediated by His representatives, has been steadily supplanted by narratives of self-discovery achieved via private, intimate revelation. Religion has thus largely moved from the public sphere to the private sphere, inauguring the privileging of individual discernment constructed through principles of the sovereign self.

Religion we can approach sociologically as a highly coded linguistic discourse; spirituality, the metaphysical and intuitive, is rather more difficult to assess. Perhaps we have to follow the leading principle of the Supreme Court Justice Potter Stewart who declared in 1973 that there was no adequate definition of pornography, only that he knew it when he saw it? Consider what spirituality means to people: how they carry out religious practice, and what they wish for in so doing. These are sociological and cultural questions and appropriate for our enquiry. In the twentieth century in the West the growing secularisation of Modernity following the Great Wars, and the large scale economic, cultural and social changes leading to a supposedly Postmodern era, has heralded a period in which many or even most people's affiliation to religion is nominal at best. Spiritual seekers and religious affiliates may not be the same at all, indeed the former may eschew the latter, considering religion to be dogmatic, rigid, oppressive, amoral, inauthentic, exploitative and even corrupt. A shift toward spirituality has coincided with a huge cultural impetus toward the belief in a mutable self, a 'cult of personality' that has had implications for us all. Through taking a spiritual path we are expectant in finding the 'truth' in our 'deeper' self, and by extension the wider humanity, in anticipation, to connect to a vaguely pantheistic cosmos.

For an extremely clear, short evaluation of the 'turn to the self' see Heelas et al.'s (2004) 'subjectivization thesis'. Latterly, this 'turn to the self' has been widely cited by contemporary social evaluators of all colours, becoming somewhat of a cliché or even insult. The concept is frequently deployed with a kind of rhetorical flourish of Gallic shrugness ('what can we do?' 'it's distasteful but inevitable'). We note though, that critical disapproval toward this greedy self is often nostalgic for a less 'selfish', more decent, just and collective era. ${ }^{9}$ Certainly, aspirations toward the acquisition of dispositions such as self-knowledge, selfawareness, self-worth, self-authority are seen as key to self-actualisation - and even the rather baleful, capitalistic archetype of 'self-ownership' - is seen as a moral and right precept for sovereign individuals to pursue. It is easy to take swipes at this vaunted 'era of selfishness'; academics are paid to appraise social norms, but professional values can on occasion be tempted to slip to into a

9 See the work of sociologist Anthony Giddens on self-reflexivity. Also useful is Skeggs (2004). A philosophical overview is provided by Taylor (1991: 26) who describes the 'massive subjective turn of modern culture'. 
humanly satisfying, general begrudgery. Academics are not detached from the society they critique. This 'turn to the self' in spiritual settings could be read as a mixed blessing, or like the curate's egg - good in parts. Suspicion toward the turn to the self is enmeshed within dominant rationalist, structuralist models of thought that are also predominantly adverse toward what has been dubbed 'the affective turn', of which religion and spirituality are associated (but not limited to). Twisting, turning: the critical sphere fashions only a small part of the cultural fabric and is not in any sense 'above' it.

Despite the decline of state Christianity in the West, there is much advocacy for a supposedly more progressive 'Post-Christian' era. Academics like David Tacey (2004), have argued for a comparable upsurge in new forms of spirituality that will replace the Abrahamic faiths that characteristically revive pantheistic, pre-Christian customs, and prioritise aspirational, individual wellbeing. Recently, sociologists of religion have been concentrating on this New Age, or 'spiritualities of life', as Heelas et al. described them (2004). These spiritualities tend to see 'life' not as to be endured until the glory of hereafter, but as a profound present energy to be celebrated and explored, and not limited to human experiences alone. Heelas, in his fascinating book Spiritualities of Life: New Age Romanticism and Consumptive Capitalism (2008), has drawn attention to the roots of New Age spiritualities within Romanticism, a view I share. He argues that:

At heart we are all the same. At the same time spiritualities of life emphasize the value of the unique ... The more experiences one has, not least those through relationships, the more unique one becomes ... The spirituality 'itself' might be universal. But since it 'flows' through the specific life-experiences of each person, it comes to be experienced as one's 'own' spirituality; a spirituality of singularity. (2008: 38 his emphasis)

He goes on to describe the collective vision of this enterprise:

... for the Romantics, 'Love ... expresses the confraternity of the one life shared not only with other men but also with a milieu in which man can fully feel at home'. (Abrams 1973: 431 quoted in Heelas 2008: 42)

This endeavour finds a 'place' for the self amongst the company of others. The attempt is a sort of life-work - rather ironically that is quite reminiscent of Foucault's aesthetics of the self - that fashions harmony inside diversity, within the here and now: 
The presence of the sacred within this world helps explain why the Romantics attached such value to unique subject-life experience. (Heelas 2008: 42 his emphasis)

So, somewhat in recent contrast to traditional Christianity, in spatial terms the new spiritualities are to be found 'here' rather than 'there'. This emphasis on life itself as sacred, the 'holism' of Gaia and of all her creatures, presses for an aesthetics of life that perceives 'living' to be an art form, a sacred practice demanding focus and attention, 'their art is the art of life' (2008: 43). The lifework of the Romantics was not just individual aggrandisement however; it was for a social good, to achieve authentic love, beauty and oneness through an aesthetic of appreciation. I will now go onto discuss why this is so relevant for Lesbian, Gay, Bisexual, Transgendered, Queer and Intersexed communities.

\section{Thinking about queer spiritualities}

For women of a certain age living in the US, Australia, and parts of Europe during the 1970s and 1980s, it seemed then that there was a lot of lesbian feminism about, particularly of the lividly separatist variety. With hindsight it was perhaps the discourse of lesbian feminist separatism that was so ubiquitous, its lived experience more rare; I remember well its permeating precepts - that women were closer to nature than men, and that it was necessary to return to an inherently pure, ecologically inspired ethics that predated masculinity in order to heal the Earth and thus ourselves. 'Nature' was a feminine state, in contrast to the polluting essence of phallocentrism, which had pulled down societal catastrophe onto our heads, including the threat of nuclear oblivion. This radical feminist ideology subsequently provoked the widespread Green Movement in the West. In Britain, much of its energy centred around the symbolic Peace Camp at Greenham Common, participation at which became a rite of passage for aspiring lesbians like myself. ${ }^{10} \mathrm{I}$ even met up with my Mother there, at the 'Embrace the Base' demo on 1 April 1983, with tens of thousands of other protestors who held hands to form a 14-mile human chain around the military base. Typically we had an argument about the fact that I was smoking cigarettes, which seemed significantly more appalling to my Mum than my evidently new-found lesbianism. That topic we mutually ignored. For my undergraduate dissertation of 1985 I compiled an archive and commentary of two years of the visual cultural practices of Greenham Common camp,

10 If you enter 'Greenham Common History' into You-Tube, one of the early results is a video entitled ' 2 girl sex video lesbian sex'. This leads me to suppose that Internet search protocols still link 'Greenham' with lesbian sex (if virtually). A cheering thought though, really. 
taking many photos and copies of flyers, banners, tent art and the general iconic mélange that represented the embodiment of lesbian feminist separatist values at that time. Now I wish I had done more data collection, because underpinning the obvious social change imperative of the camp's presence and raison d'etre was an equally strong spiritual belief system, a cultural logic that was illustrated repeatedly throughout the Greenham ethos, with reference to Neo-Paganism (Gaia, Mother Earth), Catholicism (Marianism in particular), Aboriginal and Native American spiritualities (weaving, the rainbow serpent), Wicca (spiders, hagiographies, witches), Quakers (Peace Witness) and Romanticism (see further Welch 2007 and Roseneil 2000). The remaining Greenham Women have built a commemorative and historic site to mark the nineteen years of continuous occupation of the women's peace camp:

The Site represents the four elements: earth, fire, water and air. A circle of 7 Standing Stones, from Wales, encircle the 'Flame' sculpture (symbolizing the campfire). A stone and steel spiral sculpture (representing the continuous reaching out work done at the Women's Peace Camp against nuclear weapons). Written into the Spiral is: 'Women’s Peace Camp 1981-2000. And the words You can't kill the Spirit'. ${ }^{11}$

'You can't kill the spirit' wasn't just a song, more of a creed to Greenham Women, a mantra intended to inspire and motivate. According to Christina Welch:

Greenham Common Peace Camp, as thealogian Melissa Raphael has argued, was a new manifestation of female sacrality. A female sacral space was established at the very heart of patriarchal power. 'Here the feminist sacral will expose patriarchal colonization of the mind and the land'. (1996: 23 quoted in Welch 2007: 63)

In the binary oppositional language of the time, masculinity $=$ death, and feminist femininity $=$ life. This eco-feminism was predicated on a long history of alternative spiritualities, a Romantic pastoralism that has permeated lesbian and gay histories back into the eighteenth century. Plas Newydd, for example, home to the 'Romantic Friends' the Ladies of Llangollen, Lady Eleanor Butler and Miss Sarah Ponsonby, from 1780-1829, retains multiple Gothic features. ${ }^{12}$ The Ladies lived frugally and quietly, taking long walks and reading Rousseau aloud, carefully renovating their home as an iconic retreat. The house contains ornate oak panels that enclose dense carvings depicting numerous carnivalesque, queerly sexual, animalistic figures, and Celtic symbols indicating their Irish mystical heritage.

11 See http://www.greenhamwpc.org.uk/historic.htm Accessed March 2009.

12 See images available at http://www.llangollen.com/plas.html. 
Edward Carpenter (1844-1929), a scion of my adoptive home city, Brighton, is perhaps the most notable historical protagonist of queer spirituality. Carpenter was ordained as a young man, and a follower of Christian socialism. Influenced by the (reputably) perversely queer social thinker John Ruskin, he became increasingly committed to a vision of utopian, primitive pastoralism, and began to live out his ideals in a commune, with his homosexual lovers. In Sheila Rowbotham's recent biography, Carpenter is described as considering the material and spiritual as intertwined, the 'combination of sex and spirit became his hallmark' (2008: 281). Carpenter argued against the Western religious tenet of restricting sex solely to reproduction, instead he advocated sex for the additional or alternative purpose of 'soul-union', celebrating homosexuality - 'the intermediate sex' - as part of a divinely natural sexual diversity. Carpenter became influenced by Neo-Paganism, expressing utopian desires that linked passion to building new communities based on spiritual ideals. Carpenter, writes Rowbotham, was familiar with the 'new chivalry' network of the early 1900s, a secretive association of intellectuals who produced homosexual texts coded and carefully informed by classical and biblical codes. The 'open secret' of homosexuality at Cambridge University at that time was influenced by Lytton Strachey's concept of 'Higher Sodomy', itself drawn from Plato, 'a form of love he regarded as superior to male-female desire' (2008: 282). In this period there was an urge to prove the moral equality, if not superiority, of same-sex love, perhaps as a compensation strategy for homosexuality's widespread profile as degenerate. This trend is markedly apparent in that early lesbian classic by Radclyffe Hall, The Well of Loneliness (1968 [1928]), in which the hero, the lesbian invert Stephen Gordon, is cast as the sacrificial Christ, a narrative device that was regarded as completely blasphemous during the novel's trial for obscenity. A near contemporary of Carpenter, Radclyffe Hall is notorious for a different kind of alternate spirituality, her queer Catholicism (see further Gallagher, Roden and Smith 2006). Unlike Carpenter, Hall was a reformist rather than a radical, she pleaded for public pity for the invert, as epitomised in Stephen Gordon's cry:

Acknowledge us, oh God, before the whole world. Give us also the right to our existence! (Hall 1968: 510)

Hall deploys the figure of Stephen to great messianic effect in the novel. She reads Havelock Ellis's sexual inversion through the lens of Christian martyrdom and agency. The two are not exclusive: to exist in the communion of saints, we are all impelled to die to the self, to be 'born again' as a new, shining creature, laundered by Christ. Held deep within the promise of cleansing is a reinvention of a self in which pain and degradation are eliminated, implying an unspoiled signifying space in which to conceive a new beginning, a new belonging. In that religious idealism, Hall echoes Carpenter. 
Now, Hall's entreaty that sexual inverts be tolerated, even endured, seems objectionable from the perspective of 2009, but the long history of representing sexual diversity within conventional religious traditions chiefly reflects an ethos of forbearance in preference to direct persecution. Of course, there have been LGBTQI religious in all faiths: homosexual monks, lesbian nuns, and a rainbow of queer devotees that caused a furore. As well as a punitive force, mainstream religion has also been a refuge and a nursery for LGBTQI peoples, as those of us who eagerly grasped Naiad Press's landmark Lesbian Nuns: Breaking the Silence in 1985 will remember. This book, read and discussed avidly with not a small frisson of illicitness two decades ago, made public in print the erotic diversity in one religion - Catholicism, no less. Tame by today's standards, the stories collected are testaments from ex-nuns who talk about how they negotiated their homosexuality having chosen a life of religious seclusion. This collection does not follow the well-established convention - or habit! - of nun pornography. There is a long discursive history linking sodomitical practices to Roman Catholicism, and although most of the prosecutions for sodomy involved men, some indeed were women. Fears concerning the monstrous desires of nuns have circulated for centuries, producing a whole subgenre of sexually titillating manuscripts, for example the fictional 'Venus in the Cloister; or, the Nun in her Smock' (1683/1725), taking place as a dialogue between an older and younger nun that reproduces the typical hierarchy of sodomitical pairs, and allows the reader to relish voyeuristic pleasures with the novitiate. Sister Angelica espies Sister Agnes (the 'Lamb') through the 'crevice' of her cell:

Dost thou not know, my little fool, what it was I could see? Why I saw thee in an action, in which I will serve thee myself, if thou wilt, and in which my hand shall now perform that office which thine did just now so charitably to another part of thy body. This is that grand crime which I discovered, and which my Lady Abbess * of **** practises, as she says, in her most innocent diversions, which the Prioress does not reject, and which the Mistress of the Novices called The Ecstatic Intromission. (Barrin 1683 quoted in McCormick 1997: 190)

Although Sister Agnes, when obliged to speak to her confessor claims she will 'die with shame', this comes across as coquettish rather than theological, rewarding the reader with another scene of erotic anticipation. Nun pornography is of course one aspect of the vast, diffuse eroticisation of Catholicism enjoyed throughout Western culture, from common parody to the literature of high moral seriousness. Christian and non-Christian religious sects are commonly associated with zeal for untrammelled eroticism; this line between holy fervour and erotic passion is a thin one, an association persisting for hundreds of years and regularly appearing in contemporary media coverage, indeed 'sect' has almost become a synonym for 'sex'. 
Art and literature provide a symbolic conduit for the reorientation of high emotional states, the intensification of existing emotions. The movement from one affective condition to another is what characterises the very process of aesthetic consumption. Indeed it is the function of works of art to induce sensation. Emotions seem to 'lock on' to the spectator, and artworks can be understood as interpellations that rhetoricise sets of feelings. Horror, shame, anguish and abjection form a dominant presence in the pantheon of Western art, particularly religious art, implicating the viewer in a Foucauldian confessional mode (often very somatically emphasised). The aesthetic (some would say the 'gay sensibility') of Western art is to interpellate the viewer via her abjection, into transcendent deliverance. The artist and the viewer together experience a kind of collective or mutual release from abasement; this is extremely ritualised in Western religious art, drawing upon long established structures of catharsis. Despite the vast panoply of Western aestheticism being arguably so 'queer', it is currently unacceptable to talk about spiritual feeling in critical discourse, but yet how common those feelings or experiences are in those people that have undergone extremes of suffering.

Within secular capitalism, alternate identities have flourished, not least as a result of the assimilation of radical politics into mainstream society. Liberal pluralist democracy has come to be associated with atheism, or a loose agnosticism, perhaps the 'new religion' of the sovereign self dispensed with any need for a transcendent deity or master narrative. The logic of late capitalism and its necessary production of new markets, its continual proliferation of desires, has led to a worship of individual aggrandisement, whether that comes in material or internal, self-reflexive forms. Across the political spectrum ideologues have endorsed this acquisition of selfhood as a practice of freedom. Getting hold of religion, on the other hand, is derided as a fool's capitulation to dominant forms of restraint, a suspicious and perverse regression from advanced/late capitalism's agenda to ennoble the self with its own Nietchzean will. Identities built upon relationships, collectivity, and even 'self-sacrifice' are seen as largely antithetical to this urge to build, emboss and protect the individual self. Hence we have the situation that LGBTQI cultures are reductively perceived to exist primarily as economical structures enabled by the Pink Pound, rather than communities with an ethos of responsibility, committed to an idea of social or common good. LGBTQI identities are subsumed emblematically under a symbol of rich gay men, a trope signifying prosperity, much to the destructive envy of 'ordinary heterosexuals' struggling to pay for their expensively ruinous, non-glamorous, children. Sexual diversity has come to stand for selfishness, to be a symptom of moral turpitude, the fight for LGBTQI rights often collapses into a bitter media stereotype that all we want is more: more money, more sex, more power. The discourse of emergence of LGBTQI rights is of course bound up with consumerism and its latent expectations, but that does not mean 
LGBTQI peoples are simply products, nor are they duped into particular forms of 'homonormativity', as Lisa Duggan described it, 'a privatized, depoliticized gay culture anchored in domesticity and consumption' (2003: 50). LGBTQI peoples have been adept at inventing self-narratives (for example in the ubiquitous coming out story), and conceptions of self-development have been intrinsic to our emergence. Where subcultural identity has been struggled for with great effort, its logical progression or practice is frequently to embrace an ethics and care of the self, which is relational and dependent on others, as Foucault famously pointed out (1979, 1984, 1986b). Cultivating community, responsibility, a social or 'good' living is important, as is a particularly well-honed self-reflexivity, queer peoples had to consciously 'remake' ourselves as a strategy or tactic in order to live out our same-sex desire. The widespread suspicion of religions as wacky, deluded and self-oppressed within current (rather bourgeois intellectual) Leftist and LGBTQI politics, and their concomitant reverence for liberal secularism or critical disidentification is understandable - but spirituality has been a persistent phenomenon, a sustained comfort and a source of creativity. LGBTQI cultures have begun to acknowledge the need to experience the ineffable, enchantment, linking into a new Romanticism and the trends of self-enhancement in tandem with the broader cultural milieu. The exponential popular growth in self-spiritualities of the recent past decades has not in basic terms recruited directionless people suffering from boredom, culpable dopes seduced and beguiled by flaky gurus. We need better understandings here that are not based on condescending models of crude devotional consumerism. Intentional politics, vision and ethics are widely linked to these new values, an agenda fully familiar to queer peoples who have had to carve their space relentlessly within, betwixt, between the interstices of hegemonic compositions like 'normal' and 'acceptable'.

Sexualities and gender - their diversities, and categories shorthanded here to LGBTQI - exceed the limits of their categorisation. Like spirituality, sexual and gender difference contains something of the beyond of human experience; although understood as a shared epistemology, sexual desires are stubbornly unfixed to nomenclature and the classificatory urges beloved of some social science researchers. We are once again in the realm of the queer uncanny, except I must remark here upon the surprisingly prevalent aversion to our supposedly warm and all-inclusive terminology of 'queer' amongst our participants. Within most of our case studies, interviews and focus groups, 'queer' was frequently rejected as an offensive term, still wielded as an insult and most definitely largely unreclaimed. Their marked disidentification toward the appellate 'queer' may represent a suspiciously larger proportion of contemporary LGBTQI people than yet acknowledged, who exist steadfastly outside of university discourse. Many of our participants saw a sexual/gender identity label as irrelevant or insignificant compared to their faith, which for them was their primary life- 
ascription. For others, these worked in collaboration refusing distinction or segregation. We refuse a 'god-trick' academic move of explaining these away as internalized homophobia, nor can we simply ascribe a model of lateral hierarchies to the layers of identity a person articulates (firstly I'm a Muslim, secondly I'm British, thirdly I'm a lesbian and so on) and intertwines. The intertwining and dissolution of sexuality/gender with and from spirituality was one of the fascinating dynamics of our survey that not only differentiated between groupings but also brought solidarities and alliances. Andrew will give a further outline of current research on LGBTQI spiritualities in Chapter 2, discussing primary areas of interest and key themes. Subsequent case studies draw out the differentiations between LGBTQI people, how spiritualities and sexual/ gender identities merged such that they were inseparable, as well as how sexual/ gender identities came to matter, needing proud proclaiming. For the purposes of our Introduction I would like to draw your attention here to the historical and cultural logic of queer spiritualities, arguing that their current manifestation is far from being a jarring juxtaposition, and more like a diffractive crystal. Queer spiritualities have their own discursive logic which is not uniform, their own distinct cultural histories and their own idiomatic profiles, as we will show, maybe surprising the detached schools of Queer Theorists and sociologists of religion. ${ }^{13}$

The necessity for integrating queer thinking and religious studies and the chasm that can exist between these fields, was brought home to me (and us) in two distinct moments. Firstly, when I stood next to another researcher from the AHRC/ESRC Religion and Society Programme Launch Conference (of which this project was part), at Lancaster University in November 2007. All of the Programme's Principal Investigators and some of their teams were meeting to create early research dialogues across the projects. ${ }^{14}$ Standing in the drinks queue with my shiny plastic name badge on the first night, this was the first conversation I had:

Hi.

Hi.

I'm 'Adam'.

13 There are a very small number of people working across these subdisciplines, and we were lucky enough to have access to their valuable work.

14 The Principal Investigators and their teams, of course, had independent views from the funding panel and scheme selectors for Religion and Society. To these people we owe our grateful thanks for their belief in our project and consequent support of it via a funding award. Readers may be interested in finding out about the larger programme, at http:/ / www.religionandsociety.org.uk/. 
I'm Sally.

What's your project?

Well, we are looking at Queer Spiritual Spaces, using case studies from nonmainstream faiths in Britain and America ...

[shocked] What?! You mean there are people like that who are religious?

Sure - lots! So we're interviewing people such as gay Muslims, and lesbian Pagans, to see what they do and what they believe and where they practise.

Gay Muslims! Are there any? Don't they just put them to death?!

Er well yes, I mean, there's Fundamentalists in all religions aren't there, including Christianity, but they aren't all homophobic all of the time, there's lots of liberals too. Most of them probably.

So you're looking at gay priests then, gay paedophiles?

No we aren't, I think there's enough written about that already, don't you?

Oh well I er, I, oh excuse me a second [drifts away, assiduously avoiding eye contact]. (Research diary, Sally R. Munt)

As depressing as - in a variety of ways - this brief encounter was (and untypical of the Religion and Society conference as a whole), it did speak to me about the continued necessity of augmenting the 'politics of visibility' of queer spiritualities within academic discourse, religious affiliation, and LGBTQI politics (see also Chapters 3 and 7). Queer spiritualities make a lot of people uncomfortable. This, of course, could include members of the Queer Academy, specifically those with fundamentalist proclivity to pontificate what 'queer' should properly constitute. Our second moment in March 2009, occurred when we held a conference at the University of Sussex to celebrate the completion of our project, ${ }^{15}$ give papers on the main themes, and to disseminate preliminary findings. Among the audience was what we later termed a 'queer fundamentalist' (following Wilcox 2009). He not only grilled us in public forms, stating that 'you must' define queer in order

15 Despite this intervention, the overwhelming spirit of the conference was one of inclusivity, warmth, collective support and encouragement; it was particularly special to see so many participants there, also activists, community members and students. 
to use the term ${ }^{16}$ and then suggesting how we 'should' go about this task, he also privately commented to one of us about how he would review the book (unfavourably) in an important journal. Kath discusses queer policing further in the conclusion. Here, though, it is important to see how our experiences of how queer spiritualities can reflect hetero/homo-normative impulses (or regulation both from religious studies and queer theorisations).

\section{Thinking about conceptualising queer spiritual spaces}

I don't wish to dwell too much on the specifics of queer spiritual spaces as this is taken up sociologically in the case studies and purposefully in relation to our project findings in the conclusion written by Kath. But it might be beneficial at the outset of the book to introduce our thinking to the general area. Whether there is definitive object/s of queer spiritual space is of course debatable. Perhaps it is best to follow the conventions of postmodernism and apply the usual qualifications: that queer spiritual spaces are transitory, liminal, provisional, preposterous, fragile, strategic, mutable, contested, negotiable and multifarious. Perhaps the single most effective descriptor of queer spiritual spaces could be 'capricious', that is to say, that they can be impulsive, uncertain, unpredictable, whimsical, and erratic. Queer spiritual spaces are similar to what Gilles Deleuze (1988) adopted from Proust when he described the concept of the virtual as being 'real without being actual, ideal without being abstract'. He is alluding to the (limited) human construction of space and time, an imposition of human knowledge and consciousness, and therefore cultural rather than natural, following the philosopher Immanuel Kant. This is the argument that disrupts the Cartesian binaries such as mind/body, nature/culture, time/space, that Elizabeth Grosz takes up so cogently in her collection of essays Becomings: Explorations in Time, Memory and Futures (1999). In an Australian radio interview in 2005 'The Creative Impulse' Grosz explained her theory of art:

... there's something about art that is an abundance of excess. Art is the revelry in the excess of nature, but also a revelry in the excess of the energy in our bodies. So we're not the first artists and we're perhaps not even the greatest artists, we humans; we take our cue from the animal world. So what is it that appeals to us? It's the striking beauty of flowers, it's the amazing colour of birds, it's the songs of birds. In a way, it's that excess which, I think, is linked to sexuality rather than to creation or production directly.

16 It was a sober lesson in intellectual self-righteousness. Unfortunately, academic cultures aren't the most hopeful of places, too often I've been in academic fora being slowly reduced to parody in 'I'm right' / No, I'm right' moments. 
Spirituality is not so removed from Art in this explanation; Grosz goes on to describe her ideas about form, structures, architecture and the built environment:

At the most elementary level, of course, the built environment is our attempt to create a small territory within chaos where chaos doesn't impinge as much as elsewhere. In a way, this is the most primordial impulse of all civilization; to build a shelter which enables you to get some space to do something potentially luxurious. So chaos is maybe too strong a word, although it's not entirely too strong a word. The point is, nature is full of these teeming impulses that we don't really control, and at best what we can do is carve out a location, a territory, and in the process of carving out a territory, which is the primordial impulse of architecture, we also carve out something like a body for ourselves. So this dual operation of territory and body is produced simultaneously. (Grosz 2005)

In her description of the creative impulse and its desire to spatialise, Grosz is offering us one possible theory of queer spiritual space. This concept is of course relational - it is 'different to' normative spiritual space, if we could indeed set that in stone. A Deleuzean idea or concept of difference is not a wraith-like abstraction of an experienced thing, it is a real system of differential relations that creates actual spaces, times, and sensations. So if we take a concept like 'queer' for example, to be queer - unusual, strange, contrary, uncanny - is to act like a verb, queer has an agency of its own accord, a reproductivity. To be queer is to make queer, as it were.

We must be careful not to universalise a queer spiritual space, to fix it in our minds as a flat, static social geometry into which we wedge people. This means, in terms of our project, that we keep the concept dynamic, fluid and messy, in that yes, queer spiritual spaces are a consequence of habitation by LGBTQI peoples, but also that spirituality itself, because of its unstable otherness - its uncanniness, its intensifying qualities - can facilitate queer space. We also have to be querulous about that term 'queer space' too: if we think about Philosopher Henri Bergson for a moment, who insisted on the necessity of increasing the potential of human thought through the imaginative possibilities of intuition, which would be, according to him, the only way of approaching and gaining knowledge of the absolute, and of real life. Bergson's (1910) term for this, duration, is located in a person's inner life, it is a touch of the ineffable, perceived through mental images, not unlike meditation. ${ }^{17}$

17 Duration is first introduced by Bergson in his essay 'Time and Free Will: An Essay on the Immediate Data of Consciousness' (1910). Available online at http://web.archive.org/ web/20060424080648/spartan.ac.brocku.ca/ lward/Bergson/Bergson_1910/Bergson_1910_ toc.html. 
His own image represents how Bergson identifies the duration, as an indivisible mobility:

Instead, let us imagine an infinitely small piece of elastic, contracted, if that were possible, to a mathematical point. Let us draw it out gradually in such a way as to bring out of the point a line which will grow progressively longer. Let us fix our attention not on the line as line, but on the action which traces it. Let us consider that this action, in spite of its duration, is indivisible if one supposes that it goes on without stopping; that, if we intercalate a stop in it, we make two actions of it instead of one and that each of these actions will then be the indivisible of which we speak; that it is not the moving act itself which is never indivisible, but the motionless line it lays down beneath it like a track in space. Let us take our mind off the space subtending the movement and concentrate solely on the movement itself, on the act of tension or extension, in short, on pure mobility. This time we shall have a more exact image of our development in duration. (Bergson 1968: 164-65)

For those of you, like me, who are not philosophers, grappling with this image requires more than one reading, however once grasped it does offer us an apt illustration of one way of approaching queer spiritual spaces, conceiving of them less as fixed co-ordinates and more of 'an act of tension or extension', 'pure mobility' - a duration. Bergson also states that mobility, like time, is indivisible and infinite. Thus, we could argue that the paradox here is that we are trying to queer a norm that actually does not exist, in that a heteronormative space is a convenient fiction of purity for us, just as a queer spiritual space can be a luxurious and imaginary moment of transformation or corruption, for 'them'.

If, following feminist theorist Judith Butler (1993), we share the view that 'queer' belongs in the constitutive outside as a troubling return, and drawing upon Nicholas Royle's (2003) work on the uncanny as a 'supplementarity' - an overflow, or maybe even a distorting echo that sonically haunts our culture - we can propose that queer spirituality can occupy the space of an alternative sub-melody, recalling the String Theory which was so fashionable at the end of the last century. ${ }^{18}$ Queer spiritual spaces can operate as an alternative, vibrating

18 String theory comes out of modern theoretical physics, for a lighthearted but informed introduction see http://www.superstringtheory.com/. String theory attempts to provide a complete, unified and consistent description of the fundamental structure of our universe, by posing multiple possible material universes, like strings, vibrating side by side. (String Theory is sometimes, called a 'Theory of Everything', at which point my analogy collapses into the untenable position that 'queer is everywhere/ everything is queer' position.) For an accessible and thorough argument for string theory, see Gribbin (2009). 
worlds that exist in close parallel to the 'Real'. However, Olu Jenzen, writing about the queer uncanny suggests that there are:

... ways of tapping into the workings of the uncanny by exploiting certain anxieties and [its] strategic application. I thus suggest [the uncanny can be] about asserting uncomfortable strangeness, fissures and ambivalences where dominant culture wants reassurance, intelligibility and integrity, by reminding [us] about what ought to have been hidden. (2009: 276 see also Jenzen 2007)

She has described the characteristics of the uncanny from a queer perspective as a 'repetition out of sync', unsettling to the self, as upsetting, as exposing the ways that otherness is produced. This more sober approach poses a more disquieting view of queer spiritualities, pointing to a structural disturbance with the category of Human, raising insecurities about the borders of human/nonhuman, organic/inorganic, animate/inanimate, and human/technology for example, binaries that 'serve as normalizing and authenticating structures for a heteronormative way of being' (2009:278) - and I would add for the 'life of reason'. Conceptualising queer spiritualities, like the queer uncanny, can give us ways of rethinking our relationships to others, including non-human others, so redefining our proximity to fishes, cats, and dildoes, for example, in that the strange comes near.

Positioning queer spirituality as fundamentally disruptive is quite romantic, and follows our general observations on wider post-war cultural trends toward valourising uniqueness. Queer life in the West is still hard for the majority of us, unmanageable for a number of us, and cruel for too many, although we need the imaginative force of a queer romanticism to inspire, we still require everyday lives of safety and belonging. So, the extraordinary and creative queer theory of universities, which values discomfort and disruption, and that valenced term 'unhinged', often has limited applicability when perceived by non-academic LGBTQI peoples, who can hanker after intelligible selves, relative sanity, and embedding collective loyalties with like-minded friends. The haughty imperative to be 'critically distant' is not necessarily helpful to such people, who rather prefer to be close. We need to be careful not to impose our righteous dreams of marginalisation onto people who are already suffering the unhealthy effects of alienation; by pushing queer as radical message we can unerringly appear to be bullying people into what are, for them, unsustainable ontologies. Conversely, for all of those who yearn for affiliation, there are others attempting to detach, spirituality being one of the few domains of knowledge that can endorse the recluse.

Intimacy is very disturbing; it threatens the sense of self so carefully wrought and protected over the years of a lifetime. Intimacy is conceived spatially, in a constantly vibrating trope of near/far; and temporally, in a similarly vibrating 
trope of past/present/future. I am reminded of a memorably queer animal body from my childhood, from the 1967 film Dr Dolittle, the pushmi-pullyu. Dr Dolittle, played by Rex Harrison, you may remember, is a doctor who, although some of his best friends are human, prefers treating animals, and he speaks their languages too.

In the books (now out of print for their outdated representations of ethnic groups), the pushmi-pullyu (pronounced 'push-me-pull-you') is an antelope that has two heads at opposite ends of the body (see Figure 1.3). When it tries to move, both heads try to go in opposite directions. Dr Dolittle meets it on his voyage to Africa, in the early Victorian period in which the stories are set in Africa, representing the Dark Continent of the unknown, and the projection of supernatural fears. Hence, the pushmi-pullyu is a pretty benign symbol for the most part. In the 1967 film the pushmi-pullyu was portrayed as a double-headed llama, and in the more recent 1998 version with Eddie Murphy, it appears in a brief scene where it passes by in the background, obviously now able to negotiate a linear trajectory. The pushmi-pullyu has enduring cultural resonance, as demonstrated by this fictional interchange I found online:

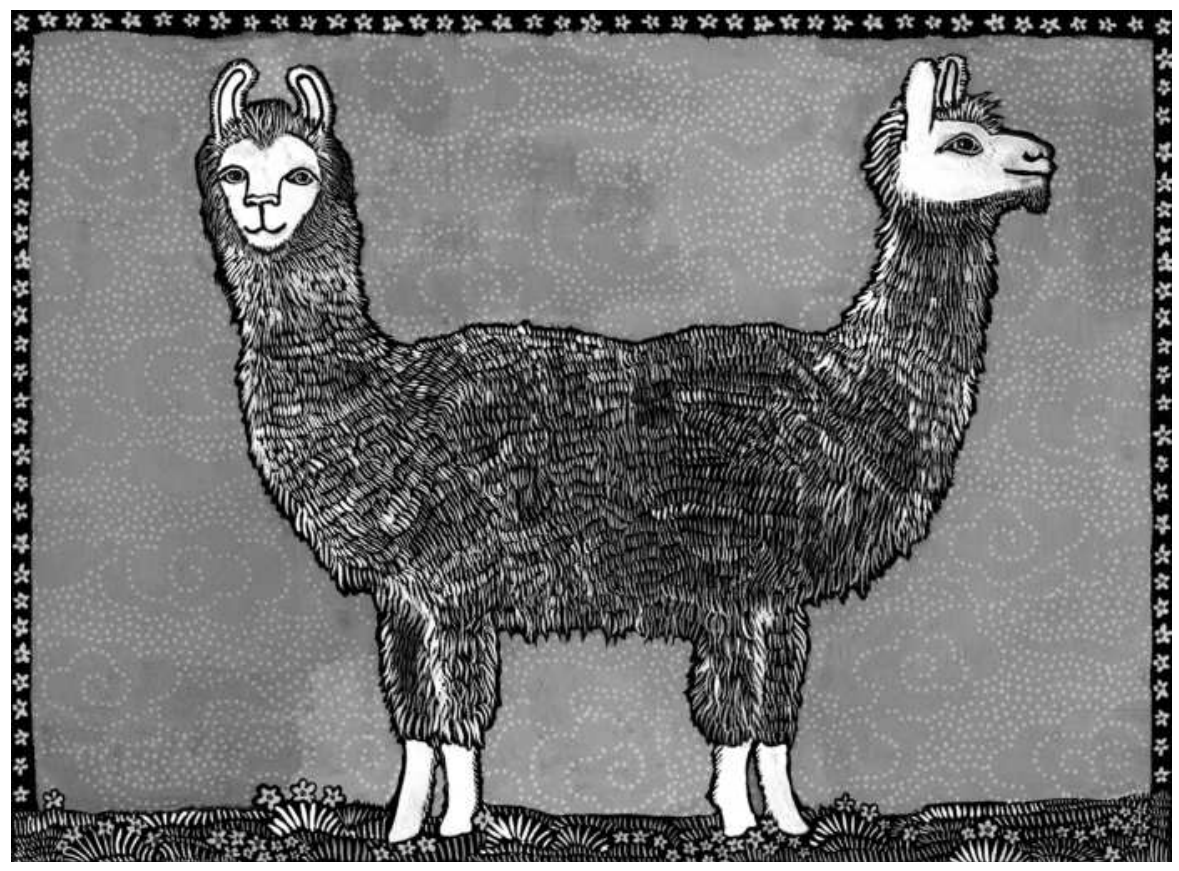

\section{Figure 1.3 The pushmi-pullyu}

Source: Courtesy of Tania Covo. 
A two-headed horse, Watson? How ridiculous. I am surprised that you have allowed yourself to be taken in by a hoax.

You may laugh, Holmes, but I have seen the animal, and hundreds of others have flocked to see it, too, and it is real. Surely you can believe that Siamese twins are a possibility with horses.

That I can, but not with a head at each end. That's not a horse. Not even in mythology is there a pushmepullyou kind of thing.

Holmes, you once said 'When you have eliminated the impossible, whatever remains, however improbable, must be the truth.' I appeal to you to see the animal and you will be convinced by the evidence of your eyes.

This is what I wished I had said to my colleague in the drinks queue, who, like the vaporous silhouette in the closet, 'knew' without wanting to know his proximity to the sexually irregular. Watson goes onto explain that the 'pushmepullyou' is a visual trick:

Ye gods, Holmes, how could I be taken in by such a simple trick? Descartes said 'I think, therefore I am.' You didn't think. If you had put Descartes before the horse you could have worked it out. ${ }^{19}$

Ah Descartes, that paragon of reason, however we have to remember that in the Holmes/Watson dyad, Watson is the proverbial plodder, and Holmes is always right. Uncanny figures like the pushmi-pullu give us problems with reality, in Nicholas Royle's words 'a crisis of the natural' (2003: 1). The logic of the pushmi-pullu is that we want to be radical but we also want to belong, perhaps this is why so many of our participants averred the term queer, because they don't want to be disruptive, they want to be homed.

Touching others, touching ourselves, these seem to be the basic desires of queer spiritualities, so that queer spiritual spaces can become simultaneously eerie and comforting, alienating and accepting, enabling and constraining. Our research into this area can only ever be inconclusive, because queer spiritual spaces are necessarily slippery, but participants did describe the importance for them of finding intimacies, of finding places to be comfortably extant, but also to embody enabling places in which to stretch themselves out into the unknown. Queer in this context has less to do with the death drive than it has with the life drive, with Bergson's élan vital, his 'current of life', an idea which Deleuze takes up in his work as a force that clouds the distinction between organic and

19 'The Pushmepullyou' available at http://www.geocities.com/geotassie/twoheads.html. 
inorganic matter, and which brings me back nicely to the warm seas of scuba. To 'swim with the fishes' is an English idiom for being dead, reminding me of the association between the uncanny and the un-living, contrarily however urban slang also deploys it as acting in accordance with some specified standard or authority "typically that of "The Man" - conforming. ${ }^{20}$ Scuba is a contentious sport, no doubt as I have said my critics would berate it as indulgent postcolonial leisure. But it is also important to acknowledge the creative unpredictability of cultural exchange, travel, immersion in unfamiliar waters, and being in the enigmatic beyond, as Emmanuel Levinas might have put it. Writing of being in the beyond, Levinas claims that transcendence is only possible in the realm of the other, touching the other enables human sensibilities to develop, both by bringing us into our own body and by touching the otherness of others, and in this 'I am the other's hostage' (see Peperzak 1997). Risk is invoked; it is surely troubling to be so interdependent, so enmeshed by repercussion. Within this exacting ontology of intimacy, as Deleuze would have said, god only differs from us by degree.

\section{The 'nuts and bolts'}

LGBTQI peoples in Britain and the United States who wished to affirm both their sexual/gender identities and their membership of a faith/spiritual community, can be faced with a question of 'spiritual immanence' - how to relate to and how to create 'spiritual space'? Our project sought to investigate Queer Spiritual Space(s) in contemporary Britain and the United States. ${ }^{21}$ Our principle aims were to explore:

- What is the place of queer peoples in existing spiritual/cultural spaces?

- Where do queer peoples go to find their own spiritual spaces?

- What does a queer spiritual space/place mean to our participants, and what do they want to do there?

- How and where do queer spiritual spaces/places exist - in the bodies of individuals, in community, in queer spiritual texts, in specific or moveable spaces of worship, in cyberspace, in visibility, in secrecy?

20 See http://www.urbandictionary.com/define.php?term=swimming +with+the+fishes.

21 This project was funded jointly by the British Arts and Humanities Research Council and the Economic and Social Research Council UK under the Religion and Society Programme, for twelve months, see http://www.religionandsociety.org.uk/. 
It drew together different existing interdisciplinary strands of research on spiritual space, queer space, LGBTQI cultures and religion, intending to extend them by considering the ontology of queer spiritual spaces, across a spectrum of spiritual practices and beliefs. We looked at the various strategies and embodiments related to imaginative, spiritual and physical inhabitations of queer spiritual spaces - as text, as community, as virtual, physical, fixed and mutable architectures. We explored questions of spiritual space in diverse faith/tradition contexts in relation to Western LGBT identities (including de/ $\mathrm{re} /$ constructive practices within religions).

In exploring the 'lesser known' avenues of religious and spiritual affiliation, we concentrated on a mixture of mainstream minoritarian faiths (Islam, Buddhism), a sect (Quakers) and smaller, eclectic place-based clusters of spirituality at Findhorn in Scotland, and the Michigan Womyn's Music Festival. The last case study was commissioned to look specifically at the spiritual seekers, and more particularly 'virtual believers'. Chapter 8 explores the complexity of this undertaking, its limitations and possibilities, we deployed the premise of the queer spiritual seeker as an organising focus or critical prism. These case studies offer valuable and unique insights into the intersections of religions, spiritualities, LGBTQI lives and geographies.

\section{Methodologies}

Around 150 people were directly involved in the data collection for the Queer Spiritual Spaces project, with other stakeholders joining in conversation with assorted researchers throughout the two year duration of project. Our interdisciplinary approach meant that there were plenty of debates within the team about what was meant by $\ldots$ almost everything. Our resolution was not to proscribe or dictate, but to remain open, uncertain and messy. This is not an easy or comfortable positioning. Accommodation had to be made by all in order to show consideration for this temporary network of disciplines. One of the many things we could not manage to define satisfactorily was spirituality, perhaps this was too idiosyncratic, disciplined and/or directly personal to express. It also meant that our interpretations of the material were all slightly at variance, according to our subject training and positionalities. However, one unifying characteristic was our curiosity and excitement, each of us having some degree of personal investment in our theme.

Each case study ran at least two focus groups and recorded approximately a dozen individual interviews, each of which deployed a semi-structured approach, the interview/focus group guides are included in the Appendix along with a demographic chart giving participant's details (anonymously where this was requested). Researchers proceeded with their respective communities in slightly different ways according to sensitivity to local practices and their own 
positionality. Our research participants contributed kindly their time, attention and insight, so their individual effort needs particular acknowledgement from the outset, the varying relationships that those undertaking data collection had with the participants are explored in each of the chapters. The case studies sought a diversity of participants, to varying degrees of success, often depending on how the researcher themselves were positioned. For the most part there are no published demographics on which to measure membership, whilst we strove for diversity, we do not claim that these are representative samples.

As Chapter 8 shows the Internet can be perceived as a mystical domain for those who have never been there, and for those who perhaps go there too much. Although we have a chapter dedicated to the spiritually curious online, the Internet was used across the research by many of our participants in their search for like-minded support. We set up our own website, www. queerspiritualspaces.com in Spring 2008, which offered full information on the project and discussion boards. This website will remain live until 2011. The Queer Spiritual Spaces website was made available to the public at the beginning of May 2008 and in the first year has received 20,600 visits from 63 countries (see Barrett 2009 for a definition of visits).

Considering Table 1.1, the visits to queerspiritualspaces.com, the peak activity for this website was February 2009 with a daily average of 104 visits. Website visitors were searching in relevant (as well as irrelevant!) areas to find our site, an indicator that their website use was effective. The collected search terms appear, for the most part, to be relevant to the actual project, so we can surmise that the visits to the website are for in the main by people who have

Table 1.1 Visits to www.queerspiritualspaces.com over 12 months (May 2008-April 2009)

\begin{tabular}{|l|c|c|}
\hline \multicolumn{1}{|c|}{ Month/Year } & Daily Average & Monthly Totals \\
\hline May 2008 & 2 & 81 \\
\hline June 2008 & 9 & 298 \\
\hline July 2008 & 42 & 1,321 \\
\hline August 2008 & 59 & 1,858 \\
\hline September 2008 & 62 & 1,862 \\
\hline October 2008 & 67 & 2,100 \\
\hline November 2008 & 69 & 2,082 \\
\hline December 2008 & 71 & 2,207 \\
\hline January 2009 & 82 & 2,542 \\
\hline February 2009 & 104 & 2,913 \\
\hline March 2009 & 85 & 2,639 \\
\hline
\end{tabular}


an interest in the website content as opposed to those who stumble upon it by mistake. Of those that perhaps came across our site accidentally, we had around 100,000 hits. Whilst it was not what they were looking for, we do hope that the visible profile for the project perhaps resulted in some pausing to consider queer spiritual spaces.

As a team we were geographically dispersed to three countries and six cities. This meant that regular team meetings were impractical. We set up virtual meetings from the start of the project. Initially we met at the 'home institution', the University of Sussex online on its virtual reality site on Second Life, a global software programme used by millions (see Boellstorff 2008). On the virtual campus, as in life, the centre of our grassy campus has as its core a commonly understood to be multi-faith Meeting House, which has served historically as a focal gathering place for contemplation, worship and fellowship for the university community. After our second meeting I approached a key university official and asked for the small iconic Celtic crosses to be removed from the Second Life virtual Meeting House Chamber for the duration of our event, explaining that as we were composed of agnostics, Muslims, Buddhists, Neo-Pagans and Others, the Christian symbolism present felt inappropriate.

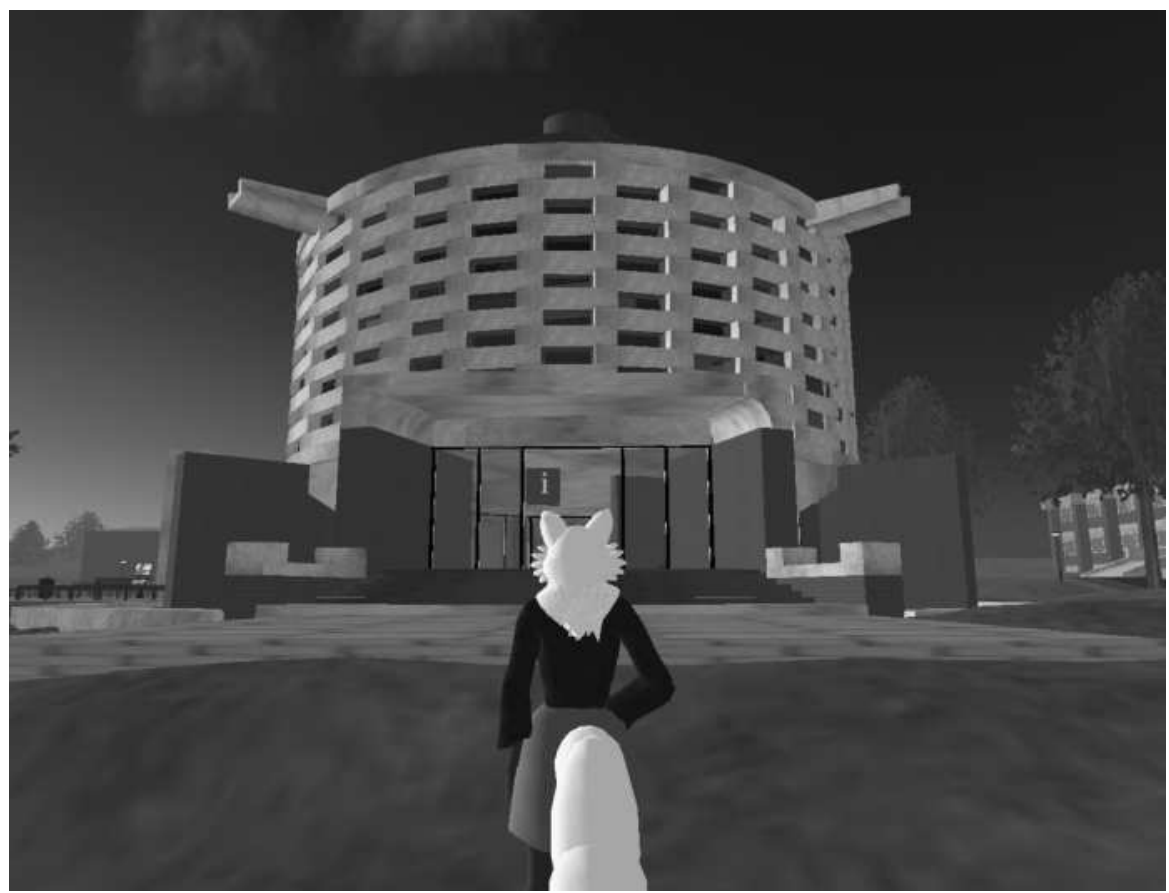

Figure 1.4 'Limpid Pool' looks toward the University of Sussex Meeting House Building in Second Life 
My request provoked an enraged response, heatedly comparing our presence in the Meeting House to 'prostitutes in the Library'. The officer concerned then immediately phoned the university web team to demand that a gigantic big cross be installed at the front of the chamber! This once again illustrated the need for this project, even in supposed or assumed 'multi-faith' environments (which turned out not to be).

So, our Queer Spiritual Spaces project was confronting its limitations; we certainly needed to look elsewhere. On Second Life, Patrick found another venue, some rather beautiful sacred grounds, also non-affiliated, but the owner was reluctant to incorporate our desire to design our own corner within it. So, we approached the virtual city of my home - New Brighton - on Second Life, where owner Bernard happily embraced us and positively supported us in building our own structure, in a fresh spin on 'town and gown'. The edifice, the Queer Spiritual Spaces project building became homed, and not so far away after all - one might even say, in a 'parallel world', complete with cats and an owl.

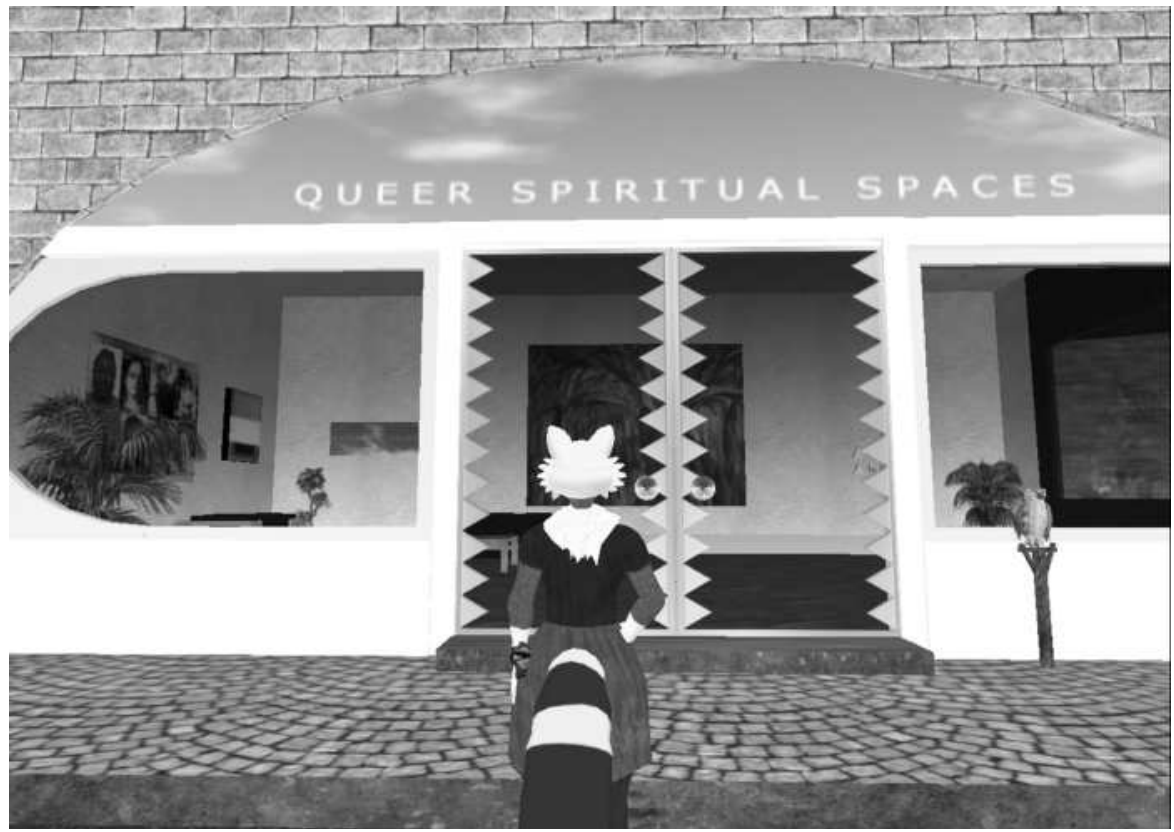

Figure 1.5 'Limpid Pool' standing outside of the Queer Spiritual Spaces Building, New Brighton, in Second Life 
It was necessary for all the team to adopt avatars ${ }^{22}$ for our meetings, so some of the personnel on the project became suddenly and creatively enhanced by, for some, flirty playful alter-egos, several of whom changed with each appearance. In these guises we went on trips in a submarine, and a balloon, we had parties, we had fireworks. Time tended to run away with us, it was becoming a different kind of (research?) practice, in which we mused, and danced, and were not always altogether serious.

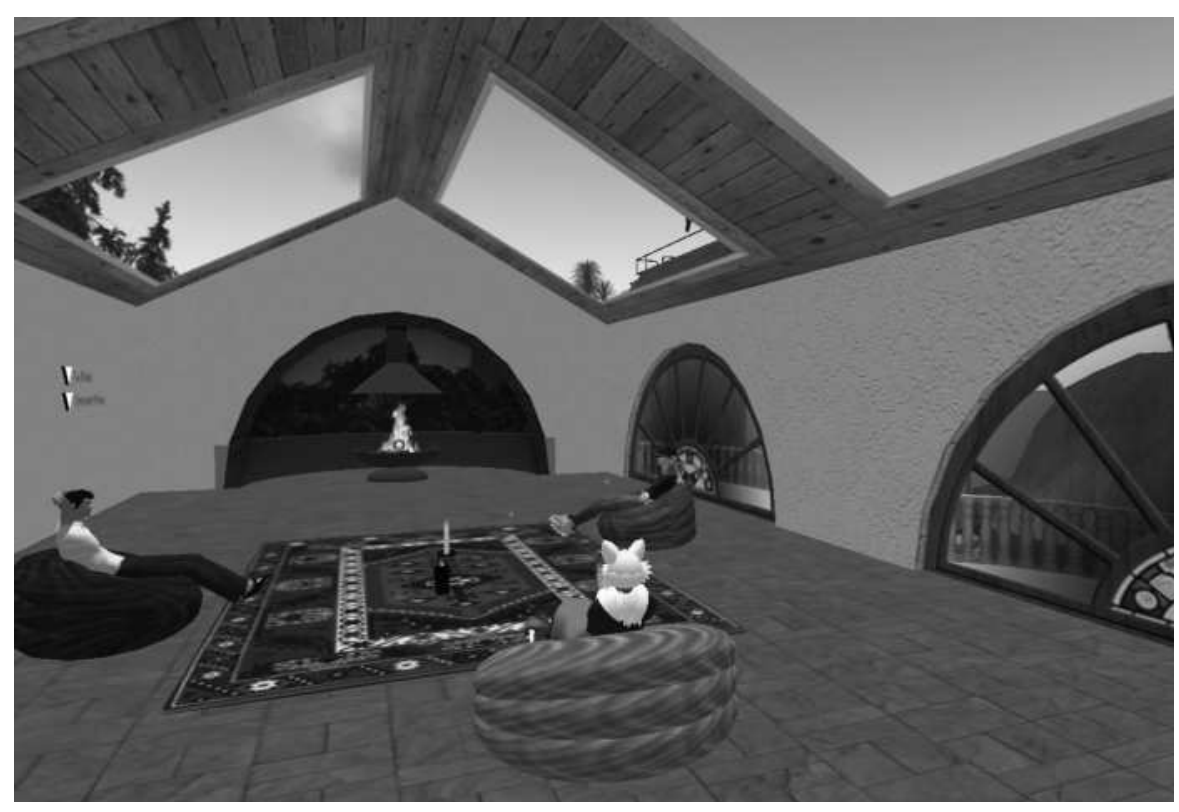

\section{Figure 1.6 'Limpid Pool' with Bernard (site owner) and 'Only Messing' (Patrick) in the Queer Spiritual Spaces Building in Second Life (interior: on the third floor, the contemplation room)}

Methodologically this had the effect of transforming the project into an activity that could also accommodate play and the strange, alongside traditional scholarly enterprise. It was not just play that was permitted, researchers reported back that their relationship with participants involved a range of emotions and

22 The use of the term avatar is common in virtual environments and gaming, the word itself connotes the materialisation of the divine, and the embodiment or materialisation of an idea. Second Life $[\mathrm{SL}]$ requires that participants create a 3D graphic avatar, and residents traverse this environment in the digitality of the avatar - whether male, female, androgynous, or nonhuman. Animals and fictional/fantasy avatars can be used in SL. 
affiliations; we were implicated as people, as well as professionally alert. Ethics on the project were intricately thought through, many of us found that our personal reactions were colouring our responses, and we spent considerable time talking about the implications for our findings. Part of this complexity was caused by our intention to be open, and to shun judgmental attitudes toward any faith-based practice. This was harder than it sounds!

\section{How was this book written?}

The research project involved a team of interdisciplinary researchers: Professor Sally R. Munt, Principal Investigator and Project Director, two advisors Dr Kath Browne and Dr Andrew Yip, and a digital media specialist Dr Kate O'Riordan who was brought onboard once it became apparent that queer spiritual seeking could be productively explored online. There were four postdoctoral research assistants employed on the project: Dr Elizabeth Dinnie, Dr Amna Khalid, Dr Sharon Smith, Dr Heather White, and a postgraduate student in digital media, Mr Patrick James. Dr Olu Jenzen organised the Queer Spiritual Spaces conference of March 2009, and helped us as Research Assistant in compiling, editing and checking the manuscript. In addition, in the early stages of the project two British academics, Dr Jenny Alexander and Dr Gavin Brown also contributed positively to our thinking. We deliberately amassed expertise across several disciplinary fields in order that our perspectives were varied and informed by a mixed intellectual framework. So clearly, many people have been essential to informing our work and contributing to our book.

The three named co-authors of the book, Browne, Munt and Yip have written the manuscript collaboratively, taking a section each to write as primary author and then revising each other's chapters, with O'Riordan being the principal author on the virtual believers. This last chapter was also revised and edited by the three principal authors. Each author retained final control over their chapters, and is thus responsible for the content therein. Four of the chapters are significantly dependent upon the data collected by one of the postdoctoral researchers, Dinnie, Khalid, Smith, or White, who are also credited in the relevant chapters.

The book is not a completely anarchic miscellany, however, it is structured to represent the more 'mainstream' religions first (Quakers, Islam and Buddhism), before addressing the spiritual spaces that are presumed to embrace, refuse and refute traditions whilst re-establishing their own norms (Findhorn, Michigan Womyn's Music Festival and Spiritualities online). Each of these case studies stands on it's own, and yet reading them together makes the interconnections, commonalities as well as the diversities apparent. As authors we have varying styles, we began this journey through a cultural and literary experience that swam through the sublime. We conclude with a more 'traditional' conclusion 


\section{QUEER SPIRITUAL SPACES}

that draws together only some of the plethora of possible themes. Prior to these the book will now offer an engagement with the key social scientific and theological literature that have to date intersected sexualities (and to a limited extent gender diversity), with religion and spiritualities. 



\title{
Chapter 2
}

\section{Coming Home from the Wilderness: An Overview of Recent Scholarly Research on LGBTQI Religiosity/ Spirituality' in the West}

\author{
Andrew K.T. Yip
}

Following Sally's wonderful introduction which emphasised the emotional spaces and possibilities of queer spiritualities, this chapter turns our attention to the literature on religion/spirituality, as it intersects with, in the main, lesbian and gay identities, practices and lives. Religious communities have been criticised, and at times vilified, for their resistance to progressive change in recognising sexual difference, rights, and equality, which is increasingly evident in secular institutions and spaces. There is indeed much truth in the dominant view that organised religions lag behind the secular sphere in embracing sexual diversity as a social reality. Nonetheless there is no denying that since $1960 \mathrm{~s}-$ in the West at least - LGBTQI (but particularly lesbian and gay) people within religious communities have experienced increasing social visibility and political clout. Four factors contribute to this: broader socio-cultural shifts that promote sexual liberalism; progressive legislative reform; increasing sophistication and effectiveness of secular and religious/spiritual lesbian and gay politics; and

1 This formulation of 'religiosity/spirituality' is deliberate to emphasise its inter-related character. Often, 'religiosity' is used to denote an individual's habitual - and uncritical deference to, and observance of, institution-led religious proscriptions, teachings, and rituals; while 'spirituality' represents a subjective, reflexive and critical exploration of flexible and fluid meanings and practices devoid of institutional control and surveillance, thus more democratic and inclusive. I find such formulation too rigid and unhelpful, because it constructs 'religiosity' and 'spirituality' as bipolar opposites. Thus, being 'spiritual' assumes an air of superiority, as opposed to being 'religious', as if an individual who operates within an institutional setting is less capable of being critical and subjective in the management of her/his religious identity, compared to her/his counterpart outside of an institutional setting. This is a simplistic construction that underlines much of the misunderstanding - and indeed hostility - that many religious LGBTQI people experience in the broader (mainly secular) LGBTQI community, a point that I shall further develop in this chapter. 
proliferation of scholarly research, particularly in theology, scriptural studies, and the social sciences, albeit with a heavy focus on Christianity.

Given the remits of our book, this chapter aims to give an overview of the last factor, which of course is inextricably linked to the other three (for a good overview of these factors see Engel 2001, Francis, Pratt and Chedgzoy 2002, Hunter, Joslin and McGowan 2004, Weeks 2000, 2007). This chapter begins with an analysis of the emergence of lesbian and gay-affirming sexual theology, which has generated much-needed theological capital, namely inclusive scriptural knowledge, imagery, and language. This form of capital serves as a resource for religious/spiritual LGBTQI ${ }^{2}$ people to find solace, support, and nourishment, against a heterosexist institution, and a community of believers, many of whom are still ill-informed about LGBTQI lives.

The chapter then addresses an exciting development in recent years, namely the convergence of such theological capital with social and political capital, in the form of secular discourse of equality and human rights. This convergence unleashes even more empowering currents that help religious/spiritual LGBTQI identity politics to scale greater heights in its tussle with heterosexist teachings, ideologies, and attitudes with religious communities. Finally, the chapter will proceed to reviewing key social scientific research on LGBTQI religiosity/ spirituality, by offering four emergent themes.

It must be acknowledged at the outset that the chapter will focus extensively on organised religions; particularly Christianity, but also Islam and Judaism. This is a reflection of the current research and political focus in the West. Further, it will become apparent that the spotlight of research and debate in this respect is on homosexuality (particularly male homosexuality), although terms such as 'LGB', 'LGBT' and 'queer' are routinely used. In other words, current literature focuses primarily on gay men, and to a lesser extent, lesbians. This signifies another limitation of the enterprise thus far, which heightens the need for expanding and diversifying the current research agenda, a point that we develops further in the concluding chapter.

\section{Turning savage texts to texts of love and acceptance}

In the popular and academic discourses of sexuality and gender, religious texts play a significant role in the construction and perpetuation of varied forms of phobia toward sexual and gender dissidents living outside of the heteronormative framework. Whether it is a religious leader who claims

2 As we noted in Chapter 1, we use LGBTQI to represent lesbian, gay, bisexual, trans and intersex people. Most of the literature that is addressed in this chapter is focused on gay men, and to a limited extent, lesbians. 
exclusive authority to pontificate on - or a theologically untrained lay person who simplistically condemns - homosexuality, texts are often deployed to justify their position;whether it is the literal citation of scriptural passages/ verses or evocation of principles (e.g. 'natural order'), based upon a historical interpretation of such texts. In the case of traditional scriptural exegesis, it is indisputable that homosexuality - specifically genital acts between men - has been subjected to the most negative of treatments. Thus, the text becomes the source from where the venom of homonegativity ${ }^{3}$ flows. It is perhaps understandable that radical queer Christian theologians such as Goss (2002) have called Christian texts 'texts of terror' that commit 'biblical terrorism' and 'textual violence' against LGBTQI people. Against this backdrop, religious texts become an arena where power relations are played out, in the construction and contestation of often opposing truth claims. In this respect, LGBTQIaffirming scriptural scholars - many of whom are religious/spiritual LGBTQI people themselves - have produced a fascinating and rich corpus of work that could be divided into three broad and inter-related categories.

\section{Defensive apologetics}

The first category generally constructs defensive apologetics that aim to re-contextualise textual passages/verses which have been conventionally deployed as an indisputable basis for the moral exclusivity and authenticity of heterosexuality, and the unacceptability of homosexuality. From this perspective, Biblical passages/verses (e.g. Genesis 19, Leviticus 18:22 and 20:13, Deuteronomy 23:18, Romans 1:26-27, I Corinthians 6:9) and Qur'anic suras (e.g. 6:85-87, 38:11-14, 54:33-40), are read through an alternative interpretive lens. Thus, the widely-cited story of Sodom and Gomorrah in the Bible (or Story of Lot in the Qur'an) is re-interpreted (i.e. re-examined, often in relation to the original languages in which such texts were written) and re-contextualised (i.e. understood in relation to the historical and cultural context of the time). In the process, a story traditionally used as the justification for the Creator's disapproval of sinful male-male genital acts appropriates a new meaning of male-male sexual violence and inhospitality, incompatible with the Creator's law of love and compassion. Put another way, what led to the cities being destroyed by the Creator's wrath was the sexual acts committed within a context of violence and force. That they happened to be male-male genital acts is immaterial. In the

3 Some scholars have argued that 'homonegativity' is a broader and more accurate term to describe negative feelings and attitudes towards, and treatments of, homosexuality and homosexual people; rather than the clinical term 'homophobia' which denotes a psychological/ medical condition (i.e. 'phobia') (for a broader discussion see e.g. Hudson and Ricketts 1980, Mayfield 2001, Roderick, McCammon, Long and Allred 1998). 
same vein, seemingly anti-LGBTQI sexual codes and proscriptions in scriptures have been re-cast as temporally and spatially specific, which do not accurately reflect contemporary understanding of human sexuality and intimacy (for a summary of such debate see Yip 2005a).

This category of scholarly work represents the initial stage of the development of the reverse religious discourse that challenges the truth claims of the heteronormative dominant discourse. The achievement in this respect-in theological, scriptural, and historical studies of Christianity at least - is nothing short of spectacular. This body of work - for Christianity, see Boswell 1980, Goss and West 2000, Hanway 2006, Jordan 1998, 2000, Long 2004, Macourt 1977, Stuart 1995, 2003; for Islam see Jamal 2001, Kugle 2003, 2007, 2010, Nahas 2001; for Judaism see Goldberg 2009, Greenberg 2005, Roden 2009; for Buddhism see Leyland 1997, 1999 - collectively performs stigma-removal on homosexuality, and constructs it as a historical existential reality which is part and parcel of the created kaleidoscope and diversity of human existence.

Recent years have also seen the proliferation of exciting theological attempts to de-stigmatise trans lives, bodies and identities (e.g. Althaus-Reid and Isherwood 2009, Cornwall 2009, Mollenkott 2007, Mollenkott and Sheridan 2003, Sheridan 2001, Tanis 2003), deploying similar strategies of scriptural reinterpretation and re-contextualisation (e.g. Genesis 1:26-28, Deuteronomy 22:5, Deuteronomy 23:1, I Corinthians 11:14-15). Through this lens, the act of challenging fixed sexual/gender boundaries or subverting gender categories is far from tampering with the created order. Rather, it is an act of assuming what Mollenkott (2007) calls an 'omnigender paradigm' in the understanding of gender, having been liberated from the tyranny of rigid gender binarism or dualism. Thus, transgenderism becomes an embodied process of spiritual growth, intimately connected to an individual's relationship with herself/ himself, God, and others, as a gendered, sexual, and spiritual being. Therefore, bodily transformation and modification could be part and parcel of spiritual transformation (for a summary of this debate see Yip and Keenan 2009).

Interestingly, rigorous and robust theological de-stigmatisation of bisexuality has yet to be developed, to the best of our knowledge. I am of the view that this is partly because bisexuality - as far as dominant theological and popular discourses go - is even more subversive of heteronormativity compared to transgenderism and homosexuality, particularly in terms of relationship form and management. The prevalent misconception of bisexuality as simultaneous sexual attraction to both sexes could lead to the misunderstanding that one has to have two partners of different sexes at all times; thus a triadic formation. This could fundamentally render the dominant model of committed and faithful - assumed to be dyadic or coupled - relationship unworkable. I think there is much fear within religious communities that, unlike sanctioning same-sex relationships and dyadic intimate relationships involving a trans partner - but 
firmly within the dyadic model - supporting bisexuality would tantamount to undermining this entrenched ideology of relationship formation. Therefore, bisexuals are often thought of as being promiscuous and incapable of dyadic (in dominant religious and popular terms, faithful and committed) relationship (see also Browne and Lim 2008, Klesse 2007). This generates much pressure on bisexuals to exercise choice and opt for 'normality', namely being in a relationship with a different-sex person. It would be interesting to see how LGBTQI-affirming theologians incorporate the range of bisexual lives and identities, challenging not only misconceptions that equate bisexuality solely with triadic formations, but also the conventional dyadic model of religioussanctioned relationship formation that could be questioned by queer relationship and kinship forms that problematise monogamy, commitment and dependency within such a model.

\section{'Cruising' texts}

Far from being apologetic, the second category of work exudes confidence and creativity in 'cruising' religious texts by uncovering same-sex eroticism, intimacy, and sociability within them, not only as evidence of the existence of 'our own people', but also as a spiritual guide for religiously-sanctioned ways of expressing same-sex intimacy. From this perspective, such texts are far from anti-LGBTQI, as widely believed. Rather, their LGBTQI-affirming imagery and language have been systematically silenced and suppressed by traditional and heteronormative theology. In Christianity, the biblical accounts of intimate relationships such as those between Ruth and Naomi, and between David and Jonathan, have often been used in this respect. Further, the Song of Songs, the treatise to love in the Old Testament, has also been appropriated in a LGBTQI-affirming fashion (e.g. King 2000, Koch, 2001, Stone 2001a, 2001b). In addition, this corpus of work also 'queers' significant figures in such texts (e.g. Jesus, the Prophet Mohammad), by demonstrating their acceptance of, and alliance with, socially disenfranchised people, including sexual dissidents (e.g. Goss 2002, Kugle 2010, Moore 2001). Jesus, for instance, is often constructed as being critical and subversive of unequal socio-political structures, and was unafraid to challenge them in the pursuit of justice. Thus, such reading of the texts instils pride and a sense of belonging to the family of believers. Far from being outcasts, LGBTQI people, as these texts evidence, have always been a part of religious communities.

Contributing to this body of work is the emergence of sophisticated scriptural commentary from a LGBTQI standpoint (e.g. Guest 2005, Guest et al. 2006). Such literature guides the reader to approach the texts with queer sensibility, relating them to the diverse experiences of being LGBTQI. It is hard not to be moved by the thought of a lesbian or gay Christian declaring with 
pride, honesty, and confidence that, 'God, you fashioned me in my mother's womb ... For I am awesomely and wondrously made' (Psalms 139:13-14). Appropriating verses such as these turns them into empowering statements of faith and ontology, underpinned by the unshakable certainty that one's sexuality (and gender) - no matter how despised and persecuted - is not just a choice or random genetic predisposition, but divinely willed and planned. This development, at this juncture, is fairly restricted to Christianity, but no doubt this is only the beginning of a rich and empowering journey in the production of theological capital that not only de-stigmatises LGBTQI people, but also instils pride in religious LGBTQI people about their claim of belonging to the family of God, the community of believers.

\section{Turning theology upside down}

The final category of theological work builds on the strengths of the first two, but operates within a broader framework, with a more extensive aim to fundamentally overhaul theology, not only in relation to the body, gender, and sexuality; but most importantly the character of the divine and the human, and their relationships. Their explicit aim is to develop a sexual theology and ethics that adopts a 'bottom up' approach; one that prioritises embodiment and experience, rather than 'top-down' systematic theology that dichotomises the body and the spirit. This is a theology that is not afraid of the body, its desires, wants, and passions. It conceptualises the inseparability of sexuality and spirituality, and sexuality as not only genital acts, but human capacity for sensuality, relationship, companionship, commitment, and faithfulness, reflected in our own relationship with God, as the following quote illustrates (see also e.g. Ali 2006, Bohache 2003, Loughlin 2007, Nelson 1992, Rudy 1997):

[S]exuality is much more of an integral and holistic part of the human experience than the activity of genital sex. It is the source of our capacity for relationship, for emotional and erotic connection, for intimacy, for passion and for transcendence. It is a holistic expression of our human experience as body-selves ... Consequently, sexuality is 'neither incidental nor detrimental' ... to spirituality, but an important and integrated dimension of it ... In other words, it is through the sensuality of human sexuality (which includes but is not limited to genital sex) that individuals can experience a direct erotic connection with the God of one's understanding. In the language of Christian theology, embodiment is incarnation - the Holy is known and experienced in the flesh. (Horn et al. 2005: 81-82 emphasis in original)

This body of work also seeks to expand current heterosexist theological framework for, for instance, the institution of marriage, making it also inclusive 
of committed same-sex relationships (e.g. Ali 2006, Boswell 1994, Jordan 2005, 2006, Shannahan 2009, Stuart 1992, 1995, Thatcher 1999, 2003). More generally, this body of work also aims to re-orientate our understanding and relationship with faith and the Creator, underplaying the role and authority of religious structures, and highlighting the authority of the self and personal experiences (e.g. Althaus-Reid 2000, 2003, Countryman 2007, Manji 2003, Ruttenberg 2009, Salzman and Lawler 2008, Thatcher 1993). Collectively, this work shows that - as the title of a book proudly proclaims - 'Religion is a queer thing' (Stuart et al. 1997).

\title{
The ethics of reading texts
}

On the whole, the theological and scriptural literature I have reviewed illustrates an ethical and moral point of paramount importance: we must take great care in the deployment of religious texts. Using examples such as slavery, anti-Semitism, sexism, racism, alongside homosexuality, Thatcher convincingly argues that when the Bible is elevated to a status above Christ and embodiment of love and grace, it turns into a 'savage text' that perpetuates persecution, oppression, and pain:

\begin{abstract}
No, the savage text is not the Bible. It is what Christians have made of the Bible when they have used its pages to endorse cruelty, hatred, murder, oppression, and condemnation, often of other Christians. The savage text is what the Bible, or parts of it, becomes when it enables Christians to convert the good news of God's revealed love in Jesus Christ into the bad news that people are the wrong color, or race, or gender, or denomination, or orientation, or religion, or class, or empire, just because they differ from the Christians who are preaching this bad news. The savage text belongs to a 'mind-set' that authorises condemnation of any view or practice which is not that of its official or most powerful readers. When the Bible becomes a savage text, the theology that is proclaimed from it is already faulty. The savage text makes hatred holy. It makes seekers after truth its jealous guardians. Perhaps the worst feature of the savage text is the divine authority it claims for it strictures. The savage text is implicated in the moral case against Christianity. (Thatcher 2008: 5)
\end{abstract}

Indeed, the key issue here is the deployment of religious texts. Deployed wrongly, it could perpetuate evils. Deployed correctly and sensitively, it leads to the enhancement of humanity. Text is neutral, but the reading of it is not, since the reader engages with the text from a specific standpoint, reflecting her/his own ideological, political, cultural, and socio-economic leanings (e.g. Goss and West 2000, Lozada 2000, McFayden 2000, Yip 2005a). In this battle, all competing parties uphold the sanctity of the texts, but they battle over the legitimacy, validity, and authenticity of their respective perspectives; as well as 
the position of the text in the broader scheme of evaluation vis-à-vis significant factors such as personal experience and ijtihad (i.e. independent reasoning) (e.g. Kugle 2010, Manji 2003, Yip 2005a). It is exactly this kind of religious individualism - confidence and trust in their embodied experiences - through which religious/spiritual LGBTQI people find, in religious texts, love and acceptance, rather than hate and rejection.

\section{From shame to pride: The convergence of reverse religious discourse and secular discourse of equality and rights}

In the above section, I have provided an overview of the development of LGBTQI-affirming theological and scriptural studies which collectively construct a reverse religious discourse that challenges the dominant traditional discourse by exposing its heteronormative underpinnings, its blindness to history and changing socio-cultural realities. While such developments are a modest step forward compared to the giant steps that have been taken by secular institutions in many Western countries in terms of legislation and social attitude (e.g. Beger 2004, Weeks 2007, Francis, Pratt and Chedgzoy 2002), this 'silent revolution' cannot be denied.

Yet, this progress is often drowned out by the occasional but high-profile moral panics within religious communities specifically over the issues of homosexuality and gay priests. Perhaps it is not surprising then that even non-religious LGBTQI people themselves are so critical of their religious counterparts for seemingly choosing to remain within an institution that seems to actively and systematically exclude them. I find the representational binary that assumed to exist between a society that is pulling away, propelled by the wind of liberalism, and a religious community that is left behind in a time warp, a lazy exaggeration. Such dichotomous construction is also unhelpful, because it concretises the pervasive view that religious communities are so antiLGBTQI that staying within it is tantamount to 'sleeping with the enemy'; even a reflection of false consciousness, underpinned by a toxic guilt and shame that corrodes LGBTQI peoples' humanity. Further, this construction also casts the religious and the secular as opposing forces. This view is widely held by secular LGBTQI people, whose intolerance of religion and religious LGBTQI people could be as forceful as heterosexuals' intolerance of LGBTQI people in another context. In this respect, Puar argues that:

Queer secularity demands a particular transgression of norms, religious norms that are understood to otherwise bind that subject to an especially egregious interdictory religious frame. The queer agential subject can only ever be fathomed outside the norming constrictions of religion. (2007: 13) 
Thus, secularity - and I would add, the rejection of religion - becomes a passport to what Puar (2007) calls 'homonationalism'. Indeed - others' and my own personal and professional experience of relating to the LGBTQI community as well as the LGBTQI Academy is consistent with Puar's assertion (e.g. Wilcox 2006, Yip 2005b). This one-dimensional ideology could lead to norms and practices, however implicit, which undermine the sense of belonging of religious people within the LGBTQI community. They also refuse to recognise the importance of religion/spirituality as a resource for the construction of meaningful LGBTQI lives.

There is no denying that religious/spiritual spaces for LGBTQI people within religious communities have been expanding, largely because of their own strenuous effort to construct such spaces; but partly also due to some of their heterosexual counterparts who have become more accepting of sexual difference, informed by broader socio-cultural change. Indeed, the discourses of 'equality' and 'human rights', and to a lesser extent, 'sexual/intimate citizenship' (e.g. Plummer 2003, Richardson 1998, 2000a, 2000b) that have been 'mainstreamed' into political agendas have in recent years been making inroads into religious communities. Such discourses focus on the dignity of difference and the right to live such difference in all contexts, in ways that does not cause harm to others, and without any fear for discrimination and persecution.

Focusing on Christian communities in the West, we witness the appropriation of the language of such discourses in the contestation of their presence by LGBTQI Christians within religious spaces. Over the years, this demand of presence has transformed from the apologetic 'We should be here because ...' to 'We are here, get used to it!' - an articulation of confidence and pride. This is a case of turning externally-imposed shame to an internally-generated pride (e.g. Munt 2007). This sense of pride stems from the ontological security and existential foundation of the subjective assurance that, despite what religious authority structures officially pronounce, God is on their side, and Christ is on their side. This is because they have learned to trust their own lived experiences of the goodness and mercy of God, a God who created - and continues to sustain and renew - difference and diversity; an irrepressible truth of life. They have also learned to separate their personal walk with God from the humanmade (especially man-made) rules of engagement that control and regulate the positionality of LGBTQI believers and their access to the nourishing space within religious communities.

Thus, the belonging of LGBTQI believers in religious communities is no longer merely a theological debate, but a debate about rights and equality. The Lesbian and Gay Christian Movement in the UK famously coined the term

4 Established in 1976, this organisation is widely considered the most high-profile support organisation for lesbian and gay Christians in the UK. Its professional and political agenda at times 
'Christian homophobia' (1999) in a report that carries 74 recommendations of good practice for churches in their treatment of lesbian and gay believers. Indeed, the development of LGBTQI Christian support networks has played a significant role in not only generating social capital for individual LGBTQI believers, but also adapting theological capital to contest religious orthodoxy (e.g. Hunt 2009). Although religious authority structures have attempted to argue legally for exemptions from some of the legislations on sexual equality (e.g. employment in religious authority structures, church-owned adoption agencies placing children in same-sex households), their efforts have largely failed. Observing such developments, Yip and Keenan (2004: para. 1.6-1.7) have argued that:

Not only does this reverse discourse engage with scriptures and traditions ... it also, rather significantly, draws upon contemporary cultural discourse of citizenship and human rights. Strengthened by such religious and cultural resources and vocabularies, the reverse discourse attempts to reflect much more accurately contemporary socio-cultural reality, arguing that moral absolutism is, or should be, a thing of the past, and that in today's society, respect for cultural pluralism and social diversity (thus sexual difference) is the value on which contemporary life should operate. The value of deferential compliance to institutional authority is increasingly being eclipsed by the value of personal liberty and rights. Thus, there is a convergence between the religious reverse discourse and the cultural discourse that in turn lends the former significant social and political currency. Against this backdrop, the traditional discourse appears authoritarian, disrespectful of diversity, averse to progress, and irrelevant to contemporary socio-cultural reality.

Indeed, I envisage that the appropriation of the secular discourse is going to be more extensive, not only among religious LGBTQI people, but also among their heterosexual counterparts who become more aware of the importance of recognising diversity and difference. Social scientific research in this respect has a particular important contribution to make to this development, a point to which we shall now turn.

has attracted criticism for underplaying the religious dimension. Nonetheless, its effectiveness cannot be denied. In recent years it has also expanded its agenda to working with secular lesbian and gay rights organisations and non-Christian religious LGBTQI support organisations to establish a more comprehensive framework for its ministry. For more details see http://www. lgcm.org.uk. 


\section{An exploration of lived experiences - The contribution of social scientific research}

Having considered the contribution of theology and scriptural studies to the de-stigmatisation, affirmation, validation, and celebration of LGBTQI lives within religious communities, this section aims to round up the contribution of social sciences to the exploration of LGBTQI religiosity/spirituality and the political and policy debates this ensues. The importance of the documentation of lived experiences cannot be underestimated. Whilst theology often engages with 'what ought to be', empirical work grapples with 'what is', amidst the messiness of life as lived. Thus, the focus is not so much on precepts, teachings and institutions, but on how an individual's appropriation of various resources to construct meaningful lives within an everyday context (e.g. Ammerman 2007, McGuire 2008).

There has been an encouraging proliferation of literature in this field in the past two decades. However, as I have acknowledged, research in this respect focuses primarily on Christianity, and lesbian and gay believers (though the label 'LGB' or 'LGBT' are often deployed). Nonetheless, recent years have witnessed a much-welcome expansion of this dominant framework, examining specifically the experiences of bisexuals (e.g. Kolodny 2000, Toft 2009a, 2009b). However, much more needs to be done to address trans, intersex and those otherwise queer, as Kath rightly argues in our concluding chapter. I have organised this corpus of social scientific literature into four themes as follows, with the first being the most developed and extensively researched.

\section{Diverse management strategies of homonegativity}

Mirroring the development of theological and scriptural research, the first theme focuses on LGBTQI people in institutional religious settings, specifically the strategies they have developed to manage the tension and dissonance between religion and sexual and gender difference, since such resiliently heteronormative spaces are perceived to be the most vociferous in the condemnation of such difference (particularly homosexuality). On Christianity, works by an increasing army of scholars such as Gross and Yip (2010), Henrickson, Neville, Jordan and Donaghey (2007), Mahaffy (1996), O’Brien (2004), Phillips (2005), Thierry (2005), Thumma (1991), Trzebiatowska (2009), White and White (2004), Wilcox (2002, 2003, 2005), Yip (1999a, 2004a, 2005a, 2005b) have generated findings which broadly suggest diverse management strategies.

There is indisputable evidence which demonstrates that the weight of heterosexism and homonegativity could have significantly negative effects on LGBTQI Christians, in the form of the creation of negative emotions such as shame and guilt, which grossly undermine their mental, emotional, and 
spiritual health. At times this leads to disillusionment with religion, resulting in the dissociation from particular religious communities. For others, or at different times, it can lead to various possibilities. Such possibilities include participation in LGBTQI-friendly religious and spiritual spaces, for instance, in the Metropolitan Community Church which is renowned for its inclusive ethos which attracts socially disenfranchised people of various kinds (e.g. Gross 2008, Lukenbill 1998, Rodriguez and Ouellette 2000, Walton 2006, Wilcox 2001, 2003, Yip 2000).

The most positive narrative generated by this body of work is undoubtedly that which demonstrates LGBTQI Christians' ability to transcend such structural constraints and challenges. By deploying various strategies, they not only defend their existence, but take the bull by its horns, and actively contest for an inclusive religious space, for not just LGBTQI people, but also for all people. In other words, their pursuance of sexual justice is closely related to their commitment for social justice for all. Much of such an endeavour is empowered by the emergence of theological capital which I have discussed above (see also Neitz 2000, Yip 1999a, 2005a). Having gained the confidence about their legitimate place in the created order, such activists mobilise themselves in the construction of social and political capital that further solidifies their power base, from which they launch an increasingly sophisticated programme for change (e.g. Aune 2009, Buisson-Fenet 1999, Comstock 1996, Comstock and Henking 1997, Dillon 1999, Gill 1998, Maher 2006, McCall Tigert 1996, Moon 2004, Yip 1996a, 1997a, 1997b, 1998, 1999b, 2005b, 2007, 2008a, 2008b, 2009a, 2009b).

Beyond Christianity, there is a gradual development of research which has generated similar narratives within the remits of management of difference within resilient heteronormative environments, but less extensive for the transcendence of structural constraints. In this respect, key works on Islam include: Haqq 2000, Minwalla et al. 2005, Nahas 2004, Naz Project 2000, Rouhani 2007, Safra Project 2003, Siraj 2006 (On Judaism, see e.g. Alpert 1997, Alpert, Elwell and Edelson 2001, Beck 1982, Gross 2007a, 2007b, Halbertal and Koren 2006, Schnoor 2006, Shokeid 1995; and on Buddhism, see e.g. Cadge 2005). I think it is extremely important that we do not assume that the experiences of LGBTQI people of non-Christian religions will mirror that of LGBTQI Christians. As I have argued elsewhere (Yip 2005b), it would be culturally arrogant and anthropologically naïve to assume that LGBTQI politics within minority religious spaces would necessarily follow the same trajectory that LGBTQI Christian politics has travelled. Minority religions often take up an additional dimension in a religiously different mainstream society as a form of cultural defence, which introduces specific dynamics into the management of religious identity and life. Within the Western context, Islam, being so highly politicised and often misrepresented, is an example par excellence. I shall return to this point later. 


\section{LGBTQI people's religious beliefs and practices}

This theme, as well as the next, is conspicuously less developed compared to the first, which signifies the need for more research. Further, they also focus almost exclusively on Christianity. This theme focuses on the exploration of LGBTQI religious people's beliefs and practices, for instance, how their sexual and gender difference may inform the way they perceive the divine and religious texts, and how they practise their religiosity publicly and privately (e.g. Bardella 2001, Gross and Yip 2010, Sherkat 2002, Yip 2002, 2003a, 2003b). Importantly, such literature shifts the focus from the moral and ethical debate of homosexuality and LGBTQI believers' management of it to LGBTQI believers themselves as people of religious faith. The spotlight is not necessary on their sexuality, although it remains prominent. On the whole, such literature demonstrates that religious LGBTQI people adopt some form of 'religious individualism' in the construction and expression of their religious faith, significantly informed by their sexuality (Wilcox 2002, 2003). In other words, their sexual and gender identities place them in a particular standpoint in terms of their positionality in relation to the divine and their own humanity; and hence in how they to live out that connection.

While this is a reflection of the contemporary Western religious landscape that increasingly prioritises subjective experience as the locus of authority and basis of authenticity (e.g. Heelas 2008, Heelas et al. 2004), I have also argued that their stigmatised sexual and gender lives have also informed religious LGBTQI Christians' conception of God, Christ, and the Bible. For instance, God is more likely to be perceived as someone who upholds love and justice, rather than someone who controls and prescribes. The Bible, on the other hand, is respected as a pivotal text; nonetheless a guide for everyday living, rather than a behavioural template or blueprint. On the whole, personal experience is prioritised over tradition and religious authority structures in the fashioning of their lives (Yip 2002, 2003a). Wilcox (2002, 2003), who has been utilising gender as a significant factor in analysing the experiences of lesbian Christians, has provided an even more nuanced picture of how gender intersects with sexuality in lesbian Christians' lives her recent book (2009).

\section{Intersection of identities}

The last theme of this body of literature focuses on religious LGBTQI people's broader web of social relations, for instance, in relation to work such as priesthood (e.g. Keenan 2007, 2008, 2009), family members (e.g. HammoudBeckett 2007, Wilcox 2009, Yip 2004b, 2006), intimate relationships, including the issue of marriage/union (e.g. Yip 1996b, 1997c, 1997d, 2004c), and the primarily secular society at large (e.g. Abraham 2009, Yip 2005b). In terms of 
the relationship with the broader society, the experiences of religious LGBTQI people who are also members of ethnic and religious minorities within the Western context are particularly fascinating. LGBTQI Muslims are a good case in point: the intersection and multiplicity of their sexual, religious, and ethnic minority identities offers significant and interesting insights into the complexity and inter-connectedness of contemporary social life. As Abraham (2009) and Yip (2005b, 2008a) have shown, in LGBTQI Muslims' everyday life within the Western context that is often hostile towards Islam, the management of Islamophobia, racism, and homonegativity is inextricably linked. In fact, the management of the first two challenges is often more urgent and embedded in their daily life. Such experiences are may be less evident for LGBTQI people of other less politicised and contentious religions. Chapters 4 and 5 will demonstrate this point further, whilst other chapters points to the salience of other social differences, such as class (Chapters 3 and 7), age and generation (Chapter 8), and gender (Chapters 6 and 8).

\section{Moving beyond the institutional and appreciating the power of personal experiences}

Two other points deserve a mention before I end this section. While almost all of the social scientific on religious/spiritual LGBTQI people focus on institutional settings, for reasons that I have already mentioned, there has been a small body of research that examines spirituality within spaces that are not explicitly religious or spiritual, such as the LGBTQI community spaces, bars, and clubs (e.g. Boisvert 2005, Gorrell 2005, Gray and Thumma 2005, Long 2004, Peterson 2005, Sweasey 1997). Research in this area is worth supporting, because it will enrich our understanding of the creative ways LGBTQI people seek spirituality in different spaces and contexts. It could offer a much more nuanced picture of how contemporary religious/spiritual social actors live religion/spirituality. In some ways, our book is forging a path for this type of research.

Accompanying the development of social scientific literature is the emergence of anecdotal narratives and personal biographies (e.g. Brown 2004, Glaser 1988, Khan 1997, Leyland 1997, 1999, Marks 2008, Robinson 2008). The importance of such writings cannot be denied. They often offer moving and powerful stories of courage, resilience, and wisdom. In many ways, they could be more effective than scholarly writings precisely because they are not wrapped in an academic language. In terms of offering religious/spiritual LGBTQI people capital, their impact must not be underestimated.

The documentation of lived experiences is important on many levels. Politically, it signposts the presence and visible existence of LGBTQI people, even in spaces where their existence is most contested and oppressed. Sociologically, 
it shows how marginalised people understand and manage experiences of oppression, and transcend power structures such as heteronormativity by exercising their agency to change such structures through a myriad of strategies, for example, by remaining within seemingly homonegative spaces to effect progressive change. Indeed, their stories also demonstrate the resilience of the human spirit against adversity. In the area of sexual and gender difference and religiosity, literature also demonstrates the agency of religious/spiritual LGBTQI people as social actors, namely their capacity to transcend, challenge, and subvert religious orthodoxy, and creatively re-contextualise and adapt their faith. Whilst there are stories of victimhood and victimatisation, there are also positive stories of the transcendence, transgression and shifting of oppressive structures as a spiritual, material, and political experience. This is an exciting and heart-warming reminder of the resilience of the human spirit in the face of adversity and oppression, a theme that some of the chapters in this book has also captured.

\section{Concluding remarks}

That the proliferation of theological, social, and political capital in the West has mainstreamed LGBTQI religiosity/spirituality is an undeniable reality. This mainstreaming has promoted not only greater sexual and gender justice, but social justice and inclusion in general across religious and spiritual institutions and contexts. Nonetheless, there is still much work to be done for the ripples of inclusivity and reworking to be extended. This process of mainstreaming has also shown that LGBTQI subjectivities - and indeed LGBTQI spiritualities - is a product of contestation, negotiation, and renewal. Religious/spiritual LGBTQI people not only construct their presence within religious spaces, but also in the process transform their character. In fact, once banished to the wilderness, their voices are increasingly heard in institutional and non-institutional settings. Indeed, it is precisely their marginal positionality that offers them new eyes to look at religions from 'the outside in'. These new perspectives teach us not only about gender and sexual difference, but also broader issues about religion, faith, self, life, the divine, humanity. Indeed, such issues underpin this book to a great extent.

In the concluding chapter, Kath provides us with a tentative agenda which encourages us to be even more inclusive and extensive in scholarship and politics that intersects religion/spirituality and gender and sexual difference. I would also like to add that scholars need to ask themselves how they should not only talk to, and with, one another; but also how to communicate their work much more effectively to various stakeholders and users such as policy makers, equality and human rights professionals, religious/spiritual leaders, and 
politicians. If we truly are committed to the view that sexuality is much more than a private issue, and that it has a significant public and policy dimension (e.g. Plummer 2003, Richardson 1998, 2000a, 2000b), then we need to think about not only creative ways of engagement with, and dissemination to, user communities, but also more means of researching religious/spiritual LGBTQI lives and spaces. I am in a rare minority in this respect, but I genuinely believe that - notwithstanding the ideological, methodological, and political objections I often hear (in Western Europe particularly, see also Chapter 8, and Browne 2008) - we can do even better if we consider utilising quantitative methodology more extensively and effectively in tandem with qualitative methodology that has thus far made an indisputable contribution in this respect (for more details of my reasoning, see Yip 2008b). With such methodological pluralism, we may be able to propel the process of mainstreaming even more effectively (should this be a desired goal). Of course, as Chapter 8 points out definitional categories needed for such a methodology are problematic, and Chapter 7 explicitly notes the problems of segregating sexuality (in this case) and spiritualities. As we now move into the case study chapters, it becomes evident that nuance and complexity characterises explorations of lived experiences in this field. 


\title{
Chapter 3 \\ Quakers: Post-Christian Selfhoods within the Liberal Sphere
}

\author{
Sally R. Munt
}

\section{The Religious Society of Friends, or 'Quakers'}

To the general public, Quakers can be seen as an old-fashioned sect devoted to very Christian Protestant, neo-Puritan principles of moral probity, conscientious work and selflessness, typically characterised by plain dress and visually caricatured as the jovial man in the black hat depicted on a box of Quaker Porridge Oats (now incidentally owned by PepsiCo, USA ${ }^{1}$ ). Some Quaker respondents commented themselves upon feeling embarrassed by, and distanced from, this iconography. However, in Britain, nineteenth century industrial success in foods (Jacobs biscuits, Cadbury's, Joseph Fry, and Rowntree's confectionary for example) continues to be associated with an idea of Quaker wholesomeness. The Quaker Fry, Cadbury and Rowntree families dominated the British chocolate industry for two centuries, and it is this public commercial presence, associated with goodness, simple pleasure, and probity, that linger today. Quaker families went into business primarily because in England other professions were closed to them by law; as a religious sect they had undergone significant persecution since their first appearance in the mid-seventeenth century. Quakers became famous quickly for their economic fundamentals of 'fair-dealing' and plain living, their refusal to kowtow to conventional authorities, and their repudiation of submitting oaths to such powers, believing instead in egalitarianism and progressive education. Their combined religious aesthetic of mysticism and discipline provides an image of stillness and containment.

1 Most of us have seen the Quaker Oats box, with its image of a Quaker in plain dress. However, the Quaker Oats Company has never been connected to members of the Religious Society of Friends. The developer of Quaker Oats liked the qualities described - integrity, honesty, purity - in an encyclopedia article about Quakers. http://www.quakerinfo.com/quakfood.shtml accessed 31 October 2008. 


\section{Histories of belief and injustice}

The pioneering Religious Society of Friends, or 'Quakers', was initially dedicated to living in accordance with what they called the 'Inward Light', or direct inward and individual apprehension of God, without screening or interference by set creeds, clergy, or other ecclesiastical forms. ${ }^{2}$ Friends felt that their 'experiential' discovery of God was based upon a personal and transformative spiritual journey that would lead eventually to global peace and social justice. Emerging originally from the North of England, George Fox and James Nayler were early figures, but later came the renowned female Quaker figures Elizabeth Fry, Susan B. Anthony and Lucretia Mott. In the early days though, the movement grew quickly to embrace a radically non-hierarchical model of congregationalism that during that time presented a steep theological and social challenge to highly naturalised concepts of ecclesiastical authority. Friends were hounded by penal laws for not swearing any oaths, for not going to the services of the Church of England, for persisting in going to Quaker meetings, and for refusing to pay tithes. In the seventeenth century some 15,000 suffered under these laws, and almost 500 died in or shortly after being in prison, but they continued to grow in numbers. Quaker belief and practice also spread to the newly colonised America. In 1656 Quaker women preachers began work in Maryland and in the Massachusetts Bay Colony, but the persecution of Friends in Puritan Massachusetts grew intense: Quakers were lashed behind carts, whipped from town to town, branded with a ' $\mathrm{H}$ ' for heretic, had their tongues bored through with a hot iron, their ears were cut off, and they were banished. Finally the Governor of Massachusetts, John Endicott, invoked the death penalty for any Friends who returned to the colony after previously being banished. Consequently, in 1659 and 1661, four Quakers were hung on Boston Common: William Robinson, Marmaduke Stephenson, William Leddra and Mary Dyer. Mary became the first woman to suffer death in the US for her religious convictions. Despite this, Quakerism took strong root in the US as well as the UK. The most famous Quaker colony became of course Pennsylvania, for which Charles II issued a charter to William Penn in 1681. Penn's 'Holy Experiment' tested how far a state could be governed consistently with Friends' principles, especially pacifism and religious toleration. Quaker Meeting Houses sprang up in most English towns, and the faith continues to have a strong presence in the North of England; in the UK today there remains a vibrant faith of 481 weekly meetings often held in buildings that have been local town fixtures for hundreds of years.

The Society of Friends is proud of its history and traditions - the London library of the Religious Society of Friends in Britain is the repository for one

2 Histories of Quaker belief are widely available, a good source to start with is Dandelion (2007) An Introduction to Quakerism. Other useful titles can be found in the main bibliography. 
of the most important collections of materials in the world relating to Quakers and their activities, it is their 'archaeology of knowledge' and indicates the importance of the written word to its members. Started in 1673, the library adopted a policy to acquire two copies of everything written by Quakers and one copy of everything written against them. The collection covers Quaker history and thought, including topics in which Quakers have been socially and politically active, such as peace, anti-slavery, penal reform and relief work. The library also holds the central archives and records of the Britain Yearly Meeting, the governmental process of the organisation. Quakers tend to be a highly literate group of organic intellectuals deliberately cognisant of their religious identity and history, but also significantly cosmopolitan in their curiosity toward other faiths and views.

Modern Quakers sustain their story of origin in multiple ways:

1. They continue to profess their belief in the 'Inner Light', democratically unmediated by prophets, priests or kings;

2. They continue to ascribe to the four testimonies of peace, equality, integrity, simplicity;

3. Their worship is (compared to other neo-Protestant sects) unprogrammed and unstructured, depending crucially on an ethos of silence, and 'listening';

4. They adhere to a message of tolerance yet mobilise against social injustice;

5. Although they are non-credal, they do subscribe to a textual authority, or more precisely a 'guide', revised periodically and available on-line and in book form for reference at every Meeting: Quaker Faith and Practice.

From 4-12 October 2008 the Religious Society of Friends in the UK ran a series of newspaper advertisements (see Figure 3.1).

\section{Thou shalt

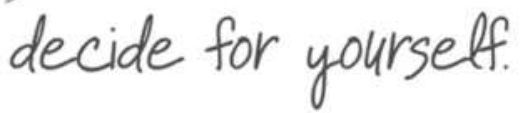

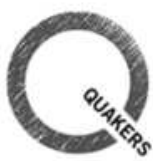

\section{Figure 3.1 'Thou shalt decide for yourself'. Quaker web page banner}

Source: Quaker web page. Accessed September 2008. Used with permission. 
The language selected for this current recruitment campaign is indicative - it simultaneously invokes the heritage of the Biblical sect ('Thou shalt ...'), which is an echo of the Ten Commandments of the Old Testament, whilst also firmly rejecting the dictatorial structure of a theistic belief-system ('decide for yourself'), replacing the authority of God with the autonomy of the individual. In this fragment of contemporary belief we see the liberal humanist essence of Quaker faith and practice emerging, a form of religious thought that can be most clearly described as post-Christian in its emphasis on the self. In keeping with this post-Enlightenment shift, the Society of Friends have prided themselves on their non-dogmatic and rational approach to religion, developing a stance that requires deference to perceived human attributes such as conscience, judgment, discernment and 'reason'.

\section{Quaker worship}

The Quaker practice of silence is described in terms of attentive listening, to 'being open to that of God'. Meetings take place in the local Meeting House usually for one hour; most participants attended regularly. The Meeting for Worship is generally what is described as an 'unstructured' session, however there are clearly established rituals taking place to do with opening, seating, appropriate speaking, and closure:

Silence is greatly valued by Friends. In removing pressure and hurry, it helps them to be aware of the inner and deeper meaning of their individual and corporate lives. It enables them to begin to accept themselves as they are and to find some release from fear, anxiety, emotional confusion and selfishness. This silence is more than an absence of sound ... Friends try to be open to that of God within ... The silence is different from that experienced in traditional, solitary meditation, which normally takes place deep inside oneself, as a devotional exercise for one's own spiritual development. The listening and waiting in a meeting for worship is a shared experience in which worshippers seek to meet God. (Weening 1995)

A Quaker meeting is not usually entirely quiet though; members are individually moved to speak, to offer fitting words to the assembled group:

Friends may worship entirely without words, but usually there will be some brief spoken contributions. This 'ministry' is intended to express aloud what is already present in the silence. Anyone may feel the call to speak, man, woman or child, Friend or first time visitor. There are a very wide variety of sources of spoken ministry and the acceptance of them is an important part of Quaker 
worship ... Friends try to receive positively what is said and to look for the underlying truth, regardless of the words in which it is expressed. If Friends are impelled to respond to vocal ministry, they should be very cautious and try to build positively on what has gone before. (Weening 1995)

The importance of silence, being able to 'centre down' into a quiet internal space, is what particularly characterises their practice:

Quaker worship happens when two or more people feel the need to be still together and seek God's presence ... In attentive waiting together in silence, Friends can find peace of mind and a renewed sense of purpose for living and joy in wonder at God's creation. (Weening 1995)

Whilst individuality is a central aesthetic of Quaker faith and practice, collectivity is also very important, as the physical space of containment of a meeting demonstrates:

The seating for a meeting for worship is usually arranged in a circle or a square to help people to be aware of one another, to be conscious of the fact that they are worshipping together. Those present settle quietly, and by corporately seeking God's will, become open to one another. This may happen quickly, or it may take most of the meeting. (Weening 1995)

It is this dynamic balance between the individual and the collective that epitomises Quaker belief. On the one hand individuality is lauded, and selfdiscovery is sustained through narratives of autonomous distinctiveness. Members are encouraged to 'grow their own soul' by listening to their private inner light. On the other hand there is a significant emphasis on responsibility for the common good, and tempering one's selfish needs with shared necessities for concordance.

This action of spiritual listening is termed 'centring down', a phrase that indicates clearly the place of spirituality within the self. The Quaker Testimonies are also to be found 'within' the self. The word 'testimony' is used by Friends to describe, 'a witness to the living truth within the human heart as it is acted out in everyday life. It is not a form of words, but a mode of life based of the realisation that there is "that of God in everyone", that all human beings are equal, and that all life is interconnected.' The Quakers still retain their historical idea of radical opposition to social norms 'It is affirmative but may lead to action that runs counter to certain practices currently accepted in the society at large.' Testimonies reflect the corporate beliefs of the Religious Society of Friends, however much individual Friends may interpret them differently according to 'their own [inner] light'. Stressing that the Testimonies are not 'optional extras' 
but 'fruits that grow from the tree of faith', basic Quaker testimonies include: truth, equality, peace, simplicity and community (see www.quaker.org for further information).

It is not surprising that some sexual and gender non-normative individuals seek membership and a secure sense of belonging within the Society of Friends (particularly if their non-normativity occurs along only one axis of social typology). Quaker principles of self-acceptance and/through collectivity are of vital interest to people whom still experience prejudice, discrimination and shame in parts of their everyday life, who for that reason seek a sense of relief from being partially othered, finding sanctuary and a position of inclusion. The Religious Society of Friends also commands a wider public reputation: it is by and large an esteemed organisation predominantly amongst liberal intellectuals, the middle classes, and petit-bourgeoisie, conferring social respectability on its members by its historical association with high moral principle, sacrifice, and social action. Joining though can mean a rebalancing of self, in which for example one's 'bourgeois' self is mutually reinforced, at the risk perhaps of the diminution of more uncompromising impulses and desires. A markedly strong sense of self was common amongst the interviewees and focus group members; my overall sense was of an unusually individuated federation of people.

\section{Methods}

This case study commenced with contacting key British and North American stakeholders in the spring and early summer of 2007, to discuss with them the best way of including LGBTQI Quakers in our research. These initial contacts proved to be invaluable in locating several clusters of participants: a regional existing 'local Quaker lesbian and gay group' comprising members from several different Meetings, both urban and rural; a UK national organisation 'Quaker Lesbian and Gay Fellowship'; a national group in the US for Quaker Lesbians, whose annual conference gathering was attended as participant observer by Heather White. ${ }^{3}$ Members of three Meeting Houses: one in the US state of Pennsylvania, one in central London and one in a South Coast of England city, were all involved in the project in various ways, and we also had helpful communication with the Friends for Lesbian, Gay, Bisexual, Transgender and Queer Concerns, US. ${ }^{4}$ Consequentially, the interviews and focus groups took place in late Summer 2008. Overall, 11 individual interviews were conducted, and three focus groups, from two countries, the United Kingdom and the United States of America, with 24 participants. In addition to this, there were

3 QLGF can be located using http://www.qlgf.org.uk/quakers.htm Accessed 2008.

4 FLGBTQC can be located using http://flgbtqc.quaker.org/ Accessed 2008. 
numbers of email and telephone correspondence with Friends who could not or did not want to participate in a recorded interview or focus group, but were interested in responding to the project and making their own comments, some of which are reported.

My own positionality in this study as Principal Investigator was as a lesbian who had long admired the Religious Society of Friends for their political stance over the years, and whose Mother had found the Quakers in the last few months of her life, finally requesting a Quaker funeral which was led by an Elder from a Yorkshire Meeting House at High Flatts, Denby Dale. I was brought up cognisant and respectful of Friends' significant history, origins, and political reputation in Yorkshire. So, I was personally favourable, and positively predisposed toward the group, and as a Unitarian Universalist myself (another liberal sect without particularly strict articles of faith), I felt 'akin' to what I perceived to be the Quakers (anti-)doctrinal convictions, and comparable social conscience and history of engagement with ethical campaigns. ${ }^{5}$ Additionally, the Friends Meeting House in Brighton, where I live, has been the venue for many local LGBTQI events over the years, and is certainly perceived as providing a 'friendly' space to our community.

In contacting and mobilising participants for this study, I also posted messages on pertinent national Internet sites, and a small number of recruitment leaflets and posters were also sent to relevant Meetings with a request to display. The leaders of a couple of Friends Lesbian and Gay groups kindly included me into their email circulation lists, hence allowing direct access to their affiliates. All interviews and focus groups were conducted face-to-face and recorded and transcribed. Some took place in Meeting Houses, while others took place in members' homes or my home. When conducting these semistructured interviews and focus groups the interviewer/facilitator organised the content and direction of the discussion using our shared project template as a basic format. However, because the emphasis of our research was primarily on 'discovery' through 'open-ended questioning', we often digressed from this programmatic model if material came up that was judged to be particularly significant or of interest. Hence, not all participants were subject to exactly the same enquiries. However the completed data did contain similar patterns of narrative and description in terms of framing personal spiritual journeys and identifying current beliefs from which summative observations could be made.

5 In the early stages of the project another case study had initially been set up and planned, to be executed by this P.I. that intended to research LGBTQ British Unitarian Universalists, based at their theological training college in Manchester and in Northern English towns. Regrettably due to time constraints this was not followed through but I hope to pick this up again in the future. 
Of the 24 people in brief summary we can see that the average age of participants was a rather high 54 years old; in terms of sexuality that out of those 24, 11 people self-identified as lesbian, 7 considered themselves to be gay, 2 were bisexual, 1 'women-centred', and 1 person identified as queer. The higher proportion of lesbians in this statistic is skewed because the US group of Quakers interviewed was an already self-defined lesbian organisation. Six out of 24 identified as disabled, a rather high proportion of participants, but this could also be explained by the higher than average age ratio. Twenty-three described their gender conventionally as female or male, with one person identifying as inter-sex (see appendix for further details).

Key conceptual/theoretical concepts that were used in my analysis were drawn from my academic background in Queer Theory, Feminism, and Cultural Studies/Cultural Geography, which led to the locus of my interest focusing around cultural identities and practices - and the performance of such - within the groups that I encountered. Like most of our participants, people held strong ideas about their identity as a Quaker and what thus that should mean in terms of personal and collective practise. A long personal history of critical activism around sexuality also meant that I brought to the study a particular sensitivity to exclusion, categorisation, and territorial behaviour, all facets of schemes of non/belonging, and the anxieties they provoke. This was my first time conducting and directing significant empirical research with people, despite having supervised many such projects before(!). Hence, I was simultaneously anxious and eager to learn new skills, and also enthusiastic for an engagement with a faith group that I had previously held in high respect. This led to some naivety on my part. In terms of my own lesbian identity, I disclosed this to all participants early on. I would sometimes contribute to the interviews with personal anecdotes, opinions or memories, referring to my own religious/spiritual histories. What I had not anticipated to be such a feature of my engagement with this case study, was a discomfort with what I encountered and describe as being the pronounced middle class ethos of the Anglo-American Religious Society of Friends' culture, coming as I do from my own background, brought up as a working class person from the North of England.

As predominantly middle class individuals, some Quakers were quite preoccupied with notions of privacy. This researcher encountered strong feelings about this when I sent an email copying in the four existing groups who had agreed to participate in the study with information about our project Second Life site, and an invitation to come to the virtual launch. By copying in personal email addresses so that they were visible to all, I allowed names to circulate outside of the specific group domains. This was due to stupidity and ignorance 
on my part. ${ }^{6} \mathrm{I}$ had, I confess, projected my own enthusiasm about the Quaker LGBTQI project, and personal ease with collective activism, onto people for whom it was probably an annoying intrusion into their personal communication networks, in my naïve, egotistic excitement I felt I was generating a small but new collective network or virtual community. Some responses, which were sent to the whole group included:

- OUR QLC mailing LIST IS SUPPOSED TO BE: P R I V A T E.

- I didn't agree to being on a group e-mail and I find it very irritating to receive unsolicited information.

- Please remove my name from this list. I did not give permission for my name to be on it. Our ... list is supposed to be private and somewhere along the line this privacy has been violated. This does not feel very Quakerly or right to me.

- Please also remove me from your distribution list - as others have said, I don't want my email address sent out to other people like this without my express permission.

These messages were sent 'Reply All'. On the other hand, some individuals wrote to me separately expressing disappointment at the hostility my message had generated, typically:

I'm sorry you've had negative responses from people. I can't believe people who have in the past been involved with [specific LGB organisation] or with Quakers could be so inconsiderate.

One individual did send a robust 'Reply All':

Hi Sally (and the rest of the email address book) - Well you've got a bit of a bashing here. How fucking spiritual!??!?!???

The majority of steamy complaints were from the US-based Quakers, with one leader writing to me with dismay that members of their group had resigned in response to my 'irresponsible' email circulation. On the other hand, the responses from British Quakers were mainly genial and supportive, so there were clearly cultural differences going on. It was difficult to tell whether these sensitivities

6 I didn't know at the time about the 'bcc' function on electronic mail. One kindly Quaker member wrote to me patiently explaining how to use it and how to avoid such reactions in the future, my thanks to him. 
regarding my perceived violation of privacy were linked to classed expectations of entitlement, or LGBTQI anxieties about being 'outed'; given the already offended sensibilities. For obvious reasons, I could not explore further, but my experience seems to challenge the prevailing notion that Quakers behave within an ethic of non-conflict and 'nicety'. The tensions invested in 'proper Quaker behaviour' are crystallised in the 'How fucking spiritual!' comment: simultaneously intentionally provocative and chastising misplaced Quaker decorum. ${ }^{7}$

\section{Towards a Quaker view of homosexuality}

Research participants, when interviewed or taking part in discussion, each described their move toward joining the Quaker faith in terms of the Society's known public reputation for tolerance, acceptance and open-mindedness, they frequently mentioned the positive idea of Quakers being 'nice people'. Participants anticipated this broadmindedness to be reflected in Friends' attitude toward homosexuality, although they did not necessarily know much of the position on sexuality in advance of joining. Most of the participants were not 'born' or 'birthright' Quakers (brought up in Quaker families), but described themselves as refugees from other less tolerant faiths of family origin, examples given included Baptists, Roman Catholicism, or Evangelical Christianity. It was typical of participants to be well informed of the Society of Friends' general history of active liberalism, and most of the British members referred proudly to one text in particular as marking a break in prejudicial attitudes that they encountered once they had joined, from 1963: Towards a Quaker View of Sex. This small book, produced by the Friends Home Service Committee (FHSC), which advocated embracing tolerance toward same-sex relationships, stated:

It is the nature and quality of a relationship that matters: one must not judge it by its outward appearance but by its inner worth. Homosexual affection can be as selfless as heterosexual affection, and therefore we cannot see that it is in some way morally worse.

Homosexual affection may of course be an emotion which some find aesthetically disgusting, but one cannot base Christian morality on a capacity for such disgust. Neither are we happy with the thought that all homosexual behaviour is sinful: motive and circumstances degrade or ennoble any act ...

7 Thank you to Heather White for this observation. 
We see no reason why the physical nature of a sexual act should be the criterion by which the question whether or not it is moral should be decided. An act which (for example) expresses true affection between two individuals and gives pleasure to them both, does not seem to us to be sinful by reason alone of the fact that it is homosexual. The same criteria seem to us to apply whether a relationship is heterosexual or homosexual. (FHSC 1963: 21-36)

To our contemporary view this reckoning may seem grudging and indisposed, however it must be remembered that it was published not long after the controversial Report of the Departmental Committee on Homosexual Offences and Prostitution (better known as the Wolfenden report), published in Britain in 1957. These opinions demonstrated part of the prelude to the historic partial decriminalisation and liberalisation of sexuality in the West that occurred during the decade of the 1960s. The Sexual Offences Act 1967, an outcome of 'Wolfenden' was accordingly passed, which maintained the general prohibitions on buggery and indecency between men, but provided for a limited decriminalisation of homosexual acts where three conditions were fulfilled. Those conditions were that the act had to be consensual, take place in private and involve only people that had attained the age of $21 .^{8}$

Gerry comments, 'In 1963 that was tremendously radical. That was a bit like, you know, whatever it's called, "The Communist Manifesto", in terms of human sexuality and church groups in 1963.' Jim asserts: 'they were probably the first religious organisation certainly to my knowledge who were taking a much more open view towards gay people. ... [A]fter they published that book quite a number of gay people came.' Jim continues, correcting his own recollection:

Jim: When I first came here to this meeting [in the early 1960s] the influential people in this meeting were lesbian women, including one who ran the first meeting that I came to, who dressed in typical 1920s, 1930 lesbian style. So she had a short haircut. She used a man's name. She wore a skirt and a jacket, sort of a pinstriped suite with a shirt and tie, thick stockings and brogue shoes.

Sally: Really?! [laughs].

Jim: So she wore a uniform. The other ones were not so obvious.

Sally: And was she an elder?

Jim: Yes. She was an elder.

8 See David Bell $(1994,1995)$ for further explorations of how Wolfenden enforced privatised sexualities upon gay men. 
Sally: Right. So that's interesting in itself isn't it?

Jim: As I say, the other ones were not so obvious but there were several who were influential who were quite open. But that particular friend was determined that everybody should know [laughs].

Jim is one of the few participants who was already a Quaker in 1963:

Sally: So when Towards a Quaker View of Sex came out, was there a lot of debate at the time?

Jim: It was said that that was the only year that the Quaker book shop who published it made a profit coz they sold so many copies, not only to Quakers, but I suppose to all religious organisations presumably who had a look at it.

Sally: And did meetings debate it much, in the next couple of years, can you remember?

Jim: I think so. I think so. I seem to remember some meetings about it. And there were some people who were attracted who came to this meeting because of it. And found the idea that they weren't being told what they had to believe very attractive, but in many cases within a couple of years, once they found that other people didn't believe the same as them, found that unattractive. And so they drifted away.

Harvey also commented in his interview on its influential and broader effect upon public perceptions:

Harvey: But in 1963, it was like a big sensation. It was all in the press. I mean when Quakers really hit the media ... See it was the first time any religious organisation had produced a work about sexuality. It wasn't about homosexuality, it was about sexuality. But in it the group actually maintained that they felt that it was the depth of the relationship rather than the orientation is the thing which is important.

And Harry similarly comments on its wider symbolism:

Harry: And there's quite an honourable history of Quaker literature, like Towards a Quaker View of Sex and things like that, which I think came out in the '60s or '70s, which for its time was an amazingly radical pro-gay statement from any religious group, about ... And some of that stuff is still in the Red Book, in the Quaker Faith and Practice book, which every meeting has now. There are a lot 
of extracts and quotes from Towards a Quaker View of Sex in the Red Book, you know, which for many people is more persuasive than the bible. So it's still there, part of our history.

The attempt to engage publically with issues of sexual morality continued, in 1973 another group of Quakers produced Homosexuality From the Inside and in the same year the national Friends Homosexual Fellowship was started. In 1987 the executive committee of British friends decided that Meeting Houses could host 'celebrations of commitment' for Quaker same-sex couples. More recently, in 1991, the Quaker Bisexual Group started. Today, these activities are combined within the activities of the aforementioned Quaker Lesbian and Gay Fellowship. Quakers believe in the sacramental quality of all of life, and that there is diversity in spiritual paths toward the Light, hence it was difficult to object to such inclusionary impulses. Nevertheless, the growing acceptance of sexual difference within the Religious Society of Friends continued, with many members being committed to greater liberalisation and moral leadership, despite some quite voluble homophobic opposition (see further Dandelion 1996).

\title{
Quaker manners
}

Most of the participants talked about the ethos of diversity in Quakerism that was enabled because of their historical and reputable practices of tolerance and acceptance:

\begin{abstract}
Stephen: The interesting thing about Quakers is the Quaker lesbian and gay spaces are very welcoming of bi people and, you know, so there is evidence that the tolerance and the acceptance goes deep into the DNA. Quakers are genuinely nice and welcoming people and therefore they've been nice and welcoming to people with mental health problems and people who are gay and people who are just very awkward.
\end{abstract}

Stephen identifies as bisexual, but bisexuality is not explicitly mentioned here. Perhaps the general openness and inclusivity of Quakers actually negates the need to having to be so explicit and specific about labels, so that 'lesbian and gay' embraces all sexual dissidents. Kathy elaborates on this quality of inclusion, fitting it into a framework of 'niceness' and 'comfort', descriptors that occurred frequently in respondent's comments:

9 For further information see the section on 'Sexuality' from Quaker Faith and Practice Third Edition, 1994 [Britain Yearly Meeting], chapter 22 'Close Relationships' (available online at http://qfp.quakerweb.org.uk/qfpchapter22.html). 


\section{QUEER SPIRITUAL SPACES}

Kathy: To me, to be in a place where it was okay to think that maybe the Druids had some contributions to spirituality that would be ... that's a nice comfortable place because everything's included and nothing's excluded.

The ethos of 'niceness' has its boundaries however:

Dominic: It's more the gay thing. I tend to find ... it's almost like the tennis. I play lots of tennis and there's something about tennis clubs, a certain tennis club where I'm a member. And I fit in, well you can imagine, like that. It's a little bit like that, but the church equivalent of it, where everyone's very nice, but I have this feeling - and they'd probably be horrified if I said this - that if I was to share the reality of some parts of my life with them, it would be a little bit outside of their experience. And that's probably doing them huge injustice, but ...

Dominic takes up a common thread in his interview: that participants were hesitant to articulate to an outsider like myself the Quakers' ambivalence shown toward minorities despite being in such a dominant moderate, noninterventionist ethos. They commonly indicated an avoidance of anything perceived as 'too political', and inferred that sexual difference was acceptable so long as it was normatised, and arguably - neutralised. Mel takes up a similar stance in relation to class:

Mel: [T] here's this other piece that I haven't talked about yet which is questions of liberal Quakerism and diversity, particularly in terms of race and class that people have been struggling with lately. And how much of what we do on a Sunday morning is about trying to ... about replicating and recreating in our nice little, you know, white, middle class, professional middle class, life. And you know, when people come to meeting and say I'm here because this is the only ... coz I found people like me. Often what they've done is they've gone and found other people with similar class positions, you know, other people with, you know, graduate educations who are doing, you know, social justice work or whatever, which is a very particular class position, but it's not what Quakerism is. Quakerism is a lot more than that. It's experiential faith that is about connection with god and community and about then going out and doing god's will. And that's not something that should be limited to people who have college degrees. So some of the outreach discussion is about how do we make our communities, our Quaker communities, less hostile to people who are not from this particular class and racial background. And you know, that can be as simple as not, you know, turning up your nose when somebody brings a meat dish to the pot luck or, you know, which you know, has been known to happen in some meetings. And vegetarianism, while arguably consistent with Friend values, is also a class statement to some degree. So if we're going to do outreach and be serious 
about outreach, we need to be serious, I think, about making our communities, our meetings, more welcoming and less just a place for the expression of some of our class identities and race identities. And that's a really hard piece of work [laughs].

$\mathrm{Mel}$ is exasperated by the tendency to reinforce centralised identities and their concomitant cultural practices. Jamie Crofts talks about these limitations specifically in relation to his sexuality being silenced:

Jamie: [1] they had a perception of Quakers at all, [it] tends to be of Quakers as being sort of nice people [laughs]. And I think probably they would probably have expected me to say something like this, you know: 'Quakers are actually nice to gay people as well'. People's general impression of Quakers is we're nice people. And I haven't had such a similar experience of being, of sexuality not being an issue in Quakerism, because I think often the problem's been 'oh it's not an issue so we don't need to mention it', and 'it's not an issue so we don't have to acknowledge it', and 'we're so equal that actually we don't need to make any reference to it because we're equal with everybody'.

Not making 'any reference' can be read as effacement through silence. Yet, Stephen described how tolerant Quaker attitudes are inclusive to bisexuals. In a debate in the British Focus Group with Gerry, the pros and cons of 'political' identities are brought up:

Stephen: I have run into organisations which were intolerant of bi people ten years ago. And then they had a conference and voted and the official ideological position of the organisation became that they were tolerant of bi people. Therefore everyone became as loud and obnoxiously pro-bi people as they'd been loud and obnoxiously anti-bi people. Because the ideology of the organisation was that the official line of the conference was what people had to think.

Gerry: They're nice to people with mental health problems, they're nice to people who are gay, they're nice to people who [Unclear]. I know what you mean yeah.

Stephen: And you know, and it's just the way Quakers are. Yes, absolutely. It throws up the way that lesbian and gay groups can create conflicts and so forth.

Gerry: I think it's right actually. I mean I think there was an element for me that lesbian and gay politics became very ultra. 
So Gerry finds respite in the 'middle ground' of Quaker liberalism. Rather than positioning 'political' lesbian and gays as a threat, Susan in the Focus Group in the US expresses frustration with this liberalism of Quakers as a cause for polite lethargy:

Susan: So I don't think we're angry enough and I don't think we're verbal enough. And I think we're very polite and very nice and very gentle and very sweet and very non-threatening, kind of thing.

Kaki: Just thinking about diversity in general and racism and homophobia, and I think gay folks are not real scary to straight people, and so it's easy to be like ... especially like Friends Conference Gathering ... we're nice and become more visible and we're on a lot of committees and we do a lot of other ... [General laughter].

Susan: And we do all the childcare and people get to know us. So it's easy to be supportive and loving, and like, well, there's these nice gay people who just like want to be and want to get married and all that. I mean to the outside folks we're apolitical, you know, like we're the 'Communist under the bed' to straight people. They're oh my god, they're going to take your children and ...

The debate around angry political action and its place in Quaker spaces speaks to the ritual of silence that is valued in meeting spaces. The ritual of silence and its relation to lesbian and gay political action will be addressed later in this chapter. Here the discussion of visibility and noise within Quakerism is perceived to be a class issue, around the issues of permissible modes of speech:

Mel: My background is upper middle class. I don't have a problem socially fitting into liberal Quakerism. I was raised in it. But there's a Friend who comes from a working class background who I know, who says that when she hears Quakers suppressing conflict and not talking about anything that's going on, then like you know, making these little sort of semi-snide comments that you have to know everything that was going on though to follow the train of like what they're doing. That feels really incredibly alienating to her because in her community she was raised to, if somebody did something crappy, you call them on it. And in a way that's much more sort of straightforward. And that's a concept that makes ... the idea that we're suppressing conflict and that our communication styles are class based, is something that makes a lot of liberal Quakers extremely uncomfortable, because one of the things they value about Quaker ... some people value Quakerism as a retreat from conflict, as a retreat from the world. That's not how I see Quakerism and that's not what it is for me, but that's what some people who are currently in Quaker meetings are looking for. So when people want to bring this, you know, conflict in, or they have styles that are like jarring to them, that's difficult. 
Harvey, a British Quaker, also addresses this frustration: 'I mean, I think that we are middle class, tend to be intellectual middle class people, and therefore that gives the tone', which contributes to a prevailing cultural norm of 'restricted diversity', and often produces fretful ambivalence toward the more radical expressions of identity. This is underpinned by the tradition's core values of reason, tolerance and acceptance, so that disruption or conflict to this equilibrium tends to be regarded with anxiety, and at worst, disapproval. The collective cultural goals of comfort, niceness and tolerance is dependent upon a gradualist model of change, compatible with the Friends' evolved style of organisational management: practised in the traditions of collective discussion, rational intercession, and communal ritualised debate. It is precisely this idea of Quakers as preoccupied by conscience and good works that ensures a governing ideology of benign sincerity, a frankness typically expressed reticently, however for those members who are directly experiencing prejudice and harassment, articulating their intense hurt and injury by means of overt political rhetoric is unlikely to be well received, they risk being disapproved of, effectively seen as displaying 'bad manners'. Visibly sexualised discourse (verbal or somatic) is similarly discouraged. The group censorship of emotional outbursts, particularly in relation to anger ensures an ongoing neutralised middle ground of consensus that contains difference and delivers it 'safely', 'comfortably'. Hence, a hectoring stance would be rebuked for being 'unQuakerly'.

\section{Public Quaker pride}

Certain participants mentioned going to annual Pride marches either as observers or participants as Jim says, 'I don't think we ever went on Gay Pride marches, but we always turned out to support them.' However one Meeting House actively supported Pride in Brighton and Hove in August 2008, as a matter of collective principle, supported by the monthly Business Meeting:

\footnotetext{
Harvey: when we came to look at Pride, the meeting gave its support to the Quaker participation, and probably did that for two reasons: a) because there was a general sense that Pride is a good thing, but also b) because there were several [LGBTQ] members of the community who brought their own experience into the thinking about it.
}

The children from the Sunday Meeting had made large papier mâché peace doves on wooden sticks for the marchers to carry (see Figures 3.2; 3.3), alongside the standard Brighton Quakers banner. Some marchers were gay themselves, some were straight Quakers who wanted to show support for LGBTQI friends and family (see Figure 3.4). They also staffed a stall at the festival, which was 
held in a large local park, providing further information about Friends in order to promote the Religious Society of Friends and encourage more LGBTQI members. ${ }^{10}$

Harry comments on his experience of Pride in Brighton and Hove, as an experience that intersects his sexuality and Quakerism:

Harry: The Brighton Prides I've been to, the first one certainly, just the year I moved to Brighton and it was a blazingly sunny day, it was gorgeous. This was last year. Blue sky, wonderful festival spirit, and I was proud because I think it was the first time the Quakers had marched in the parade and I was intensely proud to be gay, but intensely proud of being a Quaker as well.

For Stephen 'walking on Pride is another spiritual experience', and in this way he is taking his spirituality beyond the walls of the Meeting House (see Figure 3.5). Jamie Crofts explains the Truth testimony and its relation to Pride:

Jamie: It may have been thought, but not necessarily expressed, and certainly not acted upon in quite the way as we did, you know, with Pride. Cos really Brighton Quaker's presence at Pride was last year and this year, you know, so the sort of action of expressing equality is different.

Pride festivals in the UK have developed into inclusive celebrations of diversity, so much so that one Quaker rather controversially commented to me that 'Its not really Gay Pride though any more is it - I mean, it's just Pride?

Whereas one British Meeting House's impetus for attending Pride seemed to be to demonstrate political solidarity by attendance, Mel gave a different context for US-based Quaker initiatives for direct involvement with the LGBTQI worlds:

Heather: So do you think about evangelism in particular as something, as an outreach to queer communities - or is that touchy?

10 Harvey also commented on the children's support for his recent civil partnership, on the fact that they had baked a cake:

... They have a sense that this is the place in which gay people and lesbians have a value.

And I know that one or two of them have said, at school this is not the case, and that a lot of baiting and insulting language and so and so forth. So they have already noticed that within the Quaker community there's one way of looking at it, and the school community is different. And I suppose this is how they are being brought up, as Quakers to say well actually there are other ways of being. 
Mel: ... There's a perception amongst some of us that queer people might be more interested in Quakerism than your average, you know, Jo Shmo on the street. So there's some, you know, level of oh we should do or, you know, have a contingent in Gay Pride and like pass out leaflets or whatever ... [laughs].

Heather: Serve your religion as a kind of side dish to politics?

Mel: Exactly. So yeah, and also actually in my young adult Quaker group there was an idea at one point to go down at, you know, one or two on a Saturday night, to outside, you know, sort of the gay bars, and you know, just have like information. It would be like 'hey we're a welcoming congregation', you know, 'come check us out'.

Heather: Did that happen?

Mel: No, it didn't, and part of the reason it didn't is that most of the people in the group felt like it would not be taken kindly if they did it. ... it might be taken more as oh you're trying to convert us away from being queer, which is definitely not what we're trying to do [laughs]. But you know. So you know, figuring out how to do outreach in ways that people will not ... that our intended audience will not be offended by or get sort of their hackles up about it.

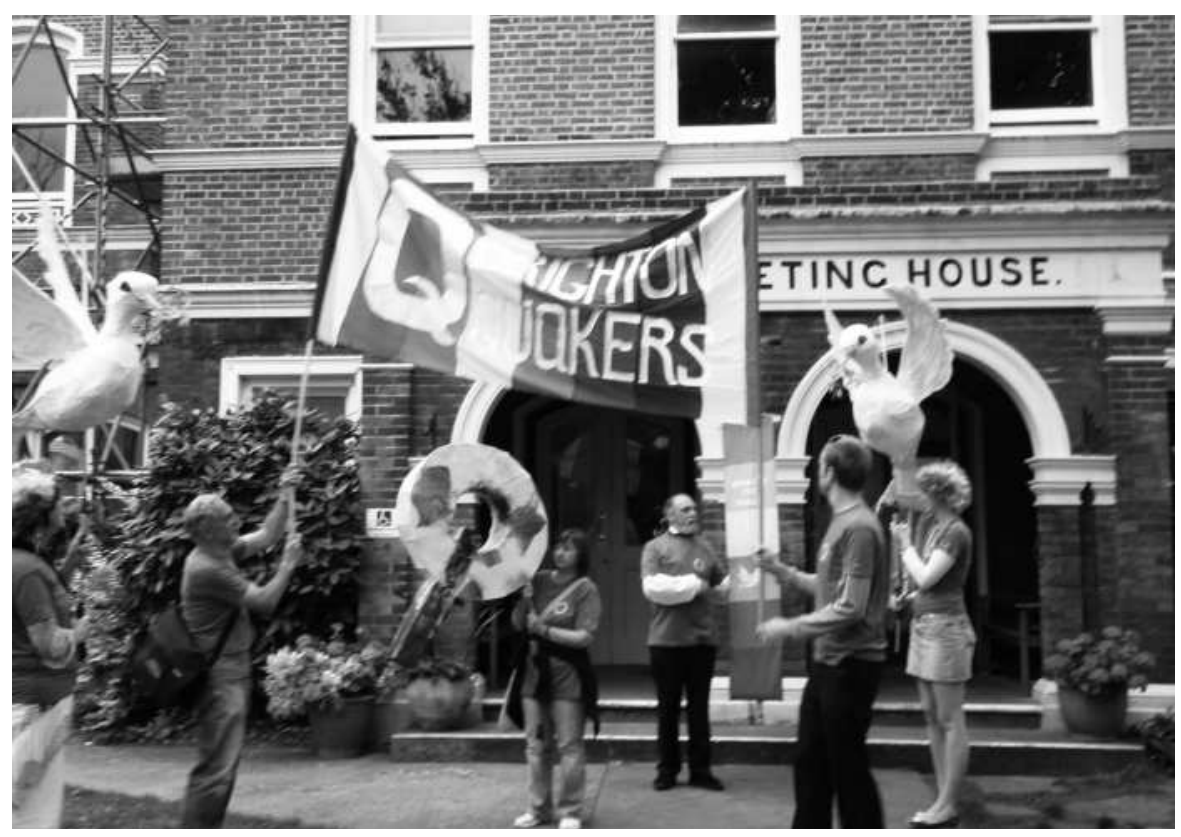

Figure 3.2 Quaker Witness: Gathering together for Brighton Pride, August 2008 


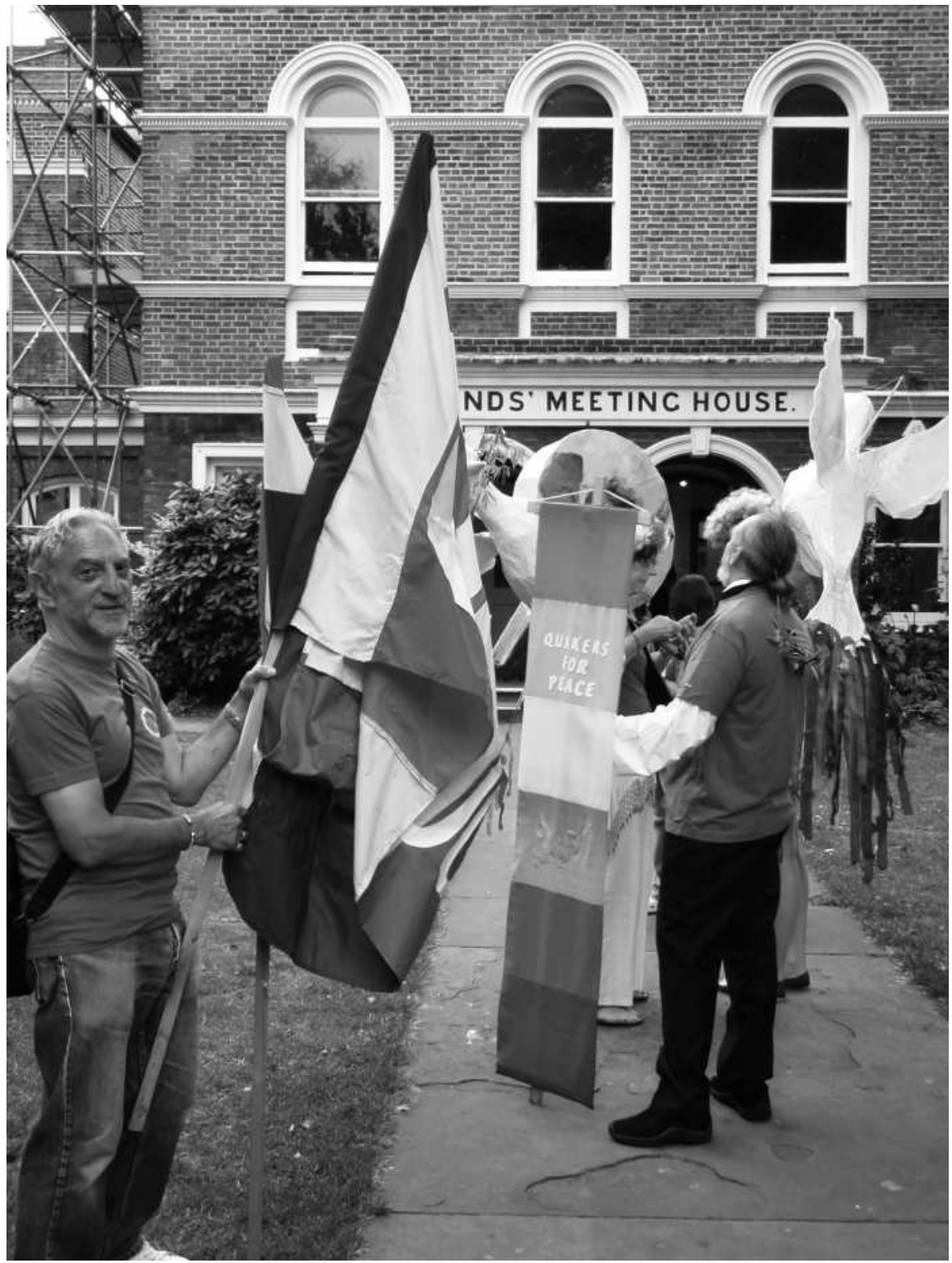

Figure 3.3 Outside the local Meeting House. Individuals carry banners and doves of peace, made especially by Quaker children 


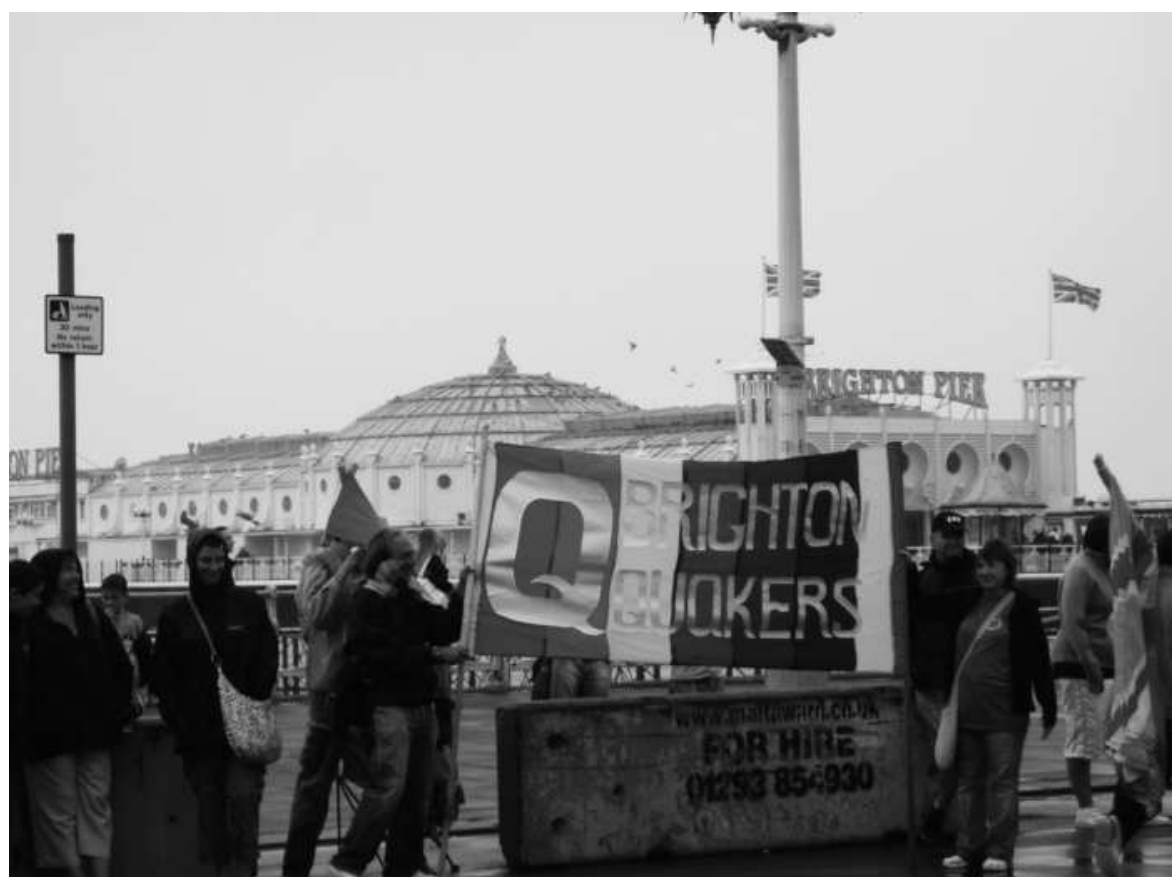

Figure 3.4 In front of Brighton Pier. Waiting in the pouring rain for the parade to start

Whereas in the British context 'recruitment' from the LGBTQI communities might be polite, indirect or incidental, and relate to a general promotion of social diversity within the Meeting, in the US direct recruitment of members was seen as a more valid practice. Such a practice could not apparently be effectively initiated toward LGBTQI peoples in the US due to Quaker anxiety that a conversion message might be construed negatively as Evangelical fundamentalism and thus 'anti-queer' (reiterating divisions discussed in Chapter 2). There was a fear that Quaker rather than being seen as a 'welcoming congregation', would instead be viewed as 'converting us away from being queer'.

With little exception, the term 'Queer' was widely perceived by our respondents to be negative, typically for Quaker participants Richard objects to it: 'To me it's an insulting word used against gay men. So to my mind it's inappropriate to use it to describe a scientific piece of research into the experiences of gay and lesbian people with spiritual paths and faith groups.' Queer, understood academically as a subaltern practice, was not welcomed by the lesbian, gay, and bisexual Quakers in this research, as it retains its older connotations as injurious speech. 


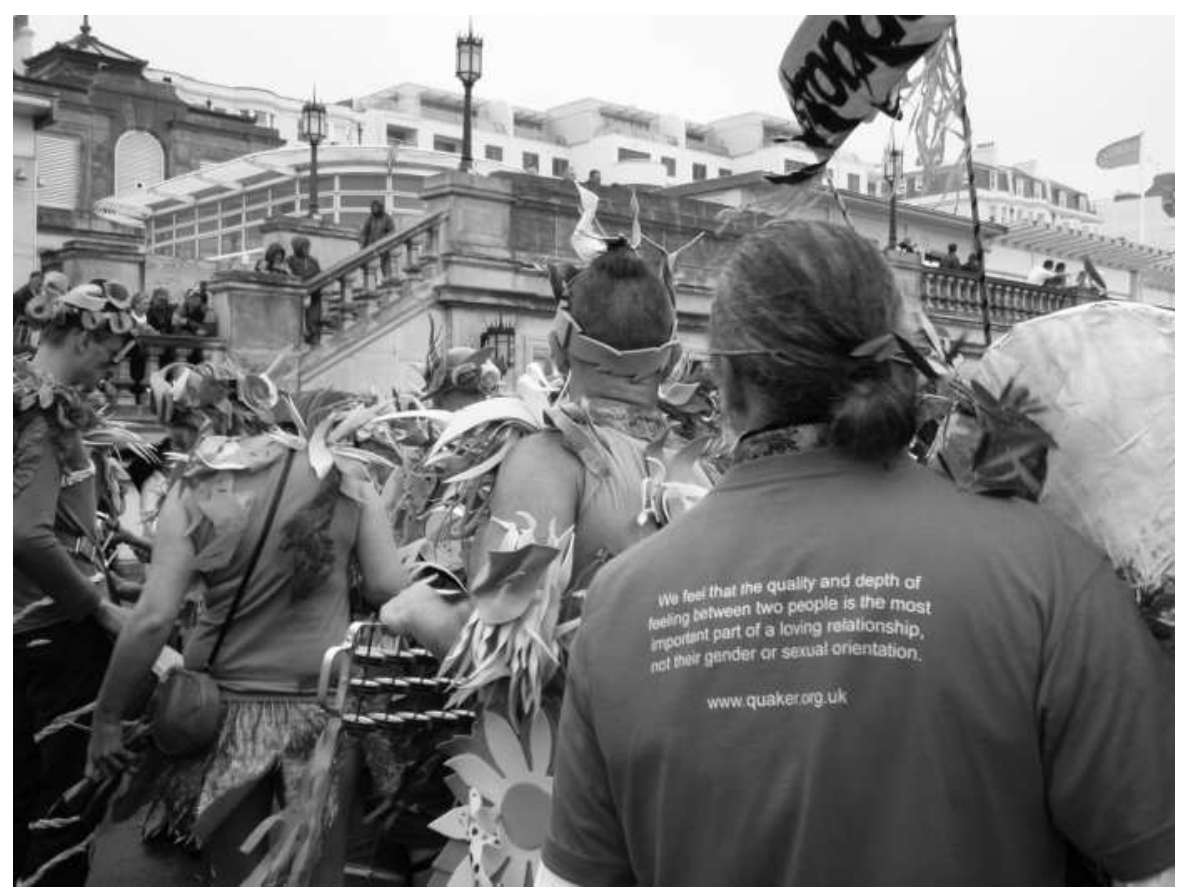

Figure 3.5 The Quaker Witness: Brighton Pride, August 2008

\section{Expanding spaces of the private self}

Repeatedly, having a secure identity and selfhood were seen to be very important by members of the focus groups and individuals in their interviews, often narrated via metaphors of a 'spiritual journey' in which Quakerism had figured as an enabling structure. The development of meaning and depth, interiority, selfhood through a community of sameness and agreement is a shared expectation. The ritual of silence was most cited as being fundamental to finding a sense of spiritual connection, in addition most participants explained that they found spiritual connection more easily achieved within the shared ritual of the Meeting. When asked about what places are sacred or spiritual for Quakers, conventional associations with nature tended to dominate responses: mountaintops, trees and storms (as well as Pride for Jamie above). But respondents also made clear that silence for them created the conditions for their spirituality, both externally and internally. When asked what would not be spiritual, many respondents said for them it would definitely be 'noisy places' that would be the worst. In various ways, Quaker culture seems opposed to what might be considered 'loud and shouty conduct' which puts their religion at odds with significant parts of LGBTQI politics. Members prefer instead to 
keep their traditional ethos of quiet, contained persuasion. This negotiation is familiar ground to perceived sexual 'deviants', or 'outlaws', forced by a heteronormative society to carve a path of personal sanity through compromise and self-management. Quaker discipline provides capsules of selfhood that float calmly within a bounded pool - too much vibration causes waves, and is to be discouraged. This means effectively that the Religious Society of Friends tends to attract individuals who arguably have a limited acquaintance with 'difference', who are able and wish to conform to an ethos of quiet, reasonable persuasion. As Dominic commented, an out gay man who is HIV positive and recovering from years of drug and alcohol addiction that he related to experiences of homophobia - he wouldn't want to tell his local Meeting House about his HIV status or his addiction 'because of the stigma':

Dominic: It's not homophobic, but it's certainly not gay friendly. I can only go on that. My feeling is it's not gay friendly and it's got, unfortunately I think it's got a lot of the things that very naturally make me feel a little bit ostracised. It's very middle class, white, older middle class. I've got to a place where, I can't quite, I'm not quite sure why, but I found myself getting a little bit, I'm sort of backed off a little bit from sort of my enthusiasm for having found a lovely - what I thought was a lovely - space to explore spirituality, feeling a little bit not part of it and wondering about not knowing how to feel part of it. That's definitely affecting [pause] feeling alone actually.

Sally: And is it that you feel that you're increasingly lacking a sense of belonging, so that you had one to start with, and is it that? For the tape, you're nodding. And is it that maybe the more fully you want to be yourself with that group, the more you're experiencing a hesitation?

Dominic: Yes. Yes. And in fact that must be with being, well, not - with being gay. I didn't feel that secure or that connected with the meeting. Well how I'm perceiving it as I say, a slightly sort of, you know different class of people, group of people.

Dominic's increasing ambivalence about becoming a full Quaker member concerns his acceptability. He describes an incident of a woman during meeting for worship offering a ministry, which lamented the loss of the old meanings (non-homosexual) of the word 'gay'. In any given case study, what is excluded, or indeed self-excluded, from a category can tell us much about the norms of that location. Many of the interviewees had this same dilemma: they were keen to tell me how much their Quaker journey had enabled them, but often at the end of their interviews made comments about what in their experience had to be put 'outside' the box. 
Quakerism is predicated on an idea of the endowed modern liberal self, indeed Quakers often describe themselves as 'Liberal Quakers', to discriminate themselves from the smaller group of 'Orthodox Quakers' who remain committed to a traditional Trinitarian God, espousing a somewhat conservative Christian theology. ${ }^{11}$ Some Orthodox Quaker churches are very accepting of homosexuality, and others condemn it as contrary to God's will. In a curious collection of essays on the formation of classic tragedy narratives within the Society of Friends, Douglas Gwyn argues against these dominant trends in Quaker thought, and in doing so he encapsulates their central, or dominant, precepts. He observes:

The American humourist Wally Shawn once quipped, 'You ask me if I believe in God - well, that depends upon what you mean by me.' The joke catches well the drift of postmodern culture generally, and contemporary Quaker identity in particular. It is no longer only 'God' that has become negotiable; the self too must be constantly renegotiated according to the multiple living contexts of a pluralistic society. (Gywn 2004: 125)

Referring first the Anthony Giddens (1991) idea of a modern protean self whose plasticity invokes constant anxiety, he then invokes Kenneth Gergen's (1991) 'saturated self', then Christopher Lasch's narcissistic 'minimal self' to indicate how these contemporary psychic structures demand both 'intense selfreflection and self-absorption' (2004: 125). Describing many British Quakers as 'strong individualists' who eschew popular culture and the seduction of consumerism, and viewing Quaker spirituality as a 'sublime, rarefied mysticism in which individual experience is paramount', Gywn ascribes to these members a belief that they have "progressed beyond the "primitive" Biblical Christianity of early Friends'. He concludes these initial comments with the remark that:

... contemporary British Quakerism is cosmopolitan, multicultural and interfaith in outlook (despite being overwhelmingly white and middle class in make-up) ... One does not have to be around Friends long to detect a spiritual elitism prone to a Gnostic scorn for the ordinariness of the religious and cultural mainstream. (Gywn 2004: 126-7)

The writer's standpoint, that 'there is a Christoform quality to the deeper structures of Quaker faith and practice that has been for too long ignored and

11 In this chapter I am referring only to the Society of Friends as practised in the West, specifically in the US and UK. In Africa for example, Orthodox Quakerism is more dominant, services tend to be structured and theology originates more directly from Biblical Christianity. In non-Western countries Quakers could not be generally described as 'Post-Christian'. 
outright denied' (Gywn 2004: 127), is both angry and nostalgic, however his trenchant criticisms seem bitterly directed toward a drift to the banal in Quaker worship, encapsulated in the following extracts:

- ... The actual spiritual practice of contemporary Liberal Friends is nothing akin to the rigour of those other mystical streams.

- One finds rather a reflexive distrust of authority and a fear of rules or expectations, both of which undercut any serious spiritual discipline.

- In their modern, liberal revision, the concrete, shared 'testimonies' of traditional Quaker practice have become a set of vague ideals...

- Most who have been attracted to the Religious Society of Friends in recent years have remained and (perhaps) become members because they find it a 'comfortable' ethos, accepting of a wide variety of viewpoints and demanding very little of anyone ...

- In the silence of Quaker worship, there is comfortable space to bask in the self's reflexivity and absorption ... freedom for each to listen or 'tune out'. (Gywn 2004: 127)

Gwyn concludes angrily that:

It is only by continuing to use the sham of right-wing fundamentalist Christianity as their rhetorical foil that Liberal Friends manage to maintain their own parody of Quaker faith and practice. By chronically trading in caricatures of 'Christianity', Liberal Quakerism has become a caricature of itself. This cannot last. (2004: 128)

It may seem strange in the context of our book to quote so lengthily from a seemingly marginal, internecine attack from within a sect or minor faith group, however I think Gwyn's disparagement of Liberal Quakerism 'from within' sets a useful framework for our understanding of the environment in which LGBTQI issues circulate. The following points about modern Liberal Quakerism can be drawn out:

1. The prioritisation of individualism, personal revelation and self-development entails a de facto principle of creative diversity - 'that of God in everyone' enables sexual and gender non-normative peoples to find a place and a life-story; 
2. Inevitably, there is firm approval for an ontological 'identity' as an expression of the above, which gifts a sense of belonging, of crucial importance for a subcultural subjectivity to form and stabilise;

3. The espousal of liberal rationality/liberal pluralism ensures a flattened structure of belief that ineluctably disapproves of prejudice, or discrimination (or indeed, outright religiosity), therefore becoming attractive to marginalised peoples typically excluded from 'a place at the table';

4. Emotional conduct is antithetical, and considered 'unQuakerly' and can be associated with the ritual of silence. Consequently, the passion and conviction of activist politics is discouraged, and perceived as inappropriately 'angry', 'loud and shouty'; hence this religion appeals specifically to LGBTQI members who eschew more public sexual activisms in favour of privatised sexualities;

5. The Quaker aspiration toward mystical 'higher goals' expressed through continuous ethical intervention constructs social prejudice as a violence toward the self. Exhibiting said bad manners or condemnatory behaviours is typically perceived to be associated with more populist, sometimes cruel and crudely drawn Christianities. This appeals to LGBTQI peoples whose experience and view of Evangelicalism (and indeed sometimes of religion in general) is wholly or predominantly pessimistic;

6. The disapproval and disparagement of 'excess'. 'Balance' and 'unity' must constantly be sought through the intervention of intelligent discernment and reasoned discussion - however these values are conventionally gendered representations of a masculinist reason/containment versus an embodied feminine excess. In Quakerism, physicality must be managed and somatic behaviours de-emphasised in comparison to cerebral vigour. These factors could appeal to LGBTQI peoples who are comfortable with conventional Protestant customs;

7. Whilst general principles are to be welcomed, the imposition of a common moralistic framework derived from them would appear suspiciously fundamentalist and potentially oppressive; a cautious, relativistic, qualified stance toward ideological positions must therefore be preferred - appropriate perhaps for those 'deviants' who arrive feeling 'burned' by the rigid moralities of their religions of origin;

8. That 'tradition' within contemporary Quakerism occurs through behavioural practices and the form of religious ritual, rather than a specific doctrine. The accretion of this skill depends upon bodily self-possession and mental discipline, containment and predictability; 
9. 'That Quakerism can offer 'comfort' and safety for social eccentrics, for the 'different'. There is a subtle expectation here for tolerable non-conformity, or bridled individualism, as an expression of that authentic self-hood.

A number of elements circulate in this picture that can help us clarify why the Society of Friends can be said to have been the recipient of (or victim to, or perhaps created by) 'bourgeoisification': a religion that values the individual conscience must create the conditions for a self to emerge, to be owned and expressed as a property or asset. ${ }^{12}$ That self must then value itself by defining its nemesis, its Other, and in the case of Quakers that logically would become their own conception or projection of an emotionalised, populist, regulated mainstream controlled by an over-arching secular and commercial state apparatus. The Quakers' religious culture therefore drives an intrinsically middle class imperative. It would be interesting to investigate whether this shift occurred precisely because of their historical (and spatial) shift into 'business', a result of their historical, discriminatory exclusion from the professions. Ironic then, that Quakerism seems to have inherited the muscular characteristics of liberal capitalism, and perhaps endowed LGB(TQI?) individuals with the security of the Protestant self.

In the same week that the American Psychological Association (APA) adopted a resolution stating that mental health professionals should avoid telling clients that they can change their sexual orientation through therapy, on 31 July 2009, at the British Quakers Annual Meeting at the University of York, the Religious Society of Friends agreed to perform wedding ceremonies for single-sex couples. The Quakers will ask the UK government to change the law to allow Quaker officers to register same-sex partnerships in the equivalent way as marriages; in human rights activist Peter Tatchell's words, it is 'trail-blazing'. ${ }^{13}$ The pace of change in sexual morality is uneven and

12 From my reading of Quaker histories of the early movement, this was not necessarily so, indeed non-conformism in the North of England was typically the preserve of the working or industrial classes, and has parallels with the growth of Methodism in working class villages and towns in Wales. See further Dandelion 2007, 2008.

13 Guardian Editorial Comment, 2009: 32. Thank you to Jamie Crofts of the Brighton Meeting for forwarding the exact minute from the Yearly Meeting 2009, as follows:

AT THE YEARLY MEETING OF THE RELIGIOUS SOCIETY OF FRIENDS (QUAKERS) IN BRITAIN HELD IN YORK DURING THE YEARLY MEETING GATHERING AT THE UNIVERSITY OF YORK

25 July-1 August 2009

Minute 23: Committed Relationships (continued)

Further to minute 17, a session was held on Tuesday afternoon at which speakers shared personal experiences of the celebration and recognition of their committed relationships. These Friends had felt upheld by their meetings in these relationships but regretted that whereas there 
subject to flux, oscillation, and recoil. What can be a breakthrough for some, appears as a symbolic capitulation for others, to be met with a groan of scorn. Whereas the APA's move seems unbearably belated, and the Quakers' choice can be read as reproducing bourgeois and even patriarchal norms, I believe these reactions to be understandable, but cynical. Both of these resolutions are outcomes of a successful reverse discourse of LGBTQI politics, albeit having an assimilationist heart, with regard to the politics of representation, the desire to occupy symbolic space, to be recognised as coherent entities not subjected to exclusion, delegitimation, misrecognition or pathologisation. At the same time, they remind us of an unpalatable truth: that social change is laboured and slow, and requires years of dedicated activity by campaigners to make it real. Nevertheless, in terms of queer spiritual spaces, soon the Quaker Meeting House will consolidate as one, and the meaning of queer will once more have to shift to accommodate or contest what some will see as a normative prerogative. Perhaps we should give George Fox, founder of the Quaker movement, the

was a clear, visible path to celebration and recognition for opposite sex couples, the options available for couples of the same sex were not clear and could vary widely between meetings.

Friends who feel theirs to be an ordinary and private rather than an exotic and public relationship have had to be visible pioneers to get their relationship acknowledged and recorded.

This open sharing of personal experience has moved us and added to our clear sense that, 22 years after the prospect was first raised at Meeting for Sufferings, we are being led to treat same sex committed relationships in the same way as opposite sex marriages, reaffirming our central insight that marriage is the Lord's work and we are but witnesses. The question of legal recognition by the state is secondary.

We therefore ask Meeting for Sufferings to take steps to put this leading into practice and to arrange for a draft revision of the relevant sections of Quaker faith and practice, so that same sex marriages can be prepared, celebrated, witnessed, recorded and reported to the state, as opposite sex marriages are.

We also ask Meeting for Sufferings to engage with our governments to seek a change in the relevant laws so that same sex marriages notified in this way can be recognised as legally valid, without further process, in the same way as opposite sex marriages celebrated in our meetings.

We will not at this time require our registering officers to act contrary to the law, but understand that the law does not preclude them from playing a central role in the celebration and recording of same sex marriages.

We have heard dissenting voices during the threshing process which has led to us this decision, and we have been reminded of the need for tenderness to those who are not with us who will find this change difficult. We also need to remember, including in our revision of Quaker faith and practice, those Friends who live singly, whether or not by choice.

14

We will need to explain our decision to other Christian bodies, other faith communities, and, indeed to other Yearly Meetings, and pray for a continuing loving dialogue, even with those who might disagree strongly with what we affirm as our discernment of God's will for us at this time. 
last word on the subject of spiritual space. In a letter on witness sent from Launceston Gaol in 1656, whilst imprisoned for his faith, Fox argued that by addressing the potential for good, that potential will become actualised. Sanctimonious or sacred? You decide:

Be patterns, be examples in all countries, places, islands, nations, wherever you go, so that your carriage and life may preach among all sorts of people, and to them. Then you will come to walk cheerfully over the world, answering that of God in everyone. (1975: 263) 



\title{
Chapter 4 \\ Looking for Allah: \\ Spiritual Quests of Queer Muslims
}

\author{
Andrew K.T. Yip with Amna Khalid
}

\section{Setting the scene}

'Being gay and Muslim? No way!' This is a comment trope that we have encountered on many occasions in different contexts, posed by Muslims as well as non-Muslims who found our research interesting, but nonetheless perplexing (including in academic circles, as described in Chapter 1). Underlining this question is the assumption that LGBTQI and Islam/Muslim are an oxymoron. Often dominant political discourse within Western societies on this issue constructs Islam as antithetical to democratic and liberal values that nurture sexual difference and gender freedom. Among organised religions, Islam is arguably the most negatively perceived in the West. If Buddhism is often associated with meditation and transcendence from worldly cares and attachments in the popular imagination and media representation (see Chapter 5), then Islam occupies the other end of the spectrum, conjuring up images of intolerance, separatism, radicalism, and terrorism; in a nutshell - a 'religion of the sword'.

While facilitating a workshop called 'Openness to Islam' in Oslo prior to the terrorist attacks on 11 September 2001, Andrew asked the participants to disclose the images that came to their minds when the word 'Islam' or 'Muslim' was mentioned. The request generated much unease and discomfort. The participants, who were all non-Muslim religious professionals and LGBTQI rights activists, were visibly uncomfortable with disclosing their thoughts, possibly being concerned about transgressing the social codes of political correctness and presumed middle-class liberalism. Insisting on using such images as the basis of challenging fear and prejudice, Andrew persisted, and in the end the participants opened up, collectively identifying two primary images - a gullible bearded young man who was easily radicalised (thus in need of rehabilitation); and an equally gullible veiled young woman whose freedom and liberty are constrained (thus in need of liberation). Following the terrorist attacks on European and American soils since 2001, and the various high-profile controversies, such as the debate about the veil in France and Britain, these two images have become even more entrenched in the Western popular imagination (e.g. Modood 2005, Modood, Zapata-Barrero and Triandafyllidou 2005). 
Thus, it is not surprising at all that in recent years, 'the management of Muslims' has become a major concern for global and national governmental policies to 'upgrade' Muslims for modernity and democracy (Turner 2007). In the same vein, there has also been a homogenising and agency-eroding perception of 'the Muslim woman' in the West, who desperately needs empowerment and 'choice', often characterised in the rejection of veiling (Cooke 2007). This kind of discourse feeds into the dominant discourse of sexuality within Muslim communities. Among organised religions, Islam is arguably the most censorious and intolerant of sexual difference and diversity (e.g. Yip 2009a, 2009b). A fundamentalist Islamic scholar who appears in $A$ Jibad for Love (2007) - the first-ever full-length documentary on global LGBTQI Muslim lives - chillingly asserted during the film that it was indisputable based on Islamic teachings that a man who committed a same-sex sexual act should face death; what was debatable was how he should be killed. Of course, this kind of cold and harsh judgment is not representative of all Muslim communities, particularly those in the West. Nonetheless, it is reflective of the force of the censure, leading to the internalisation of pervasive sexual and cultural values that constantly concretises heteronormativity, amongst heterosexual as well as LGBTQI Muslims (Siraj 2009).

Such censure of male homosexuality particularly often builds its justificatory foundation on religious texts, as I have argued in Chapter 2. The sanctity and inerrancy of such texts is often invoked to buttress heteronormativity, which in turn constructs anything not heterosexual as the sinful and polluting 'Other'. In addition to the Qur'an, which most Muslims consider the literal and unabridged words of Allah, the Shariah (a text on moral and pastoral theology; laws for public and private life) and the Hadith (Sayings of the Prophet Muhammad) also constitute a significant basis of such religious discourse. Such discourse hegemonises heterosexuality within marriage, and renders homosexuality a revolt against Allah and violation of nature (e.g. Bouhdiba 1998, Green and Numrich 2001). Jamal (2001), for instance, argues that the story of Lot (this story has been mentioned in Chapter 2 and its reinterpretations will be further outlined below), which is mentioned in 14 of the 114 suras [chapters] in the Qur'an (e.g. 6:85-87, 38:11-14, 54:33-40), is commonly used as the basis for censuring homosexuality.

Compounding - and indeed strengthening - this religious discourse (and vice versa) are socio-cultural values and practices that accentuate cultural conformity, particularly vis-à-vis the above-mentioned geopolitical context perceived to be hostile towards Muslims and Islam. The emphasis on family honour (izzat), marriage as a religious rite of passage, respect for parents and elders, and close-knit extended family network, contribute to the extension of the 'parental gaze' and 'community surveillance' on individual LGBTQI Muslims. Further, homosexuality is strongly identified as a manifestation of 
the secular, sexually permissive, morally confused, and cultural degenerated Western society; thus a 'Western disease'. Therefore, a LGBTQI Muslim could be perceived to have been contaminated by Western culture, and in turn pollutes her/his own culture through such sexual association (e.g. Yip 2004a, 2004b).

All these political, cultural, and religious complications demonstrate the multiplicity and intersectionality of LGBTQI Muslims' structural locations, as well as minority statuses and identities, with which they must engage on the everyday level. Thus, in this chapter, we shall tell stories about LGBTQI Muslims not only as sexual citizens or beings, but as whole human beings whose everyday experiences cannot be fully captured by turning the spotlight on the sexual/gendered dimension of their lives alone. The overarching message of the chapter is: not only is it possible to be LGBTQI and Muslim, but also, despite the profound challenges, many have moved on from the morality debate of their existence, and established meaningful spiritual paths and spaces where the acceptance and love of Allab are found. Before that, we shall provide a brief methodological account of this case study.

\section{Brief methodological account}

This case study focuses on LGBTQI Muslims primarily in Britain, but also North America. In total, Amna conducted 17 in-depth one-on-one interviews, and two focus groups, each with four participants. Consistent with most research on the LGBTQI community, most of the participants were able-bodied gay men despite strenuous efforts to recruit women and transgendered people (Meezan and Martin 2003). The vast majority of the participants were of South Asian origin, and based in Greater London, with others based in other British cities, New York, and Toronto (see appendix for more biographical details about the sample).

One of the main challenges Amna encountered was accessing this primarily hidden population. It has been documented that access to LGBTQI Muslim communities is particularly difficult because of the religious, social, and political implications for potential participants, many of whom live in closeknit communities with cultural values that emphasise conformity and family honour (e.g. Yip 2004b, 2008b). Participants were recruited mainly through personal networks and snowballing. Various LGBTQI Muslim user groups/ 
organisations were also contacted, including Imaan, ${ }^{1}$ Naz Project, ${ }^{2}$ Safra Project, ${ }^{3}$ KISS ${ }^{4}$ Himat $^{5}$ and Salaam. ${ }^{6}$ The project was also advertised in the LGBTQI press such as Out magazine in Manchester and the Safra Project newsletter, both based in Britain.

An issue raised by almost every participant was Amna's reasons for doing this research, given her heterosexuality. This immediately raised the issue of insider/ outsider dynamic, and Amna's positionality as the researcher (McClennen 2003). On the whole, while being as outsider (in terms of sexual identity) undoubtedly required more tact and creativity in dealing with participants' curiosity, or even suspicion, Amna found that this position offered certain advantages. Once trust was established, she felt the participants talked more freely about the politics and rivalry within the LGBTQI community, precisely because she, as a heterosexual woman, was outside of such a context. On the other hand, being a Muslim and having been raised in a traditional Pakistani family, Amna had the advantage of being an 'insider' on the cultural level, and was able to identify with issues relating to family and community disapproval that many of the participants had to manage.

In order to gain the trust of the participants, Amna adopted the strategy of being very open about her own life when asked. Her sexuality was often questioned and she had to respond to very personal questions about her decision to marry a white non-Muslim and her family's reaction. Her honest and open self-disclosure generated much-needed trust and collegiality that facilitated the data collection process. Indeed, a particular personal high point of the research was when she was given the title of 'honorary gay man' by all the participants in the second all-male focus group! While this title is undoubtedly contentious to some, it nonetheless demonstrates these participants' trust and fondness towards Amna. Andrew, in a previous research project on LGB

1 Imaan is a London-based social support group for queer Muslims, their families and friends. It was established in 1998, named Al-Fatiha UK, under the auspices of the Al-Fatiha Foundation (US). It adopted the new name in 2004. www.imaan.org.uk.

2 Naz Project provides sexual health support services to Black and minority ethnic communities primarily in London and works in particular with the queer community. www.naz.org.uk.

3 Safra Project is a London-based organisation providing support and information to lesbian, bisexual and transgendered women who identify as Muslim, religiously and/ or culturally. www.safraproject.org.uk.

4 KISS in a social group for South Asian and Middle Eastern lesbian and bisexual women in Britain. www.planetkiss.org.uk.

5 Himat is a support group run by Positive East in London to address the issues of gay men's wellbeing and health, sexual and otherwise. www.gaymenswellbeing.com/ groups/himat.

6 Salaam is Canada's main Muslim queer organisation. www.salaamcanada.org. 
Muslims, also encountered similar experience of positionality (i.e. the insider/ outside dynamic) which raise important epistemological, methodological, and ethical issues in relation to researching this sexual minority within a cultural and religious minority in the West (for more details see Yip 2008b).

\section{Living multiple marginality and multiple identities}

Almost all participants noted that they were very aware of their marginality in various identity spheres. Within this context, many had found reconciling their religious and sexual identities extremely challenging. Indeed, Amna's interactions and observations with some participants clearly demonstrated to her that some participants were struggling with conflicting emotions and understandings. On the one hand, these participants would rationally want to believe that their sexual orientation was created and accepted by Allah, but emotionally they were haunted by internalised homo-negative images and values that contributed to cognitive dissonance and doubt. For instance, Azeem, a gay man in his 20s, of Pakistani origin, said:

Azeem: [After having sex] I feel bad. I don't know about the others. After sleeping with a man there is somewhere, at the back of your mind, a guilty conscience.

While some had overcome such a struggle, many testified that it involved a long period of conflict and emotional turmoil, as El-Farouk, a Canadian of South Asian and African parentage, explained:

El-Farouk: When I started to realise I was attracted to other boys, it was toxic in terms of my psychology. How do you reconcile this when you are being taught one thing and yet your body and your sex are manifesting itself very differently from that? I [had] hoped it [the period of being attracted to men] was [a phase]. I think most queer kids, Muslim or not, who come from religious or traditional families will at some point wish or pray that they wake up the next morning without their inclination. [But it] doesn't happen.

El-Farouk's experience of dissonance was widely shared. However, as mentioned, struggling or managing their sexual identity is but one aspect of identity management which was intertwined with other significant identities, particularly cultural and religious. Reflecting on the time when he had just begun exploring his sexuality, Imran noted: 
Imran: I was going to these bars and clubs and met gay people but I felt guilty. I felt I was letting down my Pakistani side, my Pakistani identity. And because it was important to me I felt, Oh god, I will never be able to be gay; one, because I don't fit into the gay community [which was primarily white] and two, because how is this going to work with my Pakistani identity?

Amna: So you were seeing your identities in conflict?

Imran: Yes very much so. I was not a happy person. Don't get me wrong, I don't think my identities will ever sit well together. I am going to lead a very challenging life and every step of the way I will tackle these issues. Being British, Pakistani, Muslim, gay, they don't sit very well together, these four things. At the time I was finding it so difficult being myself and trying to find out what being myself was, who I was.

Imran's eloquent articulation of the challenges posed by the multiplicity of minority identities resonates with the cri de coeur of many LGBTQI Muslims (e.g. Yip 2005a, Abraham 2009). Indeed, several participants perceived this contradictory and supposedly irreconcilable position in extremely negative light. This comes across clearly in the following accounts:

Mohammed: We have it harder than anybody else in the world because we have to grow up with religion, culture. Living in this country we have two cultures. We have the white Anglo-Saxon British way of living and then we've got our Asian culture whether it [is] from Bangladesh, Pakistan or Africa ... We are fighting so many things at the same time, and then we have our sexuality.

Azeem: I don't wish for even my enemy to be gay. It is not a happy life, especially for Asians. You get misery from family. It is full of sadness, full of misery. You get pressure from family.

\section{To tell or not to tell}

Given the dominant heteronormative gender and sexual orders within the Muslim culture and its emphasis on honour and respect, the issue of disclosing one's sexuality publicly - coming out - becomes a thorny one. Some participants were very concerned about coming out to their family for fear of rejection and even persecution. Even for those who came out to their families, the process was identified as one of the most difficult and intense experiences of their lives. Imran, for instance, argued that it was a turning point and a significant moment; an incredibly emotionally intense and overwhelming experience for him and his parents: 
Imran: I will always remember this till the day that I die. I looked around to my mom who was sitting on my bed. And for one second we had eye contact with each other. I will always remember this for the whole of my life. It was one second but it seemed like an absolute eternity and two thoughts came into my mind: I can either lie my head off and get out of this somehow, or I just tell her the truth. My mouth just opened and I said, 'Ammi, I'm gay'. I don't think it was an impulse; I definitely wanted to say it. But once I said it there was no going back. She burst into tears. I started crying and I went over to her and put my arm around her and said, 'Please don't hate me for this. I am like this. Allah has made me like this. I have tried to change myself. I have really tried but I can't change. I am still your son. I'm still a human being'. At that point my dad came into the room and saw us crying and started crying as well.

Coming out, indeed, was a painful act. It was painful to most participants not only because of the fear and concern, but also the thought of having cast upon their parents' shoulders a burden that they must bear not only within the confines on their family, but also, significantly, within the close-knit extended family networks.

\section{Marriage of convenience}

Coming out often generated parental pressure on some of the participants to get married, perceived as a 'cure' for homosexuality which would bring them on the right track of heterosexuality. This pressure - at times coupled with emotional blackmail - could have significant effects on the participants, particularly those who were still struggling with reconciling their sexual and religious identities, such as Azeem, whose older brother complained that he would not be able to procure a marriage proposal for his 18-year-old daughter unless Azeem was married. Therefore, Azeem being gay and unmarried had implications for not only his own life, but he also shouldered the blame for the delay and paucity of marriage proposals for his niece. When asked if he would in these circumstances consider getting married, the following exchange ensued:

Azeem: If it is my mom's wish, yeah I will. But I will not do any, what do you say [in Urdu] 'unfairness'?

Amna: With the girl?

Azeem: I will keep her happy. I will give up my life. I have to be honest to the person I am married to, obviously.

Amna: So you will give up your sexual identity for your marriage? 
Azeem: Of course, if it is my mom's wish I have to.

Family and social pressure to conform and be 'normal' operated on several levels. Some families might on the surface accept that their child was LGBTQI but did not wish for the child to 'flaunt' her/his sexuality. In other cases, families might agree to turn a blind eye on the participants' foray into samesex encounters as long as they kept it secret, and remained married. These are management strategies that aim to maintain the status quo, thus not subvert the social code of respectability, not only on the part of the individual, but also on the part of her/his family (see also Yip 2004a). Jamal related his experience in this respect:

Jamal: I had cousins and people telling me - although it is never discussed, [as] I have never come out of the closet as such - at times people said, 'You should get married now. You should settle down with a woman. You could still "do other things"'; meaning you know what. These are cousins who have daughters, three of them. So I turned around and said to all three of them, 'How would you feel if you found out that the man who married your daughter was actually forced to get married because of his sexuality? So your son-in-law was not really someone who really wanted to marry your daughter but was being forced to. How would you feel then?' They were like, 'Well I wouldn't allow it. I wouldn't like it.' So then I said, 'Then why are you saying it to somebody else? Do you not think about the woman I am supposed to marry and what her feelings would be, her sexual desires?' That is the strong point I make.

\section{Transcending structural constraints}

Not all participants viewed their predicament of multiple marginal identities as a negative in all contexts. Some participants considered it to be positive and a resource that they could draw upon to serve different needs and purposes. For instance, El-Farouk, a Canadian gay human rights lawyer, activist and aspiring politician, noted that during the last local elections for which he ran, he managed to employ his Muslim and gay identities strategically to widen his support base to include not only LGBTQI Muslims, but also LGBTQI nonMuslims and heterosexual Muslims. He said, 'I may not go round telling people "Hi I'm El-Farouk. I am gay." But I also don't make it a secret that I am'. By foregrounding different identities to different audiences, without denying the others, El-Farouk was able to harness the support of the LGBTQI community as well as a vast majority of the Muslim community, including the Canadian Islamic Council. 
Another crucial piece of our findings that speaks to the theme of transcending structural constraints is the significance of intellectual capital, closely associated with class. Participants who perceived their multiple marginality as positive, and deployed it as a resource, were mainly those who were highly educated, thus privileged in a different sense. They had access to, and were able to mobilise online and offline resources that challenged traditional and heterosexist exegesis of religious texts, and at times offered LGBTQI-friendly re-interpretations. The most cited passage in this respect is the story of Lot, which traditional exegesis used as the justification for divine approbation of same-sex sexuality. Nonetheless, some participants are well-versed with alternative interpretations that challenge this interpretive orthodoxy:

Imran: I keep re-reading the Qur'an every week, every month to find out more. And the Qur'an only mentions gay men in two areas. It mentions the kingdoms of Sodom and Gommorah and Lot, or in Islamic terms Harrat Loot. His people were considered homosexual men. I did some research into it. Basically the people of Sodom and Gommorah were married men who had orgies with other men; who would sell their wives and have multiple sexual partners; who would rob each other; who would do many bad things like murder. There were many bad things they did so Allah decided to destroy this whole kingdom. So I realised that the Qur'an doesn't mention homosexual love, it mentions homosexual lust. It condemns homosexual lust. The translation is actually 'sexual perversion'. It doesn't talk about love; it doesn't talk about monogamy. These people were having multiple sexual partners. They were married to women; they were still having sex with men; they were selling their wives ... Another verse that I looked at says that a woman can take of her bijab - symbol of modesty and honour - in front of mehrams [men a Muslim woman cannot marry because of martial or blood ties], females, eunuchs, and men who would not desire her. Many scholars argue that the last bit 'men who do not desire her' refers to the brothers or fathers. But those are all mehrams. It specifically states that a woman can take off the hijab in front of a mahram. For me that verse refers to a gay man; a man who is either asexual or would just not find women sexually attractive. I believe that refers to a gay man.

Azreen: I didn't feel like just because I am a lesbian I have been cast out by God. Man-made Shari'ah, man-made interpretation definitely says no but if I read Qur'an myself, which I did, I didn't find anything which would say to me that because you are a lesbian, or you decided to be a lesbian, you are not part of this religion. I think the God I always believed in is above these petty issues.

The reflections above are indicative of the liberating and empowering potential of the limited but increasing online and offline intellectual and theological capital 
that has emerged in recent years. This growing corpus of resources challenges, for instance, the traditional interpretation of the story of Lot, as Imran related, and asserts that the divine retribution in the story was precipitated by male-tomale sexual violence, not same-sex intimacy and eroticism as we understand today. Thus, while the sanctity and the content of the text are upheld, the text needs to be interpreted through the lens of contemporary socio-cultural realities and knowledge, buttressed by the well-established Islamic practice of ijtibad or independent reasoning (for more details about such 'queering' of Islamic religious texts, see Jamal 2001, Kugle 2003, 2007, 2010, Manji 2003, Yip 2005b; see also Chapter 2). This endeavour calls for the rejection of a topdown theology of sexuality, conventionally produced by heterosexual and male religious authority structures, which dictates how sexuality should be defined, experienced, and lived. Rather, as I have argued in Chapter 2, it calls for a sexual theology: a bottom-up sexualised and embodied theology that is solidly grounded in lived experiences that are messy and diverse, not unitary.

\section{Being LGBTQI/Muslim}

Having considered the external structural challenges the participants encountered and their management strategies, we now explore the inner world of the participants, focusing on their perceptions and experiences of being LGBTQI and Muslim. This exploration of their inner world is of course not disconnected from the external challenges we have discussed. Many participants argued that their sexuality is an integral part of their identity, and indeed their whole humanity and being. In line with what many scholars have asserted (e.g. Grovijahn 2008, Horn et al. 2005, Yip 2005a), many participants felt strongly that sexuality and spirituality are flip sides of each other; and their interconnection and integration constitutes the foundation of the created order (see Chapter 7).

Jazed, the only trans participant in this case study, stated that his entire existence was LGBTQI from 'waking up this morning' to 'talking to [Amna]'. In the same vein, Asemeh, a lesbian of Iranian origin, asserted that, 'I think anything I do is lesbian. In my mind I don't divide things into lesbian and nonlesbian acts. I just do it.' This kind of integration on the cognitive and personal level is crucial because it generates a sense of oneness not only within oneself, but also between the individual and Allah, since Allah was believed to be the creator of everything and who accepted every aspect of their being.

On the social and cultural level, however, such unity of being was difficult to translate into social integration, as we have discussed above in relation to, for instance, the process of coming out. A significant issue here is how visible, 'loud' and intense one wants to express one's sexuality in different interactional 
contexts. Participants showed a range of responses in this respect. El-Farouk, for instance, argued for an integration of different aspects of his life, without foregrounding any particular dimension:

El-Farouk: I don't know. That's not something that I can relate to because it assumes compartmentalisation and I don't live my life in a closet. I have one closet and that is where I put my clothes. I live my life. I happen to be gay and I happen to have a partner. I live a human existence and I happen to be gay; not that I live a gay existence.

El-Farouk's response is consistent with those of participants who did not allow their sexuality to assume the 'master status' in their lives, namely, the organising principle based on which their lives are envisioned and fashioned, in the areas of social relations, political commitment and so forth. Jamal, a gay Muslim in his 40s argued this point passionately:

Jamal: It [being gay] is a small part of life. There is a movie called A Jihad for Love. So I spoke after the screening of it and I know some white people did not agree with me. They said, 'Oh you say sexuality is a small part of who I am, but for me it's a big thing'. For me, well you don't walk around saying 'I'm heterosexual'; or asking 'Excuse me, are you having sex with men, are you having sex with women, are you homosexual, are you heterosexual?' So why should a gay person have to scream on the rooftops, 'Listen, I am gay'. Being gay to me is a small part of who I am. So when I talk to parents who have issues with their children [being gay], I say, 'Listen, your son is exactly the same person. All he is saying is that that little small part that you made assumptions about, that he wants to sleep with a woman, he doesn't. He wants to sleep with a man. He wants to find a partner of the same sex. That is all. He is still the same son; he is still the same, whether he was a doctor, accountant, engineer; exactly the same human being. Nothing has changed about him; just that little bit'. So for me the same way being gay is just that little part. I'm still a wonderful son; I know I am a great uncle; a wonderful brother; a beautiful friend to people.

This form of identity articulation served as a tool for underplaying the difference between people of different sexual orientations in order to accentuate the commonality of humanity. One significant consequence of this approach is that it has the potential to immensely de-politicise LGBTQI identity: its positionality to heteronormativity. Instead of employing a minoritising politics of difference, it focuses on commonality of humanity. It is a commendable and noble goal, but it does raise the question of how to tackle discrimination and oppression that is based on sexual/gender difference. How could someone with Jamal's attitude respond when 'that small part of him' - his counter-normative 
sexual orientation - becomes the basis on which he experiences rejection and marginalisation? We shall elaborate this tension later in the section on LGBTQI Muslim politics.

\section{The gift of marginality}

Some participants had turned away from mainstream Islam, but still subscribed to, and deployed, the label 'Muslim' as a cultural and political marker of difference in Western societies. Often, this desire was heightened as a response to pervasive social and political misunderstandings of Islam and the Muslim community. The more they felt misunderstood, the more they accentuated their presence by asserting difference as a form of 'cultural defence'. Their disassociation from mainstream Islam, however, should not be misconstrued as the erosion of spirituality and spiritual quest in their lives. As discussed, many participants argued that spirituality was an integral part of the human condition, whether one understood and articulated it in religious or non-religious terms. Of course, the marginal space LGBTQI Muslims inhabit exacts psychological and social costs, for the loneliness and pain could be immense, and some no doubt crumble under the weight of such a burden.

Nonetheless, this space could also be creative and productive: marginality offers a unique standpoint, a privilege to rise above the normative framework and think outside of the box. This position often sensitises LGBTQI people to the taken-for-granted power relations embedded in the production and perpetuation of heteronormative and homonegative religious 'truths': 'truths' that enslave them in, rather than that free them from, the category of the sinful; 'truths' that undermine rather than affirm their human worth; and 'truths' that disempower rather than enable their spiritual growth. Marginal space, therefore, can offer a fresh perspective and healthy distance from the mainstream, the takenfor-granted; in other words, the normalised, the naturalised, the legitimised, and the idealised. Therefore, looking in from the outside can offer a new and critical sensibility that not only subverts orthodoxy, but also present new insights. Indeed, some participants reported that their 'minority within minority' status had propelled them on a spiritual quest and path, on which they would not have embarked if they had not experienced marginalisation. This is clearly illustrated in Jemimah's account below:

Jemimah: I think there are particular gifts that come by being in a sexual minority and having to remake your spirituality outside of the mainstream of a faith. I think the gift in that is that we have to learn to love and to practise our faith in a different way, and we have to consider what purpose creation might have in having created us. I think there is always a gift in being marginalised and that gift 
is always a way of transforming the notion of identity altogether into something higher, it's actually to transcend stuff. And I think it is interesting, that people that are very often held up as models are people like Mahatma Gandhi and Nelson Mandela. And the reason why they are held up as icons is because people see them as having transcended the conditions that produced their struggle. Although that is a bit clichéd, I think there is some truth in that; that every time you are marginalised, it is an opportunity actually from a spiritual point of view to loosen your partial identification as something or other; and have a higher goal, a higher identity ... We experience exclusion both in the way scripture is understood and expounded and in the way that religious worship and faith practice is actually set up. There is no blueprint for our participation in those things and sometimes we are excluded or executed or eliminated explicitly and sometimes implicitly. And that is the story of queer sexuality anyway in society at large [so] why should it be any different in religion? It's more acute in religion because people think they've got the word of god behind them ... So actually the identity of being a lesbian or the lived experience of being a lesbian or the combination of the two has made me search for a more inclusive spiritual path in part that has been an influence, as well as being a woman had been an influence because I would obviously never accept anything that says I was less than a man in terms of my relationship to god.

Jemimah's moving and self-assured account shows that what is intended to be banishment to silence, shame, invisibility, powerlessness, and exclusion, had turned out to be a generative gift which has given life to reflexivity and confidence that is personally, socially, and politically transformative, in thought and praxis. This gift works in giving confidence to the individual to learn to trust her/his own inner voice, experience - her/his own 'truths' - 'truths' that truly set them free from the deceiving comfort of the mundane and the bland. Challenging though this lesson is, once learned, the individual is equipped with a self-assuredness built on a deep-rooted trust and belief in the divine as an unshakeable and indefatigable travel companion in her/his life's journey. Not only does she/he transcend the shame imposed on her/his personhood and humanity, the shame is turned and evolved into a sensibility grounded in the self, and a wisdom for the production and deployment of justice-seeking knowledge and politics. In this respect, the intricate connection of sexuality and spirituality takes on an explicit political dimension, on both personal and social levels, as Lorde reminds us:

[W] hen we begin to live from within outward, in touch with the power of erotic within ourselves, and allowing that power to inform and illuminate our actions upon the world around us, then we begin to be responsible to ourselves in the deepest sense. For as we begin to recognise our deepest feelings, we begin to give 


\section{QUEER SPIRITUAL SPACES}

up, of necessity, being satisfied with suffering, and self-negation, and with the numbness which so often seems like their only alternative in our society. Our acts against oppression become integral with self, motivated and empowered from within ... In touch with the erotic, I become less willing to accept powerlessness, of those other supplied states of being which are not native to me, such as resignation, despair, self-effacement, depression, self-denial. (Lorde 1994: 78)

The notion of marginal sexuality as a special gift from God was a recurrent theme in the study (see also Chapter 1 and 2). Describing his position in the world, Jamal noted:

Jamal: I feel very very blessed. I believe that not even a leaf can move without the will of god. So I believe every single second, everything that happens is all because of Allah and without the will of Allab it would not happen.

Queerness is then understood as Allah's gift to not only LGBTQI people, but humanity in general. While a significant number of the participants had rejected the dominant Islamic discourse on sexuality, Islam continued to serve as a canopy of meaning, an embracing referential framework, from which they drew. However, instead of adhering to the commonly understood behavioural prescriptions of Islam, manifested in religiously-legitimised cultural practices, the participants framed their spirituality in terms of the essence or the spirit of Islam. This essence tended to emphasise notions such as equality, diversity, justice, and love for all humanity. The focus on the commonality of humanity, rather than religious observances and practices, constitutes the basis of a form for spirituality that is ultimately self-based, but outward-looking not in terms of standardisation and conformity to a hegemonic model, but the valuing of difference. Jalany, a mixed-race gay Muslim, explained:

Jalany: At the end of the day if you are praying and you're doing everything that is in your religion and you're not working on your spiritual path. [There is] no point, because it is the hardest thing. Everyone can go to church and pray, everyone can go to mosque and pray but the principle of being religious [is] to be open to everyone, be nice, be helpful, having good morals. But if you are aggressive, and if you're killing children and if you're destroying and on the other hand you are going to pray and you're fasting in Ramadan and you are doing everything, what is the point? 


\section{Sharing the gift and making it grow}

A number of participants who had articulated their spirituality in these terms practised their spirituality by choosing to work in the social sector specifically in relation to sexual and gender rights. Imran, who started working for the Naz Project shortly before he was interviewed, said:

Imran: The basic of Islam is that you should be a good person, promote love, promote good relationships with your loved ones, your community, with wherever you are living, regardless of whether people are Muslim or nonMuslim. It's about spreading love. And that is what I believe and that is how I practise. I pray, I fast, I do all the farz [duties], but on top of that I believe I am a Muslim in everyday practices even if it's helping a woman across the road, not throwing litter; basic humanitarian concerns. I speak up for queer Muslims. I feel very pioneering, very representative of them.

Similarly, the desire to promote social justice, underpinned by his own experience of having been victimised by sexual injustice, had influenced Jamal's professional choices. Tracing the trajectory of his professional life involvement in voluntary work, he elaborated:

Jamal: I used to volunteer for Himat a few years ago. I've come from three years of working at Naz Project. That is my speciality, working with South Asian and Muslim men who have sex with men. That is where my knowledge is mainly located and that is where I am a strong worker. I would say that has been my passion. When I was going through my struggles I found there was no support and I really wanted to be there to make a difference.

As scholars of sexual minorities have noted (e.g. Yip 2005a, Wilcox 2009), this 'justice-seeking' orientation is not limited to sexual justice. Often, it extends to fighting against other forms of social injustice, for instances, on the grounds of class, gender, politics, and race/ethnicity. Indeed, their own experiences of oppression served to heighten their appreciation of oppression experienced not only by those who share the same minority identity label, but other oppressed social groups. A number of participants reported active participation in such broad-based politics. Malik, a mixed-race gay Canadian explained how his desire for equality for marginalised groups encompasses non-LGBTQI causes:

Malik: I'm running a programme for new-comer immigrant and refugee queer youth, with young people coming from all over the world to find safety and a place they can call home, away from homophobia and persecution because of their sexuality. I also started working with the queer Muslim community called 
Salaam back in 2002 and became one of the co-ordinators. For almost two years, I was actually running support groups for people trying to reconcile their identities - religious, cultural, family-based identities and their sexualities and that was a really important part of that. I also do lots of public speaking around the issues of identity, multiculturalism, immigration, human rights. I'm active [on issues] like Israel and Palestine. [In] the anti-war rallies on the Lebanon war a few years ago, I was in the middle of this rally with Hezbollah people carrying a big rainbow flag. That's what I was doing. So for me, it has to represent this [queer] voice [to show that] being queer can be part of the community.

Similarly, El-Farouk had actively campaigned for the rights of LGBTQI Muslims and had been awarded the Pride Award in 2006, and the Steinert and Ferreiro Award from the Lesbian and Gay Community Appeal Foundation for his role in paving the way in Canada for refugee protection on the grounds of sexual orientation and gender. He stated emphatically that his advocacy of minority rights extends beyond the fight for LGBTQI recognition and was strongly incentivised by his spirituality. He noted:

El-Farouk: To be honest it's my faith and the concept of taubid [oneness] that fuels my passion for human justice. So for me my work in human dignity is entrenched in my faith as a Muslim.

Within the British context, Imaan, though primarily a support group for LGBTQI Muslims, had collaborated actively, in a high-profile fashion, with other antiracism groups in fighting against the British National Party (BNP). This farright political party is widely considered to be exclusionary and discriminatory towards immigrants and ethnic minorities. Imaan, as demonstrated in its 10th anniversary conference in London in 2008, considers it part of their moral duty to join forces with other minority groups in their protests against BNP politics.

On an organisational level, collaboration amongst various minority groups could lead to the diversification of agenda and activity of the support group, which may differently prioritised by its members. While some welcomed this as a natural development of a sexuality-based group working towards common equality and justice, other lamented the loss of focus on supporting its members. We shall return to this contentious point later. In the following two sections, we are going to take a closer look at the participants' spiritual experiences and quests. 


\section{The sensuality and embodiment of spirituality and spiritual practices}

In articulating their meanings of spirituality, some participants emphasised the lived and embodied dimension of their spirituality, within the personal and interactive contexts. Such lived dimension was found in everyday activities such as meal preparation, cooking, love-making, and bodily performances such as the use of smell and objects. Parmal asserted in this respect:

Parmal: There is a sense of accomplishment in creating a meal, especially desserts. They look so pretty and you can't even taste them in advance, like a cake. It's a special ... it's a way to honour people; to show love, appreciation and respect; to create a bond between people. It's like the breaking of bread. A lot of cultures talk about sharing of food. There is almost a spiritual aspect to a meal. Like why do people say grace before a meal and not before something else? There is also the idea of hosting people. It comes from my family. We say giving people maan (respect, honour). It's an important thing.

Even more precisely, Sunali, a lesbian of Pakistani origin, explained that cooking was a lesbian act; it involves touching the food, feeling the texture:

Sunali: The sensuous part of it, I would say, is very lesbian ... You're touching everything, you're making love with it; you're enjoying it ... You're not really worried about how much of this is going in it - this is what I call cooking. So you are finding it out, you experimenting with it, you are playing with it.

The interconnectedness of spirituality and sexuality is probably most evident in the act of love-making, as Imran explained:

Imran: Islam is not even a religion, it's a way of life. It's about spreading love. And being spiritual is being in love with yourself in order to spread love. The act of sex for me is to spread love. And it's the pinnacle of my sexuality and my love for the person I want to be with, and the person I love the most. For me to be totally turned on, I need to be turned on sexually, physically, emotionally and spiritually and mentally. For me to feel wow! It's a whole experience.

In this respect, sexual act and erotic passion are not separated from spirituality. Indeed, sex is inextricably fused with spirituality (e.g. MacKnee 2002; see also Chapter 6). Sensory experiences of other forms also carry a significant spiritual dimension. Several participants mentioned the importance they attached to pleasant scents in spiritual practices. Jamal said that every Thursday night he would recite durood [a form of prayer] and bless his house. An important part of this ritual was burning lubaan which perfumed the air in his house: 
Jamal: Lubaan is actually a rock from Mecca. It smells divine. It's used in East African and Arabic tradition. You burn it on charcoal for the smell. We also burn it on funerals. The scent of lubaan brings angels into the house; any nice scent does. I burn it for prayers. It's like frankincense, but it's a rock from Mecca ... It smells divine. For me fragrance is very important.

In the same vein, Asemeh also emphasised the importance of aroma in her spiritual practice:

Asemeh: I do practise with aromatherapy oils; I do gemstones. I have my altar there and I have statues of angels or pictures of angels. Not every day but I do feel like there is something calling me, draws me to it. I put a candle on and pray there. I burn the oils.

The very definition of spirituality as a connection with the divine or supernatural energy incorporates a sensory dimension. Sensation is a pre-requisite to feeling connected; just as it is to sexual activity. Describing what exactly she found spiritual when she was out in nature, Asemeh continued:

Asemeh: I feel a lot. I can hug a tree and feel the energy coming towards me from the tree. ... Like in a park I will take my shoes and socks off and put my feet on the grass and I feel the tingling, the energy that comes from the earth. ... If I am on a mountain I feel lifted. By the sea I feel drowned by the waves; and then the ocean, the endless ... you can't see the end; it's just massiveness ... the outer space, just looking at the stars ... This makes me feel both like I am as small as an ant but yet when I feel the energy coming through the nature and the ground, even the fire, then I feel fulfilled.

Asemeh's account incontrovertibly demonstrates the embodied nature of spirituality. Far from only participating in religious rituals, events or following teachings and precepts, spirituality comes alive when felt and lived, through the body (Nelson 1992).

While not all participants articulated an understanding of spirituality and spiritual practice with an explicit embodied dimension, all demonstrated their agency as social actors to draw upon central Islamic rituals and practices and adapt them to suit their individual needs (see Chapter 2). For instance, many of them noted that they did not consider praying five times a day - the salat; one of the five pillars of Islam - to be of ultimate significance. Many did not conform to that mode of prayer at all.

One of Amreen's spiritual practices, for instance, was that she would never step out of the house without reciting a combination of Qur'anic verses which she had learnt in a certain order from her maternal grandmother. Raminah, on 
the other hand, had adapted the prescribed salat to construct her own spiritual practice - one that did not problematise gendered bodily performances and positionality. She would pray standing next to her partner, who is a trans man.

Raminah: Within Islam you have to have a different line [for] men and women, but well [as far as I am concerned] it's up to you. Forget about how it should be. It's about how you feel, [how] you want to be. You know, in Islam, you shouldn't pray if you are in your period, but I miss praying. So when I'm in period, I miss the connection with me and my Creator. So I started to question why we as Muslim women are not allowed to pray when we are in period. [But] there is no satisfactory answer for it. It's just like, you are not allowed [if you are] in period. And me personally I just pray. So, this is the thing that I would say is personal. Lots of people wouldn't understand why, why do you pray in period? It's even against Islam some people would say. But I say, 'No, you don't understand how I need to pray. I feel I want to pray'.

Raminah's determination to reject the conventional injunctions against mixedgender praying and praying during menstruation was subversive of religious orthodoxy, yet personally fulfilling. Here, we see the self becoming the determining factor in the fashioning of personal spiritual practices, against institutional injunctions and proscriptions. In this case, the inner voice of the self, rather than external structures, gave such counter-normative practices authenticity and authority.

Interestingly, a significant number of the participants noted that their spirituality was informed by Sufism: a more tolerant and less hierarchical mystical tradition within Islam. It privileges the direct personal experience of God instead of institutionalised ways of accessing the divine; and emphasises the non-dualism of nature and existence as well as fluidity (Long 2004). ElFarouk explained his appreciation for Sufism:

El-Farouk: I am more attached to Sufism because of the emphasis on love and spirit. I think Islam has been reduced to a bunch of dos and don'ts. I often find myself in Muslim spaces where there is nothing that appeals to the heart or sings to the soul. And I don't think that a relationship with God should be based on fear or on a list of dos or don'ts. In fact I don't think God really cares about most of the dos or don'ts anyway. I mean I think they are there for us to be able to lead healthy, socially productive lives.

One of El-Farouk's spiritual practices was to engage in the Sufi tradition of ziker (chanting). Jamal also said that he regularly did riker and believed in the Sufi saints. On the other hand, Jemimah and Amreen reported that they found spiritual nourishment in Sufi devotional music. For Jemimah, Sufism also held 
deep significance in its emphasis on one's subjective experience of the divine. However, she had also moved on to a New Age understanding of spirituality called the Course on Miracles, which was similar to Sufism in that it was an 'uncompromisingly consistent statement on pure non-dualism'.

Jemimah: God is one, absolute, complete. God is the only Reality. This Reality cannot be put into words. Words, as the text says, are just 'symbols of symbols'. Words such as 'perfection', 'love', 'light', 'peace', and 'grace' faintly hint at the absolute quality of God. Words such as 'eternal', 'infinite', and 'unchanging' hint at the Reality of God. Any state that is not perfect love is not God and therefore does not exist. ... The Course is aimed at more than experience, because experience in our world is based upon perception and is therefore partial and imperfect. As with most forms of mysticism, with which the Course has many resonances, it is aimed at direct knowledge of God while still appearing to be in a body (rather than waiting until the body dies); such knowledge being timeless, beyond space and beyond experience ... The ego is an illusion of the split-off mind, whose entire existence is predicated on the idea that the separation from God - and therefore sin, and therefore punishment - is real. As soon as we really believe that no sin ever took place, and that there is no punishment, the ego has no basis for its reality.

Others also borrowed traditions and rituals from Islam as well as other religions and spiritual traditions (see also Chapter 8). Asemeh explained this syncretism in her spiritual practices:

Asemeh: I take some from Muslim tradition, I take some from Buddhism, I take some from Christianity or even Zoroastrians; any which ones that I feel connected to and touches me, so I practise that way.

Other participants said that they did not have separate spiritual practices in terms of distinct rituals but instead their spirituality was embedded in their everyday lives, particularly in their day-to-day interactions with others. Their spirituality was an embodied practice, the experience of living itself. Being positive and supportive of others was part of their spirituality and helped them form a connection with others and the universe more generally. For Jalany, his spirituality manifested itself in 'trying to be nice and polite and decent and helpful ... and hurt no one'. For Asemeh, her spiritual practice was interpersonal and conceptualised in terms of doing things for other people:

Asemeh: I just try to be nice to people and encourage being nice and being helpful. And in Islam we have zakat (charity); I do at least once or twice a week give a part of the financial thing I get, I give it out ... So my spiritual practice 
is more related to action than prayer ... to be helpful and nice; to bring peace really; to talk about peace.

Elaborating on what she considered spiritual, Asemeh argued that, for her, the act of 'self-sacrifice' for someone else to gain something was highly spiritual. It was a means of transcending oneself and one's own desires. Thus, while participants did mention some specific spiritual practices, they all stressed that more than acts and rituals, their spirituality was in the mind and an integral part of their beings. Spirituality was understood more as a sensation that engulfed them and a feeling of being complete, fulfilled and connected to another force/ energy. It was embodied, rather than institutionalised.

\section{Spiritual spaces - The mosque and the alternatives}

The mosque plays an important part in the life of Muslims. It is a space for worship and prayer where Muslims could be nourished through personal learning and social interactions within a religious context. Most of the participants, however, rejected the mosques as a spiritual space. They noted that they were distinctly uncomfortable in this space; as they felt judged and preferred not to visit it. The mosque was seen as a space where social control and surveillance operated; where one was required to conform to a certain type of personhood and public performance. In the main, the mosque was perceived as an oppressive space. Some even compared it to a theatre where a circus of rituals occurred, but devoid of soul. The accounts below illustrate this perception:

Rasal: Mosques are so not sacred. No one seems to be imbuing them with spirituality. It's all about like, you know, some kind of odd grander organised control, but it doesn't seem to be a real personal connection.

Jamal: I am sometimes uncomfortable in a mosque, depending on who is there. There are people who don't understand that ibadat (worship) is between you and Allah. There are people who want to impose their ibadat on you. I'll give you an example, I go to [the mosque] and people say 'Oh brother you've got long hair. Brother come and cut your hair. Brother you must come to this event etc.' And I say 'Oh no, leave me alone. I ain't your brother.' But there are times when that does get to you and you think you know what, I just want to come, say my prayers and go. I don't want to be involved in the politics, or find out why I should do this or that. I don't want that. All these people always feel that they want to change you. 
There is no doubt that the participants resisted, and even rejected, the mosque as a space for the production and perpetuation of conformity and a hegemonic form of Islamic sensibility. Nonetheless, another significant reason for this was the gender and sexual inequality that operated within such a space, which hegemonised heterosexual masculinity. Amreen stated that she did not go to the mosque primarily because she felt 'more scrutinised' as a woman in such a space:

Amna: Is that [also] because of your sexuality?

Amreen: No, not only sexuality. Sexuality comes later, it's just because I am a woman. It is a gender issue.

In the same vein, El-Farouk articulated the problems of gendered spaces and his resistance of them:

El-Farouk: I think gender is a social construct and I think it is used as a vehicle of social control. As the Muslim world continues to find itself emasculated, for want of a better word, controlling sexuality, particularly women's bodies seems to be the paramount function of Islam. I say screw that and I will not be part of that. So I don't go into spaces that are heavily gendered. Separate but apart is apartheid.

Amna: So you wouldn't go to a conventional mosque?

El-Farouk: No I don't.

Amna: So spaces where you feel it's not egalitarian, you will not enter.

El-Farouk: Absolutely. I had a conversation a while ago with another Muslim lawyer. We were talking about this and he said, 'Well, I don't care about these things. I just go in, say my prayers and I leave.' And I said, 'Well, first of all, you have the privilege of being able to say that as a man because you're never going to be the one stuck in the back behind the shoes, down the basement in some dirty little dungeon. You'll be in the main prayer hall. And how can you be in a space and ask for justice when you don't give justice in that space?' So that is my ethos. If you are in a space where there is no justice and human dignity is not recognised, then what good is it praying to your God? And what kind of God is it that you are praying to that would condone that kind of difference? 
The accounts above demonstrate a heightened sense of social justice - not only sexual justice - which we have discussed. This pervasive sense of justice significantly informs the participants' decision in accessing and participating in specific institutionalised Muslim spaces.

\section{The alternatives}

Despite their unfavourable view of the mosque, there was an explicitly institutionalised space that some participants found spiritually nourishing and nurturing - the Al-Masjid al-haram, the holy mosque in Mecca. Highlighting the difference between a conventional mosque and the al-haram, Rasal noted:

Rasal: I hate those [mosques]. But then Mecca's different because Mecca was like ... For me it [al-haram] is the grand shrine. It's a space of prayer. In Mecca you've got groups of people just sitting and experiencing it, which is what you'd do with a shrine, and then you've got people who are praying, which is what you'd do in a mosque.

Imran also spoke passionately about his visit to the al-haram:

Imran: I went on haj (pilgrimage to Mecca) last December and took my mom [along]. It was the most liberating journey of my life. I finally felt acceptance from Allah. [It was a] superb feeling. Absolutely superb feeling!

In the same vein, Omar, a British of Pakistani origin, also recounted his spiritual transformation as a result of visiting the al-haram at least every other year:

Omar: I use to pray to Allah, 'Please God change me [from being gay]'. The first time I went there I couldn't cry. I was numb. I was performing the rituals like every other Muslim was doing at that holy place. I was doing it but I was just numb. My entire body felt as if it was stone. I felt filthy that only holy and pure people come to this sacred place. [Over the years] I feel very happy inside, that, okay, Allab is calling me here again and again, so there must be something in me. Allah must have accepted me, that is why He calls me here. There are people with millions [money wise] but who are unable to visit Mecca because He does not beckon them. It is not in their fate. But He calls me - so why shouldn't I go?

Though all Muslims are strongly encouraged to perform baj, finances and physical distance may serve as obstacles for the fulfilment of this duty. On the everyday level, the participants did constantly access spaces that not only nourish their personal spirituality, but also offered them the opportunity to share 
their faith. El-Farouk, for instance, regularly went to the Noor Cultural Centre in Toronto, which was an open and inclusive place. He had even led jumma (Friday prayers) as an imam (religious leader). He was particularly impressed by the nonjudgemental nature of such a space for him:

El-Farouk: I went for jumma one day and I hadn't planned on going. It was summertime so I was wearing low-slung jeans and a T-shirt. Well the jeans were a bit too low-slung. The Centre that I went to, the women pray on the right and the men on the left. So it was summer and I was wearing a thong. So I went down into sajdah [prostration] and I soon realised that things were not riding in synchronicity! We always have munchies and coffee after the jumma and this 70-something old lady came across to me and said, 'Dear, thongs are very sexy, but maybe next time you can wear a longer shirt.' Someone else turned to me and said, 'What was she doing looking over from the other side?' Since then I've made sure I wear a longer shirt. So the following week when I went and was at the back tucking my shirt in, this other guy who was there, straight, older, Arab man leaned forward and said, 'Don't worry, you're all covered!'

In addition to selective social spaces, many participants also identified their own homes as spiritual spaces. The home was a space where they felt safe and in control of the environment. ${ }^{7}$ This sense of safety, control, and comfort underlines many participants' view that their homes could also be quintessentially LGBTQI spaces for some. Indeed, for some the home engendered the sense of security that allowed them to fully experience their spirituality and sexuality and to be at peace with themselves (see Gorman-Murray 2008). Jamal explained this connection:

Jamal: I can lock my door on a Friday evening if I am not going anywhere and open it Monday morning and I am happy in my own place. I know people who don't feel happy. Their own loneliness eats them inside out. They have to get out and meet people. But I can be very very happy in my own company; I don't have to be anywhere.

Another significant characteristic of a spiritual space is that it did not have to have a physical and geographical stability. A spiritual space could be amorphous, transcending physical boundary, an often personalised space where one was able to have a spiritual experience or moment. Imran argued that a spiritual

7 There is, of course, an extensive literature that explores and problematises simplistic meanings of the home as safe and welcoming particularly for LGBTQI people, see Blunt and Dowling (2006), Gorman-Murray (2008). 
space was 'somewhere where I can connect with God'. The accounts below further expand this perception:

Raminah: Well, my spiritual space is very personal, just between me and my Creator, I guess because I don't think anyone can understand my spirituality except me. And the same as my sexuality as well. No one will understand me except myself. It's very very personal. Just me and him.

Jamal: If you ask me what gets me very spiritual, the sight of a river; the sight of a mountain; the sight of the sky in the evening, at night; looking at stars. It's like God is connected with me.

Amreen: For me, a spiritual experience is not going to be bounded by any place; it doesn't say that if I am in a pub or in a club I can't really be inspired or have a spiritual experience over there. So it's not bounded by the physical location.

Asemeh: I do believe that my body is the temple of my soul. And when I meditate or pray I feel the soul reaching out and that is where I feel the spiritual space for me.

We can see clearly from the above accounts that spiritual spaces are multifaceted and multi-dimensional, moving from embodied spaces to boundless experiences. Indeed, spiritual spaces can be anywhere within and outside of oneself, inspired by the least explicitly religious sensibility. If spirituality is a lived experience in the messiness of everyday encounters, then the conventional association between explicitly religious spaces and spirituality is not only limiting, it is also inaccurate (e.g. Ammerman 2007, McGuire 2008; see also Chapters $6,7,8)$.

\section{LGBTQI Muslim politics and its discontent}

In this section, we would like to explore the participants' experiences and views in relation to the development of LGBTQI Muslim politics, specifically in the form of support networks, such as support groups like Imaan, Naz Project, and Safra Project. It is well-documented that support networks established on the basis of sexual orientation are crucial to sexual minorities, not only in offering a theoretically safe space for identity construction and reinforcement, but also in increasing the social visibility and political prowess of these groups to effect change. Thus, the presence of a group such as Imaan in a high-profile event such as London Gay Pride (see Figure 4.1) plays a significant role in increasingly visibility and raising questions. 
QUEER SPIRITUAL SPACES

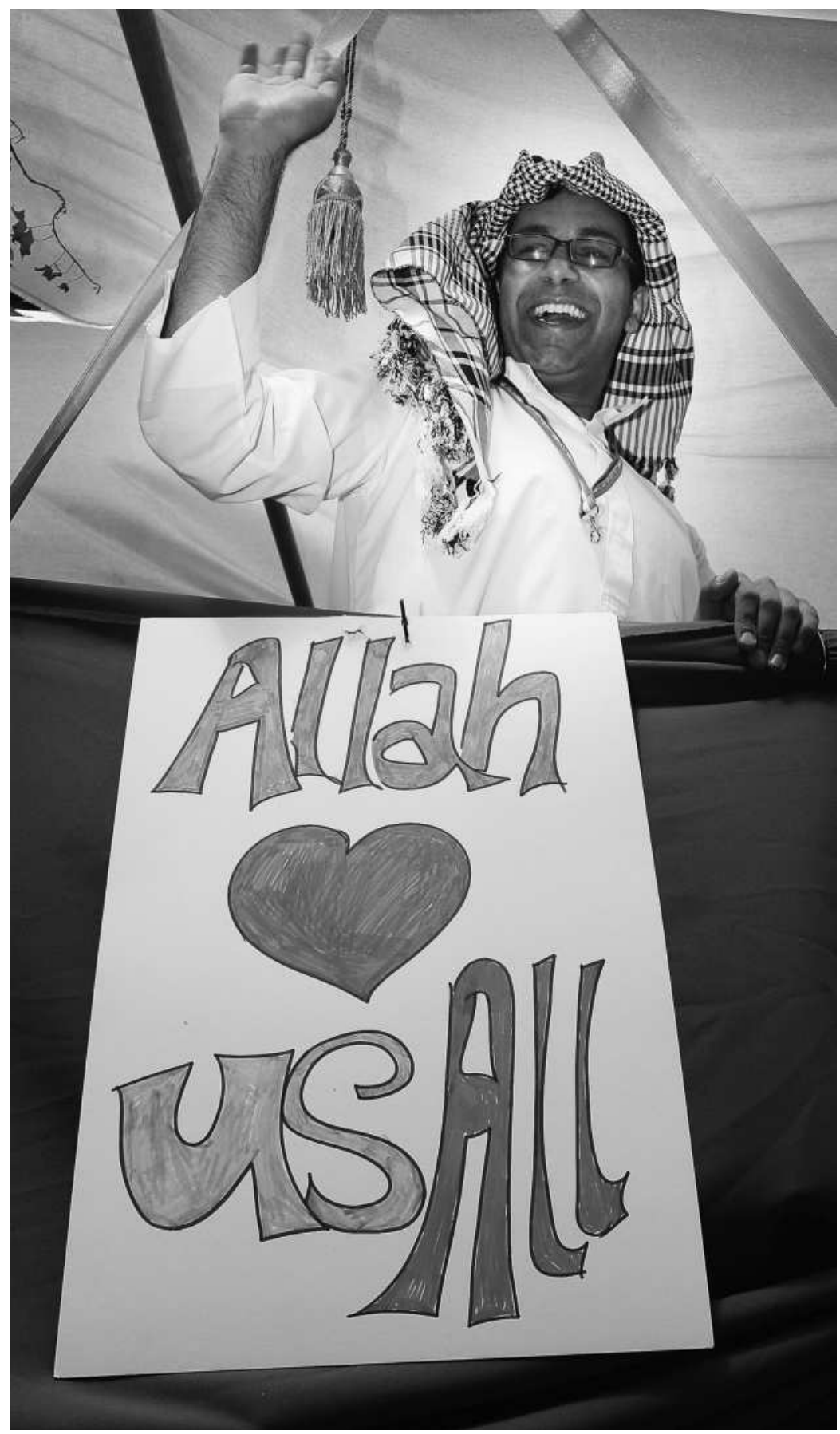

Figure 4.1 'Allab loves us all'

Source: Getty Images. 
Ironically, the organising foundation of such an endeavour often has a homogenising and essentialising effect, which establishes 'normativity' and orthodoxy that produces and demands conformity (thus the notion of 'homonormativity' that prioritises urban-based, middle-class, secular, and white gay men). This can produce a unitary and one-dimensional minority identity and experience that de-sensitises its members about internal diversity, and therefore the need to address inequality within the boundary of the group (e.g. Plummer 2003, Sen 2006, Yip 2005a).

While all participants recognised the potentials of LGBTQI Muslim support networks in providing indispensible social and political capital, and some had indeed benefitted from this, we were surprised by the high level of criticism levelled at some support groups. Such criticisms were founded on the basis of the groups' exclusionary practices, ironically, on the basis of gender and sexuality. Referring to Imaan, by far the most organised and high-profile LGBTQI Muslim support group in Britain, the female participants below expressed their dissatisfaction about gender inequality they witnessed:

Amreen: You have to behave in a certain way. You have to be a certain way. They box people. You have to conform to a certain kind of behaviour. Let's say it is an Imaan meeting and we had a dinner and I decided to have a beer after the dinner. Everybody is going to turn away from me. You can only be part of Imaan when you are a 'proper' Muslim.

Raminah: They know where I stand. It [Imaan] is like specially the men, not the women. The men, it's like, they are ok, they are gay, they check out men, but still they want the woman to cover the head.

The above quotes highlight the dominant Muslim norm particularly in terms of the practices of femininity and its policing by men. Thus, in being a Muslim, particular structures and morals should be upheld, in these cases in terms of drinking and female covering. Such orthodoxies and 'proper Muslim' embodiments can become more important to portray in order to illustrate the compatibility of particular religious structures and gay (and to a limited extent LGBTQI) identities. This relates to discussions above regarding normative sexual practices and relationships, the desire to be Muslim and LGBTQI requires a particular propriety. Gender conformity, of course, did not just relate to women. There was also the implication that hegemonic masculinity should be enacted. Some participants also noted that Imaan had become transphobic:

Imran: They are very transphobic. They have a lot of issues with people if they are camp or slightly effeminate. They see masculinity and femininity as very structured. They don't see them as mixing or fluid at all. All the trans members 
don't go anymore. They left because of discussions that happened. Imaan is not great to their needs, [but] when it comes to media attention they are there. But they do nothing.

The forceful accounts above incontrovertibly demonstrate the challenges of minority identity politics - the empowering and liberating effect generated by the focus on a unitary and single identity marker, on which the gaze of justiceseeking political struggle is fixed. Yet this focus and single-mindedness also has a homogenising and essentialising effect that is insensitive to internal diversity and inequality. This debate has been ongoing in feminism and lesbian and gay studies, and continues to be controversial in activist and political circles, for example the controversy regarding 'mainstream' gay and lesbian organisations such as Stonewall, in the UK context; and the ongoing debate regarding the usefulness of coalescing around gay marriage in the US context. Given the scarcity of human and financial resources and the relative recentness of LGBTQI Muslim support networks via-à-vis stringent religious and cultural censure (compared to those for LGBTQI Christians, for instance), it is perhaps understandable that there is still much work to be done and much room for improvement. Nonetheless, the subaltern and explicit gendered and sexualised cultural codes and expectations that lead to gender and sexual exclusion within LGBTQI Muslim support networks are significant issues with which the LGBTQI Muslim community must now engage. Notions of 'modesty' and 'respectability' which privilege men are deep-seeded within the Muslim community, problematising women's bodily performances and identities (e.g. Ramji 2007, Imtoual and Hussein 2009). LGBTQI Muslims are in a unique position to lead the way in addressing this significant issue, because sexual justice cannot be achieved without gender justice, and vice versa.

Imran noted that Imaan garnered much media attention but that 'they do nothing'. In our view, some support groups' foray into the media will prove to be a double-edged sword. It will serve to promote the plight of LGBTQI Muslims, and in principle increase awareness, understanding, and support from the Muslim community and wider society, but it will also alienate some LGBTQI Muslims because of the expansion and diversification of its agenda that moves away from a strictly support function. The development history of the Lesbian and Gay Christian Movement (the largest support organised by LGBTQI Christians), established more than two decades before Imaan, illustrates such tensions (e.g. Gill 1998). Nonetheless, such tensions need not be negative, for they could be the impetus for a more nuanced and layered response to the diversity within the LGBTQI Muslim community. There will be times when more specific (e.g. gender-based) support groups are called for to provide more focused support; but there will be time when coming together as a community based on sexual orientation is the most productive way forward, particularly in effecting political 
change in collaboration with other groups/organisations - religious or secular; LGBQTI or non-LGBTQI - working towards the promotion of sexual and social justice.

\section{Conclusion}

In this chapter, we have taken you on a journey through some of the lived experiences of LGBTQI Muslims - their fears, struggles, discontents, aspirations, sensibilities, and hopes. Occupying multiple marginal spaces, LGBTQI Muslims testify to the intersectionality of sexuality, religion, politics, ethnicity, and culture that affect all aspects of their lives. They also offer significant insights into how social actors exercise agency to negotiate and contest structural constraints, whose prominence is real and unavoidable.

Equipped with the self-assuredness built on the conviction that their sexual and gender identities are divinely willed and sustained, LGBTQI Muslims embark on a creative and self-reflexive journey of life, with far-reaching implications for personal and socio-political lives. The oppressive and alienating effects of marginality are undeniable and keenly felt, but the same space also produces a reflexive and politicised spirituality that engages with religious and cultural orthodoxy, yet transcends its grip, and transforms it in the process.

LGBTQI Muslims' search for Allah demonstrates the possibility of an inclusive, fluid, and listening spirituality that may engage with institutionalised Islam, yet not constrained by its taken-for-granted precepts and practices. This spirituality is found in the everyday, where transcendence and immanence are lived as an embodied experience and as the chapters that follow show, the everydayness of spirituality can be seen across the case studies. It also shows that a spiritual space is indeed what one makes it to be, a product of ongoing negotiation between the self, others and culture. 



\section{Chapter 5 \\ Queerness and Sangha:1 Exploring Buddhist Lives}

Andrew K.T. Yip with Sharon Smith

\section{Setting the scene: Sexuality, gender and Buddhist teachings}

In the West, the dominant view of Buddhism is one of peace, calmness, and detachment, offering therapeutic practices for personal growth. Needless to say, this homogenising and essentialising view belies the religious, philosophical, and cultural diversity within Buddhism practised across the world. Just as LGBTQI identities are Western and modern-day constructions of sexuality and gender, the idea of a religion called Buddhism is not ahistorical. It has itself come about as a result of modernity, in particular the colonial and Orientalist enterprise (King 1999).

In the same vein, although Buddhism is generally perceived as being highly tolerant of sexual and gender difference compared to other organised religions, there are varied understandings and practices across Buddhist societies and traditions. Corless has argued that, 'The concern of Buddhism in sexual matters is with the danger of sexual desire in general, with only subsidiary attention being paid to the gender or orientation of the sexual partners' (1998: 253). Buddhism, especially in its earliest phases, has therefore tended to see monastic celibacy as the ideal lifestyle for the practice of its teachings on the grounds that sexual activity stimulates the increase of desire and attachment that hinders the cultivation of Enlightenment. Monastic codes for both monks and nuns therefore tend to prohibit all forms of sexual activity. As a religion, Buddhism can therefore be regarded as in principle sexnegative rather than sex-positive (Keown 2003, Smith 2007). This feature of the tradition, although not homonegative, does problematise its relationship with notions of LGBTQI identities that emphasise the celebration of diverse sexual expressions.

1 Definitions of sangha vary within the Buddhist world. Following Keown (2003), we define it as a Buddhist community or movement of ordained and/or lay women and men. 
Buddhist monks and nuns are governed by a set of rules known as the $V$ inaya that has been developed on an ad hoc basis. Although within Indian Buddhism (the earliest form of Buddhism) there are no inclusive terms for what we now refer to as 'homosexuality' and 'lesbianism', the authors of the Vinaya seem to have known some of the practices that designated these terms and prohibit them. However, the Vinaya seems to pay relatively little attention to these deeds and does not punish offenders severely (Faure 1998, Zwilling 1998). We also need to consider how Buddhist traditions approach those who do not comply with the strict binary definition of male or female such as transgendered people. As Mrozik $(2002,2006)$ suggests, within parts of the Buddhist tradition, the physical form of any sentient being is seen to be the effect of its karma. ${ }^{2}$ Meritorious actions in one's current life give rise to normatively sexed bodies (male if one has generated enough merit) that are not marked by impairment or disfigurement in this or subsequent lives (i.e. rebirth).

Corless (1998) suggests, for laypeople, that the basis for sexual ethical practice is what is termed as the Five Precepts. These prohibit: the harming of life; theft; sexual misconduct; false speech and the imbibing of intoxicants. However, there is no normative interpretation of these precepts as there is no overall religious authority structure for Buddhism. This means that there is no standard definition for 'sexual misconduct' and it has been open for each tradition to explicate that for itself. Corless further asserts that sexual misconduct tends basically to mean 'conduct that violates the established mores of a given society' (1998: 254). Furthermore, the precepts tend to assume heterosexuality so that homosexuality and homoeroticism are largely ignored. Corless further suggests that this is due to the lack of self-identified LGBTQI communities in the cultures where Buddhism has developed. However, Harvey (2000) calls for a more cautious approach. He notes that while Buddhists have seldom, if ever, persecuted those who have been found engaging in same-sex sexual activity, some commentators within various Buddhist traditions (especially some Tibetan Buddhist schools, and schools based on the Theraväda ${ }^{3}$ tradition) have made negative remarks about homosexual practices. Therefore, as Cabezón (1997) argues, we should be cautious about interpreting the relative silence around homosexuality in the earliest Buddhist scriptures as an indication of approval. Overall, given these caveats, it does seem reasonable to conclude that

2 Sanskrit for action that inevitably entails consequences. A wrongful thought, word, or deed is one committed under the influence of the three roots of evil: greed, hatred and delusion; while good deeds stem from the opposites of these, namely the three 'virtuous roots': non-greed, non-hatred and non-delusion (for more details see entry for karma in Keown 2003).

3 The Theravada tradition consists of sects based on the earliest forms of Buddhism, i.e. Indian Buddhism. 
homosexuality has been de-emphasised in comparison with heterosexuality within the various forms of Buddhism.

Nonetheless, Buddhism could play a stigmatising role in some contexts. Focusing on Thailand, Jackson $(1998,2000,2003)$ suggests that while there are no legal or formal sanctions against homosexuality in this country - often considered a 'gay paradise' - a wide range of cultural sanctions operate to stigmatise LGBTQI people. Reviewing the arguments against homosexuality given by some Thai Buddhists, he notes a divergence between ethical judgments on homosexuality in the Thai translation of the Pali Canon (the scriptures of early Buddhism). He also suggests a similarity between scriptural definitions of pandaka (generally means a man who lacks 'normal' characteristics of maleness, with diverse forms of manifestations (see Harvey 2000, Sweet and Zwilling 1993)) and the Thai kathoey (commonly known as ladyboys but the term is basically used to describe transvestites, transsexuals and male homosexuals). These views based on scripture are used to justify negative views on homosexuality. However, some Buddhists consider that homosexuality or transgenderism occurs as a karmic consequence of violating precepts on sexual misconduct. In this context, homosexuality is a congenital condition that cannot be altered for the homosexual in their current lifetime, although it may be for future lifetimes. This view has been used to argue for a more compassionate response to samesex loving people.

While some Buddhists have argued for compassion, others have suggested that homosexuality is a wilful violation of 'natural' (hetero)sexual conduct arising from a lack of ethical control over sexual impulses. In this view, homosexuality is seen as antithetical to Buddhist ideas of self-control. Such accounts were linked to vehement anti-homosexual rhetoric and vocal attacks on male homosexual behaviour as the cause of HIV/AIDS as the pandemic developed. The tension in terms of who holds the Buddhist 'traditional moral high ground' is therefore not unlike that in current debates around homosexuality within faith communities, especially Christian ones.

So what can we make of all this? In the main, Buddhism has taken a range of stances towards same-sex desire, especially that between males. Some can be deemed celebratory as in medieval Japan, but nowadays, especially if a global view is taken, the overall approach is a paradoxical one, what Jackson (1999) calls 'tolerance yet unacceptance'. The tension can be especially seen in countries such as Thailand where non-gender normative people face the polarisations arising out of globalisation that give rise to both heteronormative nationalisms that repudiate same-sex desire and gender non-normativity, in opposition to moves towards global queering. We shall proceed to examining these important issues by focusing on the British context, exploring how being LGBTQI affects Buddhists' practices, the implications of practising Buddhist traditions for LGBTQI people, the place of LGBTQI Buddhist practitioners 
within their Buddhist communities, and of LGBTQI Buddhists within wider LGBTQI communities. Before that, we offer a brief methodological account of this case study.

\section{Brief methodological account}

This case study focused on London which, according to the 2001 Census, is home to a large proportion of Buddhists in the UK (36 percent of an estimated 149,000 in the UK as a whole). Therefore, we decided that London would form a good base for accessing potential participants who were recruited using snowballing methods. A key challenge was the variations in traditions amongst UK Buddhist organisations: non-denominational, Theraväda, Zen, Tibetan, Nichirenist (followers of the Buddhism of the twelfth century Japanese monk Nichiren Daishonin), Diasporic (usually described as 'ethnic Buddhists'), lay, monastic, to name just a few of the varieties. This means that it is not a simple matter to select organisations that are representative of the entire UK Buddhist scene.

A variety of UK Buddhist groups were contacted either directly or though the UK umbrella body for Buddhist groups, the Network of Buddhist Organisations. It was especially hoped that this would give rise to a range of voices from different Buddhisms, especially those from Diaspora Buddhist groups who are often marginalised in research on Western/UK Buddhism. However, despite all these attempts, the majority of participants - who came from the Friends of the Western Buddhist Order (FWBO) ${ }^{4}$ and Söka Gakkai International - United Kingdom (SGI-UK) - were recruited via contacts made through Sharon's previous research.

Sharon's self-definition as Buddhist, and her familiarity with this community and her research contact networks, helped immensely in the sampling process. The remaining participants were recruited through LGBTQI groups and a Zen

4 The FWBO is non-denominational, accepting the validity of all parts of the Buddhist tradition and this is reflected in the wide range of practices it offers, especially in terms of meditation and literature it draws on. It is the overarching organisation with the Western Buddhist Order (WBO) at the core of it. A Friend is anyone who attends FWBO activities to whatever extent. They have not made a formal commitment to the Movement. A Friend who wishes to express an initial commitment to this Movement can become a Mitra. A Mitra who has undergone a period of training then becomes a member of the WBO, and is called Dharmachari (for a man) or Dharmacharini (for a woman). Members of the WBO generally direct the activities of the FWBO. Throughout the text, when we refer to a Dharmachari/Dharmacharini, we use 'Dh.' followed by a letter (not the first letter of their name). A Friend or Mitra is generally referred to by a pseudonym. 
Buddhist group. In total, Sharon conducted a focus group with seven women (Mitras and Order members) from the FWBO, and interviewed 19 individuals (though one of them later withdrew from the study). As Sharon has uncovered in her previous research (Smith 2008), most people who have converted to Buddhism within the British context are middle-class and white. This is reflected in the sample for this case study (see appendix for more details of the sample).

Sharon is an African-Caribbean lesbian who is a Buddhist practitioner affiliated to the FWBO. She has also been a member of the WBO since 2003. Furthermore, she is familiar with the SGI-UK as a result of her previous research. This meant that Sharon was not only an insider in terms of the FWBO, but quite familiar with the practices and traditions of many UK nonDiaspora Buddhist groups. At times this insider status could make her too ready to make assumptions and this required vigilance on her part to avoid the presumption of shared meanings. Most of the time, however, Sharon felt able to create rapport with participants from a variety of traditions and so her insider status worked overall to the advantage of this case study. In addition, Sharon's previous research sensitised her to the ways in which Buddhist spaces were racialised, classed and gendered, which offered her some insights into the workings of multiple axes of 'difference' in Buddhist traditions as well as sexuality and gender.

\section{Locating Buddhism in LGBTQI lives}

Participants tended to describe Buddhism as being more or less the central axis of their lives to the point that it became an overarching framework for their positions of identification. Their understanding of Buddhist teachings of a lack of a fixed, essential self led them to de-emphasise their LGBTQI identities relative to their being practitioners of Buddhist techniques of the self. In fact, several preferred the identity of 'practitioner of Buddhism' to one of being 'Buddhist'. For example, Dh. B described the Buddhism aspect of his identity in these terms:

Dh. B: [I am] Buddhist 'cos I'm ordained into the Western Buddhist Order. I do identify in that way for that sort of purpose, but it would be more accurate to say that I try to practise precepts and so on, to the extent that I can and just saying 'I am a Buddhist' like as a noun implies that you're already there and you're already fixed as it were, whereas for Buddhism is much more about the process. 
Participants did not therefore regard their Buddhanature ${ }^{5}$ as basically 'queer' in the way that Corless (2004) suggests, even where they did agree that practising Buddhism encouraged the transcendence of identity categories. Rather than queering Buddhahood, ${ }^{6}$ their perspective on the teaching of 'non-self' led them to place more stress on their identities as 'human beings'. So when asked if there were times when being 'gay' (or whatever category the participant had chosen) was not a priority, participants always replied in the affirmative, especially if they felt that their sexual and gender identities were accommodated and that they were closely linked to the tradition with which they were affiliated. Dh. A, a longstanding member of the WBO, asserted this view clearly:

Sharon: Are there times when being 'gay' is not a priority?

Dh. A: Yes. Hopefully a lot of the time!

Sharon: That's interesting that you say 'hopefully'. Why?

Dh. A: Why hopefully? 'Cos I suppose I don't see it as being the most important, you know, I'm a human being first and a Buddhist second and 'gay', you know, comes further down the line in terms of identifications that are important as it were. So that's why I mean 'hopefully'. I don't think it's the most important thing in life one's sexual orientation, certainly not my sexual orientation.

Pervasive though such views are, some participants did recognise the political dimension of their LGBTQI identity, and feel the need to work for social change. Some asserted that they had this commitment because of feeling like a 'fish out of water' (to follow the metaphors introduced in Chapter 1) in their sanghas and the wider society to varying extents due to their experience of being minoritised on the basis of gender, race/ethnicity and/or class. Such participants were more sympathetic to others' adoption of identity positions while wanting to see a collective context where these could be put down. Dh. $\mathrm{B}$ argues in this respect:

Dh. B: I think there needs to be some kind of space where one's identity is not, where we can put all of that down. Which is not to be disrespectful to people who self-identify very strongly around those ideas and descriptions, but we're bigger than those [ideas and descriptions]. I mean they exist in the social and political and other ways for really good reasons, but they don't describe the whole person. [T] here needs to be a space where people can be people beyond

5 Buddhanature is the potential for Buddhahood that lies within every sentient being.

6 Buddhahood is the state of being a Buddha, an enlightened one. 
the way society labels them. Because a lot of these you know, movements that are connected with civil rights have had to emerge as a way of creating a safe space or brokering a more equal conversation. But they're still in relation to that whole process of sort of labelling, and it will be good to be in a space where one didn't have to try and protect civil rights, that all of that was kind of a Stage One and that there's stages beyond that.

Some participants also felt that their LGBTQI identity was subsidiary because of their desire to enact and obtain 'normal lives'. A few were very strongly opposed to the politicisation of their sexual identities, as something that might mark them as different/other and even marginalised. Alex, a member of SGI-UK, said:

\begin{abstract}
Alex: Yeah, I mean I go to work and I do my job and I'm myself, not because I'm gay. So I don't bring Nichiren Daishonin's Buddhism in everything I do. I don't bring my sexual orientation in everything I do ... I'm one of these people that absolutely hate Gay Pride and stuff like that. 'Cos I think it just, it sends along the wrong message. 'Cos I'm gay and I do my job, I wake up in the morning, if it happens, if they ask me, 'Oh are you married? So where's your wife from?' I'd say, 'Well actually I'm married to a man. You know, he's Brazilian. We got married in Canada.' 'Ooh that's interesting!' full stop. If they wanna know more I tell them my whole story, I don't have a problem with that. But I wouldn't do Gay Pride because doing Gay Pride for me is proving that I'm different in a wrong sense. It's proving that I'm in a minority, and I don't feel a minority. I feel a perfectly normal human being, so I don't need to, as there's no Straight Pride, there should be no Gay Pride ... So for me doing Gay Pride is affirming that in a way we are inferior and that we need this sort of expression ... to celebrate the fact, to pretend that we're on the same level when we're actually not. And it's the same reason why I hate, for example Women's Day 'cos I think it's a very sexist celebration. You don't separate Women's Day. You are a woman and you're equal to a man, as there's no Men's Day, there should not be Women's Day. But for me, it's exactly the same in principle.
\end{abstract}

Perhaps in keeping with the perspectives of the normalisation of 'gay' and seeking not to be different but to be 'normal' (Weeks 2007), this participant phrased his narrative in terms of equality requiring the sidelining of (politicised) differences. Presuming equality across gender and sexuality, he argues against visible displays that could mark otherness in ways that are discriminatory. Celebrating difference rather than presuming/seeking normality and sameness can be a manifestation of powerful gay subjectivities. This has been understood as homonormativity - the impact of which and other perspectives will be considered below. Here we focus on sexual ethics as key to understanding LGBTQI experiences and understandings of Buddhism. 
Most participants belonged to a tradition that had a codified system of ethics (precepts), with it being up to the individual to judge for herself/himself how to apply the code in the situations they encountered as part of a Buddhist emphasis on personal responsibility and a commitment to avoid doing harm. Generally, it was felt that the spirit of precepts on sexual ethics did not have particular implications for same-sex desire, although there was some variation in tradition, with Tibetan Buddhism potentially being most negative towards same-sex desire (see below). In this respect, we observe some gender differences, with male participants tending to interpret the precepts more loosely and some female participants giving more detailed consideration to sexual ethics. Take for example Doug from the Karma Kagyū tradition:

Doug: [T] here are the five, the sila, the precepts. There're almost like three pillars of Buddhism: wisdom; concentration and meditation; and ethical discipline. But it's not like the Ten Commandments, 'You shall' and 'You shall not', the sila are about avoiding those things that can lead to your mind being clouded, and from a sexual point of view, the most standard interpretation of sexual misconduct is to, if you're in a relationship, to sleep with somebody else; or if you're not in a relationship to knowingly, and this is the key, knowingly sleep with someone else's partner. But there isn't an imposition of avoiding sexual, any sort of sexual contact if you're not in a relationship, and notice I never once mentioned marriage either, because it's not a case of you either have to be married and you can have sex if you're married, or if you're not married you can't have sex.

For Doug, the issue was presented in very broad terms of not being confined to a sacramentalist view of sex and marriage, such as that found in many Christian traditions. The primary issue was one's intention, along with the impact of one's sexual activity on others, especially if they were in relationships - although one was ethically culpable only if one intentionally had sex with someone in another sexual relationship. For some women though, the issue demanded greater scrutiny, and for them, ethical sensitivity, as Dh. Vimalāsāra - a member of the WBO who was now in a committed relationship - suggested when asked how her Buddhist practice affected her approach to sexual ethics:

Dh. Vimalāsāra: I mean I was somebody who was very promiscuous, and was happily promiscuous and into non-monogamy and that kind of stuff, but actually for me now in the relationship that I'm in it's not a question of monogamy or non-monogamy. It's a question of living the precept of sexual misconduct, which is very interesting. It's very interesting because you know I'm aware it's not just about, if I go and sleep with somebody else. You know, it's about the sexual games I can play with people. It's about if somebody shows an attraction towards me, do I play with that or not play with that? So it's very more, yes, I'm 
very aware, and so for me it's yes in this relationship I don't want to be sexual with anybody else. And you know, and that is, it's very much to do with the precepts. That's where it's come from. It hasn't come from monogamy or nonmonogamy. It's actually come from that, that precept.

So for this Dharmacharini, observance of Buddhist ethics had led her to distinguish sexual misconduct from monogamy/non-monogamy, and extend sexual practice beyond physical acts and genital contact, to include sexual interactions that include flirtation and 'playing' with another's attractions. In respect of sexual misconduct, Nichiren Buddhism is different from other Buddhist traditions as there is no fixed ethical code, as Alex explained:

\begin{abstract}
Alex: Nichiren Daishonin Buddhism doesn't tell you what you have to do and what you don't have to do. So, for example, it doesn't tell you that you don't have to cheat on your partner, or it doesn't tell you that your relationship has to be exclusive. But what I think it teaches is respect. So it sort of goes along those lines that you shouldn't be cheating on your partner or whatever. And also we believe in karma, and once a friend of mine said something very true, and it's the best way sometimes to explain Buddhism: 'Karma is a motherfucker, it always gets back to you.' And it's very true. You know, you cheat, it doesn't mean he's gonna cheat on me, but it might mean that you might lose interest in him. In that sense I think that's the best sort of ethics that you can have. But it's not in the way that it tells you, 'Don't do this, don't do that' you just figure it out by yourself. On the other hand, gay people that are in open relationships and they're very happy because they both know what's happening and they're very happy with it.
\end{abstract}

For Alex, then, he saw the issue as one in which members of SGI are encouraged to take responsibility for themselves, their actions and their impact upon themselves, others and their environment. The construction of 'cheating' as wrong relates to respect, but also the individualisation of the consequences, karma moves the outcomes of the actions away from immediate implications for the relationship, but the individual is centralised both as responsible and eventually culpable. There is heterogeneity to this individualisation, although Alex had chosen to be monogamous in his relationship, this did not mean that others had to act similarly. Nichiren Buddhist ethics therefore did not require any de facto approach to one's sexual practice but neither did it absolve accountability that is figured 'out by yourself'. 


\title{
Locations of spiritual spaces in LGBTQI Buddhist lives
}

In terms of where the 'spiritual' was located, for most participants regardless of their Buddhist tradition, it was embodied in such a way that any space could be potentially 'spiritual'. As, Dh. E, one female member of the WBO said:

\begin{abstract}
Dh. E: Where is spiritual for me? I suppose I don't really locate it in a geographical place or in a house, in a sort of structural place. For me, spiritual is a connection, it's the clarity and strength of my connection with what I call the living presence of love, which has got some sense of the Unconditioned about it. So, I think for me, what I would call spiritual is the moment where you notice you're about to do something that you're conditioned to do, and you're aware of it and then in the moment that you choose to do something different, that to me is the highest; not being the sum total of your history and your egocentric identity, that to me is the highest moment of spiritual. It's where I'd locate the highest sort of moment of spiritual, where spiritual is.
\end{abstract}

Spiritual space therefore became so because of the psychic state of the beholder, especially where that was oriented towards moving away from negative habitual responses to one's environment and experience. Andrea, a SGI-UK member, defined a spiritual space in very simple terms, informed by her experience of previous involvement in an evangelical church:

\begin{abstract}
Andrea: [Spiritual is] right here, wherever I am. Spiritual to me, it's like me being me, it goes wherever I go and that's pretty much 'spiritual'. Not sure what, because I don't really use the word spiritual a lot 'cos in Buddhism it says like wherever you chant the daimok $u^{7}$ that's your butsudan ${ }^{8}$ your temple, not your temple, just wherever you chant it that's where the Buddha and stuff, and I know when I practised Christianity like there's an emphasis on the church, but the one that I grew up in was actually you know, 'Your body is the temple' like there's you know, 'God's in you, Jesus is in you.' And that's why I think like Buddhism is expounding something quite similar that your Buddhahood is there completely in you.
\end{abstract}

Andrea's account demonstrates a simple yet profound truth - if one was conscious of one's Buddhanature, anywhere could be a sacred space (a theme that is also reported in Chapters 4, 6, 7 and 8). Similarly, Tibetan Buddhist Doug was also quite clear about the primacy of the mind in making spiritual space:

7 The chanting of the mantra nam-myoho-renge-kyo, a key practice for Nichiren Buddhists.

8 Literally 'Buddha-house', a cabinet used by Nichiren Buddhists to house the Gohonzon (sacred scroll). 


\section{QUEERNESS AND SANGHA: EXPLORING BUDDHIST LIVES}

Doug: Are there places I think of as spiritual? No. Tibetan Buddhism is a form of 'Tantric Buddhism, and in the practices that you take on you're taught to think of everywhere as a sacred space, and everything as a sacred space. Now on one level, that's not only yourself but everything that perhaps other faiths may teach you to reject, your emotionality, your intentionality, desire. You're taught to see everything as a sacred space. And one of the great testings of that is if you can walk down the street in somewhere like [name of place], which is not exactly the most salubrious joint in South London and actually imagine it as what's called a Pure Land. Because the only thing that makes the difference between a temple and a High Street in [name of place] is your imputing something to it in your mind, 'This place is better than that.' And from a Buddhist point of view there is no place that's better than another.

Through his practice of Tantric Buddhism, Doug could therefore consider the entire cosmos as a space totally pervaded by the influence of the Buddhas and Bodhisattvas, ${ }^{9}$ i.e. what is referred to in Buddhism as a Pure Land; it was this consciousness that he was seeking to cultivate as part of his practice. The 'test' then was not to differentiate places, but instead move beyond such differentiations. Such a practice questions assumptions of 'sense of place' that seeks to explore emotional diversity between places as a facet of place itself. For Dh. B, spirituality was an interplay between the internal and external: a relationship that one sought to constantly embody through one's state of mind, yet he sought 'spaces of worship' to connect the relationship between external/ internal:

Dh. B: Yeah, I mean I think it's primarily a relationship between the internal space and the external space, and the internal space nobody can take away from you. So our practice can be with us all the time, albeit it that we're falling short in various ways for much of the time. But then externally, where is spiritual, I mean the obvious space or place I suppose is the Buddhist Centre, my local Buddhist centre. But I don't think I go there to be 'spiritual', and you know, do my spiritual practice and then you know, that's it. It could be in different spaces of worship. I can think of, for example, the time I was in Berlin, in the Brandenburg gate there's a peace room, that I used to sit in the peace room, or when I'm travelling sometimes I look around places of worship, churches, or wherever. All of those spaces are spaces for contemplation and I feel I can take my internal practice in those places, if I'm a long way from a context for specifically Buddhist practice.

9 A Bodhisattva is a figure from Mahāyāna Buddhism (the movement that arose out of Indian Buddhism) who is devoted to gaining enlightenment for the sake of all beings. 
However, participants recognised that one could not always embody the 'spiritual' in the way one desired. For some, space being 'spiritual' came about through one's desire to actively create one, as Dh. A suggested:

Dh. A: Personally I use it [spiritual] to mean anything that is to do with, in a way those twin endeavours that I described in terms of trying to gain a greater understanding of Reality and/or trying to be of benefit to others, in a way based on such whatever understanding as I might have, might be able to muster ... I think [it has] more to do with behaviour and mental states than particular places. I mean, yeah, I can think of places like the Buddhist centre as being 'a spiritual place.' But in a way that seems to me that's more secondary to do with the association of spiritual practice that's gone on there ... [A]s a Buddhist practitioner I think for something to be spiritual there needs to be really the intention. I suppose the critical factor is intention to either develop that sort of mindset that is pursuing truth or helping beings or carrying out those sorts of activities like helping beings.

One's intention to practise Buddhist spirituality and 'behaviour and mental states' therefore made a space 'spiritual' in terms of a desire to pursue truth and practise altruism. This means that any space could be potentially sacred, something particular germane to this participant who lives in a Buddhist shared house and works for a Buddhist centre. Place, as in physical location, in this context is unimportant, it is the creation, practice and being of spiritual space that is emphasised.

Although being 'spiritual' was perceived as creating space that negates place specificities, external factors such as designated spaces that might or might not be Buddhist, nature, the presence of Buddha statues, quietness, spaciousness, a space for collective Buddhist practice and so on, were seen as conducive by some participants to enhancing the relationship between internal and external that made a given space 'spiritual'. Some participants valued particular ritual focal points to stimulate the psychic space required for them to consider their environment as 'spiritual'. For Susanne, this focal point was the sacred scroll to which Nichiren Buddhists chant, the Gohonzon.

Susanne: I suppose the source [of a spiritual space] is in front of my Gohonzon, or anyone's Gohonzon. It actually doesn't matter 'cos at the end of the day it's a bit of paper. But being in front of that representation is a spiritual space, and all it's a source of it that's tapping into it at its most powerful level. But actually it's everyone. I mean there's not really a separation for me. If I've got a high life-state and I'm coming at it from a point of real openness then walking down the street is a spiritual space. Being in prison is hugely spiritual ... Spirituality in a way is about interconnectedness. It's about knowing your place in the universe 
... So yeah, I don't really have a division in terms of space, although when I want to recharge then it would be in front of my Gohonzon or I think going to a meeting, a Gohonzon at a meeting.

This paradox of the relationship between the internal and external space that frames the spiritual perhaps best sums up the ways in which many participants described what made spaces spiritual for them. It had little if anything to do with LGBTQI identities as such, although one's gender and sexual identities and practices could momentarily erupt into a spiritual space or assume a spiritual significance. Further, distinction was made between formal spiritual practice of, for example, meditation, and generally keeping a spiritual mindset no matter what one's surroundings. Where that distinction between formal practice and keeping a spiritual frame of mind was made, some participants said that they would bear their environment in mind when doing their formal practice and not do it in a place where it might cause people concern or where people would show disrespect for it.

Given that a 'spiritual' space was an embodied one based on one's mindset, some participants felt that it was primarily that which created the 'sanctity' of place. One's ethical practice as a Buddhist as well as one's state of mind, how one thought, communicated and acted bodily within a particular place produced its sanctity. There was, however, a significant gender difference amongst members of the FWBO in terms of keeping sex, which was generally seen by women as a representation of craving (compulsive desire), out of spiritual spaces. In contrast, one trans male Order member said how he had on retreat during a pija (a Buddhist devotional ritual) read a poem in which he said he would like to copulate with particular Buddhas and Bodhisattvas.

Finally, in terms of spiritual spaces that participants felt uncomfortable in and were less likely to visit, most mentioned those spaces designated by religions as spiritual that had gender and sexuality exclusive practices. These were generally seen to be those of traditional Christianity or Islam.

\section{Being Buddhist and LGBTQI in LGBTQI spaces}

Some participants expressed their appreciation for LGBTQI spaces because in such spaces they were not minoritised in the way they were in heterosexual spaces, on the basis of sexual orientation. However, several were critical of spaces such as clubs and pubs on account of what they saw as the sexualised nature of much LGBTQI culture. These participants said they felt excluded because of the focus of such spaces on noisy music, youth, and image (particularly body image). Some also felt uneasy in such spaces on account of the ways in which they were gendered. This did not only apply to lesbians and 
bisexual women in male-dominated spaces. For example, Dh. C, a cross-dresser, noted the normativity of trans/cross-dressing clubs which he had been to:

Dh. C: Part of that [enjoying the club he went to] was that the trannies there didn't have to look good. The trouble with most trannie clubs is that, part of why I don't go to them is all the guys tend to wear ... they want to look good so it's pretty standard outfit of wig, makeup, mini-skirt, high heels, shaved. And I can't be bothered, I don't really wanna do that, you know, certainly not shaving and everything and I'm a hairy guy.

As a result of not fitting into mainstream mainly lesbian and gay youth orientated music venues, participants often sought other social spaces in which they felt comfortable, and were successful to various extents in this endeavour. Some participants indicated that although they were not so much part of the 'scene', they had informal networks with like-minded LGBTQI people and were able to gain support from these. This was especially the case for white gay men.

In terms of communicating their religious affiliations with other LGBTQI people, most said they were willing to volunteer information to people who asked, but did not usually take the initiative in terms of introducing it as a subject of conversation. Some participants saw no difference between talking about their religious practice with other LGBTQI people than with anyone else. Others, due to their concern about the negative approach taken by many religions to LGBTQI people, had taken part in initiatives to promote the use of Buddhist techniques of the self such as meditation to other sections of LGBTQI communities. For example, one participant led meditation classes for lesbians, and another led introductory retreats for gay men. For those who had been involved in dialogue with LGBTQI people around Buddhism, the response could sometimes lead participants to encounter stereotypical responses from their interlocutors, such as that described by one member of the focus group, Dh. Y:

Dh. Y: One thing that I've noticed is that when I'm with other gay, lesbian people; if they don't know that I'm a Buddhist, or they might know that I'm a Buddhist, but they don't know I'm ordained and then it suddenly comes out that I am, they suddenly go all serious and they stop talking about sex, and think that I'm this really holy person or something, if they don't understand anything about Buddhism. So it suddenly changes into like you're a holy nun. And not necessarily that you're weird, but like, 'We've got to be careful now what we say', which you get with straight people around the Buddhist centre if they see you with a kesa $a^{10}$ on.

10 A stole worn by members of the Western Buddhist Order. 
The stereotypical views that LGBTQI people held of committed Buddhists, of being particularly 'saintly', associated with abstinence and 'holiness', meant that some participants found they did not fit the mould of a 'typical' Buddhist: celibate, quiet, with shaven head, robes and so forth. This is in part due to the image of Buddhism as essentially a monastic religion as well as the low profile that Buddhism has within popular consciousness in the UK, compared to the Abrahamic faiths. LGBTQI Buddhists who like to party, are humorous, discuss and engage in various sexual practices, are energetic and extrovert, contest the popular stereotype. For these reasons, some participants found it easier to engage in dialogue around religious matters with some committed Christians.

\section{Sanghas and gender and sexual normativity}

Participants who felt like 'fish in water' within the traditions that they were affiliated with, to varying extents, were in the main those who identified as gay, biologically male, and who were white and middle-class. Whenever the tradition was seen by participants as accommodating, this tended to be within a framework that accepted them within particular norms of sexual identities, expressions and practices as well as specific gender normativities. Others found their traditions to be less accommodating: tolerant yet unaccepting (Jackson 1999). This was especially the case for female and trans participants, with trans people feeling the most marginalised. In this section, we shall consider briefly the attitudes of key figures in the four Buddhist traditions with which participants were affiliated, and the participants' views. In the next section, we shall explore their strategies of engagement within this context.

\section{Soka-Gakkai International (SGI)}

The SGI belongs to the tradition of Nichiren (1222-1282), which affirms the ability of women to gain Enlightenment through the power of the Lotus Sutra (the central canonical text of devotion of this tradition, dating from the first century CE) in several of his writings, saying at one point that female devotees of the sütra are superior to profane men and that women need not become men in order to become Enlightened (Faure 2003: 91-93). SGI has separate divisions for men and women, and for young men and young women respectively. In the UK, people from the youth divisions can decide to perform duties at larger meetings as part of the 'dedicated groups', and in such capacities wear uniforms. The young men's Söka duties involve security of the venue, lifting tables, managing parking and such like. The young women's Lilac duties involve giving hospitality by ushering, providing refreshments and ensuring that people at the event are comfortable (see Waterhouse 
1997: 124). This kind of gendered division of labour does not sit well with all participants, as Andrea reflected:

\begin{abstract}
Andrea: I felt the roles of the Lilacs and the Söka were really gendered and I'm one who would raise that argument again and again. I, it's only recently because they have this thing called 'dedicated Lilac' which is a group for two years of solid training, like you'd go to Taplow Court instead of National Centre and it's more, you know, real. You're supporting national activities and, and it's a real emphasis on studying together and, it's like they call it Ikeda University, which I like. And I recently got a place, and up until that point that I sat for that, making that decision to go and join it, I was really quite 'I hate the uniform, and I hate it being so gendered' 'cos I'm also quite involved in women's rights stuff in the UK and obviously you know, just my knowledge and stuff it's completely brought up that sort of antagonism for me really. And so yeah, I felt really restricted in this uniform that clearly identifies me as just that gendered role ... Oh, the Lilacs, they just serve water and light the candles and do all the girly things, while the Söka are out managing cars and lifting tables and doing all the boy things.
\end{abstract}

For Andrea, there is clearly a tension between her feminist leanings and her desire to be part of the Lilacs training programme. The programme is termed Ikeda University after her teacher, suggesting that the training programme has considerable spiritual significance for the young women who take part in it. The president of the SGI, Daisaku Ikeda, an increasingly focal point of authority as the movement seeks to establish itself more firmly, has also spoken of men having 'hard power' that makes them more likely to start wars, and women having 'soft power' that gives them a specific role in SGI's work to promote nuclear disarmament and world peace. This 'soft power' arises out of women's roles as mothers which seems a classic designation of (predominantly heterosexual) femininity. Usui has also suggested that 'the structure of the SGI continues to function along gender lines' (2003: 197). In the same vein, Stone (2003: 92) also suggests in her argument that SGI's approach to social issues has conservative aspects:

Gender definition is a case in point [of conservatism]. Compared, say, to traditional Buddhist temple organisations, both Risshō Kōseikai and Sōka Gakkai give women immense scope to express their abilities through leadership roles, especially within the women's divisions. However, the ideal image of the female lay Buddhist espoused in these groups is largely limited to a traditional one of wife and mother, and few women appear in the higher echelons of organizational leadership. This has begun to change, however, in Sōka Gakkai International branch organizations outside Japan. 
One can see that gender is organised along heteronormative lines within this movement. In keeping with the lack of a codified system of ethics within Nichiren Buddhism, same-sex relationships are not proscribed although informally this has not always been the case within SGI. Previously, in the US, gay people were encouraged to chant and marry in order to become heterosexual (Corless 1998: 256). However, the mood is more tolerant and supportive now. Since the Civil Partnerships Act (2004) has been passed in the UK, same-sex couples can have their relationships celebrated at Taplow Court which is licensed to officially register heterosexual marriages. However, due to national legislation same-sex partnerships have to be registered at a registry office prior to the celebration by SGI-UK. SGI-UK also encourages members to participate in LGBT events to present a LGBTQI-friendly face (see Figure 5.1).

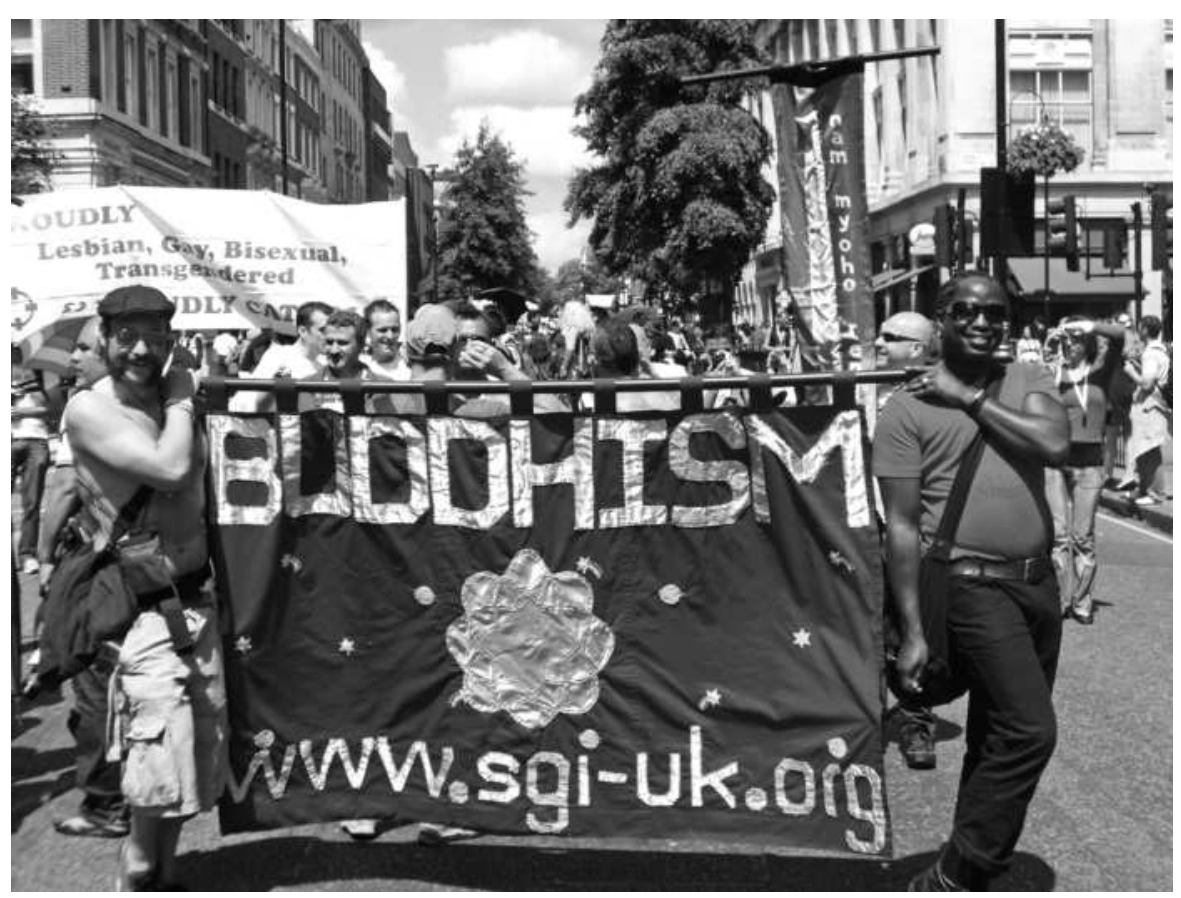

\section{Figure 5.1 SGI-UK's presence in Gay Pride}

Source: Every effort was made to secure permission to use this figure from Robert Brown.

\section{Friends of the Western Buddhist Order (FWBO)}

Sangharakshita established the FWBO in 1967 as an institution whose members are 'neither monastic or lay' and in which 'commitment [to following the Buddhist path] is primary, lifestyle secondary' (cited in Subhuti 1994: 145-46). 
Both men and women receive the same ordination and follow the same set of (ten) ethical precepts, although if a member of the WBO wishes to be celibate, they follow a different version of the third precept proscribing noncelibacy. Figure 5.2 shows The Three Jewels - namely Buddha, Dharma, and Sangha - which within this movement are considered to be the basis of a Buddhist's life.

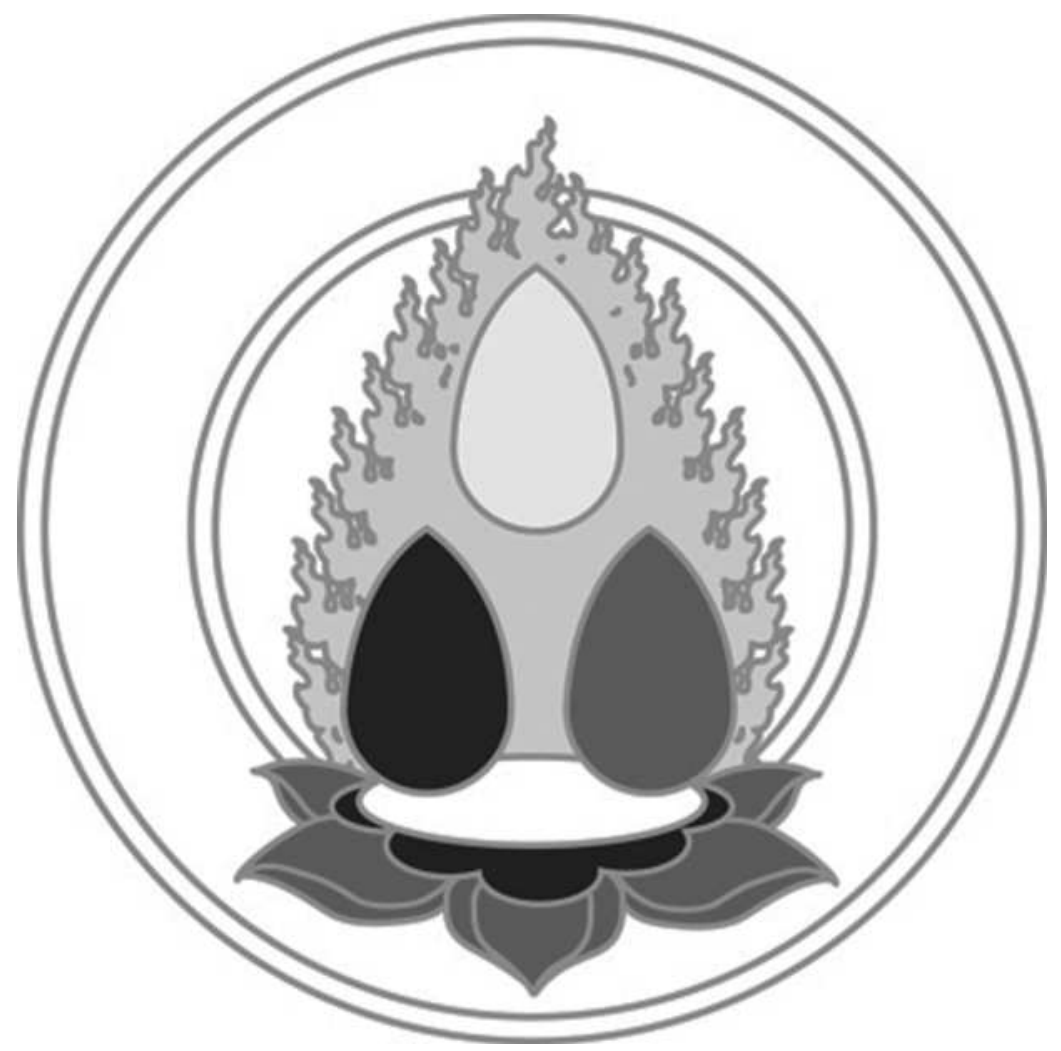

Figure 5.2 The Three Jewels

In terms of FWBO's approach to gender, Sangharakshita has said that women are at a disadvantage in terms of the spiritual life because they initially have to cultivate the masculine qualities men naturally have. These 'masculine' qualities were privileged above 'feminine' ones because masculinity provided the drive and initiative that provided the necessary momentum for pursuing the spiritual 
life (Subhuti 1995). ${ }^{11}$ In its early days, the WBO was quite critical of the nuclear family for what was described as its 'restrictiveness and exclusivity' (Subhuti 1988: 177). This provoked controversy within and outside the movement along with its favouring of same-sex as opposed to opposite-sex institutions and activities. Members were encouraged to, as far as possible, attend single-sex retreats, live in same-sex residential communities and work in same-sex 'teambased Right Livelihood businesses', which were seen as key institutions of the FWBO. This became known as the 'single-sex principle' of the FWBO, and its introduction in the 1970s was by no means a smooth and easy process, leaving many women feeling marginalised, as focus group participants also mentioned.

Homosexuality has never been proscribed by the Movement, and Sangharakshita has said that there should be no discrimination on the grounds of sexuality within the FWBO. Men involved in this movement were encouraged to prioritise friendship with men over their relationships with women, and not fear any homoerotic feelings in their friendships with men, even if they decided not to act on these (Subhuti 1994: 166). This, along with Sangharakshita's sexual relationships with some of his male disciples, has led to allegations circulating on the Internet that the FWBO is a cult that promotes homosexuality through same-sex sexual relations between more senior and junior members in the guise of a system of mentoring. Women while being encouraged to prioritise their friendships with other women, however, received criticism from Sangharakshita that some friendships between women could become 'quasi-lesbian' suggesting essentialised perceptions of a tendency among women to excessive exclusivity and attachment. However, the single-sex practice of this sangha has proved attractive for many feminists and lesbians for social and political reasons, because of its resulting effect of providing women-only contexts that they feel are helpful for their Buddhist practice, as well as their gender/sexual identities.

We can see then that although the approach taken to gender within the FWBO is binary and heteronormative, it enabled space for some alternative gender/sexual practices. In keeping with Sangharakshita's teachings on 'true individuality', LGBTQI subjectivities - relating primarily relating to gay men - are on the fringes of a heteronormative discourse and not politicised. In the past long-term monogamous relationships were not encouraged in this movement leading to contestations of monogamy that in other Buddhist contexts might be reframed as 'sexual misconduct'. And while masculine,

11 On 6 May 2009, the founder of the FWBO, Urgyen Sangharakshita issued a paper (www.sangharakshita.org/What_is_the_Western_Buddnist_Order.pdf) that he described as his 'last Will and Testament' and a 'refounding of the Order'. In this paper he re-asserts his view that compared to men, women have lower aptitude for spiritual life, especially at its outset. He does, however, state that membership of the FWBO does not require agreement with his view [accessed 11 June 2009]. 
including gay male, perspectives were (and to some extent still are) privileged in this movement, lesbians, bisexual people and to a larger extent trans people are more marginalised. The FWBO has been less accommodating of trans people, in part due to the approach taken to trans issues by its founder. This approach to trans issues did not pass without comment by participants, as we shall see in the next section.

\title{
Tibetan Buddhisms
}

The Dalai Lama (who is not considered to be the head of all Tibetan Buddhist traditions but is generally respected) has on several occasions made comments about homosexuality being a form of sexual misconduct on the grounds that it does not meet the requirements of ethical sex involving a penis and a vagina. He has, however, said that the human rights of LGBTQI people should be respected. It is therefore interesting to consider how participants negotiate the statements of this authoritative figure within Tibetan Buddhism. Sandra, a solo practitioner of Tibetan Buddhism who considers the Dalai Lama to be her principal teacher, described her perspective as his views on gender and sexuality as follows:

\begin{abstract}
Sandra: To the best of my knowledge, there's lots of teachings about females and their place within Buddhism which are generally, they span centuries, absolutely centuries, and it's changing. The current Dalai Lama's putting a reasonable amount of work into that. With regard to lesbian, I am not aware of any one specific teaching that refers to female homosexuality at all ... I'm aware that there are teachings on [male homosexuality]. I think, I don't know about the older teachings, but the Dalai Lama himself has many times passed comment on it. Other senior lamas have been asked of it. So it's not a subject that hasn't been broached by Buddhists the world over, or by senior Buddhists at that ... I'm not aware of any specific text on female homosexuality. I'm aware of homosexuality being addressed as a whole ... [B] ut in no point of time in any language of which I've read the Buddhist teachings have I encountered the word lesbian yet.
\end{abstract}

Sandra took refuge in the fact that the Dalai Lama is reviewing the position of women in Tibetan Buddhist traditions, and of the relative invisibility of samesex desire between women that exists within heteronormativity and Buddhist traditions generally. She took the relative silence within Tibetan Buddhist texts on lesbianism, and the fact that the word 'lesbian' was not mentioned in the texts she had encountered, as meaning a lack of disapproval of lesbianism, thus resolving potential conflict with Tibetan Buddhist texts and her sexuality as a lesbian. On the other hand, Doug, a former Catholic priest, who practises 
within the Karma Kagyz tradition, saw it more as a question of prioritising the approach of modern lamas. He argues:

Doug: I do know that in some of the more traditional lamas respectively from the fifteenth and the eleventh century, there is a certain view of oral sex or anal sex as improper but I've never heard a modern lama take that sort of approach - never. I've never heard anything that's denigrating of being a gay man and being a Buddhist - ever. And I would be very sensitive to that because I spent a lot of my life struggling with that. So I've never heard anything.

Doug emphasised his experience of being accommodated as a gay man within this tradition, one that has made considerable effort to transplant itself in the UK in a way that allows individuals within a traditional framework to identify which narratives they find meaningful, and what form of emotional development is most relevant to them (Bluck 2006). In this way both he and Sandra approach Buddhist texts in ways that authorise their respective personal stance rather than pure tradition, not unlike the ways in which Christians and Muslims do when they 'queer' religious texts, which reflects the contemporary Western religious landscape that prioritises the authority of the self over that of religious institution (see Chapter 2), a strategy that has also been observed by Waterhouse (1999) in her study of the adaptation of Buddhism to the UK context.

\section{Community of Interbeing (Col)}

The Community of Interbeing UK is a network of people who practise Buddhism according to the practice and teachings around mindfulness (a calm, alert and reflexively aware state of mind) of Zen master Thich Nhat Hanh, who has an international following. Naht Hanh has adapted the five Buddhist precepts of ethical conduct for laypeople as the five mindfulness trainings. These adaptations are believed by Nhat Hanh to make the precepts more relevant for the modern day and the practice of the precepts is encouraged in order to promote mindfulness. The third precept on sexual misconduct has been adapted to emphasise, inter alia, love and long-term commitment in sexual relations. This precept is generally understood to encourage chastity in those lay members who are not already in a sexual relationship, and that for those who do have a sexual partner, the relationship is expected to be long-term and monogamous, as Brian explained:

Brian: [This] mindfulness training which encourages us to aspire towards, not to, we don't have to do it immediately, it's not a sin if you don't, but it's an aspiration to not have sex outside a committed relationship, and also to certainly 
not engage in anything with any practices that involve children or that break up a relationship of other people, another relationship. I think it encourages you, I can't remember the word that he uses, not to masturbate and [not] to watch programmes that might make you very sort of ... aware sexually.

This approach to sexual ethics is quite distinct from that taken by Buddhist groups such as the SGI and FWBO, in which the ethical code of sexual practice is not so strictly defined but rather seen to be at the discretion of the individual, thus a matter of their personal responsibility. In some respects, its framework of 'no sex outside marriage' is reminiscent of some Judeo-Christian ethical frameworks. The sangha developed by Nhat Hanh places considerable emphasis on the value of the nuclear family with family-friendly retreats and specific activities for children. It can therefore be seen as heteronormative, although homosexuality is not a specific subject of disapproval within this sangha. Nhat Hanh himself has said little about gender issues in his teaching career. Similarly, in terms of sexuality, little has been said about that within the CoI.

Nonetheless, Brian (who is on the organising team of one of CoI's London groups) did feel accepted as a gay man within this sangha and trusts the good intentions of Nhat Hanh as his teacher. He noted though that Nhat Hanh was yet to hold a retreat for LGBTQI people, although Nhat Hanh had organised retreats for other affinity groups such as doctors. In general, Nhat Hanh's public comments suggest that his approach to sexuality is to embrace it in essentialist terms as innate to the particular individual, contrary to the dictums of queer theory. Also, the liturgy for relationship commitment ceremonies says that it can be adapted for same-gender couples. This, with the interpretation of the third precept, suggests that the response to homosexuality in this sangha is basically an accepting one.

\section{Strategies of engagement}

In terms of the different positionalities of LGBTQI Buddhists within the traditions to which they were affiliated, three main strategies were adopted that could be described as follows:

1. like fish in water: open about sexual and gender identifications and accommodated by the community;

2. as saltwater fish in fresh water: dissenting engagement;

3. like fish out of water: trying to swim and breathe. 


\section{Like fish in water: Out and accommodated by the community}

Those who adopted this strategy of engagement were generally white gay and bisexual men who had found a niche in their tradition which generally welcomed and accepted them so that they felt, 'like fish in water' (Bourdieu and Wacquant 1992: 127). Dh. A, a member of the FWBO Centre's Council described his role within the FWBO:

Dh. A: Well I have a role ... the [senior Council position] of the Centre ... So there's that. So I suppose it's two fold in a sense. Partly it's just being a fairly longstanding Dharma practitioner, I've been living at the Centre for twenty-two years, involved in the Centre for twenty-four years. So, yeah, it's partly being part of the furniture in a way. But also, you know, as [official position] of the Trustees I suppose I see my role in a way as threefold. Firstly to help new initiatives keep moving, which isn't other people's initiatives ... So in a way it's helping to keep new initiatives moving. Trying to keep in relationship with the Trustees, so again it's about creating, creating Sangha. And then, troubleshooting. So when difficulties arise in different parts of the community, trying to be of help or direct help towards, towards that depending on what's happening.

This participant was so much a 'fish in water' that he felt 'part of the FWBO Centre's furniture'. Like those members of the FWBO Centre Council members who were also gay or bisexual men, as well as being a senior Order member, he had considerable influence in the direction and vision of this Centre.

\section{Saltwater fish in fresh water: Dissenting engagement}

Participants in this group typically did not feel fully accepted within their respective traditions. This was more likely the case for lesbian or bisexual women. Several members of the focus group felt part of the FWBO yet marginal to it, as Dh. Y argued:

Dh. Y: Well I'd say my main context is probably my chapter [small group of Order members] and my community. I think I engage with the Order in terms of friendship. So I have a lot of different, a lot of friends all over the world and I've quite close contact with a lot of people. Yet over the more recent years, I've kind of felt less and less affiliation with the WBO. And particularly since I've been ordained ... [I feel] it's such a struggle to get women into the centre and $\ldots$ all the support money is being spent on, well most of it is being spent on supporting men. You know, I've stopped giving them a standing order, and now I just give individual money to women to go on retreat who haven't got any money. And when people call me up from the Centre to run a course or 


\section{QUEER SPIRITUAL SPACES}

something I just feel it's quite utilitarian. You know, it's kind of "Cos you're an Order member, can you just do this?', and I just think 'Oh, piss off.'

Dh. Y's frustration about the gender inequality she observed in the Order is immense, as she continued:

Dh. Y: I think it's the kind of thing that generally a lot of female Order members are feeling at the moment, it's not just me, about in a way not being consulted about the vision of WBO. And that vision is being created by the Council, who's men and women, but that as the Order, I don't feel personally that I get asked or that we get asked as the Order that the vision of the Buddhist Centre and actually if you don't get them involved in the vision you haven't got the Centre, 'cos you rely on Order members to teach. I think it's been a constant theme since I've been coming to the Centre ... The people that are visible when you come in are men. When you call the office, all the people downstairs are men. And people say, 'Oh yeah, but the Council has got women on it.' But you don't see the Council. The people who are walking in the doorway is who you see, and I think that has an effect. For me, I'm not happy that there aren't more women, you know, [being] visible and actively engaged in kind of running things at the Centre.

Andrea, a member of SGI-UK, also expressed concern about the androcentrism she witnessed within that movement. Currently, members of SGI are being encouraged to have a sense of the third founding President Daisaku Ikeda as their personal mentor in life. She described some of her initial reservations about this:

Andrea: It's like in my mind at that time was, 'What is this?' and it was because of my stuff in the women's movement and things like that, 'Another guy taking the lead, another guy President of course.' You know when it's sort of sceptic? So I asked 'Did you find it difficult to get a mentor, to commit with this mentordisciple relationship because President Ikeda is a man?' And she said, 'No', I was like, 'Why not?' but she said, 'Because there's no difference. In Buddhism, the heart's the most important thing. And again, everything is so, it's just one like the universe and Buddhahood and everything, and so the gender and you know, he's a man in this lifetime, is manifest, his life potential will manifest as a man. And you're a woman and you have distinct missions and, and, you know, just be true to yourself.' Really, it is, he's very strong on, sort of women are the forefront of our movement and men should really deeply respect all women. And he's quite strict, really strict about that. And also I know that he sent, like in the USA there's a group for LGBT group, he sent messages to their congregation, or their conference and which have completely said, it's just Buddhism is for 
you, for everyone. Just not even going into the difference and because there's not ... Let's draw out this great desire for peace that everyone has and let's see how that goes.

We can see that Andrea resolved the tension between her feminist commitments and the observations she made in the light of that with her desire to be a fully engaged member of SGI-UK through the encouragement she received to ignore Ikeda's gender. Rather than focus on issues of ecclesiastical structures and how individuals of different gender were positioned within these from a feminist perspective, she was advised to focus on the goodwill of those involved, especially as Ikeda has made it clear that women are to be held in high esteem.

Over time, participants in this group found that their practice of Buddhist techniques of the self tempered their feminist responses and made them to some extent less militant than they had been in the past. However, they experienced their feminist commitments as being less likely to be accommodated and engaged within the Buddhist spaces they sought to take up, especially because they lacked the symbolic capital in terms of status and esteem that were accorded to the men who tended to have leadership positions in these spaces. Despite this, they valued the techniques of the self they had learned through their practice and their impact on their lives.

\section{Like fish out of water trying to swim and breathe}

If women with feminist leanings felt that their position was ambivalent in Buddhist spaces, that of trans participants was even more marginal. Mary, a MTF transsexual, explained her experience of one of the FWBO's Winter retreat:

Mary: I feel quite disconnected from the [Buddhist Centre]. I used to feel quite connected, used to help out on classes, especially when I first transitioned and helped out on classes and did quite a lot. It seems as if when I started to want to get a bit more involved then I run up [against] problems because of the way I was born. I was getting problems with certain individuals because of the way I was born, and then coped with some really difficult stages with people. And as well I feel quite disconnected because in a sense I went through this kind of transition process and now I'm trying to leave that behind. I just wanna get on with my life. And like say work, I've been working in the same place for the past ten years and people have forgotten about it and it's never raised apart from people I sort of know very well and I don't talk about it with other people. And also, where I live now, nobody knows about my past and I can just blend in and carry on with my life. But at the [Buddhist Centre] I still run across occasions when sort of people start bringing it up and it sort of becomes an issue. Like 
for example, I was on retreat at sort of around Christmas and you know, about three or four times before and quite recently, then all of a sudden I find I've sort of been put in like a room of my own, and I went, 'Hmm, what's that all about?' and then eventually I discovered that the person, that they're the sort of person there who was on retreat has suddenly discovered about my past, so he's decided to put me in a separate room and tell all the people who went on the retreat about my past as well, without sort of asking me. And even though I've kind of I've got female birth certificate, the State recognise that I'm female, all of a sudden all this stuff's going on and I don't wanna, no, nobody said anything about me at the time, but it's kind of really pissed me off you know, with the fact that you know, you just want to leave that stuff behind and get on with other things. 'Cos I find it really painful and traumatic.

Mary, like any other retreatant was hoping that her retreat would be a space in which she could feel at ease, relax and get away from the stresses of the Winter period. Instead, she was faced with denial of her gender identity and breach of her confidentiality around having transitioned. This arose out of the view common within the FWBO that birth, not choice, determines one's gender which is seen to fit within a binary frame with little room for ambiguity. However, such ambiguity could be used to queer retreat space. After all, what would happen to the idea of separate rooms for men and for women if Mary's choices and entitlements were respected? Furthermore, the segregation of the rooms relies on in the first place notions of the sexual attraction between men and women in keeping with the heteronormativity of Sangharakshita's teachings on gender. In Mary's experience, the queering of space was resisted and commonsense norms of 'women's rooms', 'men's rooms' remained, such that she did not fit and was therefore ascribed 'other' and implicitly (and explicitly) out of place.

\section{Conclusion}

The perceived neutrality of Buddhism towards same-sex desire is encouraging many LGBTQI people to engage with Buddhist techniques of the self, and take up the spaces made by Buddhist movements. Perhaps this is part of a trend of secularisation for LGBTQI people in terms of them moving away from religious and spiritual spaces that explicitly exclude them and towards spaces that are more accommodating. This can possibly be seen in terms of the turn of LGBTQI people to spirituality rather than religion as a means of selfempowerment (Sweasey 1997, Ulanah 1995).

In the main, LGBTQI people in this research approached different Buddhist traditions as techniques of the self that give them an overarching spiritual umbrella identity that usually encompassed their LGBTQI self. This 
was particularly the case for white gay men. The anti-essentialist stance of Buddhism means that LGBTQI people can de-emphasise sexuality and gender identity issues; in fact identity per se. This does not mean that all who might be described as LGBTQI Buddhists take up LGBTQI identities. Rather participants in this research chose to de-emphasise those LGBTQI identities they had as they increasingly engage with Buddhism. These techniques of the self offer empowerment and tranquillity to particular participants, but at a price, precisely because they are 'the practical methods individuals use to constitute themselves as subjects within and through systems of power' (Foucault 1984a: 25-30). We therefore need to consider the gender/sexuality, class and race/ethnicity terms on which participants enter the spaces they provide and inhabit them in varying degrees of (dis)comfort. As acknowledged, this case study has not been able to engage meaningfully and fully with class and race/ethnicity due to the methodological limitation which generated primarily white and middle-class participants. Nonetheless, we hope that we have helped paved the way for more detailed research in this respect.

The frameworks in which these techniques of the self function are also strongly gendered which may create tensions for those participants that have other commitments, especially those engaged in feminist projects and/or those with non-normative gender identities, transgendered and possibly intersex people who are often extremely marginalised and hence less able to take up the central, normative spaces opened by Buddhist practices. Such conflicts may lead to campaigning for greater recognition within the faith community on an equal basis, e.g. trans people in the FWBO, and be the focus of internal struggle. Practice can also lead to former activists becoming less militant, as Dh. X suggested had happened to her in terms of becoming more temperate in the way that she voiced her feminist concerns about approaches to gender in the FWBO.

Modern, more recent readings, especially in the West, of Buddhahood that suggest Buddhanature is fundamentally queer (Corless 2004) have been led by gay men who are affiliated with Western Buddhisms. These suggestions and the ones in Queer Dharma (of which there are two volumes, both on gay male experiences of Buddhism; Leyland 1997, 1999) have opened up spaces mainly for white and middle class gay men who want to get involved in Buddhism (see also Cadge 2005). However, others like lesbians, bisexual women, trans and intersex people have found it more difficult to take up these spaces and have been less visible as a result. There are also the issues involved for LGBTQI people who are racialised minorities, who feel that the space that has been opened up is too 'cold' for them and excludes them in the way that other white dominated gay spaces exclude them. This finding for LGBTQI people of colour replicates the findings of Smith's (2008) research which demonstrates that whiteness and middle-classness tend to hegemonise within Western convert Buddhist groups such as the FWBO. 
So is this attraction to Buddhism, especially for LGBTQI people enough to 'queer' Buddhism itself? This case study suggests that such 'queering' works only in parts, and that the strongly binarist gender system of Buddhism is resistant to this endeavour, especially if queer is taken to mean 'to fuck with gender' (McIntosh 1993: 31). The marginalisation of trans people within Buddhism leading them to be 'tolerated yet not accepted' would especially suggest that this is the case. In Buddhism, LGBTQI spaces arise as a result of a rift in the surface where 'queerness' comes through. These tend to be less regulated and not so much part of the mainstream, although they may at times seek to become less marginalised. These pockets of LGBTQI space exist in a predominantly white masculinist and gender normative context in which white male and middle-class homosexuality is privileged over other LBTQI identities.

In sum, this study has given initial indications of how Buddhists who are LGBTQI are operating within the context of Buddhism in the UK, showing that conventional hierarchies of gender and of race/ethnicity and class are highly germane in terms of those having greater visibility and voice. It has delineated some of the ways in which British LGBTQI - especially white, middle class gay male - Buddhists find a 'meta-identity' of being Buddhist that for most, de-emphasises identifications based on sexuality and other axes of difference. We would suggest two main reasons why LGBTQI Buddhists are finding niches, if not always fully-fledged spaces within UK Buddhist communities. Firstly, the largely neutral, and in some cases more inclusive attitude of British Buddhist communities. Secondly and more importantly, the insistent anti-essentialism of Buddhism, that for all their nay-saying of LGBTQI identifications (particularly that arising out of their gender normativity), has meant that many LGB (if not TQI) Buddhists can find places where identity can be put to one side if not jettisoned altogether. For these reasons, perhaps many UK Buddhist spiritual spaces are becoming 'queerer' than might initially be thought at a first reckoning. Put differently, perhaps British Buddhism is becoming more like the proverbial curate's egg - queer in parts. 


\title{
Chapter 6 \\ Dyke Spiritualities at \\ Michigan Womyn's Music Festival
}

\author{
Kath Browne
}

\section{Introduction}

This chapter will focus on the sacred place of, and the place of the sacred at, Michigan Womyn's ${ }^{1}$ Music Festival (Michfest), reflecting the plethora of spiritualities and religions that are practised, lived and felt on Michfest land. Many of these conform to recognisable categorisations of religion/spirituality such as Dianic and Judaism, others however are more individualised experiences of connection, celebration, rejuvenation, acceptance, energy and love that cannot be located within particular religions or spiritualities. What is consistent throughout however is the basis of deities, practises, experiences and rituals in the feminine, female and/or womyn's connections, subjectivities, lives and bodies. In this way it addresses Wilcox's $(2006,2009)$ contention that queer/ lesbian women's reworkings of spiritual practices are underexplored. This is perhaps unsurprising given Michfest's roots in lesbian feminist separatism and its current womyn-only policy. ${ }^{2}$ It will build on previous work that argues for a move beyond the critical (Browne 2009a, Sedgwick 2003) and develop Wilcox's contention that queer engagements with religious studies may necessitate a broader engagement with the 'positive roles that religion plays for LGBT people' (2006: 94).

1 The $y$ is used in womyn to respect the way that this spelling is used at Michfest. The y is used to take men out of 'women', as I discuss elsewhere (Browne 2009a) this moves beyond essentialist assertions regarding femaleness, but is nonetheless exclusionary. Womon is the singular of womyn.

2 Much of what has been written about Michfest focuses on the womyn-born womyn policy/trans controversy (see for example, Halberstam 2005, Feinberg 1997, Prosser 1998, Sreedhar and Hand 2006). Whilst the 'feminine' is key in this chapter, I will not be seeking to deconstruct this policy or examine camp trans - I have done this elsewhere - see Browne, 2009a. Further research should explore, perhaps critically, the intersections between 'femininities' and spiritualities at Michfest and spiritualities at Camp Trans. 
Kendall (2008) has described the sacred at Michigan Womyn's Music Festival through embodied rituals, senses and arts, recognising the plethora of religious traditions that are reworked on and off the land. This chapter augments this research, bringing in a space and sexualities focus. As such, rather than offer information on goddess spiritualities, wiccan or Dianic practices, beliefs and/or theologies (see for example Daly 1989, Starhawk 1989, Barrett 2008), I will focus on some of the plethora of spiritualities enacted, and restricted, at Michfest. Offering insights into the entanglements of sexuality, spirituality and Michfest, the chapter explores womyn's festival spaces beyond, and including the party (Browne 2007). Although this has resonances with other festival spiritualities, such as Glastonbury, the focus on the feminine is key to understanding the complexity of Michfests' sacred places and Michfest as a sacred space.

\section{Michigan Womyn's Music Festival: Spirituality and womyn's space}

Fern: I went to a women's summer solstice in Seattle this year yeah, and it was set up as a spiritual thing and rituals and things. And it was only like 150 people and it was really good. I was hoping to do that in place of coming here, but what I realised is that would be like one little tiny pinpoint of something here. This [Michfest], even though the whole thing isn't set up as spiritual, it permeates spirituality. It's like everything of it does.

Michigan Womyn's Music festival is an annual event one-week festival that began in 1976. It is a womyn only festival that currently takes place in rural Michigan every August. It is built from scratch each year, run and managed almost entirely by womyn and between 3,000 and 10,000 womyn attend. Michfest promotes itself as 'an experiment in creating a feminist community' and has sought to promote alternative ways of living free from patriarchal constructs and lives, as well as celebrating womyn's lives and cultures. The land, owned by the production company You Can't Stop the Music, 'transforms from a quiet woodland to a cosmopolitan festival equipped with electricity, running water' (Fowler 2001: 47). In the six days that the festival runs, the site becomes the largest city in the area with thousands of womyn camping and using RVs. The festival consists of three stages (day stage, acoustic stage and night stage), a shuttle service, workshops that include a spiritual strand (intensive and general) as well as a range of cultural events that are both organised and spontaneous and (re)create festival culture each year (Cvetkovich and Wahng 2001, Fowler 2001, Kendall 2008, Morris 2005). It includes poetry, music and performances, and is built and maintained by teams of workers divided into key areas (recycling, kitchen crew, stage, security). Entrance into the festival is on a sliding scale up to $\$ 490$ for the entire festival and requires up to two four hour workshifts from each attendee (attendees are also known as festigoers). 
Similar to New Religious Movements, Michfest's history consists of accusations and vilifications based on sexual perversity, including paedophilia (Machacek and Wilcox 2008, Morris 1999). Although such allegations were unfounded and based on predictably homophobic readings of lesbian sexuality as predatory and inherently deviant, the oppositional politics that were important, due to police and local invasions and other forms of discrimination womyn faced in setting up separatist lands, continue to be manifest at the festival. Michfest feminist separatist policies are evident in of ' $y$ ' in womyn to indicate distance from 'men', and the operation of a 'womyn-born womyn' policy, which effectively asks trans women not to attend. This has caused huge controversy and extensive criticism of the festival in queer and trans literatures (Halberstam 2005, Feinberg 1997, Prosser 1998). Although no one is asked about or needs to 'prove' their gender herstory to participate in the festival, many trans activists claim that Michfest operates a 'don't ask, don't tell policy' (Camp Trans 2005). Camp Trans occurs at the same time as the festival and is set up about a half a mile from the Michfest site in public camping grounds. ${ }^{3}$ This policy and its implications and productive tensions are beyond the scope of this paper (see Browne 2009a) - suffice to note the separatist policies of the festival, which have spiritual implications in terms of honouring the feminine, as well as such spiritualities re-constituting womyn's space.

Kendall (2008) illustrates how Michfest has a variety of spiritual and sacred traditions that are not necessarily connected to any particular form of tradition, and can create 'new' traditions on the land. The diverse spiritualities that are manifest at the festival have varying histories and links to the organised programme. Michfest is for many an annual pilgrimage, as it is travel to a place of womyn's music, culture and spirituality (Olsen and Timothy 2006). It may not be a place when heaven and earth 'meet', however, it can be 'heaven', home and a haven (Kendall 2008). Nevertheless, it would be disingenuous to suggest that all womyn who attend the festival would read it as sacred, although there can be no doubt that the land itself is often described as such, and this was evident in the data. Michfest, as Fern notes, was not intended to be a 'spiritual' space the music festival was set up because of dissatisfaction with other festival and women's spaces at the time (see Morris 1999). The place of spirituality in the festival is, nonetheless, important and is referred to on the stages, in workshops, as well as being experienced through the onsite interactions between womyn.

3 See Wilchins (1997) for a firsthand account of the emergence of Camp Trans. 


\section{Notes on methods}

Breaking into spiritual circles and finding those who are not only interested in spirituality/religion but also identify as lesbian, gay, bisexual, queer and so on is not easy, even at a festival that is in the main lesbian and has a strong spiritual element (see Browne 2005). Having a short time period of one week and despite attempts to attract participants in advance on discussion boards, meant that making these connections quickly became urgent. This was undertaken initially by attending festival events that identified themselves as spiritual and where possible speaking to womyn there (however usually this meant one in-depth discussion with a participant). Impromptu discussions that led to the research at times also yielded some participants, and I began to develop networks in the latter part of the festival that lead to further interviews. The interviews, because they were recruited in this way, gave rise to data that would not otherwise have been gathered in a formal setting.

The way that data was collected was opportunistic. This meant that I took any opportunity to interview people as and when they were ready. The 10 interviews took place on paths, sitting at stages, at meal times, waiting for the shuttle buses, before and after workshops, outside of tents, sitting on the side of dance floors, sitting beside the labyrinth and even one whilst swinging at opposite ends of a hammock (see Figure 6.1 for one example). Some interviews took two to three meetings and others were cut short by getting to the tent, girlfriends arriving and other festival priorities. Consent was often gained after the interviews (allowing people more time to contemplate their involvement). Interviews followed a loose structure and revolved around aspects of the festival womyn were participating in at that moment and then moved to more generic questions from the project's core questions. Interviews (and sections of interviews) lasted between 10 minutes and an hour. However, organising and arranging meetings was difficult and at times it took two to three attempts to get interviews done or finished as womyn would forget, turn up late or be interrupted. Such a relaxed, loose and unstructured process is necessary for collecting data at festivals where a lack of formal engagements characterise how time/space operates in these places. Formal arrangements would have felt imposed and out of place, moreover, they would have been counter-productive in developing rapport and research relationships, so crucial for a study such as this.

Interviews were complimented by more formal workshops that formed the focus group data for this aspect of the research. The workshops were part of the festival schedule and applied for in advance of the festival. They were advertised in the Michigan Womyn's Music Festival Brochure as: 


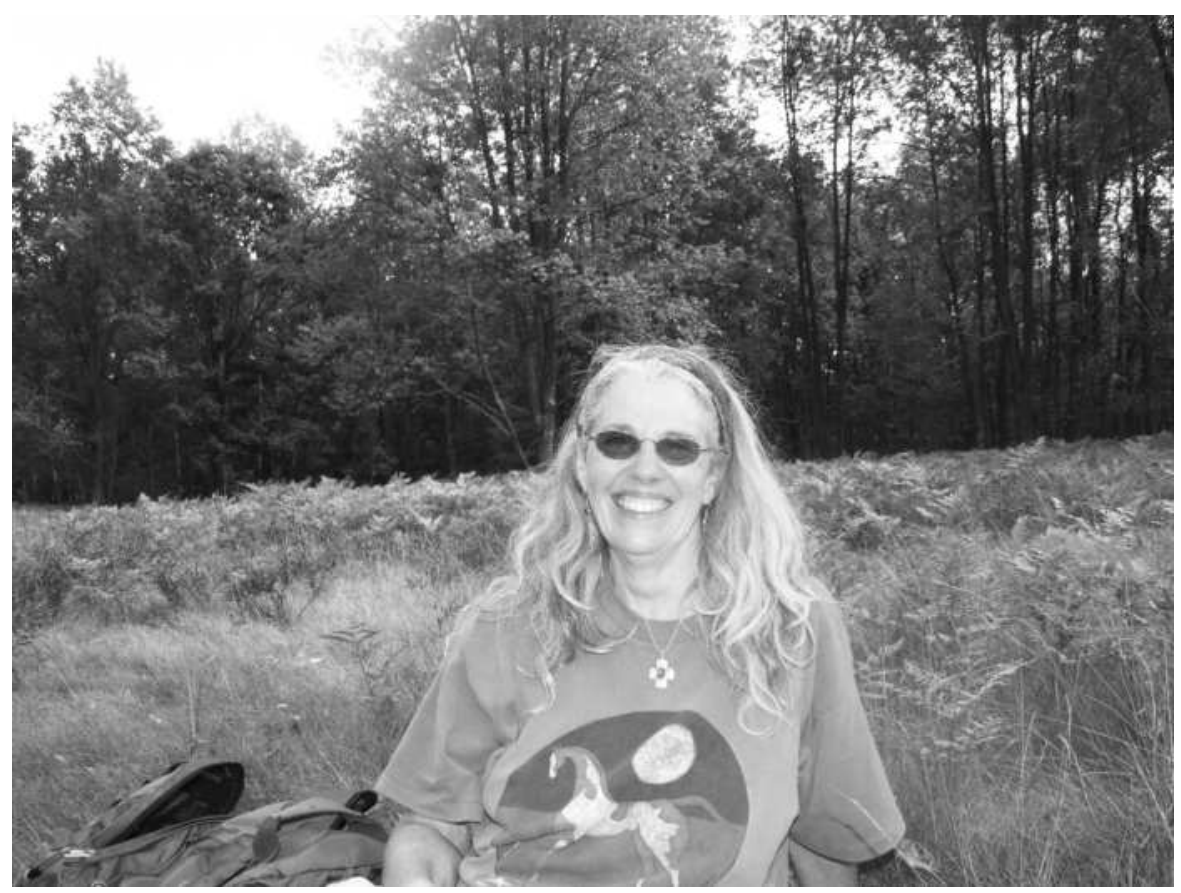

\section{Figure 6.1 Scout following our interview}

An interfaith space in which lesbians/queer identified womyn can discuss their spiritualities. Come along if you are Jewish, Buddist, Pagan, Muslim, Hindu, Christian, Wiccan, in any other way spiritually creative or just curious! You can also become part of a queer interfaith network and will contribute to a research project that looks at spiritual spaces and sexual/gender diversity. (Michigan Womyn's Music Festival Brochure 2008: 39)

These enabled womyn to participate in the project if they wished and offered a broader sample than what could have been gathered through opportunistic and snowball sampling. It also took away the need to find out definitions of sexuality and their relationship to the spiritual, prior to asking for participation. There were a total of 20 people in the focus groups (11 in the first one and 9 in the second one); these lasted just under two hours each. The data was transcribed and key initial thoughts were put online, with womyn invited to comment. All participants who gave me their details were sent a sheet that outlined the main aspects of this chapter and offered the opportunity to read this chapter prior to proofing and publication. 


\section{Positionality: Spiritual and emotional journeys}

During my first visit to Michigan womyn's music festival in 2006, I explored motivations, perceptions and experiences of the festival using questionnaires, interviews and focus groups (see Browne 2009 a, b). Returning to Michfest to undertake this project I felt that I had little understanding of 'spiritualities' either academically or personally. The trip was a journey in many ways: engaging in a humble learning role meant that I could briefly experience the plethora of spiritualities, religious traditions and spaces that Michfest has to offer. Focusing on others experiences as well as noting and observing my own offers a particular sociological participant observer analysis of this space. As such my interviews offered breadth, rather than an in-depth exposition of any particular spiritual form. As many authors have pointed out, Michfest is uncontainable, indescribable and ultimately experiential (see Cvetkovich and Wahng 2001, Fowler 2001, Kendall 2008, Morris 1999). With this in mind it is important to note that I only spoke to those who are engaging in spiritual activities or understand the place of the festival as in some way spiritual (although the diversity of this will become apparent). I did not gather data on Native American spiritualities in any depth, perhaps reflecting my own ethnic and spiritual positioning (see also Chapter 4), nor did the data I collected examine in any depth the womyn-born womyn policy and its relationship to the spiritual spaces created at Michfest. Additionally as a 'newbie' to the festival (this was the second time I went to the festival), my positionality is very different from those who have undertaken longitudinal ethnographies of the festival and its herstories (Cvetkovich and Wahng 2001, Kendall 2008, Morris 1999).

I took one of the opportunities that Michfest offers, namely to engage with, enjoy and learn from my Elders. I enjoy Michfest and this has challenged the critical edge I am supposed to have as an academic. It creeps into this chapter (and across this book), however so too does another form of analysis, one that necessitates an engagement with wonder, surprise and positive affectivities that exceed the critical negative that we academics are 'supposed' to deploy (see Browne 2009a, Sedgwick 2003, Wilcox 2006). I want to offer one of my most moving moments at Michfest to partially address the overwhelming affectivities of this festival: as is the mantra of Michfest, 'you have to experience it'.

I attended the transformation healing ritual on the Sunday of the festival. This was a ritual that invited womyn to heal, giving their sorrows, pain and hurt to mother earth. Womyn lay on the ground on rugs, mats etc., whilst healers moved between them touching (after being given permission), speaking, holding and allowing womyn to cry, wail, moan and release. This body of womyn was surrounded by another circle that was led in song/chant by a bare-breasted womyn with a sun painted across her chest above her breasts, along with singers and drummers who had been meeting in workshops throughout the week. As 
womyn leave the circle they are met by their grandmothers from the Crone Council whose role was to ease the transition from the festival to their everyday lives, offering further hugs, and oranges. The emotions and unconscious affects of that experience were palatable and inarticulable. I moved to the circle, in part because my academic 'observation' suggested I should. However, the wave of emotion that encased me was as unexpected, as it was powerful. The deep emotion in the centre of the circle, where womyn kneeling, lay flat and sat, was visible. As one of my Elders held me, I sobbed into this womon's shoulder, embarrassed at my emotional outburst but unable to contain the grief I felt for my grandmother who passed away the previous January (although she would have been mortified that a) I was attending such a festival and b) that I was publically crying!). As I apologised, she gently chastised me, I should not apologise for crying. I left the circle to return to my partner who further comforted me about 100 yards from the circle, feeling more comfortable crying in her arms and away from the intense emotion of the healing circle. That deeply moving experience highlighted not only my presence in and distance from the spiritual aspects of the festival, but also the place of spirituality at the festival itself. I was not willing to let go in such a communal space and spiritual space is not necessarily engaged with by all at the festival, but nor was I exempt from it, and it is difficult for anyone who attends the festival not to experience, feel, hear and/notice the spirituality the pervades the festival spaces, particularly those on the stages.

\section{Spectacle spirituality: Connecting the lesbian tribe}

Throughout the festival there are examples of what I term 'spectacle spirituality', that is showing of spiritual acts that are designed to be spectacular ${ }^{4}$ in some sense, often involving audience and performances. Most church services and preaching events could be understood as spectacles of religion. At Michfest there are spectacle spiritualities that are specifically designated as spiritual (such as 'the ritual honouring of the land and ourselves' on the Tuesday night), however my focus here is on the mass events which are not necessarily, specifically or solely spiritual, yet spirituality emanates from these festival stages. Such performances, words and rituals invite mass participation but do not demand it. Festival ceremonies and rituals create a 'strong circle of womyn' on the land that is open but 'not broken' when womyn leave festival times and spaces. Such bonds, interactions and rituals take specific forms that are

4 The spectacle has been seen in Tourism studies as 'inauthentic' and constructed. Here I do not make that distinction, rather the spectacle is an important aspect of Michfest spiritual practices, representations and manifestations. 
enabled by the format of the festival and centralise feminine spiritualities and subjectivities. Moreover, the land is key in such inclusivity, the 'energy of the land' is invited, celebrated and respectfully thanked during the diverse rituals. The spirituality reflected in these rituals makes references to goddess, Native American and earth based spiritualities, all are orientated toward respecting feminine ancestors, spirits, celestial beings and womyn themselves (Kendall 2008). As these ceremonies are repeated annually, they have become formalised, creating womyn's lives, spiritual practice and interconnectivities. It is possible to argue that for many womyn these festival ceremonies help them participate in the reality (for them) of feminine spiritualities and connect to each other, creating a sisterhood. Spectacle spirituality, led by those onstage is nightly aspect of stage entertainment, but it is particularly apparent and overt during the opening and closing ceremonies.

In the opening ceremony and concert, on the Wednesday night there are prayers that welcome tribes, rituals that thank the land and declare it as sacred. Permission to use the land is asked from the owners of the land and womyn of colour play a prominent part in this ritual. Moreover, artists such as Bitch reiterate the spiritual under- and overtones, sending her messages out to 'womyn, witches, bitches and trannies' and declaring that 'The gathering of us, the embrace of us' is the collective that is needed for change. The singing of 'Amazon Women Rise', a song annually performed and communally sung at each festival written by Maxine Feldman, is a key (spiritual) moment of the festival for many (see Kendall 2008). On the Sunday, the last day of the festival and of course a traditional Christian 'holy day', all of the activities on the acoustic stage are spiritually orientated and ritual becomes a key aspect. The Drumsong orchestra and the One World Inspirational Choir take to the acoustic stage (both consist of festigoers who commit to participating over the week of the festival and are lead by Ubaka Hill and Aleah Long). This is followed by a transformational healing ritual, and then later in the evening by a Candlelight Concert. In addition a water ritual is enacted with all audience members invited to engage with the sacred element of water, bring things to the water and get the blessing of the water. Two large bowls of water were placed at the stage and hundreds of womyn queued to take water in their hands spreading it on their face and head. The drum orchestra 'wakes up Mother Earth' to tell her we are here', and 'all celestial beings' are invited to join before the One World Inspirational Choir and the spirit and celestial beings are thanked at the end for coming and asked to 'keep us in mind'.

The candlelight concert that concludes the week's festival entertainment is for many womyn a key spiritual and connecting moment. This ritual is diverse, multifaceted and steeped in a plethora of tradition and herstories. It includes Dianic sisters as torch bearers leading the way via the candlelit path to the stage. In their wake, tambourines and other percussion instruments begin the concert. 
The silent audience murmurs rather than claps. The interpreters for $\mathrm{D} /$ deaf people, a key part of all concerts, are lit by candlelight. Rituals are a key part of this concert, including prayers, chanting and singing, the use of feathers as well as evoking and respecting ancestors (of the four corners of the Earth, the divine, Mother Earth). Aspects of womanhood and the feminine are evoked and the connection between womyn rehearsed through evocations of 'unified sisterhood'.

Bonnie: The Candlelight Concert is probably the most spiritual event and I've read on stage there and it's just insanely moving and cool.

Kath: What makes the Candlelight Concert spiritual for you?

Bonnie: Well it's quiet. The fact that womyn stand with these torches and act like guardians. It's not noisy. Womyn are respectful. They bring their little candles. Everyone murmurs. At the end everybody howls. Womyn choose music or spoken word that's reflective and thoughtful and hopeful. And then earlier on that same day the drum song is a very spiritually important feeling and I usually lie down naked in the dirt to feel the drum going, you know, right up my spine. It's wonderful [laughs]. It's just like that is it. And getting up and dancing with face paint and feeling very traditionally tribal. So there's a sense of the Jewish womyn as a tribe and festival people as a tribe, womyn as a tribe, lesbians as a tribe. So I would connect that tribal grove, when that happens with multiple communities, is what binds them all together.

Bonnie argues that there is a lesbian tribe is connected through the candlelight concert. I would extend this to other collective and communal moments orchestrated by the festival and usually located on the stages (particularly night stage). The candlelight concert concludes with rituals, blessings, thanks, and the claiming of sacred grounds of Michfest where 'our tribes' will gather again. After this the audience breaks into howls, a legacy of one concert many years before. Following this impromptu singing circles form amongst audience members as womyn celebrate and comfort each other, loath to leave the sacred land.

Such spectacle spirituality could be reminiscent of churches, altars (stages) and rituals. Yet, in recreating the feminine, female connections and reinstating the symbolic place of wombs, vaginas and Mother Earth, the concerts take a 'queer' feel in the sense they question the powerful norms of male (and often heterosexual) dominance (see also Roseneil 2000). As Dyke concludes:

Women who claim identity as lesbian-feminist, womanist, woman-on-to herself ... the dyke, the medicine-woman or the witch have already set themselves apart from the Euro-American homophobic, heterosexist, patriarchal norm. As a 
result the ethics [and I would argue practices and manifestations] emerging from these threads of spirituality are less a set of rules than they are principles of a process of survival and of moving farther away from patriarchal norms. (Dyke 1992: 153-54)

The processes of survival, healing and recreating norms outside of patriarchy are part of broader Michfest cultures of lesbian separatist feminism from the 1970s provide strong motivations for creating and attending the festival (Browne 2009b, Morris 1999, Kendall 2008). The pivotal position of womyn as sacred, also celebrates wombs, sisters, daughters, mothers, teens, crones, babies, tears, laughter and menstrual bleeding through communality. Musawa, who lives full time on women's land, also explores the power of female mass connection at Michfest that is held by the opening and closing ceremonies:

Musawa: So for me Michigan is just a wonderful, you know, explosion [laughs] of womyn's culture that all comes in one place. So to have, this year I think it's 2,500 womyn, up to $10,000,12,000$ womyn once, suddenly gathering. It's like wow, in the woods and everything. I mean just look around, you know, who we are and all the different music that we make and the artwork that we create and the relationships that happen on this land. I love how there's the opening ceremony and the closing ceremony and the sort of holding spiritual space here on the land. Sometimes it's difficult with all the other influences, all the ways in which lesbian culture also tries to imitate heterosexual culture in terms of, when people think about butch and fem and this kind of thing, or you know, some version of that, it's just sort of an imitation. Feels to me a lot like imitation of heterosexual society which we are kind of like a sense of relief to get away from that kind of limitation. So why in the world would we want to re-enact that. ... So Michigan itself has to deal with the contradiction of kind of hard-ass city culture kind of in some ways and loud and, you know, the more times you say 'vagina' and 'cunt'. Some of that isn't terribly inspiring to me. It can be a little more sensationalist and stuff. So you know, there's those differences. But everybody gets to find their own world that they connect with and that's great, you know, goddess speaks to each one of them in their own language, whatever that is. And there's room for all of that.

Here, spiritual spaces are manifest through alternative rituals, practices and performances. However, there are clearly exclusions too. These have similarities with the identification of butch and femme lesbian genders as imitative of heterosexuality, which echoes angry cultural debates between butch/femme lesbians and specific groups of feminist lesbians from the 1980s (Kennedy and Davis 1993, Munt 1998). There can be no doubt that there are organised spiritualities that are managed in particular ways, including through historical 
precedent and contemporary stage management that both resist and recreate dominant spiritual and often sexual norms. Musawa explains that lesbian and womyn earth based spiritualities can also stand in contradiction with 'hardass city culture' which womyn also embody and enact at the festival. Although Musawa appreciates sexual liberation, she is concerned by what she identifies as 'heterosexual imitation'. Linking diverse sexual and gender expressions to the openness of her spirituality Musawa both creates room for 'all of that' and yet also distances herself from it.

The diversity of rituals, prayers, chants and performances that create a 'lesbian/womyn's tribe' and Michfest as sacred grounds, can never be fully captured. I have described them here in my terms, knowing that there are probably many labels, names and traditions that these could be placed into. Importantly, whilst the traditions, herstories and ancestors are crucial, these are never experienced, read or understood in singular ways. Rather such spiritualities as they are manifest at Michfest not only enable multiple readings, interpretations and practices, they defy traditional attempts to classify, categorise and contain spiritualities. Moving to examine how womyn discuss the sacred ordinary the chapter will then put this into conversation with 'Michigan Magic'.

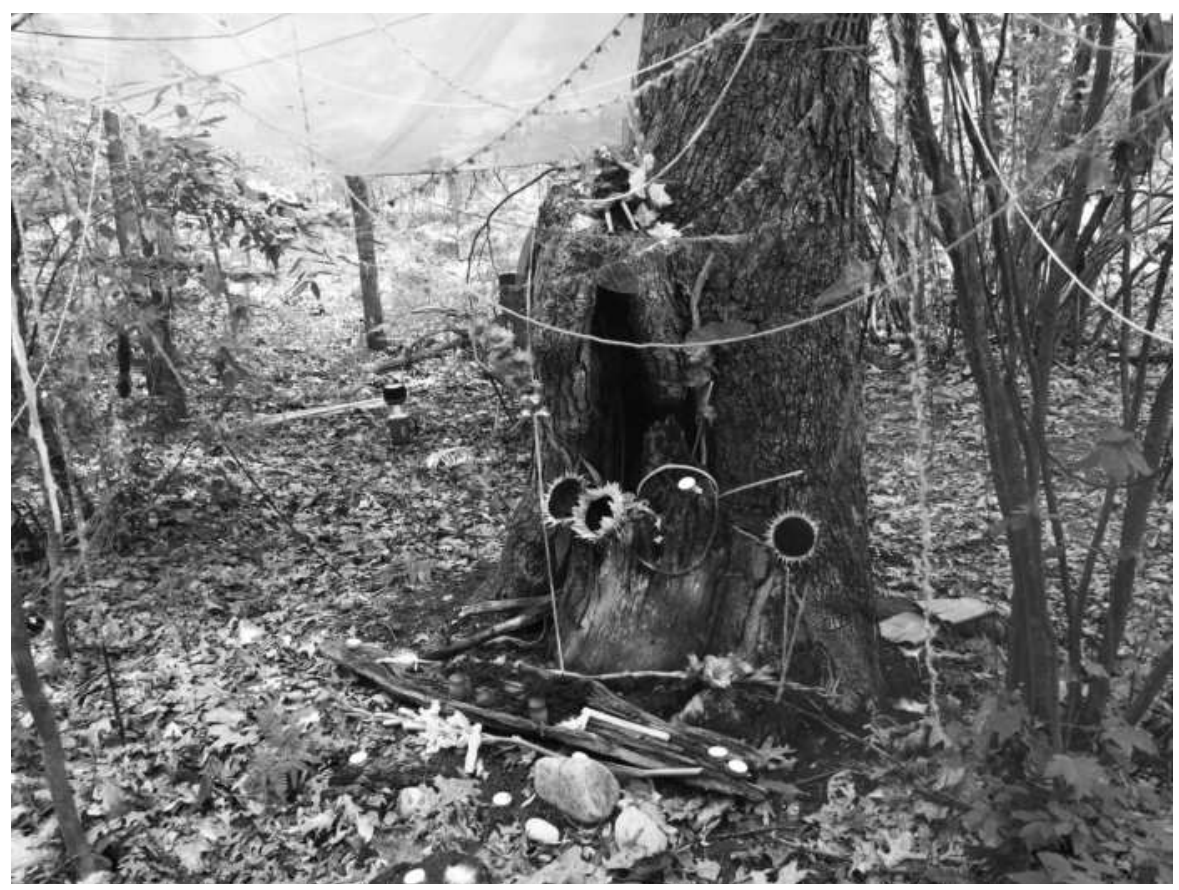

Figure 6.2 Tree altar at Michigan Womyn's Music Festival 


\section{The sacred ordinary: Michfest as sacred and sexy space}

Feminist spiritualities have long illustrated that spirituality is not separate from everyday life but permeates all aspects of it (Dyke 1992, Daly 1989, Kendall 2008, King 1989; see also Chapters 5, 7 and 8). Such sacredness celebrates the gathering of womyn, and also enables informal rituals that may not be understood or articulated as such. These rituals vary from celebrating puberty through communal leg shaving (Kendall 2008), to personal altars created throughout the camping areas as well as the more 'formal' altar in the mediation circle, all lovingly created with objects that hold personal and communal significance (see Figure 6.2). Ellen explains what the sacred ordinary can mean:

Kath: what's sacred space for you, where is sacred?

Ellen: Wherever you go you're walking on holy ground [laughs]. Really, I have my sacred bathroom [laughs]. I'm going to the sacred goat pen now [laughs].

Kath: And what makes it sacred then?

Ellen: Because there are goddesses everywhere. She's walking with me, even when I'm in, you know, the Jane [the portable toilets at the festival] [laughs]. She's not ... she hasn't gone away, she doesn't live in a house [laughs].

Kath: Or at Michigan.

Ellen: Or at Michigan. No, she's on the bus. She really is on the bus [laughs].

Dyke (1992) notes that feminist spiritualities can derive from an understanding of patriarchal religion as creating attitudes and actions that damage the planet. Understanding womyn as (part of) the solution to environmental degradation, ecofeminists, particularly those who are within earth-based spiritualities, understand the spiritual as immanent, interconnected and compassionate (Starhawk 1989). This form of consciousness is evidenced in workshops such as Grandmothers/Crone Council which invites womyn to 'come council with crones to share spirit guided perspectives for personal/planetary healing' (Michigan Womyn's Music Festival Brochure 2008: 36) and read through the practices of the festival itself:

[B]ecause these women consider the land to be sacred, and believe it should be returned to its natural state, after the festival is over the whole city is torn down and packed away in storage, where it waits for the women to return to Michigan and rebuilt it the next summer. (Kendall 2008: 2) 
Eco-feminism has been heavily critiqued as presuming an essential link between womyn and natural environment, however Nightingale (2006) suggests rather than dismissing eco-feminism, instead we should use it to explore how gender is conceptualised in relation to the environment. Similarly instead of dismissing the 'sacralisation' of nature (Banerjee and Bell 2007), it is important to recognise the place and importance of earth-based spiritualities and practices at the festival:

Scout: Coming to Michigan was hugely important because this was like the embodiment of womyn being with womyn and creating community. I'm only 57 and yet having had a stroke I also have had the experience of being shot into physical limitations and mental limitations of womyn 20 years my senior. This is a supportive place for having disability and being out and not having to pretend or hide anything. That is part of what makes a culture like Michigan unique. And when they do something like have a ceremony and honour the earth, to me this [tapping the ground] is where it all comes from, you know, it all starts here. And the planet is in my world, the planet is our mother and it's everybody's mother.

Scout's location of the sacred in the earth is not limited to Michfest, although she is conscious of it and enjoys honouring the planet at the festival (see Figure 6.1). Scout notes the intertwining of Michfest's womyn's community, disabled access, openness to sexual difference that all starts with the earth and is honoured at Michfest.

Although Scout and other womyn see the connection and consciousness with the sacred and the spiritual as being heightened on the land, others saw Michfest as sacred in itself:

Kath: Where do people consider sacred?

Alethea: When you drive in the gate. [General laughter]

Kath: What makes it sacred?

Alethea: It's just a calming. It's just you're entering in your higher power.

Judith: Well the whole thing is sacred and special cos it's a walking meditation. Like when I'm walking through here I'm hearing these sounds and all of this is god. The people, all the people here are expressions of god. And I'm here to be god's light in that I do nice things for people while I'm here. Like if I see a woman struggling with her gear or whatever, you know, I just help her do it and that's like god working through me. 
Kath: And what about Michigan in all that, does it fit in or ...

Judith: Oh yeah, this fits in. This is all about it. I mean being in nature. God is in all these trees and god is in all these people.

Michfest is often described as 'home', 'sacred ground' and 'sacred time' (Kendall 2008). The sacred for Alethea is driving into Michfest, the process of entering the festival entangled with emotional and energies that she 'enters' through the Michfest gates and into her 'higher power'. For Judith, god is in the trees, people as well as manifest through her actions at Michfest. She feels the festival is significant because it is a 'walking mediation'. There can be no doubt that the love, respect and care embodied at Michfest plays a part in this, as does the conscious and intentional creation of womyn's community and womyn's spaces:

Tracey: Well I think that a lot of people find spirituality in religion. And a lot of religions aren't typically open to people who are queer. So here in Michigan is an openness to any kind of sexuality. Well I mean that's not getting into the whole trans issue. Not dealing with that and that is a huge issue that is an important one and needs to be addressed. I mean that like coming here and being queer. It's sort of taken for granted. And it's like let's get on with the business of just being ourselves and being the spiritual people we are if we are. There's no inhibition, you know, that's the song saying like there's room for everybody in the circle. There's room for everyone in the circle ... I'm looking for those places where I can integrate the different parts. So when you're talking about, you know, the Judaism, the Jewishness, the spirituality, the queerness, looking for places that embrace all of that. And certainly Michigan is one of those places.

The hurt, exclusion and expulsion that some womyn participants have experienced because of their sexuality, can mean that Michfest can lead to spiritual awakenings, openings and acceptances making the festival itself sacred (see also Kendall 2008, Morris 1999; see also Chapter 7). The sacred can be associated with recognising and celebrating diversity and difference, creating a sacred that is not underpinned by institutional hierarchies or power structures (Yip 2005b). For Tracey, Michfest enables her to focus on the spiritual as well as moving across traditional divisions and compartmentalisations that she feels are not mutually exclusive. More than this, and in part through collective empathy and support, Michfest can offer healing from the abuses, prejudices and hurt of the 'world outside' (Morris 1999, Kendall 2008, Browne 2009b). This can be a spiritual experience, where womyn consciously pack up their hurt 'with their camping gear' (Kendall 2008: 176), and use Michigan to heal from experiences that they and their loved ones have suffered: 
Fern: I'm a lesbian to the core. So there's nothing I do or nothing who I am that doesn't relate to my sexuality. To me the whole land permeates, everything permeates spirituality and acceptance. It's just energy about everything. It's not a theoretical god or religion. It's safe. It's a place where you can ground and be who you are and have emotions. And I scream, and it's welcomed as healing and as spiritual.

And this year my sister killed herself. [crying] Two weeks ago.

Kath: Oh I'm really sorry to hear that.

Fern: Thank you. She was a lesbian. [It was] a real shocker for me. So this year is especially important. I am using it as a place to heal. So for me tangibly what it is, it's a place where I can come and heal and it's not a conscious thing. It's so safe, the stuff just oozes out. The emotion oozes out and it's a place where people hold it. The land holds it. People hold it. The space holds it. Tangibly that's what it is to be here. A place that, even when I don't know people, it's like I feel more connected.

Being gay is a non-issue, here it's a non-issue, so then I can get to the other things. And that makes it sacred, it's a non-spoken. Cos any place where gayness is accepted, it's sacred, [laughs]. I mean we articulate it in different ways, but in our body you just have this breath of 'yeah'. And then you can get on to business.

Having a place where queer is perceived as a 'non-issue' is for Fern vitally important, as her sexuality and spirituality were at times at odds with each other. She reiterates Tracey's point regarding the 'non-issue' of gayness and the place of 'non-spoken' acceptance in creating sacred spaces. Her narrative also illustrates the entanglements of healing, sexuality and spirituality at Michfest spaces, where womyn can move into the woods to scream and are supported in their mourning. Emotion seems to be 'held' by the land, the people, the place and the space. Such connections are for Fern powerful and move beyond a 'theoretical god or religion', importantly they are also intimately interconnected with her sexuality.

Locating the sacred everywhere also places the sacred in the bedroom, tent or in sex areas of the festival. Sexuality and sexual expression can be an important part of spiritual practice (Lorde 1984, Lynch 2007; see also Chapter 4). Yet, discussions of sex can be avoided, where charges of 'perversion' and issues of disgust are apparent, as has been the case in Michfest's history when lesbianism was vilified and the festival accused of paedophilic practices (see 
Morris 1999; parallels can also be drawn here with Findhorn, see Chapter 7)..$^{5}$ Sex can be a part of ordinary spirituality and conversely can create, and be created by, particular spiritual affinities, desire and attractions:

Scout: My spirituality has definitely influenced that. I think that it created the end of the last long-term relationship I was in because mine was moving very much more in my life into having a spiritual practice and she was supportive and not there for herself. And I had this feeling that I wanted my partner to be there. The partner I have now is a pagan priestess. I was very much attracted to that. Knowing that she has practice, a spiritual practice cos it doesn't matter to me so much what it is. Although I doubt I would be really drawn to someone who was very Christian.

Other participants addressed the combining of sex and ritual reiterating a particular aversion to Christianity:

Ellen: Sex as ritual for example is really important to me. It's very spiritual. It's very contacting the goddessey stuff, which I mean I guess it's not essential that my partner be on the same page as me in that, but certainly is useful [laughs] to have the same context going on. And gosh I certainly couldn't partner with a born again Christian who would think that I'm going to hell and tell me about it. That would be pretty annoying.

Ellen in seeing sex as ritual offers insights into the complex ways her spirituality intersects with how she partners. Although it is not essential that her partner is 'on the same page', she rejects the idea of being with a Christian, who, for her, has the potential to judge and potentially demean. It is difficult to delimit or segregate sex, sexuality and spirituality for both Ellen and Scout as these are intimately intertwined. There is clearly far more that can be explored in relation to sex as ritual and the place of sex in goddess and pagan spiritual (see also Chapter 4). However, the spiritual relationships between with sex, sexuality and spiritualities can also exist in tension with particular other religious traditions and ethnic pressures:

Kath: do you see your spiritual practice and sexuality interlinking?

Bonnie: Absolutely. Totally. I feel god is other women. Spiritually I felt very at home and married to the women's movement. So for me, a sense of outrage at how all religions have made women 'other' or bad or different. Reclaiming

5 This has resonances with broader religious engagements with LGB sexualities (see Wilcox 2006). 
woman as the primary source is certainly part of my sexuality. I certainly feel, as a lot of Jewish lesbians do [have], a touch of guilt at not reproducing, because there's that pressure from the losses of the Holocaust to repopulate the community. And there's a lot of us who quite egomaniacally are proud to identify as smart girls or academic girls and why aren't we passing those genes along, because we really don't want to mate with men. So in bed I'm aware that I am reclaiming sex not for reproductive purposes, but for total woman loving, positive, making light in the world, va-va-voom. And I have never, that I can even remember, felt there was anything bad or immoral about homosexuality. I never had any guilt, or fear, or anything holding me back that it was wrong.

Bonnie's marriage to, and feeling at home with 'the women's movement' makes her 'outraged' at the treatment of women by 'all religions', and yet she claims and re-works her Abrahamaic Jewish lesbian identity in part through sex and sexuality. As argued in Chapter 4, stigmatised and marginalised sexuality can offer spaces where critical spiritual and political reflections can take place. This can be about adaptation, re-contextualisation, and in the process, innovation; rather than an outright rejection of tradition/institution. Thus, in this context womyn can have nuanced relationships with organised religions.

Tensions exist between traditional religions and lesbian sex both on and off the land. Musawa above pointed to 'hard-ass city culture' that can be seen as different from the earth based spiritual practices that are present on the land and created through spectacle spiritualities. This has embodied sexual materialities:

Musawa: I have a hard time with all the penises and all the [dildos]. To me what feels more like the imitation of male sexuality and that somehow that's like really cool and really hard core sex or something. But that's to me not what sexuality is. Sexuality is whatever it is for you, but it's not necessarily objects, it's not body parts [laughs], it's not imitation body parts. Sexuality is a natural and deep part of who we are and can be another expression of your spirituality. Tantric sex for instance, is, it's about oneness. Actually it's an ancient women's tradition in Buddhism where that sexuality is one of the modes for experiencing deep union with yourself and with another and with spirit. So there's actually spiritual traditions that are in touch with the flow of your own body and then the energy with another where it's one flow between you. A lot of times I think our culture misses the point of a lot of stuff and has it all about physical and all about technique or something, or objects or toys or [pause] And the rest kind of gets lost. The physical thing gets sort of separated from the deep emotional or spiritual wellbeing and gets very shallow. I don't only mean Tantra, I mean also all the emphasis on physical implements or, you know, I don't know, like the L Word [USA 'lesbian' TV series] or something. It's just like fuck, fuck, fuck [laughs]. It's exciting in one way to have a liberated sexuality where yes where 
women really are sexual beings, but I don't know, it can get very superficial and some of the extreme sex stuff that is exciting like, the twilight zone [the sex area at Michfest] here and stuff.

Musawa links sexuality and spirituality enabling a conceptualisation that does not underplay or demonise bodies in our exploration of spirituality and in this way points to the inseparable connections between spirituality and sexuality. Yet, it is important to note that the linking of sexuality and spirituality on the land does not always produce harmony, peace and ecstasy. At Michfest, the emphasis on particular forms of sex in the Twilight Zone and the focus on dildos in the sex shops of the crafts booths bothers Musawa and reflects broader historical feminist debates regarding the appropriate place and use of 'imitation body parts'. Consequently, such arguments whilst manifest, developed, augmented and resisted at Michfest, are not only located there. The diverse conceptualisation of sexuality and spirituality that reproduces a different 'ordinary' at Michfest can also reiterate, reproduce and, occasionally resolve, broader debates around S\&M, the place of sex toys, and emotion and sexual connection that have energised certain lesbian debates in the West for decades. In that sense Michfest is not segregated away from where womyn come from and the local, national and even global debates. Its spatiality and temporality can act to intensify certain disputations and positions that trouble particular forms of lesbian feminisms, and also to some extent it temporarily 'contains' the diversity of such positions.

\section{Michigan magic: Experiencing the sacred 'extraordinary'}

Alongside readings of ordinary spiritualities and sexualities at Michfest space as part of broader communities, debates and conflicts, the Michfest experience is also seen as containing moments of 'magic' that are unique, extraordinary and 'other':

Teela: there's a saying that goes with Michigan, that all your needs will always be met in Michigan. And I have never, not once in ten years, have I come here where that hasn't proven to be true. Not only for myself, but for everybody I know. You know, there's just sort of these Michigan miracles all over the place where your needs really are met if your heart is open to it.

Spiritualities at Michigan exist in a dialectical relationship that refuses the dichotomous separation of magic/normality (this relates to what O'Riordan and White Chapter 8, call 'ordinary transcendence'). For Teela, keeping her 'heart open' means that her needs will be met at Michfest, which is what 
Michigan Magic means for her. These both relate to the sacred ordinary of the festival and also makes this 'ordinary' extraordinary. This ethereal concept had resonances with other participants:

Clare: After we'd arrived and pitched up our tent, we walked down to where the day stage was and down where the Porta Janes [toilets] are. There was a seat there and we were just sitting there washing and a woman asked me about my tattoo. It had got Ben on it. I said 'It was for my son'. I said 'My son died'. And I said 'It was my only child' and she said 'Oh my only daughter died', and this was out of 3,500 womyn that year and this was the first woman I'd chosen to speak to. I wasn't going to speak about Ben while I was here, cos I always leave him at home. But this was the first woman I spoke to and she'd had exactly the same experience of losing and changing her life. That was magic, you know.

Kath: So do you think Michigan has kind of a spirituality then to it?

Clare: I think it's got a magic and I think it's got a peace. I feel a peace here. I don't very often feel at peace, you know, cos my son's not here. But I feel, you know when I feel that yeah it's not a space for him, he has to stay at home. His spirit has to stay at home. So it's my space and I feel, I feel ever so peaceful.

Clare's experience of peace in 'my space' relates to the intense pain she experiences because of the death of her son. Leaving Ben at home, her first encounter at Michfest was with a woman who had a very similar experience. This for her was Michigan Magic. The encounters at Michfest can be experienced as 'spiritual'/'sacred', in ways that contest not only the location of the sacred but also its creation or consciousness through ritual. This is more than transcendence. It can also be seen as immanence (e.g. being filled with the sacred/spiritual/spirit) and beyond rising above the constraints and structures of everyday life and being in the moment - being filled in the 'now'. Clare's encounter was deeply moving even in the retelling. It was unimportant that she had little to say to the main questions that I was supposed to ask regarding overt spiritual content, structure, or ritual. This not only illustrated the importance of flexible methodologies it also pointed to the lack of spiritual structure, practice or tradition needed to experience Michigan Magic. Other forms of Michigan Magic can be experienced in more spectacular and wondrous ways:

Amy: I went to the Healing Circle one year for healing. It felt transformative. There were certain womyn here that I met after that, that were just there when I needed them. I was very confused and very upset and wondering what was happening, but it was a powerful experience and I couldn't understand it. A couple of months later I was on vacation and sitting on this huge rock by this 


\section{QUEER SPIRITUAL SPACES}

waterfall and thinking about festival, about those experiences and those womyn. And all of a sudden this female voice, and it was not my voice, said kind of laughingly, 'You know those womyn were not there by accident.' And then she said 'How can you not believe in me?' It was amazing. It was just the start in a series of things that happened. The spirituality group I was in at the time, we did this journey work and I'd never done that before. And this female guide led me up through this area and all of a sudden I was at festival here. And she led me over to the meditation circle and I was sitting there, I was watching myself crying in the meditation circle, which my original festival experience I was crying over there cos I didn't understand everything that was happening. And then I went into myself in the meditation circle and then I rose up and floated above the tree altar. It's this tree stump with these branches out of it and womyn put tokens and articles and offerings and it's beautiful, it's beautiful [see Figure 6.2]. So in this journey, this dream, I hovered above it and then the tree altar lifted up out of the ground and entered my body. It was just amazing. So it was just this huge metaphor of, I think, this spiritual journey I'm on.

Amy's experiences move her literally, spiritually and metaphorically into and out of the spaces of Michfest. Her healing and spiritual experiences drew upon memories alongside spiritual work that reflects other experiences of Michfest that are interpreted as meaning that these meetings and encounters are not 'accidental' but intentional, or divine.

Michigan Magic is also created through on site interactions that are special, sacred and spiritual, these are not necessarily spectacular, revelatory or 'spiritually' orientated:

Kath: What other kind of spiritual stuff do you do on the land?

Tracey: On the land? Well you know what? It's in the moment. It's in the magical moment with people. I mean spirituality is hard to define right, but it's in magical moments with people. It's in a smile. It's in a conversation. It's amazing to see someone you haven't seen in a year or two years cos you met them here. And how we affect each other's lives and don't often know it. Like the magical moments are happening everywhere.

Tracey brings Michigan Magic back to in conversation with the sacred ordinary at the festival. It is made through hugs, interactions and memories that connect womyn in ways that are 'magical', although they can also be read as 'normal' in this space. 


\section{(Re)working the sacred: The womyn's Shabbat}

The extra/ordinary spiritualities at Michfest are often based in, and articulated through, particular forms of non-traditional religions, this is reflected through the onstage visible spectacle spiritualities. Alongside these spiritual creations, Michfest manifests, reworks, and rejects, more traditional, established forms of religion and religious practice such as Judaism and Christianity. Bonnie Morris has written extensively about lesbian Jewish identities and their place on the land. Her work has explored how Michfest grappled with the inclusion of Jewish womyn, the place of Jewish musicians and how she created Jewish spaces, including a tent and Friday night Shabbat (Morris 1993, 1998). Such reworking of religious traditions recreates spiritualities, in ways that are empowering and important to Jewish-identified womyn:

Tracey: The Jewish, the Shabbat evening ceremony has also been at times very spiritual. I guess it just depends. I mean it's involved a lot of singing. It's so, so trippy to see, you know, bare-breasted womyn singing Friday night songs. I mean that's like what?! And outdoors and really incredible. Something that's unique to Michigan for me anyway is the feminisation of a lot of the prayers where it's usually the masculine form of Hebrew is typically used when referring to God, and so there's a lot of feminisation of the words, which is pretty cool. And it's nice to connect with all types of Jews and, you know, how they really would define themselves of queer whatever, and all different ages. It's just very empowering. Incredible to see kind of non-mainstream part of Jewish people and Judaism, you know. So just quite incredible to be claiming Jewish life in life in a different way.

The Shabbat on the Friday night has a structure that is inclusive, womyn identified, and uses feminine Hebrew, but also is committed to retaining traditional aspects (see Figure 6.3). Tracey notes the 'trippy' and unique elements of a very traditional and ancient Jewish ritual as it is re-worked for Michfest.

Alongside the other forms of spectacle spiritualities described above, there is also an incorporation of Jewishness into festival spectacles, for example:

Bonnie: [We had] a couple of womyn get out on the night stage and do poems in Yiddish that were really ancient and beautiful. The first time that we all got up and danced the Horah was at the day stage and I think it was when Charming Hostess performed. They do some traditional Yiddish music. But dancing in front of the night stage when you had hundreds and hundreds of womyn got up and you realised how many were here. And everyone got to see we all knew the same dances. Everybody knew how to do the grapevine, everybody knew how to do the Horah. Other womyn wanted to join in and it was obvious that this is a huge cultural 


\section{QUEER SPIRITUAL SPACES}

heritage that's shared that is not seen by womyn who've never been around Jews. So any time we've had a performer who's played that kind of music and everybody gets to get up and be very ecstatic. And the stuff that comes up to the surface, for instance at a Hasidic wedding traditionally it's separated men and womyn and you put the bride on a chair and carry her around, well we had two brides and we put them on a rickety chair - rented and womyn just knew automatically that that's what we were supposed to be doing. So womyn who at that point could not marry anywhere in America were treated like traditional brides at a traditional wedding, with their shirts off in the woods, and that was great.

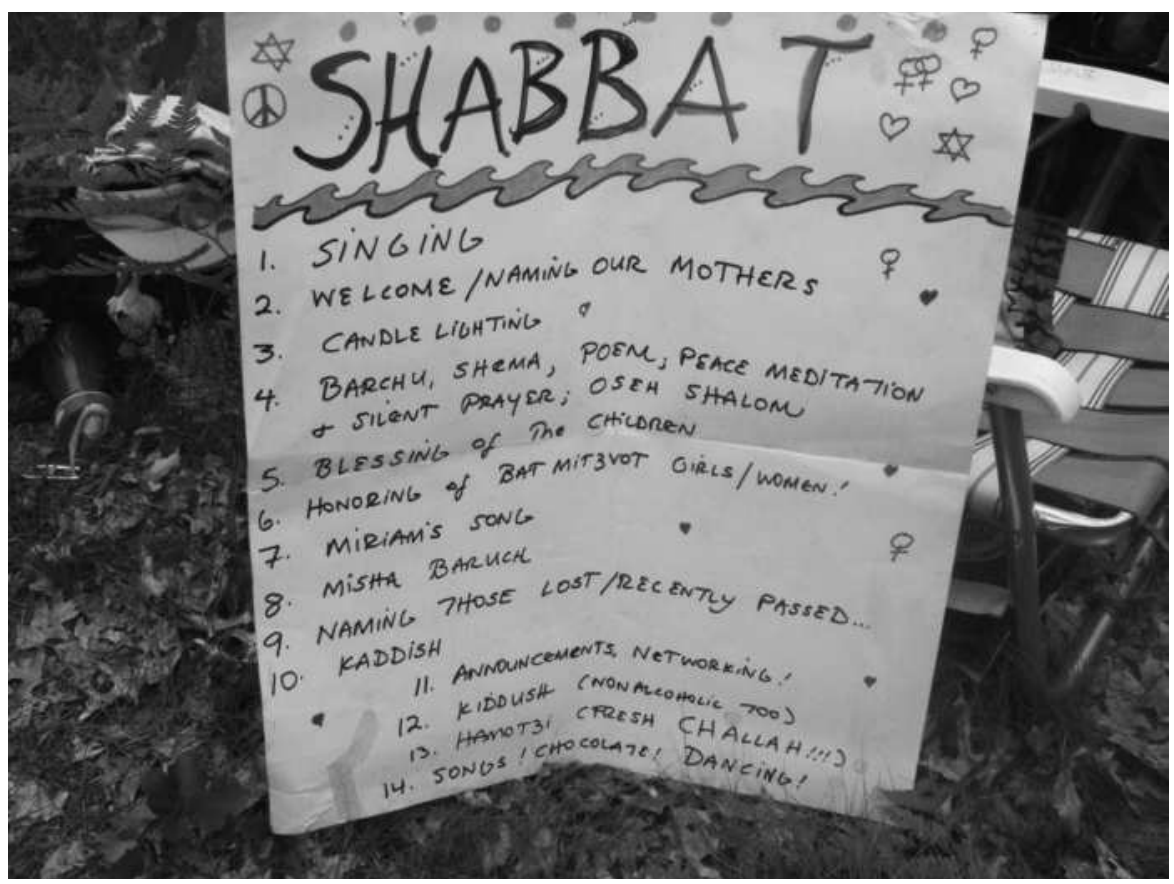

\section{Figure 6.3 Running order for the Shabbat on Friday night}

Bonnie (Morris) describes how Jewish festigoers create a space that recognises womyn's marriages in a traditional, yet also radical, way, negotiating religious tradition. The feminine reworking of Jewish traditions also includes giving girls Bat/Bar Mitzvahs, and in 2008 when the Jewish band The Isle of Klezbos played, the right hand side of the stage became a sight of Horah dancing, with womyn once again carrying a newlywed couple above their heads in celebration. Intermingling sexuality, religious tradition and festival practices also inclusively enabled womyn 'who've never been around Jews' to experience this form of religious and ethnic tradition. 
However, Morris (1998) has also written about the issues of exclusion, prejudice and marginalisation experienced by Jewish lesbians within and outside the festival gates. She recounts her experience of sitting on nightstage whilst she and other Jewish womyn described the anti-Semitism they have experienced at Michfest. In addition to this, Morris also notes how 'once, even, when I was invited to give a Hebrew welcome in the festival's opening ceremonies, a well intentioned performer urged me to speak in Arabic too' (1998: 11). In the early 1990s Morris recounts the blood, sweat and tears she put into creating Jewish space, which took the form of a shared tent with Deaf womyn. This became a networking, information sharing and workshop space allowing Jewish womyn to connect, discuss key political, religious, spiritual, sexual, festival and other issues. This space enabled womyn to be lesbian and Jewish 'without ranking these identities or watering them down' (Morris 1998: 11). There, however, continues to be tension relating to Jewish visibility on the land:

Bonnie: We have to be sort of careful not to fly an Israeli flag off the top of anything. Some womyn want there to be a visibility because there's so little in a Christianised America. One of the problems that many womyn report is too often the Old Testament is blamed for inventing patriarchy and that womyn who want to continue any kind of religious practice are seen as perpetuating an oppressive culture, blah-blah. A lot of womyn just don't know much about Jewish matriarchy or the goddesses or Lilith or any of the stories that are very feminine or about birth, and a lot of womyn want to reclaim or tweak ritual to be lesbian positive. As the occupation became more of an obsession with social justice activists and discomfort with policies in Israel [it] began to trouble a lot of people, especially considering the US involvement in the Middle East as a nonbenevolent force in Iraq. Fewer and fewer womyn really wanted to spend their time here arguing about Israel or feeling bad or guilty. They were more interested in going to kissing workshops and the dildo Olympics and having a good time.

Bonnie points to the lack of visibility for lesbian womyn in 'Christianised America' and the importance for some womyn of reworking ritual to be lesbian positive but, she also recognises how Jewish womyn on the land are affected by perceptions of the Old Testament as 'inventing' of patriarchy. This illustrates the tensions of a festival that allows and enables diverse forms of spiritual and religious practices, as well as welcoming a plethora of ethnically, religiously, spiritually and ideologically diverse womyn. Linking festival spaces to broader geo-politics meant that there were many heated and unpleasant debates - as Bonnie suggests that womyn didn't want to 'spend their time arguing about Israel or feeling bad or guilty'. Bonnie describes how she felt that the desire to have a good time with dildo's became more 'interesting', a gesture that indicates how some womyn 'just want to have fun’ at Michigan Womyn's Music Festival. 
Jewish space, whilst important in terms of the night stage dancing and the Friday night Shabbat was no longer produced in workshop form, nor was there a specific Jewish tent. This not only related to broader geo-politics and the lack of a desire to spend valuable festival time 'feeling bad or guilty', there were localised issues and adjustments that the festival itself made due to smaller numbers:

\begin{abstract}
Bonnie: In the whole festival the numbers are down. There's fewer womyn brought in as staff, so we had to consolidate. So we turned the Jewish tent into a teen tent and we moved deaf womyn into a well-lit corner. And my response to Jewish festigoers who have concern about whether the festival's slapping them off, we're all working harder and longer. We had to give up a lot of things. Everyone has to tighten their belt. The festival, to survive, is going to be smaller and not everyone is going to have their own tent. But it's not because they don't programme Jewish visibility and the fact that we have the Isle of Klezbos on Friday night is no accident. Really thoughtful programming on Lisa Vogel's [festival producer] part. That's all that a lot of womyn want. They wouldn't come to anything that I might schedule, but they will show up Friday night for one big event and then to dance, and then they meet who they want to date the rest of the festival then.
\end{abstract}

There were a number of workshops in the programme that were specifically aimed at Jewish womyn, although they were all open to everyone. They included Israeli Folk Dancing, Jewish/Non-Jewish Interfaith relationships and Minya and Torah Study. Recognising the place of the party in festival spaces (see Browne 2007), Bonnie argues that the Friday night programming, that facilitates Jewish womyn collectively dancing, gathering and dating, is key. She believes that this is a sign of commitment by the festival producers to Jewish womyn's visibility.

Alongside these productive tensions and controversies are the mutual constructions of sexuality, religion and festival spaces (see Browne 2009a, Morris 1999). These are inflected with tensions regarding; the place of lesbians in broader ethnic histories, reading of patriarchal histories as coming from and being inherent to specific religions, and contemporary global geo-politics. Festigoers as we can see seek both to escape and to influence such political, religious and controversial issues. The negotiation of these frictions illustrates the spiritual and religious diversity of this space that challenges simplistic readings of an 'openness' and acceptance of all forms of spiritual and religious expression. 


\section{Whose sacred? Christianity at Fest}

Where celebrating Jewishness is a visible part of festival culture (perhaps in part because of the crucial intervention described by Morris 1998), Christianity and Christian expressions have a much more ambiguous presence amongst festigoers. The lesbian revival tent, part of the intensive and general workshop programme, was an interesting moment of reworking Christianity into and through evangelical radical lesbian feminist sermons, that were concluded with 'sacred songs' such as 'Sit on my face and tell me that you love me'.

Wilcox (2002) points to how in LGBT lives, identities and coming out experiences can call into question Christian identities. The rejection of Christianity was apparent in the data and Michfest reversed the assertion that churches exclude and push out. Womyn and lesbians can also reject that which does not accept them:

Scout: Religious spaces, very Christian spaces I find uncomfortable. I want to accept them for who they are and so I want that in return and I don't always feel it, you know, in a Christian type space.

Kendall (2008: 304) points to the hurt that womyn and particularly lesbians experience from traditional religions, preferring Michfest spiritualities such as Dianic practice that 'helps them connect to the sacred in ways that a male centred religion of God never could'. Van Dyke (1992: 154) notes: 'The [spiritual] model for the lesbian feminist woman is the Goddess in her many guises.' With Michfest's roots in a contemporary separatist form that seeks to contest dominant patriarchal structures and norms, it is perhaps unsurprising that there was a rejection of Christianity by festigoers in favour of other more accepting spiritualities:

\footnotetext{
Lisa: I was raised Catholic. I can remember the first time sitting in that [religious studies] class and kept hearing he, he, and Jesus, Jesus, Jesus, and something inside of me told me that this was not the religion for me. And finally my parents kind of let the choice be mine and I decided not to go back to the church and kind of just went along with my life and fell into paganism and Wiccan and all kinds of other religions.
}

Lisa and others in the focus groups often began the description of their current spirituality by pointing to diverse spiritual/religious biographies, many of which started with various forms of Christianity. The rejection of Christianity following coming out and, at times, experiences of ostracism and persecution was common. These womyn are, in part catered for in the festival with workshops such as 'Hurt by the Christian Church'. Others however, pointed to 
the difficult reconciliations, negotiations and compromises they experienced in maintaining Christian beliefs and lesbian relationships and coming to a space where 'patriarchal' religions were rejected:

Chelsea: I come from a very, very fundamentalist Christian family. I rebelled and came out and I didn't need religion then. I was just trying to survive. But then I went away to college and I really, really missed my parents and I needed some way to connect with them. So I went back to going to my parents' church. I found the church there and it really gave me the traditions that I need. I needed a tradition, a culture or something to hang on to for my parents, because I couldn't lose my family, they mean so much to me. I don't know still my take on Lutheran beliefs. I have to kind of cut some of them out to kind of fit my needs. Things that don't fit into the doctrine, just I deal with myself, that's for me. Like my sex life, it doesn't have any spiritual at all. It's just me. Whereas other parts of my life I have God and Jesus to help me with that.

This is only my first year here [at Michfest], but I've already figured out that well I have to disconnect here from my usual religion. There's no place for it here. There's some other energy and it's amazing. I haven't figured out what to do with it yet. I disconnect from my religion wherever it doesn't fit, and it doesn't fit here. It's patriarchy. That's not here, but I do feel this amazing feeling from this land.

For Chelsea experiences of coming out, family, traditional Christianity are all interlinked. The disjuncture she perceives between 'fundamentalist Christian' doctrine and her sex life are dealt with by compartmentalising these as moments where she can receive 'help' and those which do not have any spiritual element (her sex life) (see also Chapter 4). She points to Michfest as one of the spaces where she 'has' to disconnect from her Christianity because 'it doesn't fit'. Chelsea argues that this is because of the patriarchy of her Christianity, such that the complex relationships that she negotiates between her sexuality and spirituality is once again brought into question (see also Aune et al. 2008). In this way she mutually negotiates and reworks her sexuality and spirituality in ways that move beyond simple stories of rejection and exclusion.

For those 'not raised in the Christian faith' there was also a workshop called 'Dealing with Christian Normativity' which offered a space to share experiences and tools to 'combat' Christian normativity in a culture where 'the assumption is that we are Christian' (Michigan Womyn's Music Festival Brochure, 2008). This reflects an interesting understanding of spiritual norms that can be contested at Michfest. Christianity as the dominant religion in the US, as well as the close ties between Christianity and George Bush, is perhaps exactly what Michfest seeks to offer an alternative to. This can perhaps be used to explain why Christianity 
and Christian practices are not visible and overt parts of the spectacle spirituality. Nor are these traditions part of workshops (that can be organised and run by anyone at the festival) in ways that celebrate or embrace this religion:

Sarah: I've never seen a workshop [at Michfest] that's from an inclusive, LGBT inclusive Christian perspective. I see things that are sort of border on a little bit antagonistic toward Christianity. I make some assumptions that it comes from founders who were hurt by Christianity. I certainly understand that, but I wonder whether it's been looked at, whether there's been any intentionality about well can we make room for LGBT inclusive Christianity in the same way we make room for other LGBT inclusive spiritual practises.

[Speaker unclear]: There is that whole sense within the lesbian community, that I have been associated with over the years, that we don't deal with Christianity. We'll deal with paganism, we'll deal with Wiccan, we'll deal with other religious traditions, but we don't deal with Christianity.

Denise: I think that there's an opportunity being missed, by, either intentionally or unintentionally, the festival positioning itself as over against Christianity. It certainly is against a certain brand of Christianity, but it's not the only brand of Christianity that's out there, the LGBT exclusive brand. The reality is that even within mainline Christian denominations, there are more and more groups that are advocating for LGBT inclusiveness. If that can be recognised, then that could broaden the appeal even of the festival, as appealing as it is.

Louise: Every year I look in the book and see what spirituality workshops that there are. It's one of the first things I look for. And a lot of the time I feel disappointed and then I have to remind myself this is a music festival. It's a music festival. It's not a spirituality festival. It's a music festival. But I do find it interesting that they've got a couple of workshops on being hurt by the Christian Church and nothing really to equal that out.

Denise: I was curious about it. There was the one that it was very much having to do with you were hurt by the church and kind of [now being] outside the church. There are those of us who have been hurt by the church but choose to remain in it in some fashion. But as I understand it the festival is something that we kind of create, so if there's something that we feel like we really want, then we should offer a workshop.

The tension between lesbian communities and Christianity is clear in this dialogue, and was also a topic of discussion in the other focus group. These participants highlight the key issues at stake within and beyond the festival, 
namely the antagonism between lesbian communities and Christianity in contrast to other alternative forms of spirituality. The participants recognised the need to explore issues of power, particularly the power of particular forms of Christianity outside of the festival that could be strategically used, but they at the same time recognise the place of Christianity in causing harm and pain. This was also reflected earlier in this focus group in a nervousness to 'come out' as a Christian on the land. Denise, however pointed to how she openly discussed her Christianity at Michfest, saying that it had lead to many connections and interesting discussions. Interestingly however, what could have been quite a negative critique of the festival at worst, or less critically a need the 'broaden the appeal' was referenced back to the DIY nature of the festival. Denise suggests that if this space was desired and wanted that 'we should offer a workshop' and this was supported by other members of the focus group.

Michfest as an alternative space unsurprisingly foregrounds and celebrates spiritualities that are not mainstream (or connected so overtly with ruling political elites) and have been used by womyn to 'heal' from their experiences and interactions with Christianity. This creates, perhaps unintentionally, exclusions and others, those who may have been 'hurt by the Christian church', but continue to have connections, affinities and ties to these forms of religious traditions, rituals, identities and practices. Their experiences have expanded our conceptualisation of the spiritual/sacred, yet there are also clear relationships with institutional religions.

\section{Dyke spirituality and Michigan Womyn's music festival: Conclusion}

$[Q]$ ueer spiritualities smack of something male led or male inclusive, whether past, present or future males, and a huge invisibilisation of Dyke spirituality and Dyke and womyn's empowerment issues ... [M] lesbian centered Female Centered spirituality [is] where I honour the Sacred Female as a Dyke Amazon Warrior/Amazon Witch from the sexual to the spiritual and everywhere in between. I have no need to give any energy to any kind of penis at all and they [gay male pagans] do. (Post from the Michigan Womyn's Music Festival Discussion Board in response to a post asking for interest in the project)

Wilcox (2006) has argued that religion should be part of queer investigations and theorisations, as an important 'locus of power'. Augmenting queer geographic understandings by including religion and spiritualities, further reiterates the spatialities of power. It also points to the need to include the positive whilst also recognising the temporal and spatial contingencies and realities of re-working power relations. The post that begins this conclusion illustrates the separation and difference of Michigan that enables some dyke spiritualities that contest 
heterosexual and male norms, reclaiming their visibility and empowering womyn (see also Van Dyke 1991). In this way Michfest can be described as 'queer', but it also normalises new (womyn, spiritual) hierarchies - particularly notable here is the practice of exclusion of Christianity, and the comments from participants of anti-Semiticism. Wilcox (2006) contests the male/female segregation of LGBT research that can serve to marginalise bi, trans and intersex people, and may not offer adequate justifications of these gendered experiences. When I posted my concerns regarding the little mention of 'trans exclusions' in my data, one womyn objected 'to the framing of it as "trans exclusion" ... that's like saying that Fest is a "festival that excludes men" rather than saying it is a womyn's music festival'. Whilst there is no doubt that specifically bi and trans lives, stories, experiences and his/her/hirstories need to be included, there is also a need to specifically address the potential erasure of women within queer, and especially the oft-unacknowledged masculine focus. What I hope is clear from this chapter is the centring of womyn within this 'queer spiritual spaces' research project, recalling that this is only one specific (and controversial) version of 'womyn'.

Womyn's, lesbians' and dykes' spiritualities, including and as well as trans spiritualities, need further nuanced explorations that recognises, respects and elaborates gendered/sexualised lives, experiences, bodies and discourses. Questions that could be considered include: where are the gendered/sexed bodies in spiritual and religious practice and how are they (re)constituted through such practices? What is the place of religion/spirituality in actively (normatively) sexing bodies? What about sex, in a fucking, dirty, visceral sense? How are bodies who have and do sex (including sexual practices) sacralised, vilified and/or celebrated? How is sex itself sanctified and how is sanctification sought through sex? How do sex and ritual intermingle, co-create and 'reproduce'? Whilst such questions can, and should, be addressed using the 'contained space' of Michfest, they should not solely be located there. 



\title{
Chapter 7 \\ New Age Spiritualities: \\ Findhorn and the Sexual Self
}

\author{
Kath Browne with Elizabeth Dinnie
}

Personal spirituality has been described as part of the significant subjective turn of modern life, whereby people increasingly come to live their lives and construct their identities according to internal beliefs and ideas about who they 'really are', rather than according to external roles, duties and obligations (Heelas et al. 2004; see also Chapter 1). 'New Age' is a term used loosely to refer to a wide range of beliefs and practices which have become culturally significant since the late 1980s (Bruce 1996: 196) in organising personal spiritualities. Many of these ideas trace their roots to the esoteric culture of the late nineteenth century; others are extensions of the new religions and human potential movements of the 1970s. Despite these origins there are sufficient differences of belief and structure to justify treating New Age spirituality as a subject in its own right and not just as a continuation of older movements (Hunt 2003: 131). New Age spirituality is also referred to as self-spirituality (Heelas 1996), spiritualities of life (Heelas 2008) or, most frequently, just simply the shorthand term 'spirituality'. In discussing New Age, a balance needs to be struck between presenting it as so heterogeneous as to defy all attempts to identify common features, or as a joined up, integrated system of spiritual ideas and practices. Sutcliffe has called for a problematising of the category 'New Age' itself, by 'question[ing] the representations of unity and homogeneity undergirding typical models of the "New Age movement" in order to connect New Age studies to wider issues in the politics of representation (Sutcliffe 2003: 13). There is, he says, 'a need to shift attention away from an entextualised "New Age movement" and towards an analysis of the discursive and practical uses made of the "New Age" emblem" (Sutcliffe 2003: 14). New Age should therefore not be seen as a standardised movement; there is no centralised structure, bureaucracy, creed or authoritative beliefs and rituals (Clarke 2006: 30), and this chapter offers a case study that can be seen as specific to New Age cultures in the UK.

The Findhorn community in Scotland, the subject of our case study, is generally discussed under the New Age label (Bruce 1996, Dinnie 2008, Heelas 1996, Clarke 2006). Within the milieu of groups, practitioners and clients which constitute New Age spirituality a number of organisations have become 
recognised as exemplary, amongst them Findhorn. However, community members no longer use this term and prefer to be seen as spiritual rather than New Age (Walker 1994, Sutcliffe 2003). The New Age movement in general and Findhorn in particular are united by the objective of transforming human consciousness. In moving from Sutcliffe's call to analyse the practical uses of the New Age emblem, this chapter explores the ways in which sexualities and spiritualities at Findhorn are created, negotiated, intertwined, segregated and discussed. Following a contextualisation of the chapter within Findhorn's history and a discussion of methods, the chapter examines the contradictions of locating divinity within the self. In particular it explores the supposed freedoms created by the absence of external sexual morality located in a transcendent deity and how the intertwining of sexuality and spirituality often result in a rejection of labels, segregation and exclusive identities based on sexuality alone. The chapter then examines the limits of linking alternative sexual practices and spirituality, leading to a discussion of the tense creation of lesbian and gay space at Findhorn. In this way the chapter investigates individuality and collectivities at the site, offering insights into the complexity of discussing (and segregating) sexual and spiritual practices and lives. It only addresses lesbian, gay and bisexual identities as there were no trans or intersex people known to be in the sample, although throughout the chapter the deployment of these identities is contingent and limited.

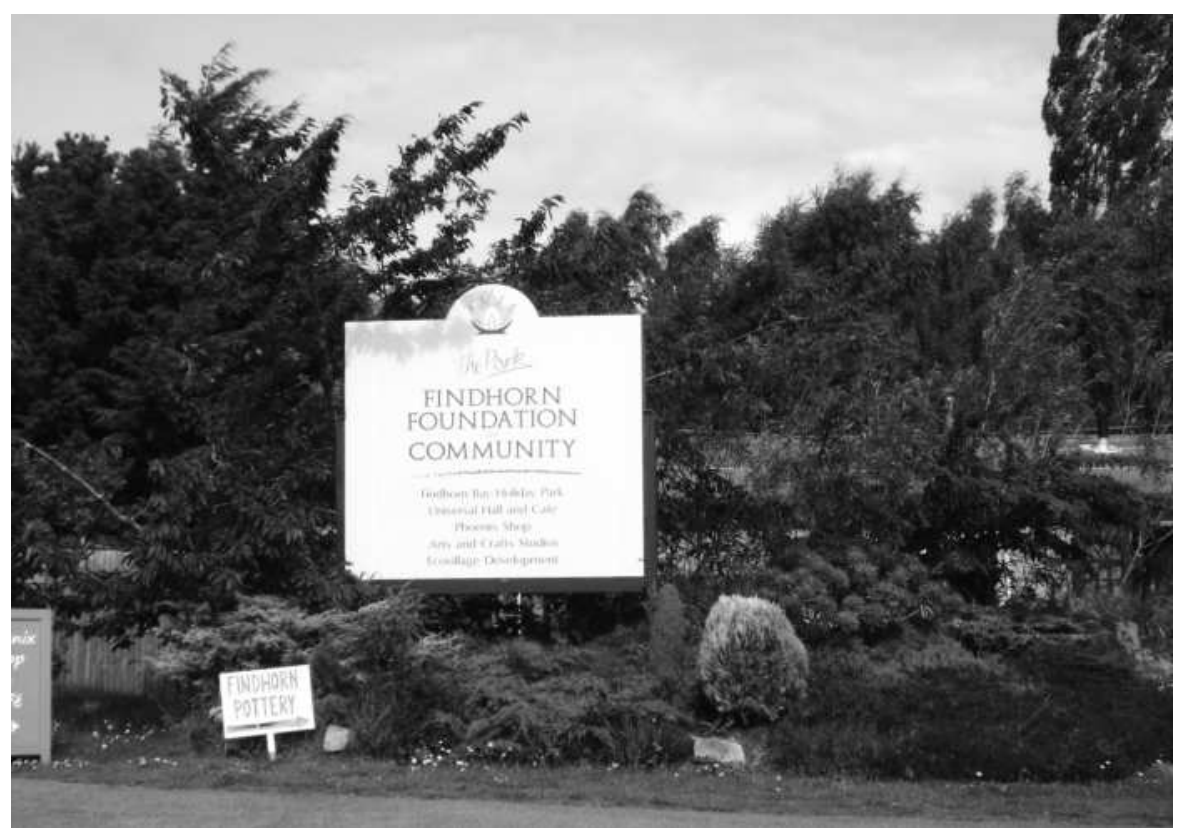

Figure 7.1 The entrance of Findhorn Foundation 


\section{An introduction to Findhorn}

The Findhorn community is a spiritual education centre and eco-village situated in the north-east of Scotland (see Figure 7.1). Founded in 1962 by husband and wife Peter and Eileen Caddy, and their friend Dorothy Maclean, the Findhorn community has grown from a dozen people living and working together, communing with nature and meditating on the underlying spiritual purpose of their lives, to an international spiritual educational centre of around 500 residents. The community is one of the few survivors of the many communes started during the 1960s (Heelas 1996). Its history shows that the original purpose of creating an alternative way of life has been replaced with education and demonstration as a way of bringing about an individual change in consciousness that will lead to world transformation (Walker 1994, Riddell 1991). Contemporaneously, this ideal is apparent in the Findhorn vision:

The Findhorn Foundation is a spiritual community, ecovillage and an international centre for holistic education, helping to unfold a new human consciousness and create a positive and sustainable future. (Findhorn Foundation, no date b)

The present-day community is organised as an educational centre, the Foundation, which runs a year-round programme of residential workshops, and an associated wider community of individuals and small businesses which includes organic farming, Steiner education, waste water treatment, ecological building construction, performing and creative arts, alternative medicine and therapy, and local currency exchange projects (see Figure 7.2). The Foundation currently employs around 120 staff in its work departments (services, education, administration and communication), three-quarters of whom live in Foundationprovided accommodation at one of its two campuses in Moray. Foundation members live either at the Park (see figure 7.3) or at Cluny (the Foundation's other campus five miles away in Forres). The Foundation is a charitable trust; legal responsibility lies with a board of Trustees. Day-to-day running is in the hands of a management committee, which takes decisions after consulting with the Council, a voluntary group of about 40 members which meets fortnightly to discuss issues which arise in the running of the community, such as noise, litter, the behaviour of young people and traffic.

Since 1974 the Foundation has offered residential workshops for visitors. Annually over 2,000 people take the Foundation's programmes, which account for three-quarters of its income, the remainder coming from profit-making ventures and private donations. Workshops fall into two categories: the core programmes, in which 'realizing one's full potential' is done through living in the community and working in one of the Foundation's service departments, which can lead to a staff position in about two years; and workshops in which 


\section{QUEER SPIRITUAL SPACES}

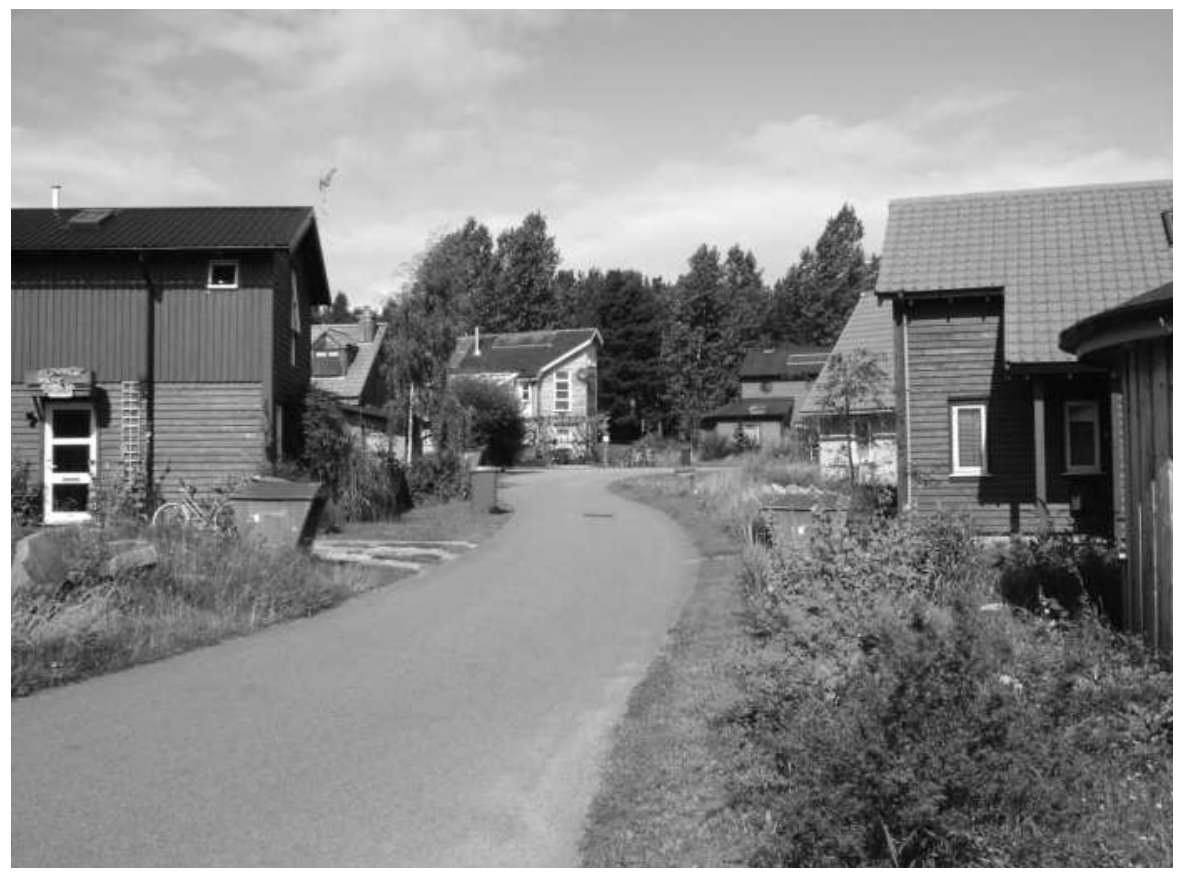

\section{Figure 7.2 Ecohousing at Findhorn}

the focus is on self-development and the 'realization of one's authentic human nature' through various practices, rituals, group work, exercises, dancing, singing or meditation (Findhorn Foundation, no date a). The Foundation also has two major conferences each year, at Easter and in October, and four to six special events annually which usually involve a guest speaker from the New Age circuit giving lectures to visitors and community residents over three to four days. Most residential workshops are held at Cluny; its large public rooms and meeting spaces give glimpses of its former function as a luxury hotel and are ideally suited to group work.

The wider community has a resident population of around 320 people, who share the aims and beliefs of the Foundation but who do not necessarily want to be a part of it (Walker 1994). Community residents are scattered throughout the local area; some live at the Park, the Foundation's campus near Findhorn village, with others living in local towns and villages. Community members work in a variety of occupations. Many are self-employed or owner-employees of the 30 or so businesses that make up the New Findhorn Association, the community's organisational body. These small and individually-owned businesses, charities and projects are engaged in a variety of activities and which include several ecological and sustainable experiments, education, therapy and alternative medicine, local currency exchange systems, arts and crafts, organic 


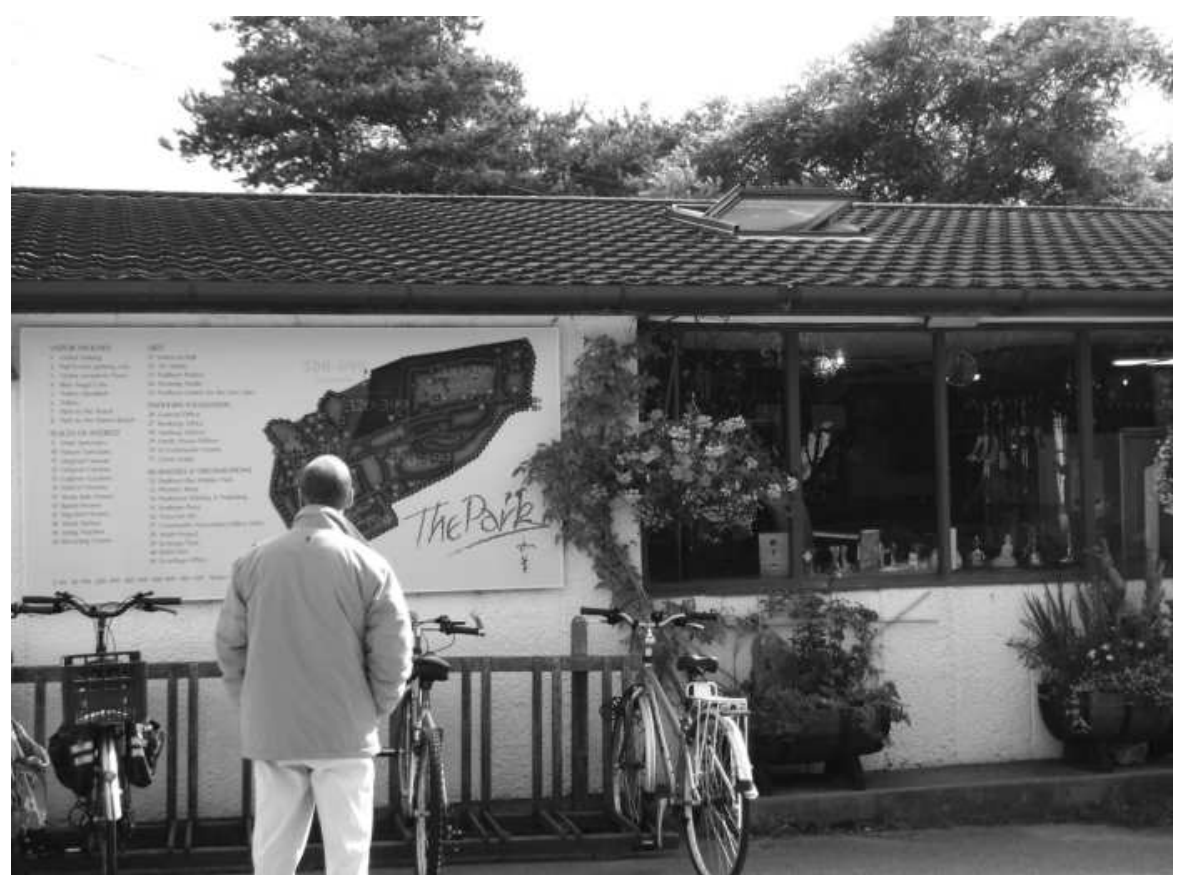

Figure 7.3 Map of the park outside the Phoenix shop

farming, retailing, holiday accommodation and bed and breakfasts. To join the wider community one does not need to take the residential programmes of the Foundation. All one needs to do is find accommodation locally and a source of income if needed. Many wider community members live at the Park, the Foundation's main campus near Findhorn village. The Park was previously a residential caravan site; it consists of bungalows, residential caravans and some newer eco-houses. Cluny was a hotel prior to the Foundation's purchase of it in 1975. Life at Cluny is more institutionalised than life at the Park.

The wider community has a council, the New Findhorn Association, which is headed by two listener-convenors, who each serve a two-year term of office. As well as formal organisations shaping community structure there is a cultural side to living in community. People create a community by doing things together, creating networks of friends, neighbours and colleagues. Items and chores, including washing machines, baths, gardening, and splitting wood are shared - partly out of economic necessity, partly for ecological reasons. Social events include performances and films in the hall, rituals to celebrate the winter and summer solstices and Celtic festivals, harvest festivals, birthday parties and barbeques on the beach; evenings in the pub; bonfires in the garden; yoga and dance classes, sauna and hot tub, community projects and meals, as well as community meetings and get-togethers with friends for a drink or a meal. 
The Findhorn community has grown from a small group of typically middle-aged, middle-class spiritualists and mystics, committed to spiritual exploration and trying to create an alternative way of life, into a diverse community and spiritual education and environmental centre. This may not have been the founders' original purpose but is regarded by some as its greatest achievement (Metcalf 2004). The change from creating a way of life to individual transformation and self-development mirrors a similar shift in the New Age movement as a whole (Sutcliffe 1995). This is exemplified by a semantic shift in usage from 'the' New Age, referring to a coming era which will be heralded by an apocalyptic, seismic or extraterrestrial event, to New Age as a broadly descriptive term for a diverse collection of practices, rituals and therapies, groups, organisations and communities which claim to be bringing about changes in individual consciousness leading to the realisation of full human potential (Sutcliffe 1995). Furthermore, Findhorn's conflicts with the surrounding local communities have also (seemingly) all but vanished, reflecting an interesting apparent 'acceptance' of alternative spiritualities in this area of rural Scotland as its boundaries have become less rigidly enforced.

\section{Sexuality and Findhorn}

The Findhorn community includes a number of people in same-sex relationships ${ }^{1}$ or who identify in some way with non-hegemonic sexualities although, as we shall discuss later, this does not always mean that they identify with the nomenclature of LGBT. The Foundation runs workshops specifically for gay and lesbian people (this term is used rather than LGBT/LGBTQI or queer), including gay and lesbian experience week (an alternative to the standard experience week, an introduction to life in the community) in which 'we will celebrate being lesbians and gay men together' (Findhorn Foundation, no date c); gay pioneer, gay men's retreats (at the community's retreat house on Iona in the west of Scotland), and woman2woman, 'a personal and spiritual inner journey for lesbians':

How can all that we are come together: spirituality, sexuality, dreams, hopes, longings? This is a week for women who love women to explore together and strengthen our connection with ourselves, with spirit and with each other. Using the Transformation Game, ${ }^{2}$ life stories, meditation, sharing and ritual, we will create a safe and supportive circle where possibilities abound. If you have a

1 Exact numbers are hard to find but one person estimated that one-third of female community members were, or had been, in a same-sex relationship. Females make up two-thirds of the community's membership.

2 A self-development tool played as a board game. 
desire to share with other lesbians and bisexual women on a spiritual path, join us for this week of discovery, insight, healing, growth, celebration, play, laughter and joy. (Findhorn Foundation, no date c)

These workshops make gay and lesbian sexuality visible in the community and attract gay and lesbian people as visitors, some of whom eventually stay on and become residents.

In contrast to the known habits of some intentional communities or sects, where sexuality was often highly regulated by leaders, sexuality in the Findhorn community is perceived as a matter of personal choice. The community's founders and first members had very traditional arrangements, although the founders' biographies show that issues to do with sexuality were lying just under the surface (Caddy 1995, Caddy 1988). ${ }^{3}$ In the Findhorn community there are many different kinds of relationships and sexual arrangements. There have been controversies over whether certain relationships are exploitative (and therefore 'ego-based'), however sexuality is seen, in perhaps a liberal pluralist fashion, as primarily a private matter of concern only to the individuals involved. Some people are monogamous; others decide their spirituality is best expressed through open relationships, or in same-sex relationships.

Accounts of the Findhorn community by current and ex-members and academics make little mention of sexuality or the place of LGBTQI-identified people in the community. A book by a former member of the Foundation mentions same-sex relationships only once, and underlines their private rather than public status:

\begin{abstract}
Although the community is overwhelmingly heterosexual, we accept relationship between people of the same sex without hesitation, where there is a feeling that love rather than ideology or exhibitionism is the basis of the tie. We had a most moving blessing of a relationship between two women not long ago; their partnership over a number of years had been a model of commitment and awareness of personal freedom in a couple situation. (Riddell 1991: 157)
\end{abstract}

In making sexuality a private matter between individuals based on a model couple's love and commitment, rather than a public, (single or polyamorous) affair, same-sex or any non-normative relationships can become what we term a 'present absence'. There is no separate organisation for LGBTQI-identified people within the Findhorn community. Rather, alongside specific experience weeks and the groups mentioned above, there are small, informal and ad hoc groups based on friendship networks, which are sometimes based on sexuality

3 Peter Caddy, who was married five times in all, eventually left his wife and the community in 1979 to start a new life with a new partner in Hawaii. 
and sometimes not. This chapter will discuss the place of lesbian and gay groups and experiences and sexual lives and normalisations that tread tense boundaries between visibility/invisibility, and public/private. In particular, it will address ruptures that can be seen as intermittent occurrences which draw attention to the present absence of $\operatorname{sex}(\mathrm{ual})$ issues that often remain unnoticed and invisible until they are brought to the fore by disputes, conflicts, and disagreements.

\section{Methods}

The interviews and focus groups for this chapter were undertaken at Findhorn by Liz, who had previously conducted her doctoral work as a participant observer with this community (Dinnie 2008). Identifying potential participants for this project was fairly relaxed because individual community members and visitors are generally open about their sexuality, and Liz had many established contacts. Yet, it was also difficult because there is no separate LGBTQI organisation within the community, so there is no way of knowing people's sexuality apart from asking them directly, and being dependent upon them offering this information to a researcher. The nature of interaction within the community, which is predominantly through networks of friends and people who share similar interests, meant that contacting people directly, explaining the project and asking them to participate was the best way to obtain a diverse sample which included people who had a variety of roles within the community. The absence of a formal LGBTQI organisation within the community meant that it was sometimes awkward having to explain to people how it was known that they identified as lesbian, gay or bisexual. The postdoctoral researcher's own heterosexuality meant that non-normative people engaged in the study asked her why she was so interested in this topic, displaying a typical defensiveness or curiosity expressed frequently by minority groups under academic study, as Amna in interviewing LGBTQI Muslims also reported (see Chapter 4). ${ }^{4} \mathrm{Liz}$ responded by explaining that she was interested in the spiritual experiences of

4 Liz wrote in her report:

Although queer can be used as \collective term for non-hegemonic sexualities, it can also be used to draw attention to the processes of categorization of any kind. I did think about labelling myself as queer in recognition of this attempt to undermine all sexual identities however, on reflection. I decided this was not appropriate because it further diluted the term and because the people I spoke to associated it primarily with sexual identity rather than its theoretical task of problematising categories of all kinds. I felt that if I used queer to describe myself it detracted from the experiences of the people I interviewed because I have not had the struggle to have my sexuality recognized in the way that many people described to me. 
people who identify as LGBTQI, and how (if at all) their sexuality affected their spirituality. Some people, for example the visitors on experience week, did not ask her about her own sexuality, however there were also research benefits: 'My identity as straight sometimes allowed me to ask for clarification of responses in interviews because I was not familiar with the experiences they were describing, or some of the terms people used.' Liz also reports that 'I was, at times, "mistaken" for a lesbian, the research dictating my perceived identity', perhaps reflecting the (prejudicial?) assumption that 'only queers would be interested in researching other queers'.

In spring 2008, just as the research project commenced, the gay and lesbian experience week (an introduction to community life) was dropped from the forthcoming publicity brochure. A community meeting was organised to discuss issues of sexuality, gender and identity within the community, (which Liz attended as a participant observer). She reports that what the 45-50 people who attended really seemed to want to discuss were the reasons for the cancellation of the workshop, and, more than anything else, what implications did its cancellation have for the rest of the community, and the message it sent to the 'outside world' about the Foundation's position towards gay and lesbian people. At the end of the meeting there was some time to discuss 'next steps' and Liz stood up, introduced herself and explained the Queer Spiritual Spaces project. For New Agers, who see synchronicity guided by divine forces in the timing of apparently unrelated events, the arrival of this project at the same time as sexuality, gender and identity had become a 'hot issue' in the community, signalled that the project had a symbolic importance and was more than a coincidence. This did not necessarily mean that people were willing to participate, but that they saw the project as having greater legitimacy and timeliness according to their value system.

After the meeting six people approached to say that they would like to be interviewed. Subsequently four of them were, and they spoke of other LGB people living in the community who they thought it would be 'good to interview'. A focus group was also held with the visitors on the gay and lesbian workshop, two of whom were interviewed separately. Another focus group was set up for the wider community members. Participants thus represented all types within the community - visitors, staff members and wider community. This combination of snowballing and identifying people according to their role means that this was not a particular representative sample demographically, but that people were chosen for their position and roles within the community, their willingness to be interviewed and in some cases their availability.

However, in relying on word of mouth other possible respondents may inadvertently have been missed. Eleven interviews and two focus groups were undertaken with visitors, Foundation staff members and community residents. Six people did both an interview and a focus group, meaning there were fifteen 
participants in total. Seven were long-term residents of the wider community, three were staff members of the Foundation and five were visitors on one of the Foundation's gay and lesbian workshops (see appendix). Three of the long-term community residents were still closely involved with the Foundation although they were no longer staff members. Some people had lived at Findhorn for more than 15 years, others had been there only two or three years, and the two visitors just one week. Both focus groups had five participants. One was all-female; these participants had a long-term association with the Foundation and the community although only one was a Foundation staff member at the time. The second focus group was all male and all these participants were on a residential workshop. All interviews took place at Findhorn and were conducted face-to-face, recorded and transcribed. Interviews were semi-structured using the standard question format designed by the larger project team.

\section{Oil and water? Integrating sexualities and spiritualities}

This case study, similar to Chapters 4, 6 and 8, found that the 'ordinary' and the 'everyday' were both contexts for and incorporated into spiritual practices. Connecting with Findhorn could be an important part of this experience, but for participants, spiritual insights, practices and occurrences were not limited to this space alone. In line with other key writings on New Age, all individual experiences and the self are centralised as an epistemological priority (Bruce 1996, Heelas 1996, Hunt 2003). Perhaps because of this the ritualised format of spiritual practice produced by the 'Findhorn experience week' can also be questioned by participants for its formulaic quality.

Some participants on experience weeks referred to a 'battery farm' raising the spectre of commercialised, 'café-style' spirituality used by critics to denigrate New Age activities. There is some self-conscious ambivalence, then, toward the imposition of any formal structures of authority, even where these are designed to enhance spiritual/community experiences. The absence of an external divinity and the reliance on mentor-teachers exists in contradiction to the idealised pursuit of a lone divine self discovering its core authenticities. When this is contextualised within sexuality the belief that the self is divine or, if it is not yet, then it can become so with the right ritual, therapy or training (Bruce 2002: 82) - means that there is no one who can sit in judgement upon or circumscribe 'deviant' sexualities. Sexuality and the body can be integrated into the sacred diversity, rather than being seen as something that is shameful, evil or sinful, according to historical Judeo-Christian traditions (Tacey 2004: 115). Contrasting their spiritualities with conventional religions brings to the fore the possibilities of an absence of external divinities: 
Jason: I don't use spirituality to reinforce that it's ok. My spirituality is there to hold me in times of hardship, it's my emotional safety net, I don't need the pope or somebody from 2,000 years ago to tell me it's [who] ok to sleep with. Bollocks. I'm not interested, that's not what I go to spirituality for that's why I don't cling myself to a certain church cos I don't believe in, spirituality isn't about rules and regulations.

Mike: But I can't help feeling, having heard that, that that's one of the major weaknesses of Christianity, Judaism and Islam is the fact that they seem not to even recognise sexuality other than in tiny amounts where things are disallowed, and to have, I don't think we're talking about spirituality, we're talking about religion here aren't we, and to have a religion that ignores a huge part of somebody's life.

The rejection of the Christian church was a strong theme in this and other case studies (see Chapters 5 and 6), relating conventional dominant forms to imposed sexual moralities that were seen as alienating. Participants commented upon the unhealthy forced separation of sexuality from spirituality, seen as problematic to a person's whole self, which was perceived rather as being more integrated in mind and body:

Liz: So the first thing to ask you is how you see yourself sexually? How do you see your sexual identity? What kind of terms do you use around that, are you comfortable with?

Hazel: It's much more than only sexually, first that, it's already actually a very narrow question. This is comment on the whole research cos if I only have to answer on that it means that I'm only talking about my sexual or gender identity and for me, being a lesbian has influenced every aspect of my life. There's been times that I identified myself clearly as being bisexual. I think I've always been at least that in my life, in the very early stage when I had, when I was already involved with women. I've also had relationships with men but there was always feeling, but often I thought I would have liked to have this relationship with a woman but the universe had decided at that moment that that was not the case and there was something very important for me to learn, so, and especially later in life when I realised that I went with it as ok, this is then also my path.

Hazel's trust in her spiritual path and the accruing of 'experience' means that her biography is one that can accommodate relationships with men, and a past identification as bisexual. In the New Age context selfhood is not just about sexual freedoms, but also about spiritualities that cannot be siphoned off from sexual identities, practices and experiences (Yip 2005a, Wilcox 2006). 
Such entanglements can mean that common 'labels' for sexual identities are problematic or perceived as externalised, because they differentiate the self into parts:

Rebecca: With the Christian religion maybe or something where you're being told it's wrong to be homosexual or whatever. I see a link between identifying people, loving people not for their gender but for who they are, I see a link of that and my spirituality but I don't see my spirituality telling me what my sexual morality should be necessarily, I suppose it does in a way 'cos my spirituality's telling me that it, I should be open to who the person is, who the soul is, rather than who, what they look like.

Camilla: I think that for me being honest in looking at myself and where I'm at and being authentic that is like a core thing for me in my spirituality and I think that following my heart or my, following my, where the pull is somehow is also one of those, I wouldn't call that a rule but like a kind of a something I try live by and I think where that can hinder me sometimes in terms of, gender, sexuality could be being seen as disloyal somehow to the labels that have been created or to sort of move between things in a way that may not be strictly sort of, yea, permitted somehow so that can be like a hindrance sometimes but I think that's also the, for me, yea, this whole thing of fluidity, that is the kind of gift of that.

Lianne: I found the questions very, I was very conscious that it's a rigid thing, that has made these up, it's like your sexuality is here, your spirituality's over here and instead of it all being seen as, as part of the whole. I felt, yea, it just, very hard its all of me, it's like the colour of my skin, it's like my weight, my nationality, the colour of my hair, its all of me, I can't take one away, you know it's just all of me, and I did struggle with that with the questions. I just see mainstream here coming from a very rigid, a very rigid place asking these rigid questions whereas for me, why I'm here, it to get me out of the rigidness, out of the boxes.

Diana: It feels like it's fitting mainstream, conventional and those religious categories 'cos for me I could understand the questions if it was like you were in like a Muslim society or a Christian society where there is a, there is a structure there in place, or a rigidness, where as for here because it's just anything goes really. The morality questions would make more sense you know if you're talking about the bible you know, and, but that doesn't kind of, or whatever religion, but that doesn't have a connection with spirituality here does it. 
Camilla and Rebecca reflect a fluidity and intersectionality that is common in contemporary queer engagements with gender and sexual identities (see also Chapter 1). Yet the possibilities for such intersections were not attributed to 'rigid' mainstream religions (reiterating, perhaps, conceptualisations of Christianity and Islam that have been contested in Chapters 2 and 4). Whilst sexuality and spirituality are perceived to be inextricable from the self, morality does not 'have a connection with spirituality here' and is displaced as a negative. In this paradigm usually fluidity is valued whereas inflexibility or rigidity is denigrated. Liz ran into challenges in almost every interview and focus group relating to perceived definitions and distinctions between both spirituality and sexuality; these were understood in relation to, and inseparable from, each other even at the point of naming, as mutually expressive qualities of the self. Yet, there were exceptional moments where claiming a sexuality label was seen as politically important, within the heterosexualised context of Findhorn:

Hazel: The last [few] years it's definitely very clear that I needed even to identify myself again as a lesbian to make it visible. It's very easy in this still heterosexual world to become invisible, especially if you don't have a relationship. People don't see who you are with. It is automatically believed that you are heterosexual, and I thought for that reason I have to, even in a spiritual or in a community on a spiritual base I have to come out as a lesbian again.

Hazel feels that she needs to be identified as a lesbian in order to not become invisible in the 'still heterosexual world', the use of this tense invokes the silhouette of a future world in which sexual possibilities could develop. Hazel recognises that naming is occasionally strategically important in the Findhorn communities, as does Diana. Although both recognise that the size of the community means that their sexualities are de facto already widely 'known':

Diana: I wouldn't want to live somewhere where it was kind of like that would feel weird. It is part about being spiritual, this kind of not denying parts of you and if you had to deny a whole part of you.

Liz: So it's more you feel that you can show more of yourself perhaps or be more yourself in these spaces, with other lesbians in these spaces in the community?

Diana: I feel I don't have to explain myself, it's kind of like you don't have to kind of like explain yourself and then having somebody thinking it's a huge issue that colours the whole of your life, it shouldn't but it becomes a huge issue because you have to explain yourself. In a sense, I choose to identify myself as lesbian here because it's a chance for me to try out how it feels to be identified as a lesbian, and it also gives me an inroad to a group, you know, a belonging within 
that group. But if I talk about it honestly I see myself as attracted to the person and not their gender because it makes no sense to me. It makes no sense to me that you be attracted to somebody just because of their gender. Because to me it's the personality and the soul of that person and the outer appearance is not kind of important at all. It's who they are. But if I said to everyone it's not that it's the person I feel for, but to some people I'm friends with, it would seem like I was opting out. I'm kind of accepted because I'm a lesbian. It's the labelling thing again, if you don't have a label where do you fit?

Liz: So you have to have something, some kind of label to attach an identity to but that label is not everything, yeah.

Diana: I don't feel it's necessary, you know it doesn't say exactly what I am but unless I have a label other people are going to want to fit you in somewhere.

For Diana, being a lesbian is something she chooses in Findhorn in order that she can participate in the lesbian communities and have a sense of deeper belonging. She recognises however that this identification does not fully encompass her sexual desires or practices. There is a political knowledge evident here in Diana's evasion that resonates with broader historical debates regarding lesbians who move into relationships with men who then lose a precious affiliation and sense of community or subculture (see for example McLean 2008). Desiring to 'fit' somewhere, Diana recognises that even where labelling can be seen as problematic, perceptions of shared experiences can lead to common bonds, as Lianne explains:

Lianne: Yeah, my, my sexuality is one part of me and I really don't like going into spaces where it takes me out of the other parts of me and I don't know if I would ever stand up and say that I'm gay or that I'm a lesbian, I probably would, because again its exclusion, and I'm trying to include instead of exclude.

[Later in the interview] What I find when I'm around people who are, who are gay, [to] use your word, or queer, because its taking a lot of inner courage with society at the minute to actually come out. To admit that this is a part of me. Be it you know same sex relationships or be it both for me the fact where they've gone, that depth inside them to actually admit that about themselves. It's like they're easier to talk to because they've already had this deep inner journey within themselves.

Lianne's desire to 'include rather than exclude' means that she does not want to claim the identity of lesbian and gay for herself, viewing this as exclusionary. Yet Lianne also has an affinity and admiration towards those who have been on a particular 'coming out' journey, a cultural metaphor that she equates to a spiritual development within her New Age context. These emphases on 
shared processes, experiences and 'inner courage', are spiritual qualities that she contrasts with the social segregation that she relates to the limiting terms or types, lesbian and gay. There is a perceived tension or ambivalence therefore between ascribed social roles or labels, and the individual desire to connect with the distinctive 'inner divine' within each person, and yet to belong to a community of affinity, of the 'same'. Coming out in Lianne's view requires an aesthetic of confession, or 'admittance' that is still quite tightly associated with the Judeo-Christian model of homosexuality, albeit as a reverse discourse (Foucault 1984a).

\section{Sex and privatised moralities}

Many New Agers believe that an important source of connection between the self and the divine is that of sexuality and the erotic (Lynch 2007: 56): the erotic energy of the self (understood in a broad rather than just a specifically sexual sense) has the potential to draw us into a deeper awareness of the spiritual nature of ourselves, nature and the universe. This positive view of the erotic has an inclusive emphasis; sexuality, including same-sex sexuality, can be seen as a source of encounter with the divine (Lynch 2007). Heidi sees sex as spiritual related to the intention:

Heidi: I think it's the intention with which an activity is done that makes it spiritual or not spiritual. I mean I think having sex can be spiritual or not spiritual, yeah, it doesn't really matter where it's done.

Liz: So it's the intention behind the activity?

Heidi: I think so. I mean, it's my whole identity, my sexual identity is not separate from the rest of me. The spiritual practices that I do engage with nourish me as a whole being and part of that is a sexual being, I don't have a practice which is only for my sexuality.

The sexual and spiritual self are intimately intertwined and can 'nourish'; Heidi does not isolate sex from other parts of spiritual practice, linking this to the ubiquitous possibilities of engaging with the spiritual anywhere, including in the everyday and ordinary.

Niels narrates the individualisation of his sexual experiences. Encounters with other people on their journeys of course happen, influence and create, but they are separated and different from the journey that his spiritual self is taking. Niels's journey now connects his erotic and spiritual in ways that were once 'oil and water': 
Niels: One of the things that drew me to Findhorn and has been this whole issue for me around being gay and for me sexuality and spirituality have, was like oil and water, in my world had nothing to do with each other, and that has been my journey very much and still is my journey. In my ideal world it's exactly the same you know, it's just the erotic energy that is so full of life force that you know. I had my greatest experience of that, it's quite a few years ago now, I went to a workshop in Holland, with the Body Electric people there. For years and years I knew about that but I always just sit it out, [thinking] it's just an excuse for sex, and then I get a chance to have a taster of it in London once when we did a presentation for the Foundation at the University of London. They were there and I had an hour's taster of it and 10 minutes into it I knew that I had to go and do a workshop there. I would say that that is probably the most profound experience I have had in my life. I know that all the others led up to it. I couldn't have come to it without the others but, after having this Taoistic, erotic massage, then floating there somewhere between heaven and earth, and experiencing actually God in my body, a presence in my body that I thought, 'what is this?' The answer immediately was 'I'm God'. I cried and I cried and I cried and it was just like asking the question 'but where have you been, this is what I've been looking for all my life?' 'Well you have not been looking here'.

Niels sees the most profound experience of his life as culminative. He believes that this sexual experience integrates him and gives him peace.

Niels: I've struggled a lot with, sexual addiction, promiscuous sex in public toilets and parks and all the rest of it. [1] felt very guilty about it and not understood that somehow that was my journey to come to a place where I could come to peace and integrate that whole thing into one piece.

Exploring sex and stories of sexual practices can reveal some of the limits and hierarchies of sexual expression that create new sexual morality that is not predicated on an external divinity. Niels notes that in his spiritual journey he 'struggled with' 'promiscuous sex in public toilets and parks', implying the presence of judgment and guilt to which he now seems reconciled. Yet, the rejection of this sexual practice suggests a hierarchy of sexual experiences that underpins the journey, as well as the erotic connections that are supposed to be formed through sexual contact - some count more than others. Thus, whilst externalised sexual morals were claimed to be unimportant to respondents, there was also evidence that particular sexual practices were not welcomed or embraced at Findhorn: 
Holly: [Names a person] bought a woman prostitute who was into the Foundation to explore sexuality, and she works with disabled people to help them have sexual experiences. She organises sacred orgies for people. She doesn't call them sacred, in London, I mean, she wanted it to be organized in the hall, to have it there and of course the Foundation wouldn't have that, so it was in the upper cc [community centre] and she showed a lot of rather appalling slides, very S\&M actually, and put a lot of people off because she was basically talking about free sexuality, but it was a bit alienating and in your face, there was lots of leather and macho, there was a lot of macho stuff in it. In her scene it would have been pretty soft core but for Findhorn it was pretty hardcore.

The location of the discussion organised by a sex worker that sought to address sexual freedoms and including BDSM (Bondage, Dominance and SadoMasochism) was symbolically not in the main hall, but in the less privileged space, the community centre. Holly found the discussion alienating, but recognises that in contrast to this woman's 'scene' she denigrates it ('appalling') by using the language of pornography - 'soft core' 'hard core' - a sex literature that is not welcomed at Findhorn. The collective privatisation of sexual practices at Findhorn would mean that as orgies are by definition communal, public and 'out', they are excluded from Findhorn's public spaces.

Machacek and Wilcox (2003) argue that religious organisations reduce people with dissident gender and sexual identities to their deviant sexual practices, and fail to recognise the whole person. At Findhorn spirituality is not separated from sexuality, such that labels can become problematic. Spirituality is used to establish a discourse of openness to sexuality and a freedom from labels. Nonetheless, not all sex is the same. The public/private divide so pervasive in understanding LGB sexuality (see Chapter 1) is also apparent at Findhorn. Thus openness and a lack of an external divinity operate simultaneously with the policing of particular forms of sexual expression. As we will see the absence of identities and subtle forms of policing have particular effects for LGB visibility. Moreover this will be contextualised historically, in relation to the stereotypes of 'New Religious Movements' (Machacek and Wilcox 2008) and geographically in relation to its placing in rural Scotland.

\section{Creating lesbian and gay space at Findhorn: 'The controversy'}

In the early 1990s the Foundation offered residential workshops for gay and lesbian people for the first time. Details of these workshops were printed in the twice-yearly brochure, thus acknowledging the categories of gay and lesbian and showing that people who identified as gay and lesbian were welcome in the community. In his interview Niels tells how these workshops came about: 


\section{QUEER SPIRITUAL SPACES}

Niels: When I was long term guest here in ' 91 with my friend Adam, we started the workshops together, there was quite a lot of resistance in the community, so, we'd done a lot of work on that and it was a great victory when we got our first gay workshop in the brochure, it was just fantastic!

Liz: And what was the resistance in the community about, do you know, can you remember?

Niels: I remember particularly that when I came to do experience week here if you filled in the registration form you had to state whether you were HIVpositive or had AIDS, and if that was the case you couldn't work in the kitchen, and we said this, this is discrimination, you cannot do this, this is not ok.

Liz: And that was taken as an indication of your sexuality was it?

Niels: Yeah, ya ya ya.

Liz: But straight people have HIV and AIDS too.

Niels: Yeah, but that was not seen in those days you know, that was-, so, there was a lot of hard work and there was a lot of, and we started the, we started a support group here and we had a gay, lesbian, bisexual group and put notices up different places when the meetings were and they disappeared, we didn't know what it was. We started a meditation for, every Wednesday we would have a meditation, a healing meditation for people affected by AIDS and HIV and it would alternate between the Park and Cluny and these notices that were put up also disappeared you know, or now and again, so it wasn't clear where the resistance was. When we wanted to do an experience week for gay men there, the community was in a whole process around that. They came up with this funny statement that, oh no, experience week would be for everybody, if we would start to have experience week for gay men we would end up having experience week for stamp collectors, which is completely ridiculous. So we couldn't put it in the brochure, we were not allowed to do that. The community wouldn't allow that because experience week would be for everyone, and then they encouraged us to do a workshop, which we then did, but we said, ok, but we want people to not have to do experience week before they come here if they do a workshop. Because that was normally the case, in order to do a workshop here you needed to have done experience week first. So we wanted people to be exempt from having to do that which they then agreed on. 
Niels's narrative shows how Findhorn was not immune to the homophobic and anti-AIDS practices of the 1980s and 1990s. He speaks of resistance and victory, externalising 'them' - the covert operatives who made posters disappear, equated HIV and AIDS with gay men and refused to have an experience week for gay men. The 'them' is contrasted with those who got a workshop for gay men and lesbians activated. Interestingly, the 'resistance' to the gay and lesbian workshops seemed to be not against gay and lesbian people as individuals, but towards gay and lesbian people organising as a collective within the community. This moves between and beyond - the individual self (which is simultaneously spiritual and sexual) as well as communality. Together, this problematises belonging and the invocation of a collective and communal them/us. Niels identifies the nervousness toward any expression of minoritarian politics.

Contemporaneously experience weeks for visitors are also augmented by the FAGS (Findhorn Gay Men's Society), and Diva, a group that existed for lesbians for residents as well as lesbian, women's and queer spaces that are informally created:

Lianne: There are others I've been looking at, chatting on, but there's no where around here with a sign up on the door that says queer space.

Diana: Kind of doing the woman to woman workshop and things like that I kind of suppose it's like being in a, that's being in a lesbian space, in a public place. It's a difficult one isn't it, I mean if I'm sat with another person who's identified themselves as lesbian or gay or whatever and we're sat having a coffee, (laughs) outside the bakehouse, are we in a queer space?

Lianne: Sometimes the bakehouse is so gay, you look around and there's only dykes in here! [laughter]

Camilla: I think in terms of workshops we do create those spaces, social gatherings occasionally organized evening gatherings. I think most often it's gay and lesbian. I don't think I've ever really seen anything beside those two kind of categories but they're often advertised, I mean in the brochure that we have, you know, and on the web page we advertise the workshop and that it has a lesbian theme or a gay theme. The social gatherings could be something like a film evening for gays and lesbians, or something like that.

The lack of a visibly identifiable territory, as has long been noted in geographies of sexualities, does not preclude the existence of lesbian and gay spaces, particularly of a temporary or ad hoc character (Nash 2005, Podmore 2001, Valentine 1993). Dianna notes the existence of lesbian space in workshops for women as well as in public spaces where two lesbians or gay men meet. Within 
the heteronormative context of Findhorn, this could be seen as an active queering of space. More formal, if still temporary, lesbian and gay spaces are also created through workshops, in the brochure and on the website. Yet, these temporary spaces and openings may mean that lesbian and gay identities are not always comfortably enacted with 'the family' space of Findhorn:

Lianne: I will actually put in that I do find it harder in the Park, so I do.

Liz: To be open with another person?

Lianne: Yea. I tend to go outside the Park, I'm very conscious of that.

Liz: Is that because of who will see you at the Park or something?

Lianne: I think, yea, and just questions. I am quite private. I'm open on one level but in terms of my relationships I'm very very quiet about it. I see the Park as family, the community as family, not only the Park but just that whole collected with people I hang out with here. Maybe it's just me carrying judgement from home into the community here. Outside the Park I'm cool, inside the Park I'm a little bit good foot and a half distance at least between us. [laughs]

Diana: But going back to the sort of workshop like things like that. If it's not an own created space, if you're going to a bar or a club and that's specifically lesbian or gay or whatever it has a different feel, I must say from doing a workshop where you are in a space as a group that is identifying as lesbian or whatever but in a heterosexual sort of environment. I find it kind of like [in] the woman to woman [group] some of the men had to come and sit on the settee and, took over sort of singing. It has a different feel because you're still kind of like being accepted in a group to a certain extent but you're still kind of like, it's not your home. It's not your environment. If you go into a bar or, for me you're kind of in somebody else's home and they're kind of letting you be there, but if you're in a bar or a club or somewhere it's not, you know.

Camilla: You're still a minority sometimes.

Diana: Yea, it's a different feeling.

Liz: A workshop is sort of a temporary in terms that the workshop will come to an end.

Diana: Yes. 
Lianne's avoidance of public displays of affection are well recognised in recreating heterosexualised spaces that exclude, in this case same sex enactments (see Browne et al. 2007, Valentine 1996). She argues that this is because of her desire for privacy and she sees the Park 'as family' in a way that she believes she is bringing assumptions of judgement 'from home'. Further, the temporary creation of workshop and other spaces can mean that whereas a gay bar will be there next week and the week after, workshop spaces are finite, and as such there is a feeling of 'them' 'letting you be there'. ${ }^{5}$ This augments the literature regarding sexuality and the creation of sexualised spaces, suggesting that the lingering of heterosexuality and the ownership of such spaces retain significance even where they are resisted, contested and reworked to create lesbian and gay (queer?) space temporally. It also references the practice that lesbian and gay (and more broadly LGBTQI) people can exclude themselves from visibility, in order to maintain relationships and a sense of comfort in places that have the potential to be hostile or subtly unwelcomingly to them.

Diana also pointed to the ongoing, often covert tensions that pervade Foundation, life as well as pointing to the Foundations significance in being situated in rural Scotland:

Holly: It's so difficult for the, them, women in the Foundation to come out and create a space. I think, all that has been happening is the same with Second Wave Feminism is that women have been doing rearguard actions to make sure that they don't, that Women's Studies don't get hurt further, that lesbian and gay group experience week isn't hacked further.

Liz: So what would a kind of more political stance maybe look like towards?

Holly: An aggressively confrontational, yeah, right, we need to create a space that is openly celebrating sexuality of all forms, including lesbian, gay, bi - LGBT - but there's still ambivalence between the Foundation core who are responsible for running the Foundation programmes and keeping the community, centre. It's just symptomatic to me that the Foundation hasn't got a lot of very out, gay people.

Liz: so how do people in the lesbian and gay community tell each other?

5 It should be noted that not all participants enjoyed lesbian and gay bars, Sasha who would not go to anything that was labelled lesbian/gay spoke negatively about a lesbian club she went to where the women were 'predatory'. Camilla in this focus group also spoke of not feeling safe in gay spaces. 
Holly: I don't know quite how it does come out, just by gossip, just people, informal networks. I don't think its been ever made much of an issue of, as integral to whom one is and to one's spirituality and how one expresses it, and how one celebrates who one is, no.

Liz: So it's not something that has to be made kind of public, it's just known on the grapevine?

Holly: It seems to be and if there was a say a gay activist male, strongly gay activist. There was a guy called Ian he was very brave in the $60 \mathrm{~s}$ and $70 \mathrm{~s}$, because it was so illegal in Scotland you see. He spearheaded Scottish minorities group in Scotland and if he had been living here, well the fact is he would never have been allowed to live here. Because the, he'd attract so much outside criticism from the press and Forres that the Foundation couldn't cope with him. Remember [name], which was an anarchist community, I wouldn't call it that now. They were running gay weeks as well, and they don't call themselves a spiritual community but they are actually very spiritually orientated, and about 15 years ago they had about their gay men's week, the local paper had 'lock up your sons' right across [the paper]. They were banned from the pub in the village.

Holly emphasises the continued discursive tension between the political celebration of sexuality 'in all its forms' and the Foundation's behaviour which seeks to avoid negative publicity and hostility from the local community in where it is based, an attitude to which Holly demonstrates some frustration. Findhorn having moved away from such histories and fraught relationships with local communities is nevertheless still located within them. Grounding New Age spiritualities in rural Scotland, offers further insights into what could be seen as sexual conservatism that may also be related to the middle class status of most visitors and residents, who as we have shown can allow for individualised sexual freedoms so long as they are predominantly privatised.

The existence and formation of lesbian and gay spaces of course contrasts with the stated desire not to label or exclude by identity that was a central theme in many participants' narratives. Along with the initial resistance to anything that segregated the Findhorn community into groups, when the lesbian and gay experience week was dropped from the forthcoming brochure, the reason given for this was that the programme was no longer attracting many people, and perhaps it needed to be revised to make it more relevant to recruitment. Members of the community, primarily those who identified in some way with lesbian-, gayand bi-sexualities, but also supportive others who did not identify with alternative sexualities, reacted strongly to the cancellation of this programme; letters were written and published in the Rainbow Bridge, the community's weekly internal newsletter/magazine, and people discussed it informally amongst themselves: 
Liz: The future of experience week is in doubt I think is it?

Niels: I have often had this sinking feeling of do I really need to continue to kick and push and push and get in this cell. This giving up feeling and then you know, having done a week like this, then I am completely fuelled up and, well, I shall go and claim my space and say we need this. This is important. Numbers are not important in this, this is just so important for the people that has been here. So to give other people that experience I think is very needed. Then there was this whole thing about, then it wasn't in the brochure and then it wasn't on the website and we've been through all of this.

Liz: Oh right, so why would they, why wouldn't it be put in the brochure?

Niels: Well, at the time, it was a misunderstanding, but it also came to look like, what is this? Is this some kind of unconscious homophobia here? 'Oh no no no no no, we're not homophobic here', ok, that's possible. Well I hope they carry on, 'cos from that meeting I was at people were saying there's a real need just to hold this space, to keep it open, to let people know that it's ok and accepted to come here. I also think that to some extent I know that it has served the Foundation that we have done this, for them to be seen as open and not narrowminded and all the rest of it, I know that is the case.

Niels points to the continued 'fight' that he started in the early 1990s in order to have some visible and legitimised named space for lesbians and gay men. Interestingly this narrative no longer is framed via the needs of lesbians and gay men, rather it focuses on the symbolic place of Findhorn within New Age culture as inclusive and welcoming, and the need for it not to be seen as homophobic. Appealing to liberal values of tolerance and acceptance of diversity is an important aspect of New Age nurture of the individual journey of self. At the community meeting where the reasons for the cancellation of the workshop were discussed, people spoke passionately about their sexualities, and why they related, or did not relate, to the terms lesbian, gay, bisexual or queer, why the term lesbian should be honoured in recognition of the part it played and continues to play in the political struggle for women who love women, and how difficult it still was to find a space where people could be completely open about their same-sex relationships and their sexuality (all themes reported in the data above). The cancellation of the programme was criticised as short-sighted; it was argued that by putting this programme in the brochure the Foundation was acknowledging the existence of gay and lesbian identities, and including them deliberately and noticeably in the culture of the community. One of the key areas of concern expressed was: 'gay and lesbian experience week should be used to send out a message that these terms and identities are acceptable 
here at Findhorn' (fieldwork notes, Liz Dinnie). The visible deployment or even vaunting of sexual difference to stand in symbolically for the expressive inclusivity or 'colour' of New Age individualism, lies in tension with the anxiety that such identities might wish to form collective loyalties between themselves and in doing so contest the overall collectivity of the community. New Age normativity and particular forms of sexualised hegemonic values, risk being exposed, this may deeply challenge the ideals that such 'spiritualities of life' invest in: strong ideals of equality, inclusivity and tolerance. By exposing such normativities then, organised lesbian and gay (or even LGBTQI) resistance would be antithetical to the principles, ethos, and rhetoric of communities based upon the removal of exploitation and the freedom to 'be who you are'. The deployment of visible lesbian and gay diversity to symbolise all-round liberal values has been a phenomenon of late capitalism. 'Lesbian and Gay' (and even Bisexual, but perhaps not Trans or Intersex) it has been argued can be assimilated by a heterocentric economy to accrue cultural capital (see Chapters 1 and 5). Findhorn, as with the AIDS battles of the 1980s and 1990s, is perhaps not immune from these wider impulses.

The inward focus of the debate about Lesbian and Gay Experience weeks was picked up on by those people who had come for this very experience, who related it to their early experiences of coming out and visible political activism:

Jason: I've felt that when I booked the gay and lesbian week here. I thought it'd be more the fact that we were gay or lesbian people together rather than the fact that we have to celebrate being gay and lesbian. I feel there's been a slight slant and I don't know who we're nourishing who this week if we're, they're there to nourish us or if we're there to nourish the gay and lesbian situation in Findhorn. I think that has caused problems with expectations for me, expectations and I feel that a little bit from our focalisers ${ }^{6}$ and a little bit from us. Suddenly I feel if Findhorn is struggling with the gay and lesbian, that's their problem, that's not necessarily my problem but I feel it's been distilled into my problem. I feel like I'm here, you know, to sell a message to Findhorn association and directions. Maybe it's just me being naïve when I booked the course but I didn't feel I was here to wave the rainbow flag and I feel like I have to wave a rainbow flag.

Massimiliano: Here is almost like there's almost a political debate behind, which I left behind a long time ago. I thought here that if anything the focus would have been more on being gay and if you like, yes, being in a group of gay people together and if anything maybe exploring gay, the fact of being gay in relation to

6 Focalisers are those who lead the workshops, usually Foundation staff members. Focalisers have responsibility without authority (Ridell 1991), thus maintaining the ideal of individual responsibility for spiritual development. 
your spiritual life if anything because this is after all what it is all about. But I saw the stress put on things that, as you were pointing out, that are very different and I wasn't expecting that. So it's not that it has created a problem for me, it's just puzzled me a bit. I found it a bit awkward, and for me I felt a bit. It was a bit like going back 'cos I was kind of doing these things in my 20s when I was involved in a very active gay community, and so, it's kind of going back to a previous stage in a way. It's where Findhorn is itself, Findhorn needs to catch up with the outside world. I think the gay community isn't sat in a pub by itself anymore, it's more integrated in society and we don't identify as that primary label, whereas Findhorn see that as your primary [identity], in a spiritual community they do actually like to box you in.

Dewi: That's my feeling as well. I've found it, being in a gay group is almost encouraging isolation or separation from the rest of the community which for me exactly the opposite to what I wanted. I feel in terms of Findhorn it's a very open and in many ways very warm, very welcoming place. I feel in a way we've been deprived of it a little bit by saying 'oh come back here because you're the gay group, and you're not to go out there and mix with all these straight people'. Those words haven't been used but I've felt a bit of that. I do feel that we are almost being used to prove a point or something, maybe that's a bit too strong.

Jason: We're here, we're loud, we're proud!

Dewi: It's like stepping back in time you know, we're queer, we're here and you've all got to see us and we're all going to display ourselves and we're kind of separate from you lot.

Jason: And branding us as gay is what gets us there, it's not why, what stays us there, does it? There's a very subtle difference, and that brings us back to this week. It's what brought us together but it's not necessarily what we need to talk about is it. What's more important this week is that I'm gay. I'm gay Jason not Jason who is gay and that's a very, very subtle difference. I personally don't use the word cock and this week we've been encouraged to use it and I've never used it, it's not in my vocabulary, [they say] 'The battle between the cock and the heart' and I'm like - 'You what?'

Massimiliano: No no no.

Jason: Cock is a male chicken.

Liz: [It is] part of the language so that everyone is using the same terms. 
Jason: Yeah but this language was used because it [was] felt it had affinity with us, and it didn't.

This discussion by visitors highlights the tension between seeking to identify a 'gay week' and the desire to use or move beyond these identities. For these participants, Findhorn is read as being 'behind' the 'outside world'. The issues that are brought to the experience week are not the chosen agenda of the participants, but relate to participants being drawn into the ongoing Findhorn debates about the place of lesbian and gay experience weeks. This has an impact on their experiences and the segregation they feel is occurring, which reminds them of earlier periods of activism around visibility and inclusion, forcing them to prioritise their 'gayness' as legitimate. Whilst their sexuality is important and integral to their spirituality, as they point out, the way their sexuality is being addressed is unexpected and unwelcome for example in the clumsy attempt to engage with them in 'their' terms, using words such as 'cock' which was found to be alienating, patronising and aggravating. Although part of this segregation could be attributed to their visitor status, the debates regarding lesbian and gay visibility meant that there are some projections occurring here, not least in perceptions of urban male sexualities versus rural spiritualities, and the emplacement of mature lesbian and gay identities 'there' or 'here'.

Debates regarding lesbian and gay spaces and their oppositional positioning in relation to straight spaces, can mean that those who identify as bisexual or something other than lesbian and gay can be excluded from spaces that are specifically and deliberately designated as lesbian and/or gay:

Heidi: I feel comfortable in my identity maybe not wherever I am but wherever I am up here I do. I don't specially choose to go, in fact I chose specially not to go to bisexual or lesbian places. Somebody said that the café sometimes can be a gay space because they look round and it's predominantly you know, gay people in here, but that doesn't kind of register on my field of awareness in that way. My friends are my friends irrespective of their sexuality and I wouldn't chose friends because of their sexuality, in fact I would actively, no I wouldn't actively not choose to do that, that's not how it is for me.

Liz: So their sexuality is not important?

Heidi: It's not that it's not important, it's irrelevant.

Liz: Do you have a place within the lesbian and gay community here?

Heidi: My sense is that bisexual people are slightly persona non grata with the lesbian community. 
Liz: Other people have said that Findhorn is a very heterosexual place.

Heidi: The world is a very heterosexual place. I mean it's just a question of numbers. I don't feel excluded, apart from the lesbian spaces.

Liz: So how do you feel excluded from those?

Heidi: Well at one point when I was in my last relationship there was a group, a lesbian group that I went to a couple of times, and it was stated that bisexual women were not welcome or included.

Liz: Really, and was that said as openly as that or did you just feel welcomed?

Heidi: There was a sense in that group that, well, it was said that bisexual women who were looking for a relationship with a man or were in relationship with a man were not welcome. I don't like exclusivity in any forms.

Liz: So are there bisexual groups here?

Heidi: Not that I'm aware of.

Liz: So as a bisexual woman you're just expected to fit in to some other category?

Heidi: That might be the case but ...

Liz: Well the term LGBT all kind of puts all those alternatives.

Heidi: I mean that term is fine for me but round here it's almost always lesbian and gay. Full stop.

Liz: And does that make you feel excluded?

Heidi: I don’t feel included.

Liz: Right, and you know, could you do anything about that, or do you want to do anything about that?

Heidi: It's not that important enough to me to, to be so exclusive based on sexuality. 
Heidi further complicates the limited, even precarious 'lesbian and gay' space at Findhorn. Whilst comfortable in her identity at Findhorn, she does not consciously 'register' informal gay spaces specifically. She does not choose her friendship group and social networks on the basis of sexuality alone, in fact her narrative actively resists this association, rejecting the exclusivity of groups that she has herself felt unwelcome in. Although most of the contemporary discussion of gender and sexual lives refers to LGBT Findhorn, perhaps in fighting for visibility lesbian and gay, has not extended this label to other nonnormative sexualities. ${ }^{7}$ However, even with this extended label, the exclusivity would continue to be problematic for some, particularly for those who refuse definitions that seek to refer to social identities rather than 'the soul', and that are seen to effectively segregate sexuality from spirituality.

Creating lesbian and gay space at Findhorn is clearly fraught with difficulties. The heterosexualisation of Findhorn space that lingers within workshop spaces, suggests a need for not only lesbian, gay and bisexual, but also LGBTQI visibility and a greater dialogue with wider the diverse range of LGBTQI politics and cultures. Alternative sexual practices are also tightly regulated by ideologies of privacy and appropriate behaviour. Fears of damaging press reports regarding cults and the vilification of New Religious movements on the grounds of 'immoral' sexualities (Machacek and Wilcox 2003) can be used contextually to understand the regulation of sexualities and sexual practices in Findhorn, as the Foundation is anxious about how it is perceived locally. Its location in rural Scotland replicates another projection: the collapsing of 'rural' with 'conservative' which is also problematic as it reproduces particular stereotypes of ruralities leading from and to tensions that are both ideological and spatial.

\section{Conclusion}

This chapter has shown the difficulties in naming and labelling sexualities where spiritual beliefs reject and contest such divisions, within an organisation that remains predominantly geographically and ideologically apart from cultures of LGBTQI 'communities'. Defining and labelling can be seen as positive in that it allows connections but it also is problematically, and inevitably, exclusionary. In this context such exclusions segregated people from each other, as well as addressing parts of a person rather than the whole person (see also Machacek and Wilcox 2008). However, not naming also means people feel that they are not included and the lingering dominance of heterosexuality can be felt even where space is supposedly 'queered'.

7 This may in part explain the absence of trans and intersex people in this sample as well as their broader invisibility in the Findhorn community. 
We have also seen the place of spirituality in enabling reconciliation between alternative sexualities and spiritual lives, the sense of shared communality, the partial negotiation of divergent sexualities, and the regulation and hierarchisation of sex and sex acts. The chapter examined the tensions between the need to label for visibility and the spiritual desire to integrate, recognise the whole and not delimit by externalities/appearances or social roles. It also complicates lesbian and gay visibility by examining the problematic place of bisexual people. Where lesbian and gay are contested terms, it could be argued that there is little space for 'another' identity, which not only contests presumptions of heterosexualities, but it also challenges lesbian and gay space as a dominant or colonising mode itself (for a similar discussion regarding acceptable gay men, see Chapter 5).

What emerged through the data is the importance of space and place, in particular the place of the rural: Findhorn is located on the 'Celtic fringe' (including Ireland and Wales) and as such is part of a broader historical and geographical imaginary that links rurality with mysticism. However, it is also part of a Protestant, Presbyterian rurality that has judged and rejected such spiritual communities in the past. Although Findhorn clearly has established itself in this rural context, there was evidence that public sexualities are limited by these spaces as well as broader middle class respectabilities. In this context then, earth based spiritualities that are usually understood in terms of a mystified and celebrated rurality, also need to be reconciled with potentially hostile reactions that reflect a specific version of 'rural family life' (see Cloke 2003). This should not be reduced to any necessary or transcendent version of rurality (Gray 2009).

There can be no doubt from our data that Findhorn, particularly, and New Age spiritualities more generally offer nourishment, fulfilment and a way of integrating sexualities and spiritualities that have been segregated and rejected by particularly oppressive forms of Christianity. The tensions articulated by our participants between moving beyond labels and their continued salience are crucial in understanding the relationships between; practicing New Age spirituality and how this is manifest in places such as Findhorn, and enacting/ living alternative, deviant and 'perverse' sexualities (and gender transgressions) including LGB(TQI) identifications. 



\title{
Chapter 8 \\ Virtual Believers: \\ Queer Spiritual Practice Online
}

\author{
Kate O'Riordan ${ }^{1}$ with Heather White
}

If you're already outside the 'norm', the things that keep people asleep, you're in a better place to wake up.

(Jubilant, research participant)

This chapter examines the practices and connections formed around LGBTQI spirituality on social networking sites, blogs, and webpages. It brings into focus the crossings of queer, spiritual and digital. Whereas some of the other case studies in the Queer Spiritual Spaces project examined already affiliated groups, this case study explicitly sought the 'non-aligned spirituality curious', or those who might call themselves 'spiritual but not religious'. Participants for this case study responded to an inquiry, posted on various online sites, for LGBTQI individuals 'interested in spirituality'. This call attracted a wide variety of self-selecting participants with multiple spiritual interests. Confounding our intentions to investigate the 'non-aligned', many research participants listed at least one (and most gave more than one) religious affiliation. This constituency tended to give religious identities in hyphens and slashes: Zen-trained Catholic/ Daoist, Christian/earth-based spiritualities, agnostic/Buddhist/integral, 'complicated interfaithness'. 'The contours of this case study thus evolved through a reciprocal dynamic; as our inquiry shaped the object of study, our participants, in turn, shaped what we were examining.

As Jubliant's epigraph to this chapter suggests, we are interested in modes of attention - modes of wakefulness - as well as questions of exclusion and connection. Our analysis emphasizes the attention to practices and the selective processes that form queer spiritual practice. This emphasis suggests the way in which LGBTQI individuals interested in spirituality do not simply respond to a 'spiritual marketplace' of religious options (Roof 2001) but also interactively

1 Kate supervised Heather and worked with the project team to create this chapter. Her expertise in digital media was invaluable as this case study took its rather unconventional shape.

2 For the complete list of identifications, see appendix. 
negotiated and produced spiritual affinities and practices. Contemporary spirituality has received a share of scholarly criticism, excoriating it as an individualistic self-help ethos tied to a capitalist market (Carrette and King 2005). If linked to these critiques, our study, in engaging with the Internet, potentially adds to the negative framing of the subject matter, as search engines and pointand-click technologies call to mind yet more superficial connotations of the 'religious surfer' (e.g. Larsen 2004). These images of the surfer, and of a cafeteria style, suggest a manufactured plasticity and lack of attention, which contrast with an imagined authenticity and commitment of 'true' religious practice. However, our research findings challenge prevailing depictions of spiritual practice as apolitical, individualized, and consumerist. We argue that queer digital spirituality, in as far as it has a shared sense of feeling, can be markedly careful in its modes of attention. Although these modes of attention may oppose particular religious institutions, they are not entirely privatised, they also weave threads of connection (see also Chapter 7). This case study captures a snapshot of LGBTQI individuals' use of digital technology to navigate religious or spiritual connection and belonging. This navigation involves active selection and attention rather than passive consumption. Participants produce and navigate religious and spiritual meanings and use these in an active resistance to doctrines or formulations that cast homosexuality or gender variance as sinful or incomplete.

Our presentation of this research offers an exploratory map of these productions and navigation processes. Like all explorers, we had already shaped our object of study before we set out, but also and more rewardingly perhaps we have also pursued new contours and found things unexpectedly. The mapping we offer here is on the one hand limited, partial and uneven, but it is also on the other hand rich and diverse, indicating new directions for explorations of this kind.

\section{Terminology and critical context}

\section{Religion and spirituality}

Most of the participants described their practice as 'not religious', and we will follow their preferred term, 'spirituality', as a descriptive category while also attending to the work this term does to delineate cultural markers and boundaries. In these cases the colloquial distinction 'spiritual but not religious' references an imaginary, where 'spirituality' connotes individual conviction and practice, while 'religion' marks institutional or dogmatic forms (see also Chapter 2 for a discussion of the inter-relationship of these terms). This case study is not invested in distinguishing normative meanings for these terms, rather, we attend to their meanings within practitioners' accounts and their uses in boundary 
work around connection, belonging, alienation, and exclusion. In tracking these meanings, our analysis is shaped by scholarship foregrounding 'lived religion' as a mode of everyday practice (Ammerman 2007, Hall 1997, McGuire 2008, Orsi 2002) and we attend to the participants' uses of these terms to name and navigate everyday lived practices that cross and combine various traditions (see also Chapters 5 and 7).

\section{Queer and sexuality}

For this chapter we depart from the book's use of 'LGBTQI' to date. We use 'queer' both as an umbrella term (in place of lesbian, gay, bisexual, trans, queer and intersex), and for its theoretical and imaginative traction. These uses are contradictory and problematic and require some setting out. Queer as an identity is one that few people who are lesbian, gay, intersex or trans actually identify with particularly in the UK context. Many lesbians and gay men actively reject the term - and whilst there is more ownership of it by bisexuals and trans people in the UK, and although it is used more broadly as a political descriptor in the US context - this is by no means always the case. It remains most commonly owned at the site of gender queer activism and in queer theory. In using queer as an umbrella term then it is a research heuristic that (like spirituality) gave us a more open starting point than a delineation such as lesbian or gay or LGBTQI. However, it is primarily its traction as a theoretical tool and its imaginative possibilities as an orientation and a question that interest us here. We were particularly interested to note how participants used it and how it became aligned with both spirituality and the Internet, particularly in the case of Second Life (SL).

\section{Internet}

The Internet may seem more self-explanatory and less of a technical term but as both our site and method we feel it requires some clarification. The Internet is a set of media and communication technologies that entered a global mass market in the mid-1990s, the use of these technologies has proliferated more swiftly and been more thoroughly domesticated than any other digital media and communications technology to date - with the exception of the mobile phone. The Internet has quickly lost its aura of technology and has entered the everyday life worlds of approximately 20 percent of the global population. ${ }^{3}$ This use is highest in North America at around 73 percent, with Australia at 60 percent and Europe at 48 percent. In exploratory research such as this conducted through

3 The figures in this paragraph are all approximate and were all drawn from Internet World Stats at http:/ / www.internetworldstats.com in January 2009. 
what Christine Hine (2000) calls 'virtual ethnography', where the object and method are both the Internet, we would expect our participants to generally match this kind of geopolitical mix. Another defining caveat relates to language. English and Chinese account for just under 50 percent of Internet usage, with English at 28 percent and Chinese at 18 percent. As English-speaking researchers we did not follow up other language groups, nor did we have the resources to undertake translation. So in very broad brush terms the demographic that is drawn on for this chapter we anticipate would have relatively high socioeconomic status in terms of the Global North, and would be Anglophone and based in North America, Australia and Europe (mostly Germany, UK, France) (see appendix).

These broad contextual factors, and the fact that the respondents were active Internet users, are important to register. As active users they were very likely to express satisfaction in relation to Internet use and this is significant in considering the value that respondents placed on their online experiences. Many of them were long-term Internet users which also means that they were likely to have competencies in relation to the use of the technologies and they had not been turned off - or logged off - as the result of difficult experiences. A valuable follow up study would be to try and capture some of the experiences of people who have used the Internet in relation to spiritual practice and who have rejected or moved on from these technologies.

Queer Internet research has focused on community and identity development and formation. This ranges from information gathering, developing resources for resilience against homophobia and transphobia, to coming out and to meeting partners. These kinds of activities have been registered through academic research since the early 1990s (e.g. Campbell 2004, Gray 2009, Munt, Bassett and O'Riordan 2002, O'Riordan and Phillips 2007, Wakeford 1997). The Internet has also figured prominently in media representations of lesbian and gay lives, such as Queer as Folk, The L Word, and the lesbian and gay press such as Diva and G-Scene in the UK. However, like the absence of queer in studies on the connections between religion and the Internet, there is a notable absence of religion and spirituality in queer Internet studies.

\section{Religion and the Internet}

The Anglo-American academic literature on religion and the Internet emerges primarily from the sociology of religion on the one hand and media and cultural studies on the other. In these contexts the Internet is simultaneously understood as set of media and communication technologies, a space, a site of popular culture, a cultural form, and a set of artefacts and practices that underpin every day work and social lives. Each of these understandings is important in our study and the domestication of Internet technologies, and current understandings of 
them as spaces, and as particularly diverse manifestations of popular cultures, are relevant in shaping ideas about how they can be thought of as spiritual.

There is also a body of literature that posits (and critiques) the Internet as inherently spiritual (Foster 2005, Gibson 1984, Herman and Swiss 2000, Wertheim 1999). This is primarily a body of work belonging to fiction and science fiction, but it also extends to journalistic and academic literature so it has several registers. The literary genre of cyberfiction and related science fiction often characterizes the Internet or cyberspace as already having, or generating, a spiritual dimension and spiritual entities. In these fictions entry into cyberspace has a kind of transcendent quality in which the body can be transformed into spirit, or an immanence through which spirits already exist. From the iconic novel of cyberpunk, Neuromancer (1984), to the Hollywood film The Matrix (1999), fictional versions of the Internet are closely tied to these imaginaries of sacred and spiritual space. These formations are mapped by Margaret Wertheim in The Pearly Gates of Cyberspace (1999) and have echoes in the Thomas Herman and Andrew Swiss's (2000) introduction to The World Wide Web and Cultural Theory, which they frame as 'magic, metaphor and power' (2000: 2). Herman and Swiss bring together these fictional tropes and the critical engagement with them by arguing that 'magic for better and for worse pervades the web - both as a material and symbolic practice of identity formation but also as a mythic representation of this transformative capacity' (2002: 3).

Imaginaries of a digital media enchantment also inflect cultural and sociological studies of religious institutions, and practitioners' uses, of the web. Stuart Hoover for example, suggests that digital media appears to be particularly important within a modern day 'quest culture' emerging as declining institutional allegiance leaves individuals to their own devices to construct meaningful rituals and narratives of the self (2006: 37; see also Chapter 7). Research on religion and the Internet has also drawn on the image of 'religious surfers'. This descriptor has been applied to information seeking about religion. It has also been extended to those interested in finding out more about religion but who are noncommittal about religious affiliation, or to those positioned as religious outsiders. These could include religious groups such as Buddhists, Wiccans, or Sikhs who constitute a numerical minority in North America and Western Europe (Hoover 2006, Dawson and Cowan 2004). Despite this interest in surfers and seekers, and the thoughtful analysis of inequality such as minority status and discrimination, researchers on religion and the Internet have made very little reference to queer, lesbian, gay or indeed LGBTQI in their work. However, there are three themes in this literature that focus on the religious dimensions of the Internet that intersect with our study and relate closely to the arguments purported in Chapter 2. These are: the categorisation of spirituality as seeking; the framing of spirituality as popular; and the tension between individualism and community. 
- 'Spiritual seeking' is a wide ranging term taken up in the social study of religion, which frames spiritual practices as ongoing processes of narrating, exploring and shaping the self in relation to faith or belief based communities, individuals and materials. Many sociologists have depicted spiritual seeking, or religious individualism (Weber 1992, Berger 1967, Bellah 1985), as evidence of a decline in institutional religious affiliation in post-Christian Western cultures. However, more recent work (Wuthnow 2000) has challenged these narratives to chart a shift from a spirituality of dwelling to seeking in the spiritual landscapes of the US. Broadly speaking, seeking is also used to frame contemporary understandings of the spiritual subject in relation to the autobiographies of reflexive modernity (Beck, Giddens and Lash 1994, Rose 1999, Wuthnow 2000).

- The bringing together of spiritual seeking and popular culture is an important framing for thinking about spirituality online. The Internet is often constructed as the site of popular culture par excellence, and both the Internet and popular culture have been constructed in connection to the profane and thus set in opposition to religion and spirituality. Some of these tensions are captured neatly in the title of Gordon Lynch's (2007) book, Between the Sacred and the Profane: Researching Religion and Popular Culture which references Emile Durkheim's famous proposition that, 'The division of the world into two comprehensive domains, one sacred, the other profane, is the hallmark of religious thought' (2001[1912]: 36). Lynch's project examines multiple sites of poplar culture. However, it is the anxieties that have been attached to the proliferation of transformative digital technologies through which spirituality is sought, practiced and experienced, that are positioned as the starting points for his study.

- Lynch's work is an important exception to the more general focus on the US and religion. His work on 'new spiritualities' (2008) and on digital technologies (2007) looks primarily at the UK. He aligns new spiritualities with the political left in the $\mathrm{UK}$, and in an important resonance with our research he foregrounds the way such spiritualities co-exist and cut across religious affiliation and alignment. Our participants across the case studies often experienced co-existing and multiple affiliations and negotiated these spatio-temporally, and in doing so became strategic about how best to negotiate an integrated or livable self.

\section{Methodology}

This research took an open-ended approach to identifying and recruiting respondents, who are all self-selecting. Our primary aim was to produce a set of interviews with respondents about their experience of online spiritual practice and to gather fine-grained detail about the meanings attached to spirituality. 
We hoped to analyse sites, materials, and people's responses, to provide an exploratory mapping. This aim was strongly shaped by the overall project plan, which required us to explore 'non-aligned queer spiritual seekers'. We used this imagined subject as another heuristic. As a tool, it opened up a research path and provided us with a way into that which we had yet to explore. In this sense we did not intend to find the subject that we had constructed but we did want to be open to what we might find. In order to approach these aims we identified web sites where such practices were registered and followed people and links from these. The three sites we used as a starting point were MyOutSpirit, Gaia and Facebook, these were all pre-existing sites within which we established a research presence. ${ }^{4}$ We also made contact, through these sites, with participants in Second Life (SL) where several of our interviews took place. ${ }^{5}$

In addition to the sites identified through research and participant recruitment, there are two other sites that are also relevant to this research. These are the Queer Spiritual Spaces project website, and the Second Life Queer Spiritual Spaces project building in SL's New Brighton, which were constructed during the course of the research ${ }^{6}$ (see Chapter 1). The project website has a discussion forum as well as static pages. Likewise the Second Life building acted as a forum for online project meetings and a virtual project presence. These sites are also important because of the way the research project has inserted itself into the object of study - the Internet. When we first started looking for queer spiritual spaces online they were hard to find and had to be carefully sought out mapped and in some ways constructed. Now a search engine inquiry for either our imagined site of research 'Queer Spiritual Spaces', or for our imagined research subject 'non-aligned queer spiritual seeker' brings up the project site as the first hit. This reflexive relationship with the field shapes the valence, intimacy and focus of our findings, but also establishes a visible presence and platform for the kind of engagement we are making here.

4 MyOutSpirit, Gaia, and Facebook are all social networking sites which allow users to produce their own content on the site by creating an online 'profile' to represent themselves and their interests. MyOutSpirit and Gaia are both spirituality portals with MyOutSpirit specifically speaking to individuals who are 'out' in terms of sexuality. Facebook is a generic social networking site (see Lewis et al. 2008). We collected responses from 13 participants in total and these responses included initial surveys, in-depth online interviews and email correspondence over the course of the research.

5 Second Life (SL) is a virtual graphical world created by Linden Labs in 2003 which 3D graphic avatars interact, build spaces, trade objects, skills and currency. It is accessible through the web [http://secondlife.com] and is free at the point of entry. As of January 2009 it had 16 million registered users worldwide (see Boellstorff 2008).

6 We are grateful to the wider SL New Brighton community and especially Bernard Herzog for their hospitality and assistance. 


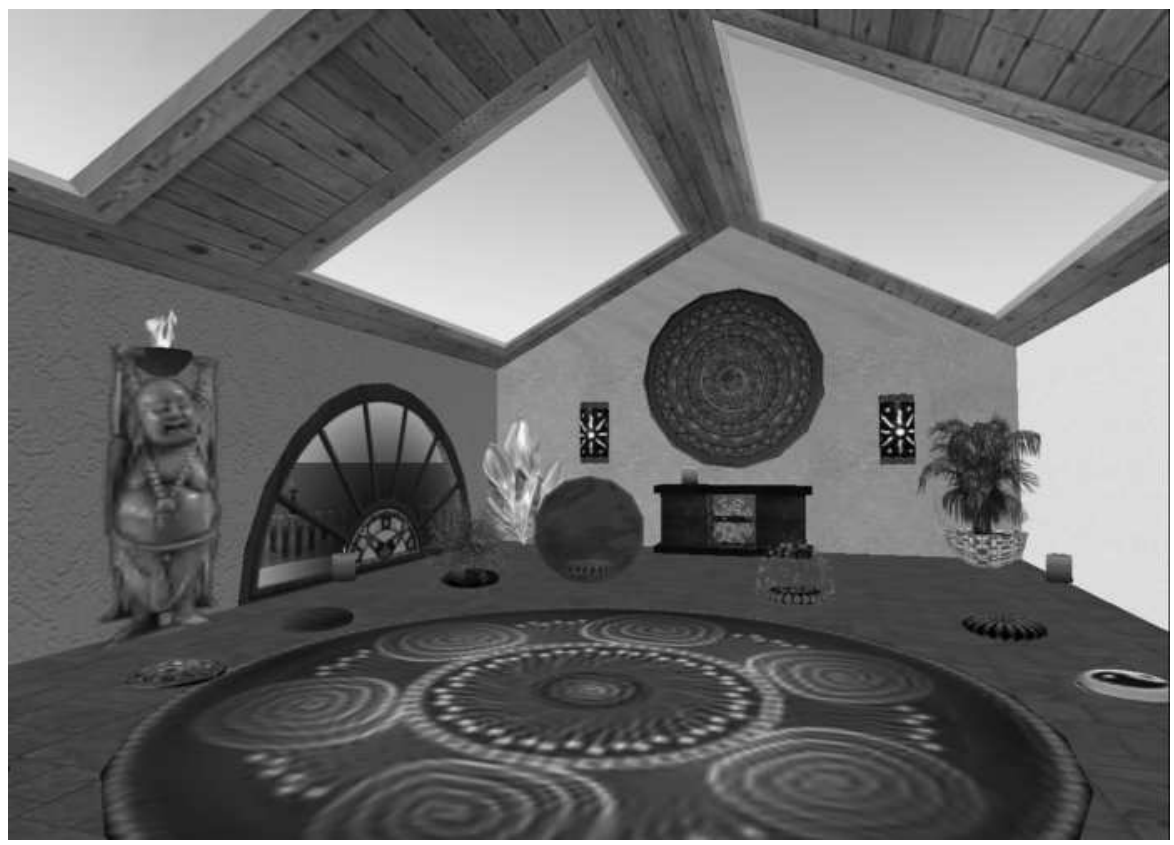

Figure 8.1 The Mediation Room in the Queer Spiritual Spaces Meeting House in Second Life

\section{Queer spiritual identities, spiritual seeking and digital publics}

\section{Envisioning spirituality}

Spirituality, for most of our research participants, took up two interconnected and sometimes contradictory meanings. Many of them spoke about 'the spiritual' as a place of mystical transcendence, or as an other-worldly encounter with the divine, on the one hand. This implied that spirituality represented an extra-ordinary encounter or space, a time or place outside of everyday habit or custom. On the other hand, alternatively and often simultaneously, many of our interviewees positioned 'the spiritual' as immanent from ordinary everyday practices, as something inextricable from the habits of everyday life (see also Chapter 4, 5 and 7). In connecting these two meanings, our respondents articulated a vision of spirituality that we could call ordinary transcendence. Thus, defining a place for spiritual connection in the habits and practices of lived experience, as both transcendent and immanent.

To begin thinking about this ordinary transcendence in this chapter and how it connects mysticism and habit, transcendence and routine, we offer the following group discussion between the primary researcher (Heather White) 


\section{VIRTUAL BELIEVERS: QUEER SPIRITUAL PRACTICE ONLINE}

and two of our participants, Jublilant and Rivka, in Second Life (SL) in avatar form. ${ }^{7}$ Rivka is intersexed and was using a 'boi-form' SL avatar, and Jublilant is a transwoman, here using a transgender animal avatar. This discussion emerged out of our question as to whether the participants had differing conceptions of religion and spirituality. The exchange builds upon a metaphor, which likens the relationship between religion and spirituality to that between a menu and a meal. In this extract Rivka is quoting from a previous exchange to introduce the menu/meal distinction:

Jubilant: I think there is a difference between a spiritual practice and a religious practice.

Rivka: ok, yes

Jubilant: they CAN overlap

Jubilant: but often don't

Rhombus Gatter (Heather's avatar name): what is that difference for you? ${ }^{8}$

Jubilant: I mean if the rosary actually connects you to the divine mystery then it's both

Rivka: I quote for you from a joint meditation:

B: I had lots of steller examples.

B: Negative examples.

B: *Stellar, even.

R: $y a h$.

B: Of seeing mystic people confuse the menu and the meal.

7 References to both Jublilant and Rivka use gender-free pronouns 'hir' and 'ze' throughout.

8 SL doesn't allow the use of actual names - there is a predefined list of surnames that must be selected although the first name is created by the user. Heather used the name Rhombus Gatter throughout the SL interviews and this is replicated here. For emails and other communications Heather is used in this chapter. 


\section{QUEER SPIRITUAL SPACES}

$\mathrm{R}$ : awnww.

B: and get obsessed with the language rather than the ...

$B: * i t^{*}$

R: nodnods.

R: ceci n'est pas une pipe B smokes it anyway.

$<$ snip $>$

Jubilant: the connection to the divine is the difference [between religion and spirituality]

Jublilant: as I see it

Rivka: I'd say the focus is different.

Rivka: on ritual, or on experience.

Rhombus Gatter: The connection/experience is the meal; the habits are the menu?

Rivka: yes.

Jublilant nods.

Jublilant: and many people use the plates and forks but don't eat anything.

Rivka laughs.

Rhombus Gatter: I like the eating analogies :)

Rivka: they're getting stretched but I'm enjoying it toooo.

Rivka: nourishment.

Rivka goes wild with the metaphor.

Rivka: not diet. 


\section{VIRTUAL BELIEVERS: QUEER SPIRITUAL PRACTICE ONLINE}

Jublilant: metaphors are for stretching.

Rhombus Gatter: ironic, though, because food consumption is a very important spiritual discipline in many traditions.

Rivka nods.

Jublilant: I personally think all religion is metaphor ... it has to be because we can't actually describe what we're talking about.

Rivka passes the matzo and the tofu.

$[\ldots]$

Rhombus Gatter: lol! ${ }^{9}$

Rhombus Gatter takes a bite.

Rivka grins.

Rivka: be nourished.

Rhombus Gatter smacks his lips.

Rivka takes a photo for posterity lol

Jublilant: so to describe the divine as food is the same as describing the divine as Vishnu or Jesus or the Dao.

In playing with the metaphor of food and eating, this exchange borrows from the most ordinary and necessary of everyday habits to name and describe something extraordinary. Here the connection to or experience of the divine is immanent to food. Thus, even as the discussion distinguishes 'menu' as habit, or practice, from 'meal' as connection or experience, the metaphor also points to the way in which these two categories are already linked in experiences of practice, or the rituals of everyday life. As we note in the exchange, coming together around food is a highly ritualised practice and is central to most religious traditions in some way. Quite a number of the participants' comments, in this case study, connected these two meanings - the everyday and the divine - in different ways. Christian, a gay man and author and founder of the organisation Revolutionary

9 'lol' stands in for 'laughs out loud'. 


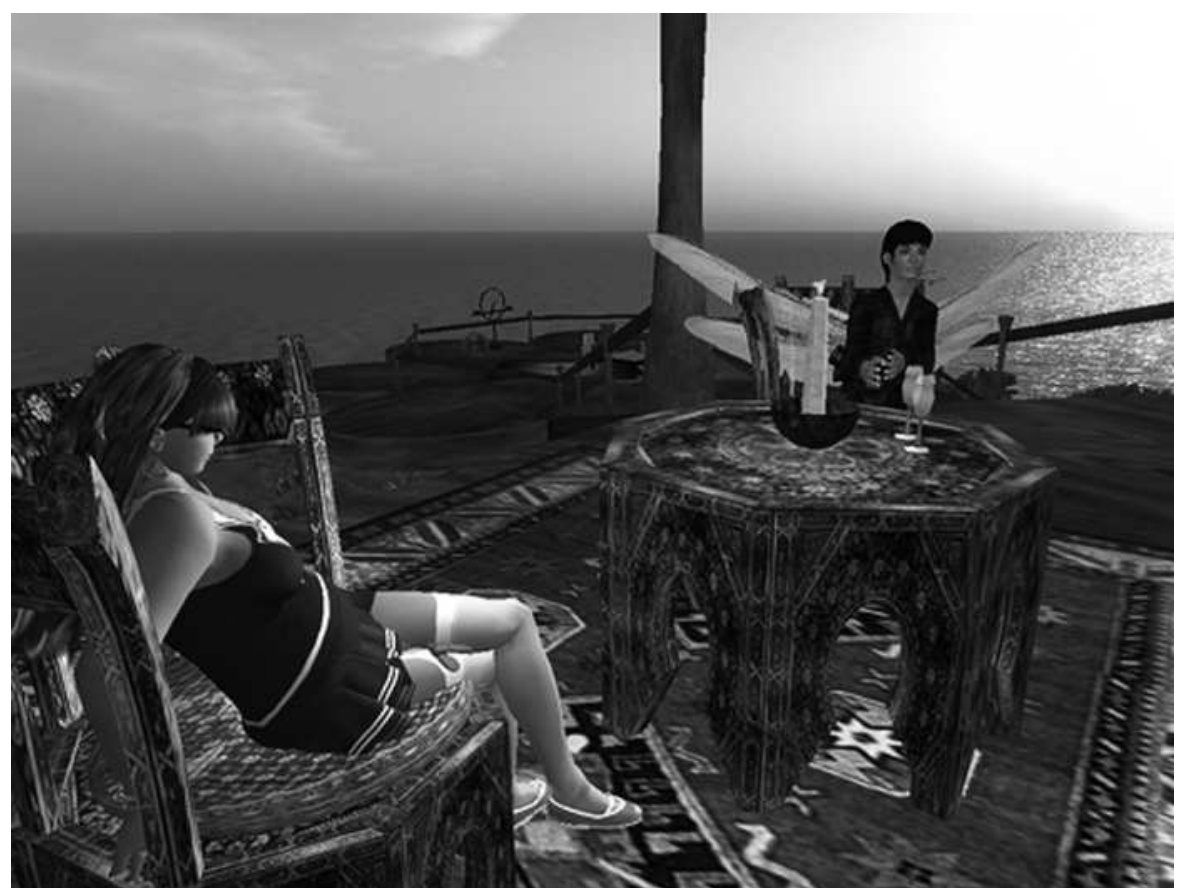

\section{Figure 8.2 Second Life research interview}

Wisdom, ${ }^{10}$ offered this reflection, which connects to a more generalised (rather than specific) sense of an everyday embodied personal life:

Christian: To me the role of religion, when religions are fulfilling their purpose, is when they are in some ways supporting their petitioners to have a direct and very personal and individual connection to the divine, however you relate to that. I think that all the other stuff that we do - you know, the ritual, the practices, and the religious calendars of events, and the music, the sense of community - those are all great things - and the sense of history, the sense of tradition - all great things that serve as reminders to the connection and doing what we need to do to maintain that connection open and going and viable. But that's what they are to me - not the religion, or that the spirituality, but vehicles to and supportive to what is real - the connection, the remembrance of ultimately what is our source and our nature - who and what we are.

10 Revolutionary Wisdom is an organisation described as 'dedicated to catalyzing a revolution of the human spirit for the evolution of all humanity' at www. revolutionarywisdom.us. 


\section{VIRTUAL BELIEVERS: QUEER SPIRITUAL PRACTICE ONLINE}

Heather: So could you say more - connected - connected to who we are? Connected to what?

Christian: That's exactly what. If I were to use the word abominate, to me what is abominable is how many many religions have externalized the sacred. How much further could we have put the sacred? Where is heaven anyway? So, as a result of that, everything that was considered spiritual is kind of esoteric and out there and away from us and away from the earth and certainly away from the body that was made wrong and less than and something to be conquered and controlled and subjugated and demonized, especially in the area of sexuality. And so everything that was physical was demonized. ... And so to me, to then put up a system of belief that just puts the divine way away from us as something you don't have access to and don't have access until you die - it's abominable. It's either a misunderstanding and a misinterpretation, or it's an intentional strategy for controlling people.

Christian, in ways similar to the conversation with Rivka and Jublilant, distinguishes between container and content, vehicle and destination by distinguishing between religions as 'reminders of connection to the divine' rather than the connection itself. At the same time, he also emphasizes that an experience of the sacred needs to be located within everyday embodied experience, rather than in 'heaven' or any other immaterial site of special access.

Several of the interviewees gave a picture of what a view of embodied ordinary transcendence might look like in a more concrete form. One participant, a gay man named Jari responded to one of the research questions 'where is spirituality?' by stating that it was everywhere. In his words, 'all is part of God to me'. As a way of clarifying, Heather asked what his spiritual practice looked like, and he responded by posting a schedule in his email:

As for my practice.

The core modules:

Body: 45 min work out at the gym 3x per week (weights and running on treadmill), healthy high protein low fat, low sodium diet as per nutritionist and my kidney doctor + supplements.

Mind: study of subjects related to the integral framework ... at least 1 hour on most days when I'm alone, recently I begun to study the Voice Dialogue therapy (taking on multiple perspectives). 
Spirit: 10 min meditation daily, 40 min on Wednesday with the group, my own form compassionate exchange during my daily walks with the dog as well as contemplations on God from multiple perspectives, self inquiry ... this is something that I do throughout the day and this seems to be coming the focus of my practice.

Shadow: a customized form of the 321 Process throughout the day as I'm with friends and others. Lately I'm also going through weekly 11 /hour of psychotherapy with voice Dialogue therapist.

Work: on Tuesdays I work/volunteer as a receptionist at the Hassle Free Clinic http:/ / www.hasslefreeclinic.org.

Sex: 1 per week :-) ... currently reading a book on Sexual-emotional Yoga by Adi $\mathrm{Da}$ (one of Wilber's teachers).

Relationships, Emotions: this is my growing edge. Right now I don't have a partner, my focus is to deepen my friendships.

When Heather responded by lightly teasing about the 'discipline' of this list, which has elements of self-parody, Jari responded:

Jari: I re-read my message again and also had a chuckle. It does look more like a black and white shopping list that a traditional spiritual practice :-) I was just trying to be brief. Integral life practice IS supposed to be a way of life though. Workouts at the gym and walks with the dog are part of it.

Thus, as Jari understands spirituality through the practice identified as Integral Life Practice, walking the dog is as much a part of contemplation on God as is the more conventional practice of meditation. Spiritual connection is not confined to rituals and practices, like meditation, that are conventionally identified as spiritual, but is also present in other routine habits, from walking the dog to going to the gym, and in the modes of active attention in engaging with Internet technologies.

One of the participants, a queer identified transman named Zander, eschewed both religious and spiritual as terms in favour of what he described as a 'practical/lived approach to [his] studies and practice'. For Zander, the term spiritual, like the term religious, represented an alienated sphere of 'beliefs, ideas, concepts and notions one must subscribe to or avoid/question'. Rather than a removed conception of spirituality, Zander described his practices, as a 'path of personal integration and striving for authenticity' that builds upon principles articulated by Vietnamese Buddhist monk Thich Nhat Hahn: 
Zander: I pay attention to life as it is happening as often as I am able to be present: I don't ride the bus with headphones in my ears, I walk at a pace where I can take my surroundings in rather than hustling to 'get somewhere', I am intentional about making time for fostering stronger connections with my close friends, my wife and I engage in regular social and romantic dates with each other, when I am at work I am thinking about work and do work related things, when I am at home I am thinking about and doing home related things, etc. ...

Like Jari, Zander's ideals for attention and intentional engagement are integrated thoroughly into the everyday in a way that includes the routines of commuting to work, spending time with a partner, and perhaps even housecleaning.

These participants' understanding of, and mode of attention to, spirituality and virtuality builds on a twofold critique of religion as an alienated space, and as a routinised practice that has lost its meaning for people. The sense of spirituality that they attempt to create, responds to this critique in two ways, it emphasises the immanence of spiritual practice, and it infuses repeated everyday habits with meaning. This involves taking up even the most ordinary chores as a path to transcendence, whether that path is imagined as connection to the divine, or connection to the divine within as the authentic self. The practices of these participants in this case study reconfigure boundaries between sacred and profane spheres and embrace everyday habits and routines infused with a renewed awareness of what might be called the 'holy ordinary' (Brent 2006). Although this term is also associated with Buddhist teachings, the term has been used in recent Quaker writings (Brent 2006), and is related to contemporary progressive spirituality (Lynch 2007), it also has a long historical trajectory through multiple spiritual traditions. However, Zander's use of terms such as 'attention', 'intentional', 'engagement', and Jari's use of 'therapy' also highlights the contemporary intersections between spiritual and therapeutic models of the self (Rose 1999, Hoover 2006). Mindfulness of this kind is a central element in both therapeutic discourses such as Cognitive Behavioural Therapy (CBT), for example, and those of 'lived religion' (Hall 1997). Queer spiritual Internet practices, in these encounters, bring together the transcendent and immanent through an engaged attention to the intersections of mediation, spatial and temporal practice, and identity.

\section{Multiple spiritual alignments}

The following section adds to our earlier discussion of spiritual seeking as both a complex current trend and a longstanding tradition, which requires interrogation. Our use of the search term 'non-aligned spiritually curious' invited a consideration of the complex kinds of alignments created by the 
participants in this research. Does online queer spiritual practice fit with the seeker framework (Wuthnow 2000) as the web surfer metaphor would seem to suggest? Here we examine the concrete meanings and practices attached to the spiritual connections created by study participants, whose multiple alignments defy the normative categories given by many demographic surveys of religion. We turn to the various ways in which study participants brought together their diffuse and shifting alliances to various spiritual traditions and practices.

Heather's exchange with one participant led to an in-depth discussion of survey data on religion. It began when Jari, asked a question about demographic data on LGBTQI individuals and religious practice. Heather answered by indicating that there is a lack of data in this area. She then solicited his response to a demographic survey on religion from the Pew Research Foundation:

Heather: There isn't any reliable data about religious/spiritual affiliation in GLBT populations as a whole, because survey data on religion hasn't asked about sexual orientation or trans identity. (at least not in the US, but I don't think in Canada either). Surveys of religious identity are also problematic, because they usually don't register the complex religious interests of people who don't easily identify with any one religious tradition.

In this email to Jari, we included a link to the US Religious Landscape Survey, a study conducted by the Pew Forum on Religious and Spiritual Life, which reports the 'religious makeup, religious beliefs and practices as well as social and political attitudes of the American public.' ${ }^{11}$ Heather asked his opinion on the religious identifications included in the survey and also asked which identification he would pick himself.

Jari: [T] he Pew Research is interesting, I suppose if I had to pick one I would identify myself as Zen Buddhist, Zen gave me the gift of regular practice. Lately I consider myself more part of the mystical contemplative traditions. For me it is more about direct experience of reality, regardless of the actual belief system.

Jari, even though he would have selected a single religious affiliation, also perceived his practice to be more expansive, 'about the direct experience of reality' over a single 'belief system'. Over the course of the exchange, Jari spoke about the range of the various individuals, organisations and practices that were part of his spiritual life, which included not only Zen Buddhism, but also Integral Life Practice, Father Thomas Keating's (a Trappist monk) writing about contemplative prayer (Keating, 1986), the interfaith movement, and a

11 The Pew Forum on Religious Life is part of the Pew Charitable Trusts - we used the results of the 2008 surveys here: http:/ / religions.pewforum.org. 
gay men's study group. While this list appears to evidence a diffuse eclecticism, Jari's various interests were motivated by a different kind of organising principle which was in his words about a 'direct experience of reality' rather than a formal religious allegiance.

Jari's distinction between 'direct experience' (something emotive and personal) and 'belief system' (something cognitive and institutional) was a distinction made by many of the people Heather interviewed. This prioritisation of personal experience and the affective (how one feels) connected both the 'aligned' (those who identified with at least one religious tradition) and the 'unaligned' (those who claimed no membership status). Indeed, in many cases, the distinction of aligned/non-aligned was irrelevant in distinguishing the ways in which individuals engaged a particular religious tradition. To illustrate this point, we compare the continued discussion with Jari to the comments by Antonia, a transwoman who participated in a forum we organized on Facebook. Both individuals had active interest in Roman Catholicism, but Antonia identified as Catholic, while Jari did not. Jari's interest was in the discipline of contemplative prayer and he sent an email link to a video of Father Thomas Keating as a response to our questions about the practice. When Heather asked Jari what it meant to participate in centring prayer from outside a monastic Catholic lifestyle, Jari explained:

Jari: I'm not heading to be trappist monk :-) Although I do believe my contemplative practice is very similar to Father Keating.

The point, for Jari, was not following prescribed Catholic traditions, but achieving the outcome brought by centring prayer:

Jari: The question becomes not religious vs spiritual but rather what is the most efficient way to overcome the separation and experience the unity with the divine. For me contemplative prayer (by prayer I also mean meditation) is the most efficient spiritual practice ...

For Jari contemplative prayer bears a kinship with other spiritual practices (particularly Zen meditation) and transcends any singular religious affiliation. The important function of these practices is to bring an individually sought unity with God, an orientation to religious practice that deliberately eschews the singular identification of religious affiliation assumed by many demographic surveys. ${ }^{12}$

12 Jari also commented on the difference between spiritual practice and church attendance: 'The survey gives only a hint about the depth of people's practice. That, to me, is not as much to do with church attendance. It has more to do with spiritual practice.' 
Antonia, who did singularly identify as Catholic, also spoke of a connection to particular Catholic practices that were deeply personal, and she retained a suspicion of most institutional expressions of Catholic faith. She offered the following thoughts about her attachment to Catholicism in response to a question about how she used the Internet:

Antonia: As someone with an essentially Catholic spirituality, the Internet has also given me the ability to investigate different devotions and organizations that would clearly reject me if it were a person-to-person meeting. I find Sedevacantist Catholicism (a movement that rejects the reforms of the Second Vatican Council in favor of the Traditional Latin Mass and Sacramental forms) very interesting. However, there always seems to be a right-wing slant to most of these churches (though not necessarily with all. In fact some are LGBT inclusive). With the Internet, it is possible to glean whatever information I can use in my personal path to Jesus and Mary without fear of reprimand.

Jari and Antonia's different kinds of connection to Catholicism both prioritize the individual. In Jari's terms, this is a 'unity with the divine' and for Antonia a 'personal path to Jesus and Mary'. Here, Antonia explicitly relies on the Internet to select and negotiate a relationship to groups that may be (but are not necessarily) homophobic. She uses the Internet to create a personal journey which can operate in relation to Catholic beliefs but route around institutional censorship. This resonates in some ways with the kind of taxonomies of religious surfers and outsiders as defined by Larsen (2004) and by the Pew Report on the Internet in American Life, but it also complicates these categories and demonstrates the specific negotiation of queer spirituality that is missed by this kind of survey (in ways that question the quantification proposed in Chapter 2). For both Jari and Antonia particular practices may be sought and experienced in spiritually enriching ways that are separable from the question of alignment or non-alignment to institutional forms of the church, or a systematic articulation of Christian beliefs.

Our research shows that far from seeing spirituality as a 'cafeteria-style' 'quick fix', which can be seen as opposed to the stricter discipline of religion, the research participants saw their individual spiritual practices as disciplines. Whether aligned or non-aligned, our respondents discussed working at their practices both physically and intellectually, and saw this as integral to the spiritual value, and part of the intersection between queer and spiritual:

Rivka: I like my practices considered, critiqued, rebaked.

Rivka: And often queer folks do this because we've been excluded from traditional religious groups. 
Several research participants directly addressed the critique of cafeteria-style spirituality directly, for example Christian argued;

Christian: I know a lot of people, including myself, are very serious about their spiritual practice. So to call it a cafeteria approach kind of denigrates that.

Critics who position spirituality in a class based hierarchy of fast food, which is opposed to the wholesome/holistic organic nutrition of religion, use the language of fast consumption. Christian's response to this debate was to frame the ways in which he drew from multiple spiritual traditions differently, although the food metaphor remains. Of all of the participants in the research Christian referenced the greatest number of spiritual traditions that informed his practice:

Christian: I'm fed by many of the spiritual traditions - my mediation practice is more Buddhist as opposed to more Hindu, but yet to me, Buddhism is missing the passion, the longing the personal connection, so I like the Hindu chanting and the Hindu pantheon. And the connection with the Christ, and I love the Native American philosophies, and that they don't have the schism that most of the world religions, and particularly those in the West, have between the physical and the spiritual. And I like the New Thought religions. So I honor them all and I also challenge them all.

Christian and many of the participants describe their spiritual practice in terms that evoke connection across, and make permeable, the boundaries between religious and spiritual traditions. Here he both 'honours' and 'challenges' the traditions that he draws from. This boundary work is both individual and collective. The individual participant does the work of making these connections, but it is also facilitated by organisations (e.g. Revolutionary Wisdom) that intentionally espouse a spiritual cosmopolitanism. As several of the narratives in this section already suggest, this traffic between and within various spiritual practices is constituted through the digital circuits of the Internet and the networked structures and linking practices of sites such as Gaia and MyOutSpirit facilitate these kinds of approaches.

\section{Spirituality and queer: Online and offline}

Some of the greatest fears and fascinations attached to the Internet are around the possibilities it offers for disassociative behaviour. The fear that anonymity allows people to act in ways that they would not act around people who knew their actual identities is manifested in warnings against the license the Internet 
gives to harass and intimidate, to participate in illicit sex, or to behave and act out a fantasy persona.

When we began this study, we were interested in the ways in which online and the offline relationships and habits connected for the participants and how the meanings attached to Internet technologies played out in their everyday life experiences. For many of the people interviewed, online social connections extended from previously formed offline relationships. However, this statement tells only part of the story, because it was also true that all of the participants formed at least one extended relationship, the one with their interviewer Heather White, which was initiated and sustained completely online. Many of the participants also spoke in detailed ways about online connections to people and to information posted on blogs or websites that opened up new avenues for understanding and expressing both spirituality and LGBTQI identity. Internet connections provided a space for exploration, and one distinct from the interactions of their offline social worlds. Some people spoke of important life changes that began with a simple online inquiry. For some, these changes involved coming out, beginning the transition to another gender, leaving a faith, or participating in a new spiritual path. The anonymity of the Internet, in some of its forms, allowed for experiences in online spaces that opened up changes in offline practices and identities.

When we asked respondents about how their use of the Internet connected to their spirituality, the most common response was an unsurprising one: the Internet provided a quick, accessible research tool. For some, however, Internet research also allowed important spiritual exploration and was a space of spiritual practice, facilitating a mode of attention that does not resonate with the surfer metaphor, nor entirely with the seeker. For Christopher, a gay man and Pagan practitioner, the Internet provided a way to pursue a new spiritual path:

Christopher: I think that online is great for doing research, I am researching a new spiritual path tonight that I was called to two weeks ago but I have to take the basics found online and then carve them out in my own life.

Heather: Are there limit[s], though, to how far a spiritual search can go online?

Christopher: I think so. You can learn all about a particular spiritual path online but if you don't do anything with all of the knowledge that you've gathered, you are short selling yourself and the need to feed yourself spiritually.

Heather: they have to be integrated into everyday - offline! - practice.

Christopher: I think so. I couldn't read, feverishly take notes, commit things to memory and then not practice them, otherwise, for me, what would be the point? 
Even as Heather's comments are cautionary about the possibilities of online research, Christopher speaks of an intense relationship with information found on the Internet. The practices of reading, taking notes and memorising information about a new spiritual practice is a precursor to carving that material into a lived spiritual path, in a process that is both felt and material.

For a number of the participants, the Internet as an information resource was particularly important for connecting spirituality with LGBTQI identities. One gay man replied simply to query about his use of the Internet: 'if it wasn't for the Internet, I would still be pretending to be straight and miserable and dying in the closet.' This interviewee had come from a conservative, anti-gay Christian background, and the Internet helped get him in touch with affirming Christian communities. The comments by Antonia the transwoman who was interested in Sedevacantist Catholicism also alludes to the ways that the use of the Internet facilitated a connection between spiritual exploration and queerness. Antonia, found that the Internet allowed low-risk access to communities and as she said above, she gleans information to use in her personal path:

Antonia: [T] he Internet has given me the ability to investigate different devotions and organizations that would clearly reject me if it were a person-to-person meeting.

Ironically perhaps, the anonymity of an online spiritual search provided an accessible exit away from homophobic and transphobic religious traditions. At the same time it also allowed a back-door access for poaching devotional practices in hostile territory.

This kind of access worked both ways however, and the Internet also helped people to rework their experiences of imagined gay norms, or a perceived homonormativity (Duggan 2002; see also Chapters 1, 2 and 5). Although some participants affirmed queerness, being gay, and sexuality as inherently spiritual, echoing Althaus-Reid's claim that 'gay bars are full of theologians' (2003: 2), others found specific experiences of gay community lacking in, or even antithetical to a spiritual dimension. In relation to this kind of experience, one of the participants replied:

Tony: I find that it's almost impossible to converse with the gay community without there being constant sexual undertones. 'Groups' that are formed that involve gay men often become a meat market for dating rather than platonic in nature. My difficulty in this respect stems from my (very un-gay) attitudes that it's possible, and desirable, to find other gay men that aren't seeking some alternative motive for getting together. 
Although his narrative separates sex 'alternative motives', and spirituality 'platonic', Tony also pointed to the rich overlaps in understandings of spirituality as at once individual, and shared. Although Tony's spirituality is not sexual here, it is relational, connecting interiority with community and an external presence. Tony defined spirituality as, 'emotional impacts, mental, out of body, deeply individual, fulfilment'. At the same time Tony was also seeking connection and a shared experience of spirituality:

Tony: Spirituality, to me anyway, is a deeply bonding experience when it can be shared with another person on a platonic level. Of course, other than my desire to find some personal peace, I hope to find the ability to share that personal peace with others.

For Tony and for many of the people we interviewed, online spiritual practices were not an alternative or a substitute for other forms of co-presence, including attending religious services. Christopher, whose comments about his online exploration of a new spiritual path online are quoted at the beginning of this section, initiated his search after attending a gay men's Pagan retreat. Many others, including Antonia, quoted in the paragraph above, maintained a connection to some kind of face-to-face spiritual fellowship.

Many web pages facilitate an anonymous web surfer identity. However, other Internet forms require investment in and attention to some kind of online profile and identity construction or maintenance and Second Life is particularly demanding in this regard. One of the most extensive responses about online and offline interconnections came from a discussion of Second Life and Torah study. Rivka attends Torah study in Second Life as well as at a local synagogue. Rivka is intersexed, and identifies with Reconstructionist Judaism and Tauism [sic] as hir spiritual practice. The following exchange is about spiritual practice in Second Life (SL) and in Real Life (RL):

Rhombus Gatter: is spiritual practice different in sl than in rl?

Rhombus Gatter: torah study, for example.

Rivka: oh

Rivka: torah study!

Rivka: it's really good here :P

Rhombus Gatter: good? 


\section{VIRTUAL BELIEVERS: QUEER SPIRITUAL PRACTICE ONLINE}

Rivka: yes.

Rhombus Gatter: how good?

Rivka: because I get to interact with people from different communities.

Rivka: many of them highly trained.

Rivka: rabbis among them of course, but lots of educated people from different backgrounds.

Rivka: and everyone has read the parsha and is excited.

Rivka: nobody's there just to look good in the eyes of their neighbors or parents.

Rivka: everyone's really into it :P

Rhombus Gatter nods

Rivka: and the hierarchies that are common in RL are missing.

Rivka: the deference to the older or more male or more rich or better family or whatever.

Rivka: the rabbi at the synagogue is female in both worlds (kk jubilant).

Rhombus Gatter: all there b/c they want to be there; nobody's impressed just bc they show up.

Rivka: yeah.

Rivka: there's a lot of flux in the crowd.

Rivka: there are some core people, and they notice when somebody is missing.

Rhombus Gatter: do you also do torah study in rl?

Rivka: yeah.

Rivka: I did an adult bat/(r) mitzvah. 


\section{QUEER SPIRITUAL SPACES}

Rivka: just a few years ago.

Rivka: and I spent a lot of time studying before.

Rivka: and did some in chat rooms and the like online too.

Rivka: and this is the most rich and wideranging discussion.

Rivka: I mean, I love my RL synagogue.

Rhombus Gatter: was this a tradition your inherited or one you chose (or something else)?

Rivka: I'm jewish by birth, but reconstructionist by choice.

Rhombus Gatter nods

Rivka: group discussions here can be chaos.

Rivka: but the torah study chaos is really rarefied lol.

Rivka describes Torah study in Second Life as a gathering that appears free of many of the social expectations and hierarchies that implicitly structure participation in a RL synagogue. This experience indicated that online participation can have a levelling or democratising effect, because it doesn't necessarily make visible or privilege aspects of social location - gender, class, or family connection - that might attract either deferential treatment or discrimination in RL settings. This reworks the hierarchies that operate in practices of Torah interpretation and mediation.

Second Life itself requires a different set of competencies, which introduce expectations and hierarchies structuring participation, as well as demanding attention. Thus, the online setting introduces new contingencies, and 'learning curves' such as the participant's ability to manage chat at the same time as SL emoting or gesturing. These techniques are not transparent and require different kinds of labour and expectations which Rivka foregrounds explicitly in an earlier exchange:

Rivka smiles down at Jubilant

Jublilant: Nice to meet you Rhombus

Rhombus Gatter: you too Jubilant 


\section{VIRTUAL BELIEVERS: QUEER SPIRITUAL PRACTICE ONLINE}

Rivka: poor rhombus is just learning how to cam and walk about reliably

Rivka: but picking it up fast

Rhombus Gatter: I still haven't mastered smiling either

Rivka: awww

Jublilant: yesh, there's quite a learning curve here

Rivka: to emote

Rhombus Gatter: other than this: :)

Jublilant: but VERY worth it

Rivka: type '/me blahblahs'

Rhombus Gatter: ‘/me smiles’

Rivka: no quotes, sorry

Rhombus Gatter: lol!

Rivka: I had to use them so it wouldn't just smile for me

Rhombus Gatter: me smiles

Rivka: you need the slash though :P

Rhombus Gatter laughs

Rivka: yay!

Rivka grins

Jublilant: a lesson learned

Jublilant: :)

Rhombus Gatter: me/leaps for joy 
Rhombus Gatter: whoops

Rivka: it took me two months to learn how to emote

Rivka: so you're ahead of me :)

Rhombus Gatter nods

Rivka: there ya go

Rivka: nodded like a pro

This exchange points to some of the disciplinary aspects of using Internet technologies. Second Life requires time, attention and a disposition towards use that respondents will have already participated in. However, the exclusions that might operate in learning about Second Life are of a different order to the kind of exclusions and hierarchies that operate in groups of religious practice. Rivka was one of many individuals in this case study who experienced digital technology as a medium that facilitated a kind of freedom from confining social expectations and prejudices about identity, and thus allowed expression or exploration of a stigmatized part of the self.

Rivka and another respondent, Jubilant had much to say about the way in which their experience of Second Life had facilitated their exploration of intersex and transgender experience and embodiment. The creation and use of an avatar, and the experience of the digital texture of SL, was significant for participants. Jubilant spoke to Heather at length about how creating and participating as a female avatar brought her in touch with her cross gender embodiment (see Figure 8.3). Although Jubilant has not transitioned physically, identifying with her female embodiment in SL through her avatar has supported her efforts to come out as transgender offline. Jubilant also spoke of her online exploration of cross gender identification as a spiritual coming out process. Jubilant the avatar on Second Life, facilitated both a transgender and a spiritual coming out process:

Jubilant: [T]the discovery/creation of Jubilant was a major step in coming out as trans. As mentioned too, I have found community through SL. As Jubilant, I have been exploring other online communities, such as the Trannyweb online community. There was a thread on that site that had spirituality in the title. Reading it, it seemed to me to be a debate between Bible dependant Christians and atheists. I wrote an embryonic version of my first blog post for the thread. 
One of Jubilant's friends encouraged her to expand that initial post, and she brought an expanded version of her writing to a 'process group' (a spiritually grounded therapy group), where she came out as trans to the members of her group. This written narrative, Jubilant called it a 'spiritual manifesto', became the first entry in a regular blog about her transition. At the top of the blog, Jubilant wrote, 'God only knows where this will lead me and maybe even Zie doesn't??!?!' This phrase captures a dual uncertainty: Jubilant is uncertain about the nature of God (is God omniscient or gendered), and the God of Jubilant's understanding of Hirself as transgender may also be finding Hir tentative way forward. Jubilant's story provides another example of overlapping online and offline worlds, as it also suggests the ways in which online connections provide a space for exploring and expressing a part of the self that feels difficult to perform in 'real life'. ${ }^{13}$

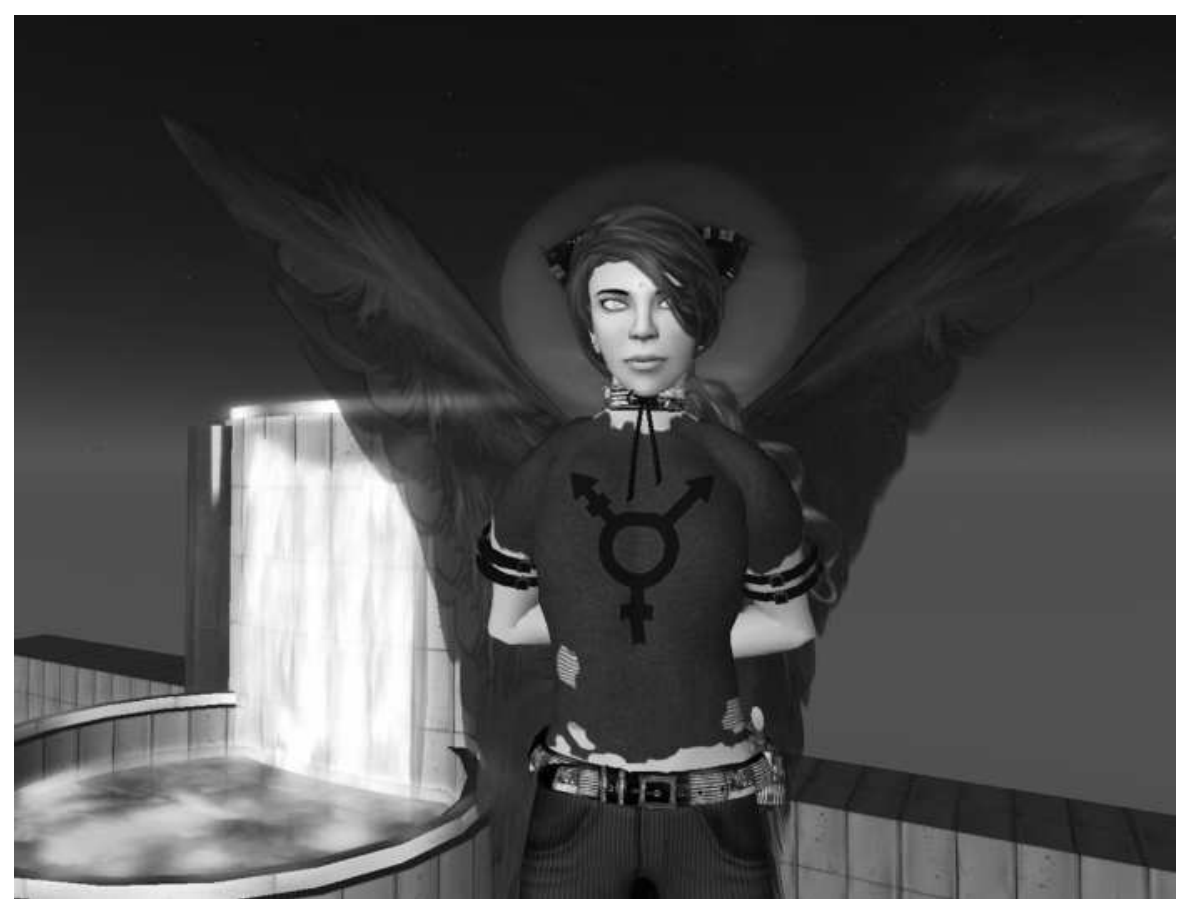

Figure 8.3 Second Life image of Jubilant

13 Another reading of this material suggests ways in which interviewees' participation in SL serves to structure 'real life' as an alternative imaginary to the virtual. 
For many of the respondents in this case study, and notably those who identified as trans (as well as the one intersexed person), the Internet was important because it allowed them access to a digital embodiment of a gender that might appear different from their physical embodiment. Digital embodiment here is both the avatar embodiment of Second Life, as well as the textual embodiments of blogs, discussion groups, and chat rooms, where participants also choose names and perform a textually embodied gender. As Jubilant explained in relation to her blog, 'writing about it [my transition] helps me understand it as I go along'. When Heather asked what that felt like, she responded: 'To actually articulate what it feels like for me to dance in a long skirt, to have a place where I can talk about it, potentially to generate dialogue about it, it's as if I have been given wings to fly with'. The wings that allow these metaphorical flights are created by words - to 'articulate', to 'talk about it', and to 'generate dialogue'. If the Internet is a place when one can fly it is not only because of virtual imaging, but also because subjects feel that it affords them a reflexive articulation or storying of identity in textual as well as audio-visual terms. The rich texture of the embodied digitality of these practices points to modes of collectivity, connection, and reciprocity. These textures trouble the binary that is evoked by studies of spirituality, which might situate spiritual seeking as an individual quest, in opposition to the more communal modes of collective spiritual practice. Such a view of individualistic spiritual seeking might position online practices as an expression of these trends at their most individual and privatised. Spirituality at the touch of a finger or click of a mouse, in the privacy of one's own home, through one's personal computer and individually purchased wireless connection seems far removed from the embodied, collective worship of a weekly religious service. However, our interviews challenge this picture and in their detail they also offer a more collective, attentive and embodied image of what it means to practice spirituality in relation to online media space.

The individualistic-community binary is also troubled by the extensive literature on the sociality of computer mediated communication (CMC), which foregrounds the active sociality of the kind participation often facilitated by digital media forms. These modes of active practice and participation can be particularly contrasted (although not unproblematically so) with the viewing positions of the watcher, reader or listener afforded by print, televisual and radio forms. The Internet facilitated explorations of spiritual experiences and feelings in an enclosed setting, for some respondents, but it did so by putting them in contact with different kind of publics. These publics were intimate and affective (Berlant 1997, Cvetkovich 2003) sites through which individual and intersubjective feelings were experienced and attached. Respondents referred to the Internet as a site that facilitated a public dimension to interiorized sensations. It was a technology of connection with others who had similar questions and struggles, and it facilitated initial steps in an exploratory process with an undetermined 
outcome. For a number of our participants, this process of exploration was as much about the intersection of spirituality with that of 'coming out' (or an LGBTQI identification) as it was about spiritual seeking. Even though we have registered the likelihood that our respondents would affirm Internet use, and this played out in the interviews, our respondents also registered difficulties about connecting online. These were both technical, such as slow connections, and affective, such as frustration or alienation (as Kath and Andrew also experienced using Second Life, see Chapter 9). Clayton the founder of MyOutSpirit, a social networking site focused on LGBT spirituality that was central to our research noted that, 'MyOutSpirit has been a real struggle to get going' and he compared his difficulties organising online to the success of White Crane, a spirituality group for gay men that emphasizes face-to-face meetings:

Clayton: Part of it may also be that men of 'that' generation don't really dig email or get the Internet (in general, obviously), and while they all seem to interact in person all the time at retreats and events, I can only communicate through emails, which are easily lost, missed or dismissed as impersonal.

Other interviewees echoed similar disappointment with the promises of digital technology, complaining about time constraints, difficulty using the technology, and mediocre responses to online inquiries. So, while it was true that many of the participants in our study found that the Internet facilitated spiritual and queer connections; others found it to be a diminished replication of relationships and experiences found offline.

\section{Envisioning queer spirituality online}

\section{Queerness}

Spiritual seeking in broad terms can provide a queer framing for spiritual practice. This is not to give it a singular identity, but to point to the ways that identities, in spiritual seeking, are always unstable, hybrid, multiple, and contested. Queer spirituality online is not general or generic but particular and textured: zenquaker, interfaith, Christian agnostic. Spiritual identification is located for our respondents within the specifics of the particular. Many of them had their own ways of understanding the queerness of spiritual practice, during one group interview in Second Life we discussed this question in some detail. The setting for our discussion was already queer in any sense of the term: Heather White, a female in Real Life (RL), participated virtually as the male avatar Rhombus Gatter. Rivka was the 'boi-form' avatar for a RL intersexed person, and Jublilant was a transgender animal avatar for a RL transwoman: 


\section{QUEER SPIRITUAL SPACES}

Rhombus Gatter: okay, another question (new topic): is spirituality ever queer?

Rivka: but that's not the test of its relevance

Rivka: in two ways for me, rhombus

Rivka: (1) when done with queer folks :)

Rivka: or

Rivka: (2) as described above lol, when it's about erasing boundaries and acknowledging the larger reality of connection

Rivka folds hir hands

Rhombus Gatter nods and smiles

Rhombus Gatter: what about you, Jubilant?

Jublilant: heh, I was going to answer with a half-joke 'spirituality is ALWAYS queer' which is my way of saying Rivka's point 2

Rhombus Gatter: :)

Rivka: in practice

Rivka: I connect well with other queerfolk, especially genderqueer

Jublilant: If it's not 'queer' it isn't happening

Rivka: so their company is good for reaching for a larger truth

Jublilant: one way of putting it is that one needs to be awakened to the more, the mystery to have a spiritual experience

Jublilant: if you're already outside the 'norm' the things that keep people asleep, you're in a better place to wake up

Jublilant: which is no guarantee

Rivka nods 
Rivka and Jublilant capture at least two meanings for the queerness of spiritual practice. The first meaning, that spirituality is queer when practiced by queer people, doesn't simply equate the identity of the practitioner with the practice. In other words it is not being lesbian, gay, bisexual, trans, intersex or questioning that makes for queer spiritual practice. In this discussion queer refers to the marginal subjectivity of the practitioner, so queer here is to be attentive to being outside an imaginary of the normal. Queer spirituality in this context is practiced by people who are aware of their own marginalisation, because this also means that they are awake to a reality outside the 'norm' of everyday life. In this imaginary, normality keeps people asleep, or unaware, of both queer and spiritual. This aligns queer with the political traction and energy of transgression, but it also constitutes a hierarchy of marginalisation, and of privilege, which excludes people who might aspire to inclusion in a normality of everyday life.

The second meaning given here to queer spirituality positions queer as 'erasing boundaries and acknowledging the larger reality of connection', in Rivka's terms. Jubilant's joke, that 'spirituality is ALWAYS queer', references hir belief that spirituality, when it's 'happening', is always about connecting to a larger, mystical reality that transcends and erases the boundaries and binaries that limit life as the 'norm'. Thus, queer spirituality is positioned as politically progressive, 'acknowledging the larger reality of connection'. Whilst this positioning of queer as an erasure of boundaries is less divisive than the exclusionary tactic of privileging transgression it also leaves out the question of who is able to erase such boundaries and who is constrained by them (see Chapters 1 and 2, Puar 2007). However, this appeal to political progressiveness also connects with other scholarship in this area, particularly to Lynch's (2007) positioning of spirituality in the UK context as aligned to the political left and as deserving of greater attention in terms of the political and social potential of such practices.

\section{Multiple alignments: Selection and constraint}

Even as our participants embraced spiritual cosmopolitanism, they also rejected specific ideas and practices linked to some world faith traditions, with the implication that those practices were unhealthy or divisive to the unified spiritual self. Finding spiritual practices that could be positioned as healthy alternatives to this constructed centre required dividing some parts of a tradition from others, for instance, embracing contemplative prayer while rejecting monastic celibacy. Our point here is to make visible the attachment, attention and labour operating in the meaning production that operates around queer spirituality online - the selective process, of choosing elements from different traditions is another kind of discipline. The right and the good spiritual selections, even in queer parlance, rely upon therapeutic constructions of the self that emphasize continuity and 
connection between various dualisms such as soul and body, spirit and sex, material and mystical, immanent and transcendent. The work of making the self connected and constant involves a rejection of religious practices that might fragment queer spirituality. This rejection works through attaching negative meanings to religion, captured throughout this research, including references to 'dogmatic', 'institutional', 'divisive' religion. This work of meaning making creates a hierarchy which affirms spiritual practices online as those that can challenge homophobia. At the same time it critiques an imagined normal religiosity that fragments the self from itself, the spirit from the world, and the particular and dogmatic from what is imagined as connected and collective.

Most of the interviewees for this case study discussed queer, spiritual, digital as sites for practicing a freedom from the constraints of heteronormativity, homonormativity, religious dogma, and sometimes life in the 'real'. These freedoms seemed to open up opportunities for a mode of attention to a queer digital spirituality. However, such freedoms also act as constraint and a future direction for this research, and following on from work such as Bryson (2004), Puar (2007) and Erdem et al. (2008), for example, would be to examine the ways in which both queer and spirituality enact sites of disciplinary practice and regulation. A question that leads from this would be to ask about the ways in which digital media forms instruct subjects in forms of spiritual and sexual practice.

Our study also opens up questions asked by other scholars about how to understand spirituality, and the spiritual but not religious, as a demographic category (questioning what is quantifiable, see Chapter 2). The non-representative, qualitative nature of our study does not offer any conclusions about the demographics constituting non-aligned spiritual curious LGBTQI individuals. However, it does complicate, and takes apart the sense in with this group can be conceived as a group at all. We have made connections here across a disparate collection of people through the body of our research. However, analyzing them as a collective was in some ways already an intervention. If queer online spiritual practice is a category at all, it is constituted by hybrid, overlapping, multiple affinities whose particularity defy categorisation as one group.

Finally we would like to reconfigure the seeker. Although we found people seeking, both in terms of people looking for information and those on a spiritual journey, we also found a wakeful mode of attention to both the everyday and the divine in queer spiritual Internet practices. This mode of attention was constituted through the practices of the individuals in their approach to queer spirituality online, and afforded by their responses to the digital materiality of the Internet technologies they used. Our analysis thus, goes beyond figures of surfers and seekers, to modes of participation and attention to the use of digital technologies, in the making of queer spiritual selves and communities. 


\title{
Chapter 9 \\ Queer Spiritual Spaces: Conclusion
}

\author{
Kath Browne
}

\begin{abstract}
Mr Ali Abdussalam Trekki, the President of the UN General Assembly, when asked what he thought of the Declaration for the Universal Decriminalisation of Homosexuality, said: 'It is a very thorny argument. As a Muslim, I do not agree with it. I believe it is not acceptable for most of the world, and it is totally unacceptable for our tradition and religion.'
\end{abstract}

The Pink Triangle Trust's secretary George Broadhead, commented:

'The President's pronouncements are despicable, but are hardly surprising given the intrinsic homophobia of the religion he adheres to. However, like other members of the General Assembly, he is surely duty-bound to represent the principles and the aims of the United Nations, according to the Charter adopted on June 26, 1945 with its respect for human rights and fundamental freedom for all human beings. Instead he has implictly endorsed the barbaric treatment of thousands of gay people throughout the world, particularly in Islamic theocracies like Iran and Saudi Arabia. He should be asked to resign immediately or be removed from office.'

Our book has sought to both develop on and encourage further discussions of queer spiritual spaces rejecting the assumptions that gender/sexual difference and spirituality are polar opposites, reproduced in the debate by both of those quoted above, and also rejecting that 'Islamic Theocracies' in 'other' countries are the only ones causing harm. Because of our interdisciplinary authorship, this book sits at the nexus of queer, spiritual/religious studies, sociological and geographical enquiry, which at times means that there are divergences and disagreements as well as coherences. Sally gave a rather 'cultural studies' introduction; however this conclusion does something very different. The chapter, written from the perspective of a social/cultural geographer, draws links from Sally's exposition of queer spiritual spaces to explore, in a more 
grounded (literally! $!^{1}$ ) way, the implications of the data in order to explore how our work on queer spiritual spaces can be used and extended. In working with the team, the conclusion in the main reflects our ideas and proposed ways forward, but retains the non-reductionist approach which allows differences among us and our agendas.

At the outset it should be noted that this project was always envisaged as a 'exploratory endeavour' and 'opening' to enable further work and broaden the possibilities of enquiries in this area. This book does not offer a comprehensive review of all the fields of enquiry that feed into engaging with queer spiritual spaces (see also Gross and Yip 2010, Browne et al. 2007, Yip 2009a, 2009b, Munt 2007, Wilcox 2003, 2006). Neither does it make use of all the material in the in-depth case studies conducted, indeed there is much more all the authors could have said about their individual case studies (and of course far more that Andrew could have said about the literature in this area). Rather than reiterating our findings, ${ }^{2}$ our conclusion instead takes the title of this book and explores key areas that interweave with the chapters, as well as suggesting further research avenues, gaps and ways of knowing. Some of these are at odds with contemporary thinking, this we see as a strength. As there is no coherent 'story' that can be told of the diversity of this book, this chapter should be read as less of a summary and more of a 'highlights' section that hopefully will enhance what has gone before.

Throughout this project, our focus on people's lived experiences has offered us rich insights into how queerness and spiritualities co-exist, are inseparable, conflict with, and mutually constitute each other and sacred spaces. Our initial ideas regarding the respective cultural openness or perceived social oppression of each of the case studies we investigated have been thoroughly reconsidered. We hope to have offered you a nuanced and engaged account of how spiritualities, sexualities and gender identities are continually negotiated, challenged, reworked and reused. The spatialisation of these relations, practices and enactments contributes to their diversity, and also allows for an examination of how where identities, practices, experiences and subjectivities come to matter. This book is not so much about adding queer into religious studies, religion/ spiritualities into queer studies or spirituality and queer into geographies, rather

1 Indeed whilst Sally and other research team members enjoyed their experiences in Second Life, I (and Andrew) found the interface clunky. (Evidencing some of the work Kate and Heather call for in Chapter 8.) I (and Andrew) were also not emotionally engaged with the technology, and the thought of watching an online representation of us float in a virtual hot air balloon across our computer screens did not appeal. Thus, whilst recognising and celebrating the possibilities of any innovative and cutting edge methodology, it is important to also critically interrogate it.

2 Sally also requested that I avoid such a conclusion! 
we have tried to engage with rethinking queer, spirituality and geographies, leaving none of these categories untouched. It has already been argued here, and elsewhere, that queer and spiritualities are both re-created through their interaction (Keenan 2008, Siraj 2006, Yip 2003b, 2004a, 2005b, 2008a, Wilcox $2003,2006)$. Hopefully we've augmented this project by offering explorations beyond Abrahamic religions that include an understanding of space that both constitutes, and is created through, enactments, connections and interactions. Following this theme, our final chapter explicitly speaks to geographies of religion that have to date sidelined non-normative sexual/gender identities.

\section{Queer and LGBTQI}

As we have noted, queer has contested and fractured uses. The current policing of academic uses of the term queer that often attempts to demarcate deployments of the concept of queerness within scholarly writing and interactions, is fascinating - if of course very 'anti-queer'! Queer by definition is paradoxically non-definitional, yet most academic books start by outlining what it is, in diffuse, extravagant and often obtuse ways. A 'queerer than thou' rhetoric can also be seen in certain academic interactions at 'queer' conferences (including our own, see Chapter 1), as well as through reviewing processes, and in other 'professional' and informal settings. There is of course an import in writing theoretically; however, any exclusive use of a term such as queer is oxymoronic as its critical purpose is to defy such orthodoxy. Moreover, queer should not be abandoned to 'brilliant' (if often inaccessible) thinking and writing. The evangelical push towards a queer fundamentalism, however 'openly defined' is hugely problematic (Wilcox 2003, Puar 2007). On the other hand, the re-entrenchment of LGBT/GLBT - or what we have used - LGBTQI, has trodden a different line, one that accepts identities as solid grounds for political equalities claims, and that can neglect global, local and individually expressed cultural creations of resistances to, and non-engagements with this term.

Queer, in my view, should be messy, unclear, unorthodox, unprofessional, undefined and evaluated by what it does rather than what is. In this book, by defying not only the boundaries and limits set around 'queer' we can appeal across disciplines and subject fields noting simultaneously that this makes people nervous, uncomfortable and uncertain. We do however retain queer's grounding in sex and gender non-normativities, noting the increasing use in academic circles of a 'queer as method' approach.

In conferences and other settings, we have been challenged both to define how we are using queer and on our perceived lack of a 'coherent' classification. It has been suggested that we should use 'open definitions' such as those proposed by one or other of the queer (mainly US literary-based) canon. We have resisted 
such a push, and would encourage others to do the same. We deploy queer in orthodox and non-orthodox ways, at times we discuss lesbian and gay, at other times LGBTQI, and still in other moments we contest gender, sexual, racial, spiritual virtual, spatial boundaries illustrating fluidities, permeability and contestations. It is not that we do not understand representations of queer, or are not well versed in theorising in this area; it is to argue instead that we need not be constrained by categorical thinking or theorising. Rather than carefully treading between the cracks, respecting and towing lines, borders and boundaries, we irreverently, leaped, contested and ignored them.

We disagreed amongst ourselves about how to label and name gender and sexual difference and in this book we present variations on definitions and deployments of queer (as well as spiritualities and space). Reflecting our diversity as a research team and the plethora of voices, opinions and ideas that constituted this book, rather than subsuming to one mode of writing this book itself 'queers' unified narratives. The book exists between an edited collection and a co-authored monograph. We have tried throughout this process to avoid forcing false cohesion through seeking one way of writing, seeing or knowing. Throughout this research the authors and researchers engagement with queer/ LGBTQI lives and identities and spirituality has varied. At times, sexual identities, spiritual practices or/religious affiliation became very important, Sharon had to negotiate the familiarity of 'insider status' using vigilance to ensure that assumed knowledges were addressed (see Chapter 5); in contrast I (Kath) blurred the 'objective' researcher boundaries in unsettling and emotional (for me) ways. Liz and Amna as straight-identified women at times found that they were read as a lesbian or seen as 'honorary gay men' (see Chapters 4 and 7). Our research relationships also varied where Heather's interactions developed over the course of the project (see Chapter 8), others were on occasion fraught and at times antagonistic (see Chapter 3). What was clear across all of our accounts was that we continuously addressed issues of sameness and difference, existing often in the folds that overlap between them.

\section{LGBTQI}

It is crucial to note the limits of written expression, particularly of the spiritual that so often are felt, known and experienced in ways that move beyond the realms of discourses. Sally's queer spiritual space under water can only ever be incompletely, unsatisfactorily described, as floating in the sea exceeds the limits of language (see Chapter 1). Similarly, all of those who undertook case studies encountered difficulties of naming, relating to both sexual/gender identifications and spiritual practices and experiences. Comments like 'I don't know how to describe it' sent us all scurrying to consider how else we could ask the question, with some of us feeling chastised for segregating this aspect of a person's life 
or experience from any other, through labelling it or asking participants to label or separate various aspects of their identities. Despite these shortcomings, the language of sexuality and gender identities was complexly interrogated and diversely reproduced. Amongst participants, there was an embrace, a qualified adoption and/or rejection of labels such as lesbian, gay, bisexual, trans, queer and/or intersex, although it quickly became apparent to many of us undertaking the data collection that the term 'queer' was particularly sticky for participants. (Online spiritual seekers also starkly highlighted the problems and contingencies of definitions of spiritualities/religions.) Yet there were also moments of connection, ease and acceptance that permeated participants' accounts. Recognising the complex and loaded histories these terms LGBTQI have, as well as their partiality in describing the 'whole person', this research found that they came into being, and were challenged through participants' spiritualities and religious traditions. Thus, sexual/gender identities and lives referred back to - but never could be contained within - lesbian, gay, bisexual, trans, queer and/or intersexed. However, across the accounts it was clear that recognition (and acceptance) of alternative sexual/gender identities - and the absence of this - has emotional, cultural and often spiritual significance.

Whilst identities and subjectivities can be rendered fluid and contested, these categories can also have social and symbolic power. This is often discussed in terms of heteronormativity and the differences between LGBTQI people and those who enact (hetero)normative gender/sexual identities (Wilcox 2002, 2003, Yip 2003b, 2008a). Differentiating experiences between those defined within LGBTQI collectives is also important. Research on non-normative sexualities and spiritualities to date has prioritised the experiences of gay men and lesbians. Thus, whilst the drive to render all labels 'suspect' has created particular openings for critical interrogation, there is an import to noting omissions within an undifferentiated term 'LGBTQI/queer'. ${ }^{3}$ For example, limited research has incontrovertibly shown that, encountering prejudice from both heterosexual and lesbian and gay communities, bisexual Christians have to grappled with biphobia and monosexism, underscored by heteronormativity and homonormativity, in their efforts to construct meaningful lives (e.g. Toft 2009a, b, see also Browne and $\operatorname{Lim}$ 2008, and Chapter 2). In the same vein, trans Christians are often seen as tampering with the divine created order (specifically in the case of those who undergo physical gender reassignment) and have to battle with their status as 'gender outlaws' and monogenderism, which profoundly informs the ways that they live their spirituality (see Cornwall 2009, Mollenkott 2007, Tanis 2003, Yip and Keenan 2009). Our research also pointed to issues of exclusion for trans

3 Indeed research that fails to recognise labels that enable differentiation between L, G, B, T, Q and/or I can unintentionally reproduce accounts that focus on gay men, as lesbian authors have long noted in relation to the term 'gay and lesbian'. 
and bi people. Further marginalisations also occur on the basis of gender and sexual difference in ways that cannot be delimited by bisexual, trans, intersex or otherwise 'queer' subject positionalities. These need attention, recognising the cultural and spatial specificity of these categories, and the associated gender and sexual dichotomies. ${ }^{4}$ Whilst, at Findhorn the spiritual spaces and practices appeared to transcend gender and sexual divisions and categorisations, there was a simultaneous need to be wary of any move that renders sexual and gender difference invisible.

In all of the case studies we sought to include a range of people within LGBTQI, this was in part through identifications such as bi, trans, intersexed and otherwise 'queer'. Yet, this research highlighted issues and moments where sexualities/gender identities were differentiated, in ways that could not solely be attributed to sexual/gender difference. Perhaps unsurprisingly given the raft of literature that explores the 'new homonormativity', such differentiations not only related to bisexual/trans/queer identifications, but also intersected with class, ethnicity and gender (see for example Vidal-Ortiz 2008, Halberstam 2005, Puar 2007, as well as Chapter 1). Whilst it is problematic to set up the straw figure of a powerful homonormative white, middle class gay man in contrast to the 'political queer' (Brown 2009, Oswin 2008), there remains a need to examine differentiations between LGBTQI people, without neglecting the pervasiveness of heteronormativity. What 'type' of 'gay' sexuality is accepted/ acceptable, or conforms to an idea of respectability? How are the boundaries and norms of sexual/gender practices policed and contained? This volume provided some explorations of this from the case studies, but there is more to be done. What is clear is that spirituality and spiritual spaces can offer important, if at times limited and contained, ways of living out difference. Our book, in beginning discussions of bi, trans, intersexed and otherwise 'queered' people in investigations of spirituality and religion has sketched out a varied picture of belonging. We have shared examples of where friendly spaces can be found, negotiated and used, as well as noting that spiritual cultures can also be exclusionary, unfriendly and/or unaccommodating, sometimes despite their 'open' theological rhetoric. There is a clear need to expand this area of research to specifically address the spiritual practices and experiences of those marginalised and excluded by a sole focus on relatively privileged lesbians and gay men. This needs further work in ways that avoids reductive formations of gender/sexual identities (and the vilification of 'white affluent gay men'), whilst

4 In referring to gender/sexual dichotomies, I am thinking here of heterosexual/ homosexual and male/female, as historical and culturally specific ways of understanding gender and sexual bodies, attractions and identifications. These are not of course ubiquitous, nor are the categories lesbian, gay, bisexual and intersex which are underpinned by them. 
including the plethora of spiritualities and religious engagements. This research may also need to investigate the consolidation of heteronormativity in the continual reconstitution of the neologism LGBTQI. This critique may require the continuous queering of sexual and gender definitions and (LGBTQI) labels, but it need not be beholden to such queering.

\section{Spiritual}

Wilcox (2006) has argued that religion should be part of queer investigations and theorisations, as an important 'locus of power'. Yet, how this power is deployed, experienced and what it produces is continually negotiated and reformed. We must not assume that the entrenched heteronormative nature of institutional religions is totally antithetical to the presence of queer or LGBTI people. On the contrary, although 'spiritual' not religious' is a common form of identification nowadays, we have found this does not mean that LGBTQI individuals disidentify with institutional religions. Indeed, within this research we found spiritual seekers deploying multiple and diverse institutional affiliations, which may not even be defined as 'spiritual'.

Whilst queer spiritualities can be described as 'spiritualities of life' (Heelas 2008), they can also be inextricably linked to public religiosity and 'dominant' religions. This finding has significant implications for activism; it is unhelpful perhaps to keep shouting that 'the Church' is homophobic or biphobic and transphobic - although what these terms can represent are often inseparable when considering expressions of abuse based on gender/sexual difference that conflate gay men with effeminacy and so on. (It may, however, be still be helpful to be loud - see Chapter 3.) That can essentialise 'the Church', and unhelpfully alienates religious communities and LGBTQI people within them.

Running parallel to the common sense thesis that queer and particular religious institutions are antithetical, is the understanding that alternative spiritualities are open, accepting, tolerant and suffused with sexual and gender pluralities. Whilst, there can be no doubt that the Findhorn, Quakers, Michfest and Buddhism case studies found all of these traits, these were also mitigated by controversies, marginalisations and contradictions. The Quakers' reaction to Sally, Findhorn's uncertain position towards its lesbian and gay group, Michfest's qualified openness to spirituality but not specific forms of Christianity, and Buddhist gender politics, - such findings all question the use and accuracy of blanket statements that neglect social, cultural and spatial specificities. Throughout this book we have particularly examined experiences that often contest the presumed relationships between LGBTQI people and their 
supposed hostile/accepting religions/spiritual traditions. ${ }^{5}$ We need to continue to ask the kinds of questions that contest any essentialising of sexual/gender identifications, spiritual/religious institutions, or countries/regions/locales (see also Wilcox 2002).

Our locus of study in Anglo-American contexts often leads to the tendency to use Christianity as a term of reference in the study of queer spiritualities, and for thinking about other religious traditions, reflecting the popular and academic discourses of the Global North. We have not sufficiently developed the awareness, sensitivity and humility to qualify this entrenched habit. While some inter-religious similarity in the treatment of queerness cannot be denied, it is important that we recognise the geographical, socio-cultural and political specificities of different religions. In the case of queer Muslims, for instance, the politicisation of Islam in the West has had a direct result on their everyday life in the UK/North America, where issues of homonegativity cannot be separated from Islamophobia and racism. How their spiritualities are lived within this context directly relates to the geo-politics of their religious faith (e.g. Abraham 2009, Yip 2008a). Throughout many of the case studies, the pervasiveness of Christianity in the Anglo-American context could not be overlooked.

Ivakhiv (2005) urges a reconsideration of religion that fully accounts for how significance and meaning are constructed within religion/spirituality, across place and space. Religion, Kong (2001: 226) contends must be subjected to the same 'historical and place specific analysis' that we afford class, gender, and of course sexualities. We would argue that such a consideration recognises the reconstitution of 'divergent' and oppositional religious/spiritual forms (see Roden 2009 for a different take on the dissolution and intersections of Jewish/ Christian/Queer). For many of our participants the search for spiritualities outside of traditional Christianity, was also referenced back to Christian norms and dominance, demonstrating the interlinking of these supposed oppositional forms. People spoke of searching for spirituality outside of a Christianity that rejects, others and excludes that has also been forced upon them throughout childhood. Some of the case studies in this book found that Christianity, and other forms of religious doctrine can be rejected by LGBTQI people as much as it rejects them. Such a rejection was not always about being excluded from particular places such as churches, temples and mosques, it was also about re-interrogating belief systems that render LGBTQI people as 'other' (see also Chapter 2). This resulted in the collective and individual reworking of

5 Another way to approach this, as Andrew has argued elsewhere (Yip 2005a), would be to explore how the presence of LGBTQI people within the religious community has helped towards the development of such spaces. Such a manifestation of the personal and socially transformative politics of spirituality/sexuality underpins the commitment for justice and change. 
particular religious teachings, as well as negotiating them (Keenan 2008, Siraj 2006, Wilcox 2003, 2006, Yip 2003b, 2004a, 2005b, 2008a). Creating self/other dichotomies pertaining to religious affiliation and spiritual practice illustrates that whilst the proliferation of research on non-Christian queer believers is to be welcomed, it should not be presumed that there is an easy separation between various religious/spiritual constructs. Rather, just as the sacred/secular has been challenged, the mutual formation of religious/spiritual forms (in part through creating them as opposites) was apparent in this research. ${ }^{6}$ This of course brings into question the power laden construction and maintenance of religious difference, which is tenuous, fractured and porous, yet holds personal, social, cultural and political significance.

Religious-sacred spaces reproduce and challenge societal forms (Holloway and Valins 2002, Holloway 2006), and societal forms produce and challenge the religious/sacred. A re-examination of this relationship in light of our data would suggest a move away from particular religious institutions, as well as their reconstitution and radicalisation, stimulated by changing sexual/gender morals and expectations. In other words religion does not only influence society and space (Holloway and Valins 2002), society and space reconstitutes religion/ spirituality. Marler (2008) argues that religious change in the West has not only affected women's lives, but similarly been influenced by the changes in women's lives. Our research suggests that religion and spiritualities are influenced by alternative sexualities and gender identities. Such a move points to the mutual creation of sexuality/gender, and spiritualities/religious institutions, teachings and manifestations. This renders spiritualities and religions, along with the gender/sexuality, fluid and performed. Of course this position also has to account for the backlash to the 'liberalisation' of sexual/gender 'morals', such that the constitution of the religious-sexual nexus requires continuous critical scrutiny. Most of 'backlash' contentions are framed in terms of 'homosexuality' (as an all encompassing catch all for anything not heteronormative) and 'the church' (again a problematic all encompassing term). This nexus is an appropriate representation of the resistance to LGBTQI identities in this context. It should be noted however, that opposite sides of the contestation around the 'inclusion/ exclusion of homosexuality', as well as both sides of the church/sexual divide are remaking each 'other'.

It is clear from our research that we need to take a more nuanced approach to our approaches to religious institutions and spiritual communities. This requires further explorations of spatial differentiations, asking why some spaces within religious/spiritual communities are used and experienced as aggressively

6 Thus, it could be argued that the tensions between different religions, or even amongst the 'same' religions (Kong 2001) can be read as productive. Whether what is created through such struggles is desirable, should be subject to critical interrogation. 
and subtly heteronormative, yet some are not explicitly so. We need to critically examine under-currents of heteronormativity and how these can pressurise LGBTQI people to toe the line; and find how other spaces that might have been 'homophobic' have become more tolerant, even accepting, and altogether how all of these practices recreate religion/spirituality.

It is tempting to leave it there, to neglect all the positive experiences and stories that are told of religious/spiritual experiences and sacred spaces, which were so carefully attended to in Chapter 1. However, in finding the spaces of exception within supposed intolerant religions, and the normalisations of particular forms of gender/sexual behaviours within spiritual communities that can be sought out - in part because of religious rejection - we cannot neglect the belonging, meaning, and comfort that such spiritual spaces and experiences can offer (see also Brace et al. 2006, Wilcox 2002). Although religion and spirituality can be analysed and explored through societal structures and interpersonal relations of power, there is a need to continually recognise the affective and emotional dimensions to spiritual spaces. For LGBTQI people spiritual engagements can have profound and powerful affects and effects, particularly where exclusion and marginalisation are regular experiences. The participants, and indeed Sally's introduction, point to the power of spiritual practices and sacred spaces in terms of reparative possibilities that can, amongst other functions, heal wounds caused by discrimination and prejudice.

\section{Space}

Queer geographies have long argued that sexualities and gender are spatially produced (Binnie 2004, Browne 2004, Browne et al. 2007, Nash 2007, Oswin 2008). However, religion is under-explored in this field perhaps because of the overt and covert hostility towards particular religious institutions showing a widespread academic 'rejection' of religion (Lim et al. 2007). This is despite the contention that religions and spiritualities are important to human geographies' contribution to understanding and engaging in everyday lives, and that sacred spaces are contested and formed through relations of power (Brace et al. 2006, Holloway and Valins 2002, Kong 2001, Park 2004). Augmenting queer geographic understandings by addressing geographies of religion reveals the complexities of spiritual and religious loci of power that are created spatially. Conversely, engaging critically with space (even where that space is virtual) necessitates some recognition of the temporal and spatial contingencies of spiritual, religious, sexual and gendered relations and manifestations.

Geographies of religion have noted the important place of religion/spiritualities in everyday lives, located in homes, workplaces, landscape, nature and tourism (Brace et al. 2006, Holloway and Valins 2002, Kong 2001) and that 'sacred 
space' is often contested space (Kong 2001: 213). Rather than exploring secularisation where the sacred 'losses its significance' (Vincett et al. 2008), this volume along with other work (Althaus-Reid 2003, Goss and West 2000, Jamal 2001, Moore 2001, Stuart 2003, Yip 2005b, 2008a) illustrates the place of the scared in ordinary LGBTQI lives. Here throughout the case studies - what we have variously termed the 'sacred ordinary', 'ordinary spiritualities' and 'ordinary transcendence' - has been key. We found that spirituality was not distanced or separate from, but an integral part of everyday spaces, intersecting with sexualities and gender identities to the extent that differentiating them was not possible. As many participants said 'It's just me' and as Jari in Chapter 8 argued it is 'All God to me'. This contrasted starkly with the representational 'homosexual other' of religious identities where the person is only associated with (deviant) sexualities (and gender identities) neglecting other facets of lives that fold over and into such identifications, practices and desires (see also Wilcox 2003). Thus, spiritual spaces were not confined to rituals or ritual spaces, although these at times held some significance, instead often they were immanent parts of everyday life.

As ritual was not necessarily needed to sacralise space the 'place' of religion/ spiritual/sacred comes into question, in fact religion and spirituality could be 'located everywhere'. It was clear in the data that the spiritual becomes conscious at particular moments, where ordinary space is re-imagined as sacred (Hume 1998, Kong 2001). As spiritual practice is normalised and routinised, the 'where' seemingly became less important. Higher states of engagement could be attained through particular forms of spiritual practice and also certain states of being. In this context, rather than a place holding particular religious meaning or inherent associations, mutable spaces of practice were created that reconstituted everyday space as spiritual (what Hume, 1998 terms the sacralisation of space). Alongside 'spiritual/religious geographies' that can seek to explicate the spiritual cultures of, and connections to, a place and the role of religion in shaping perceptions of the world and 'geographies of religion' that can seek to elucidate specific forms of spatial analyses, by examining the social, cultural and/or environmental impact of religion and focusing on the built environment; geographers can also explore the nuanced, diverse and performative constructions of space (Francaviglia 2003, Esposito et al. 2004, Naylor and Ryan 2001, Park 2004, Holloway 2006, Rose 1997, Gregson and Rose 2000, Ivanhkiv 2003). Recognising that spaces reflect and reproduce 'religious and social desires and anxieties' (De Rogas 2003 quoted in Brace et al. 2006: 30), religious/spiritual spaces are not just experienced differently related to social distinctions (Kong 2001), spiritual and religious spaces are constituted through such relations. This has a particular importance for LGBTQI people. Resisting the naming or labelling of particular places as sacred/spiritual, opens up greater possibilities for spiritualities and the co-creation of sacred spaces. 
In our research, recognising the spiritual as 'everywhere' and in the control of the individual 'states of mind', (re)placed the power of spiritual experiences and practices within the grasp of LGBTQI people. Thus, reforming, claiming and creating spiritual spaces empowered LGBTQI peoples, sitting alongside theological reworking explored in Chapter 2. Moreover, reworking religious institutional space, opening them up to new meanings, also contested any presumed essentialist opposition to LGBTQI people. In the move away from physical space, there remained a significance given to material buildings, monuments, and statues, but also particular environmental forms, usually rural, and pertaining to specific ideological constructions of the environment and nature, (but also occasionally associated with urban features too). Participants had assorted relationships with churches and specific religious/spiritual spaces. These relationships often could not be defined in advance, nor was the experience of them uniform. In contrast, and in line with current thinking regarding space, there were diverse and multiple constructions of spiritual spaces. Undefined in advance, these spaces in enabled both spiritual connections and restrictions. The intention of those facilitating (or controlling) such spaces were not always adhered to, rather they were questioned, usurped and reworked. Such processes were not confined to 'oppressive' religions - on the contrary - across the case studies the processes of spiritual connection were often related to individualised intentions and the use and deployment of additional, often spontaneous spaces to further achieve spiritual connections.

\section{Ways forward (and doing better?)}

We want to finish by offering our visions for some of the ways forwards. These strive to be indicative and to encourage further work, rather than offering strict pathways that must be adopted. Structured within queer, spiritual and spaces as with this chapter, they simultaneously refuse and refute neat boundaries.

Firstly to 'queer': This book sets itself apart from and yet still falls within the 'queer' trawl to find the 'next' boundary, normativity and subsequent 'others'. We have called for further explorations of that which does not fit into normative lesbian and gay sexualities, arguing that there is a need to be bolder in our research undertakings and to expand such inquiries into more marginalised sexual/gender subjectivities, including paying more attention to bi and trans and otherwise 'queer' lives, as well as finding more nuanced intersections with class, gender, ethnicity and other forms of social difference (including religious/ spiritual affiliations and practices). This research agenda has been developing in queer and sexual/gender studies for some time, arising from and feeding into third-wave feminist work on intersectionalities. Yet alongside all these divisions we have also found common themes, similarities and connections, even where 
the individual is presumed to be key. As Wilcox (2006) noted, one of the key tenets that 'queer' has yet to fully engage with is the safety, comfort, peace and pleasure that can be gained from individual and collective spiritual engagements. To be called upon to be constantly queer can expect human beings to live lives of continuous discomfort, rhetoric, and self-reflexivity (see Chapter 1 and Puar 2007). For some this critical injunction is unpleasant, irrelevant, and practically impossible to fulfil. Thus, looking for normativities/dissonances/others, whilst important, cannot be our only mode of engagement with Queer Spiritual Spaces. We have challenged convention by not beginning with clear bounded concepts (of queer, spiritual or indeed space) and we seek instead to feed into and depart from the paradigm shifts that have recognised the messiness of social life, that refuses to be bounded and reduced to preconceived positions, especially of obligatory radicalisation. This of course can be seen as a 'queer' pursuit, and is (for some contradictorily) set alongside the importance of investigating LGBTQI lives, claiming and deploying labels recognising the times (and spaces) when they come to matter. Others may seek to impose definitions on such investigations, we would caution, however, definitions have sharp edges, which may be conducive to queering, but also unhelpfully marginalising in their creation of 'new' others. Perhaps we need to consider: why so fearful of nondefinition, of not pinning down, of potentially not knowing? What is being held on to? Is it worth it?

Secondly to spiritualities: We have augmented the work on LGBTQI spiritualities and religions that are outwith Abrahamic religions. It is clear that incorporating spirituality/religious institutions requires a recognition of the power of those institutions which can be contested, usurped, resisted and reworked. It also necessitates a critique of that which is presumed to be 'tolerant', yet can enforce particular gender/sexual normativities. There is much more to be done, not only on the case studies we have addressed here, but in bringing forward the plethora of other spiritualities that have yet to be addressed. This should be undertaken without dichotomising Christianity/ other spiritualities, enhancing our understandings of the intricate relationships that contest the presumed boundaries between religion/spirituality/sexuality/ gender and other significant factors that create LGBTQI lived experience. This book has contributed to that, but this is just the beginning that we hope will stimulate further work.

Thirdly, incorporating an investigation of queer spiritualities into discussions of geographies of religion and spiritualities addresses the call for this area to further develop investigations of the place of religions and spiritualities in and through everyday lives. Rather than 'adding in' the intersections of religion/ spirituality and sexual/gender difference to geographies, we argued that religion, space and sexual/gender formations are crucially co-constitutive. Thus, religion/spirituality cannot stand alongside gender/sexuality as a form of social 
difference, rather the prospect is one of spatially nuanced analyses that refutes the boundaries between sexual/gender differences and identifications and religion/spirituality. This would both learn from, and augment, contemporary geographies of religion as well as the wider discussions of spiritualities. Geographers have much to gain from exploring LGBTQI spiritualities, conversely there is also much geographical theorising - queer and otherwise - that can enhance investigations of religion.

Finally working across and between queer, spiritual and spatialities, there can be no doubt that this book offers a Global North/minority world account, such that spiritualities, queer and spaces are inflected with our specific meanings, understandings and conceptualisations. Creating an 'authentic' self that is defined as historically and geographically constant has been an important line of argument both in terms of sexual/gender identities and in spiritual/religious constructs (Brace et al. 2006, Wilcox 2003). Such essentialised understandings create room for particular truth claims, but they also neglect spatial and temporal specificities. Thus, we need to be wary of the appropriation, erotisation or spiritualisation of 'elsewhere's', as well as the truth claims we create by contrasting the 'us-here' with the 'them-there'. These can be used to purport freedom, openness, connection and unity, but also can be fraught with tensions, controversies, negotiations, compromises, complicities, exclusions and relations of power. ${ }^{7}$ What this book has shown is that there is significant complexity of gender/sexual identifications and spiritual/religious affiliations, practices and lives within Anglo-American contexts (that cannot of course be isolated from 'other' places, contexts and global interconnections). Further work in this area needs to afford the same level of complexity, nuance and diversity - wherever we are. Rather than assuming coherence or adherence to cultural or religious institutions/states by 'duped followers' or even particular identifications within LGBTQI, our research shows the import of recognising resistance, negotiation and contestation that is spatially sensitive. This enables an exploration of the diverse ways sexual and gender difference can contest heteronormativities from within religious institutions, as well as challenging and reworking discriminatory doctrines and practices from the spaces outside. Conversely, LGBTQI people do not necessarily reject religion and spirituality; many find solace, peace and contentment in such spaces, doctrines and practices. Within, and perhaps

7 The colonisation of 'European', 'Celtic' and other located spiritualities needs to be critically interrogated in relation to geographical imaginations that both rely on and resist colonial appropriation. The 'genuine', 'authentic' knowledges and spiritual shapes, which such histories and geographies produce, also need to be unpicked and deconstructed. Similarly a return to 'origin' by faiths and religious traditions need examination - how does the trope of 'origin' itself recreate the spaces of the here and now, as well as those who are 'other' to dominant reconstructions? 


\section{QUEER SPIRITUAL SPACES: CONCLUSION}

beyond, the global north LGBTQI people make spiritual spaces and lives for themselves in a plethora of ways. Making these visible and engaging with their nuance could work towards contesting fundamentalisms and discriminatory doctrines, be these queer/LGBTQI, spiritual/religious or geopolitical/spatial. 



\section{Appendix}

This appendix gives details for most of the participants in this research. It uses the prompts that were on the participant information sheet, which did not detail any categories or have any specific boxes/labels to be ticked, instead participants choose how to name their identities. It also said that participants should only fill in the parts of the information sheet that they wanted to. The same participant sheet was used for all the case studies. The prompts that were used to guide the answers given were:

1. Age/stage of life;

2. Area where you live/housing status;

3. Sexuality;

4. Gender;

5. Faith/religion/spirituality;

6. Ethnic identity;

7. Do you have a disability/identify as disabled/claim disability allowance?;

8. Employment status/social class;

9. Is there anything else that is important to you?

In constructing this list we have categorised some answers (for example in housing - any form of home owning became 'home owner'), we have also removed details where we suspect this might identify participants (this, for instance, meant that actual careers are not given, indications of employment are instead included). The names used here (and in the text) are both pseudonyms and real names. Where participants asked for their real names to be used in this research, this request is upheld here through the use of their first names (except in the case of Quakers here the surname is of symbolic significance). Where participants said that they did not wish to be named we have used pseudonyms. 


\section{QUEER SPIRITUAL SPACES}

We do not distinguish between real and pseudonyms, erring on the side of caution with those who did not wish to be identifiable.

\section{Table key}

$\begin{array}{ll}- & \text { Indicates no response } \\ * & \text { In the Queer Spiritual Seekers chapter (Chapter 8) some participants } \\ & \text { had multiple names } \\ * * & \mathrm{M}=\text { male, } \mathrm{F}=\text { female } \\ * * * & \mathrm{FT}=\text { Full time employed, PT = part time employed, S-E = } \\ & \text { Self-employed, Prof = professional } \\ * * * * & \mathrm{HO}=\text { Home owner }\end{array}$


Table A.1 Chapter 3: Quakers

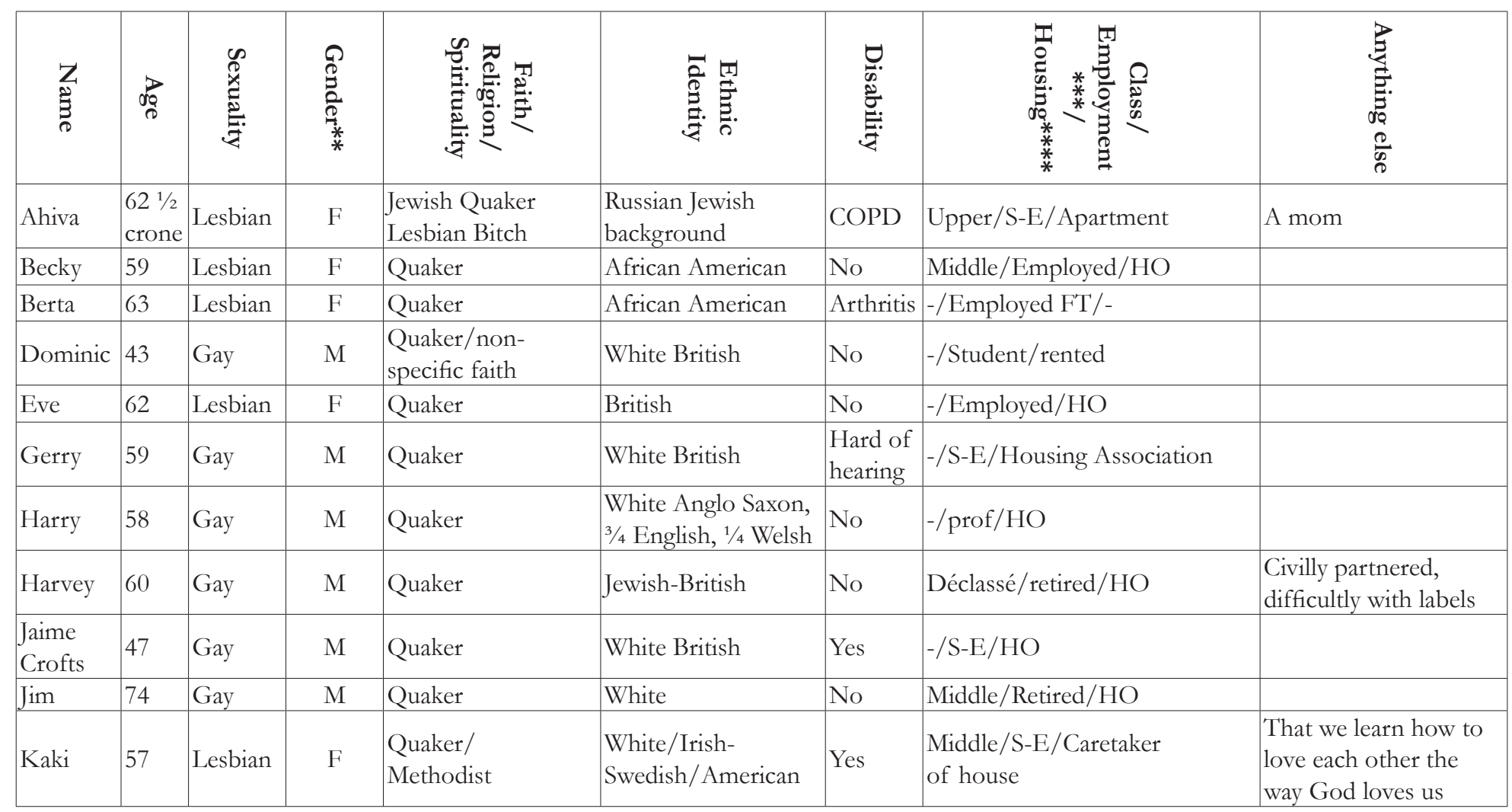


Table A.1 continued Chapter 3: Quakers

\begin{tabular}{|c|c|c|c|c|c|c|c|c|}
\hline $\begin{array}{l}Z \\
\vdots \\
0\end{array}$ & d & : & 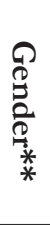 & 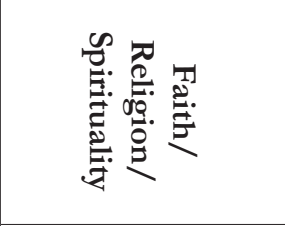 & 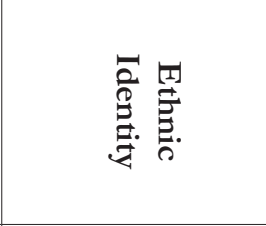 & 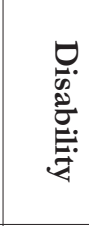 & 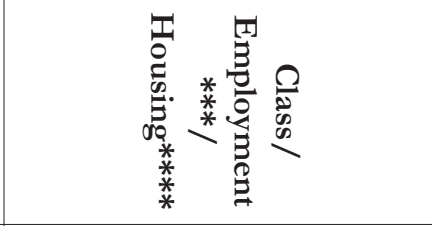 & 蛋. \\
\hline Kristin & 44 & Lesbian & $\mathrm{F}$ & Birthright Quaker & European & No & -/P'T Employed/HO & $\begin{array}{l}\text { Mother of two } \\
\text { daughters. Separated } \\
\text { from husband } 2 \\
1 / 2 \text { years ago }\end{array}$ \\
\hline Lisa & 57 & Lesbian & $\mathrm{F}$ & $\begin{array}{l}\text { Religious Society of } \\
\text { Friends (Quaker) }\end{array}$ & $\begin{array}{l}\text { White Eastern } \\
\text { European }\end{array}$ & Yes & $-/ \mathrm{PT} / \mathrm{HO}$ & \\
\hline Liz & 46 & Lesbian & $\mathrm{F}$ & Quaker attender & English & No & Middle/prof./- & \\
\hline Mel & 27 & Queer & - & $\begin{array}{l}\text { Religious Society of } \\
\text { Friends (Quaker) }\end{array}$ & White and Jewish & No & $\begin{array}{l}\text { Upper Middle of origin, } \\
\text { current social class is } \\
\text { contradictory/Student/Rented }\end{array}$ & \\
\hline Meryl & 69 & Lesbian & $\mathrm{F}$ & Quaker & White & $\mathrm{No}$ & Middle/Employed. Prof/HO & \\
\hline $\mathrm{N}$ & 28 & Lesbian & $\mathrm{F}$ & Quaker/other & White/Irish & No & Middle/-/- & \\
\hline Nancy & 58 & Lesbian & $\mathrm{F}$ & Quaker & White-Irish & - & Working/-/- & \\
\hline $\mathrm{O}$ & 51 & $\begin{array}{l}\text { Women- } \\
\text { centred }\end{array}$ & $q$ & $\begin{array}{l}\text { Love, oneness, } \\
\text { Quaker }\end{array}$ & $\begin{array}{l}\text { African-American, } \\
\text { Polish, Native } \\
\text { American, French }\end{array}$ & No & $\begin{array}{l}\text { Lower/-/Quaker Spiritual } \\
\text { Conference centre }\end{array}$ & $\begin{array}{l}\text { I have an amazing } \\
\text { daughter. She is } \\
28 \text { and a pisces }\end{array}$ \\
\hline Rachel & 59 & Lesbian & $\mathrm{F}$ & Quaker & White-Jewish & No & Middle/PT, Retired/HO & \\
\hline
\end{tabular}


Table A.1 continued Chapter 3: Quakers

\begin{tabular}{|c|c|c|c|c|c|c|c|c|}
\hline 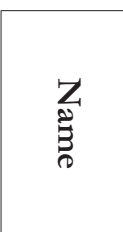 & 召 & 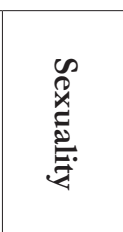 & $\begin{array}{l}0 \\
0 \\
0 \\
0 \\
0 \\
* \\
* \\
*\end{array}$ & 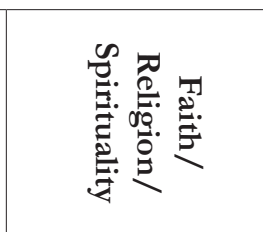 & 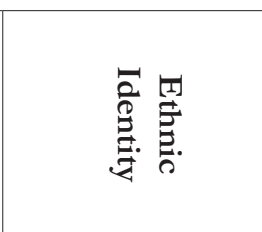 & 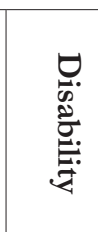 & 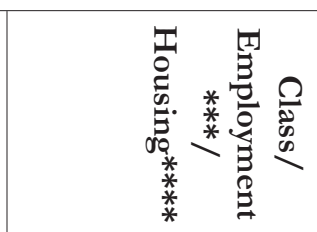 & 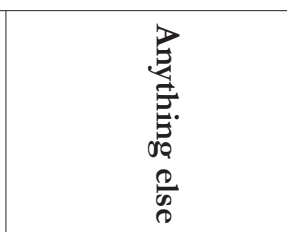 \\
\hline Richard & 60 & Gay & M & Practicing Quaker & White British & No & -/S-E/HO & $\begin{array}{l}\text { Bisexual at periods } \\
\text { in my life. I attend } \\
\text { Quaker meetings } \\
\text { regularly but am not } \\
\text { actually a member }\end{array}$ \\
\hline Sarah & 47 & Bisexual & Intersex & Quaker & British & No & -/Prof, student/HO & \\
\hline Stephen & 45 & Bisexual & $\mathrm{M}$ & Quaker & White British & No & -/employed/HO & \\
\hline Susan & 61 & Lesbian & $\mathrm{F}$ & Quaker & $\begin{array}{l}\text { Second generation } \\
\text { American (Italian- } \\
\text { Polish descent) }\end{array}$ & No & $\begin{array}{l}\text { Middle/Employed } \\
\text { Prof/HO }\end{array}$ & \\
\hline
\end{tabular}


Table A.2 Chapter 4: Queer Muslim

\begin{tabular}{|c|c|c|c|c|c|c|c|c|}
\hline 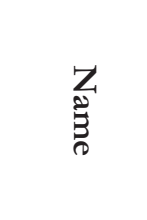 & 忿 & 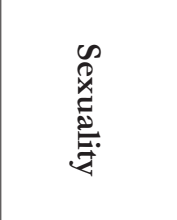 & 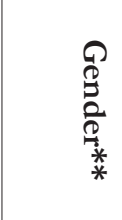 & 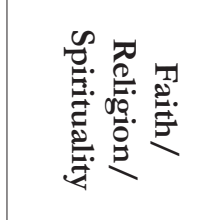 & 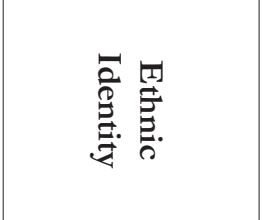 & 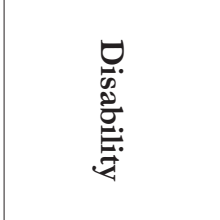 & 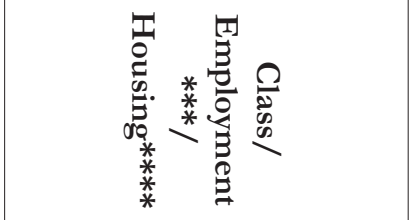 & 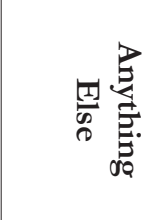 \\
\hline Al-noor & 44 & Gay & M & Muslim & British Pakistani & No & -/Employed FT-HO & \\
\hline Amreen & 38 & Lesbian & $\mathrm{F}$ & Muslim & Pakistani & No & -/Unemployed/Rented & \\
\hline Asemeh & 36 & Lesbian & $\mathrm{F}$ & $\begin{array}{l}\text { Muslim } \\
\text { background }\end{array}$ & Iranian & Yes & -/Student/Rented & \\
\hline Azeem & 27 & Gay & M & Muslim Sunni & Pakistani & No & Middle/unemployed/Rented & \\
\hline Bashir & 23 & Gay & M & Islam & $\begin{array}{l}\text { British } \\
\text { Bangladeshi }\end{array}$ & No & $\begin{array}{l}\text {-/ full time employment/ } \\
\text { Living with family }\end{array}$ & \\
\hline El-Farouk & 44 & $\begin{array}{l}\text { Always } \\
\text { (Gay) }\end{array}$ & M & Muslim & $\begin{array}{l}\text { (Canadian)/ } \\
\text { African - of mixed } \\
\text { South Asian and } \\
\text { African descent }\end{array}$ & No & -/S-E, prof/HO & \\
\hline Farzana & 28 & Lesbian & $\mathrm{F}$ & $\begin{array}{l}\text { Culturally } \\
\text { Muslim }\end{array}$ & British Pakistani & No & $\begin{array}{l}\text {-/Employed and part } \\
\text { time student/HO }\end{array}$ & \\
\hline Imran & 25 & $\begin{array}{l}\text { Gay/ } \\
\text { homosexual }\end{array}$ & M & Islam & Pakistani & $\begin{array}{l}\text { Partially } \\
\text { sighted, do not } \\
\text { claim DLA }\end{array}$ & -/FT/Living with family & \\
\hline Jalany & 30 & Gay & M & Muslim & Arabic White & No & -/Employed/Rented & \\
\hline Jamal & 41 & Gay & M & Muslim & $\begin{array}{l}\text { British South } \\
\text { Asian }\end{array}$ & No & -/Employed/HO & $\begin{array}{l}\text { The love } \\
\text { of Allab; } \\
\text { Bollywood; }\end{array}$ \\
\hline
\end{tabular}


Table A.2 continued Chapter 4: Queer Muslim

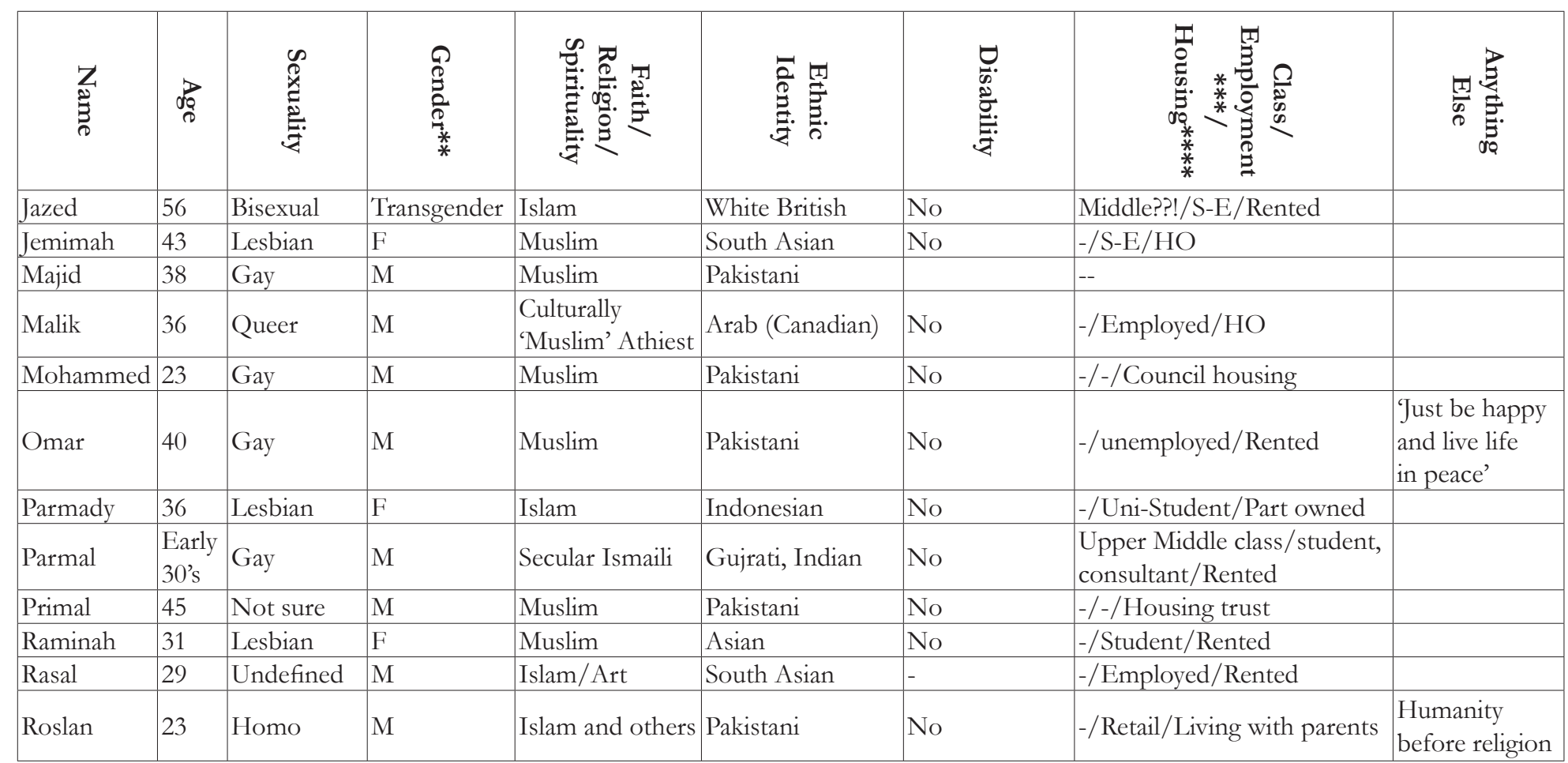


Table A.3 Chapter 5: Queer Buddhists

\begin{tabular}{|c|c|c|c|c|c|c|c|c|}
\hline 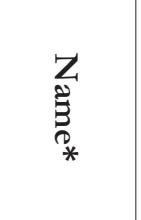 & 裉 & 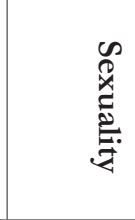 & $\begin{array}{l}0 \\
0 \\
0 \\
\frac{2}{2} \\
* \\
*\end{array}$ & 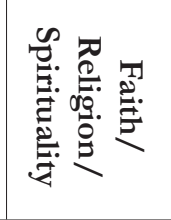 & 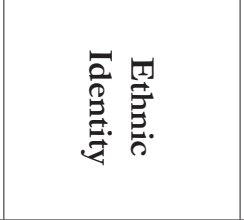 & 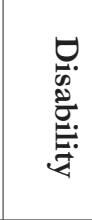 & 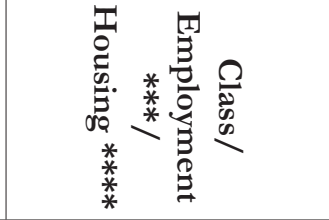 & 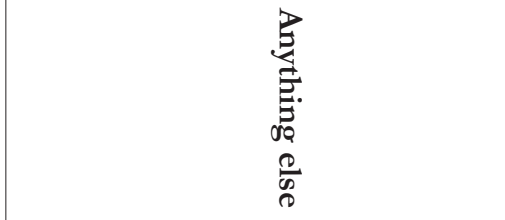 \\
\hline Ajamu X & 44 & Queer & M & Buddhist & Black British & No & -/S-E/-Housing co-op & \\
\hline Alex & 29 & Gay & M & Buddhist & White European & No & -/FT/- & \\
\hline $\begin{array}{l}\text { Boua } \\
\text { Geun }\end{array}$ & 22 & Gay & M & Buddhist & Laos & No & -/unemployed/- & \\
\hline Brian & 48 & Gay & M & Buddhist & White & No & Middle/employed/HO & Raised in Africa to 'colonial' parents \\
\hline Daisy & 37 & Lesbian & $\mathrm{F}$ & Buddhist & White British & No & -/own company/HO & \\
\hline David & 37 & Bisexual & M & $\begin{array}{l}\text { Buddhist/ } \\
\text { Christianity }\end{array}$ & White & No & -/PT/renting & \\
\hline Dh. B & 43 & - & M & Buddhist & British-Asian & - & -/S-E/- & \\
\hline Dh. D & $\begin{array}{l}\text { Senior } \\
\text { citizen }\end{array}$ & Gay & M & Buddhist & British & $\mathrm{N}$ & -/employed/- & \\
\hline Dh. E & 46 & Bisexual & $\mathrm{F}$ & Buddhist & $\begin{array}{l}\text { Black African } \\
\text { Caribbean+ } \\
\text { white English }\end{array}$ & No & Middle/S-e/- & Practicing Buddhist \\
\hline Dh. G & 48 & Lesbian & $\mathrm{F}$ & Buddhist & White UK & No & -/PT/Renting & \\
\hline
\end{tabular}


Table A.3 continued Chapter 5: Queer Buddhists

\begin{tabular}{|c|c|c|c|c|c|c|c|c|}
\hline \begin{tabular}{l}
$Z$ \\
\multirow{2}{*}{} \\
\multirow{2}{*}{} \\
$*$
\end{tabular} & do & 象. & @ & 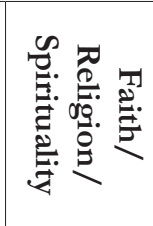 & 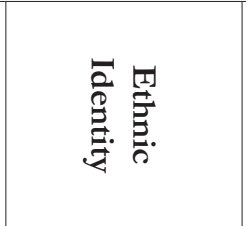 & 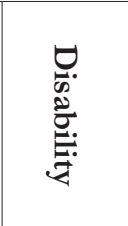 & 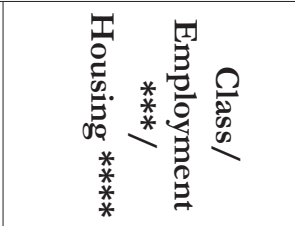 & 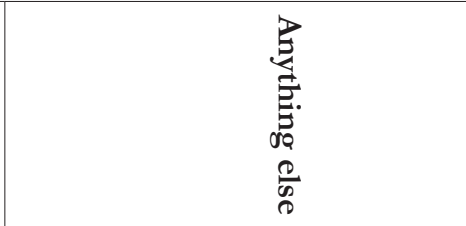 \\
\hline Dh. X & 45 & Queer & $\mathrm{F}$ & Buddhist & Caucasian & No & $\begin{array}{l}\text { Working class } \\
\text { origin/prof/rent }\end{array}$ & \\
\hline Dh. Y & 34 & Lesbian & $\mathrm{F}$ & Buddhist & Welsh & Epilepsy & -/Employed Prof./- & \\
\hline Dharma & 45 & Dyke & $\mathrm{F}$ & Buddhist & Black British & No & -Freelance/HO & \\
\hline Doug & 40 & Gay & M & Buddhist & White British & $\mathrm{HN}+$ & $-\mathrm{S}-\mathrm{E} /-$ & \\
\hline Jayamirn & 52 & $\begin{array}{l}\text { Mixed/Loose: } \\
\text { hetero/bi } \\
\text { cross dresser }\end{array}$ & M & Buddhist & $\begin{array}{l}\text { White British/ } \\
\text { Jewish }\end{array}$ & No & $\begin{array}{l}\text { Lower middle/ } \\
\text { employed }\end{array}$ & Spiritual practice, communication \\
\hline Marina & 33 & Lesbian & $\mathrm{F}$ & Buddhist & White European & $\mathrm{No}$ & -/Employed/rented & \\
\hline Mary & 40 & $\begin{array}{l}\text { Not sure, not } \\
\text { very interested } \\
\text { at the moment }\end{array}$ & F & Buddhist & White & No & $\begin{array}{l}\text { /FT/housing } \\
\text { association }\end{array}$ & $\begin{array}{l}\text { Although my gender has always } \\
\text { been female, I was born with a } \\
\text { body that appeared male and was } \\
\text { brought up as a boy. This is a } \\
\text { mistake that I have corrected }\end{array}$ \\
\hline Monica & $\begin{array}{l}43 / \\
\text { middle } \\
\text { aged }\end{array}$ & $\begin{array}{l}\text { Lesbian } \\
\text { (mostly) }\end{array}$ & $\mathrm{F}$ & Buddhist & White British & No & -/PT, student/ & \\
\hline Susanne & 38 & Lesbian & $\mathrm{F}$ & Buddhist & White British & No & $\begin{array}{l}\text { Working/PT/ } \\
\text { Communal house }\end{array}$ & \\
\hline Will & 45 & Gay & $\mathrm{M}$ & Buddhist & Irish & No & Middle/S-E/- & \\
\hline
\end{tabular}


Table A.4 Chapter 6: Michigan Womyn's Music Festival

\begin{tabular}{|c|c|c|c|c|c|c|c|c|}
\hline $\begin{array}{l}Z_{0} \\
\vdots \\
0 \\
0\end{array}$ & 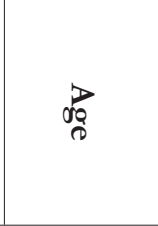 & 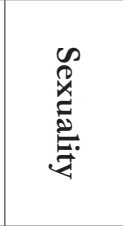 & 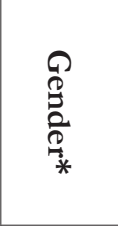 & 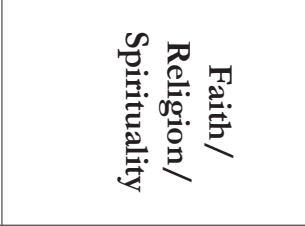 & 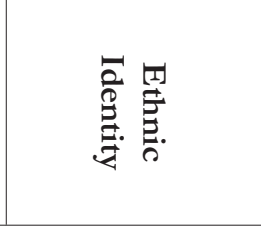 & 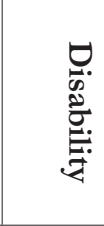 & 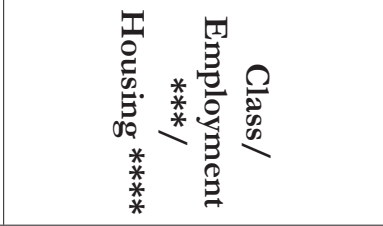 & 递 \\
\hline Alethea & 39 & Lesbian & $\mathrm{F}$ & Spiritual/Buddhist & African American & $\mathrm{No}$ & $-/-/ \mathrm{HO}$ & \\
\hline Amber & 24 & Lesbian & $\mathrm{F}$ & Queer Christianity & Caucasian & - & Middle/student, petsitter/- & \\
\hline Amy & 44 & Lesbian & $\mathrm{F}$ & $\begin{array}{l}\text { Personal faith: } \\
\text { follow the goddess, } \\
\text { member of Unitarian } \\
\text { universalist church }\end{array}$ & Caucasian & - & $\begin{array}{l}\text { Middle/Employed/ } \\
\text { Ho with partner }\end{array}$ & \\
\hline April & 35 & Lesbian & $\mathrm{F}$ & Pagan & Caucasian & No & $\begin{array}{l}\text { Professional working } \\
\text { class/-/- }\end{array}$ & \\
\hline Ashley & 25 & Queer & $\mathrm{F}$ & Buddhist, wiccan & Caucasian & No & $\begin{array}{l}\text { Lower Middle/ } \\
\text { educator/co-operative }\end{array}$ & \\
\hline Bonnie & 47 & Lesbian & Woman & Jewish & - & No & $\begin{array}{l}\text { Raised middle-upper } \\
\text { class/prof/- }\end{array}$ & \\
\hline Chelsea & 19 & Lesbian & $\mathrm{F}$ & Evangelical Lutheran & White American & - & $\begin{array}{l}\text {-/student/living } \\
\text { with parents }\end{array}$ & \\
\hline Clare & 51 & Lesbian & $\mathrm{F}$ & None & Pakeha & No & -/Employed/- & \\
\hline Denise & 54 & Lesbian & $\mathrm{F}$ & $\begin{array}{l}\text { United Methodist- } \\
\text { women- }\end{array}$ & White & No & -/FT employed/- & \\
\hline Ellen & $\begin{array}{l}52 \text { middle } \\
\text { aged }\end{array}$ & Lesbian & $\mathrm{F}$ & Witch & White & No & -/-/Professional & \\
\hline
\end{tabular}


Table A.4 continued Chapter 6: Michigan Womyn's Music Festival

\begin{tabular}{|c|c|c|c|c|c|c|c|c|}
\hline 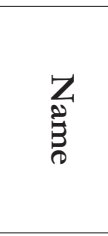 & do & & 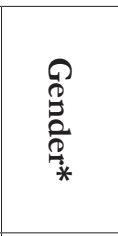 & 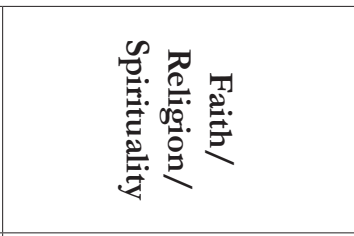 & 島 & 导. & 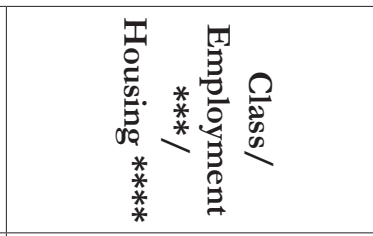 & 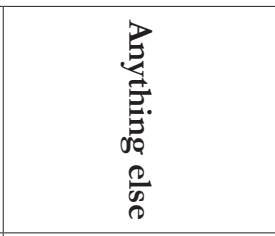 \\
\hline Eve & 62 & Lesbian & $\mathrm{F}$ & Alternative & Caucasian & No & Middle class/-/HO & \\
\hline Fern & 55 & q9 & $q$ & $\begin{array}{l}\text { Eclectic irreverently } \\
\text { spiritual }\end{array}$ & White & $\begin{array}{l}\text { CFIDS/ } \\
\text { on social } \\
\text { dis }\end{array}$ & $\begin{array}{l}\text { Raised poor, homeless } \\
\text { in the } 50 \text { 's } /-/ \text { - }\end{array}$ & \\
\hline Jeanne & 39 & Bi dyke & $\mathrm{F}$ & UU Buddhist atheist & White & No & -/Student/rented & \\
\hline Judith & 47 & Gay & $\mathrm{F}$ & $\begin{array}{l}\text { Catholic Episcopal, } \\
\text { Eastern Spirituality }\end{array}$ & $\begin{array}{l}\text { African American } \\
\text { (Black), (Native } \\
\text { American) Irish }\end{array}$ & No & $\begin{array}{l}\text { Middle class } \\
\text { American,born and raised } \\
\text { in economically depressed } \\
\text { area (ghetto)/-/- }\end{array}$ & $\begin{array}{l}\text { I am here as a } \\
\text { child of God. I am } \\
\text { woman, I am black, } \\
\text { I am gay and I am } \\
\text { proud to be me. }\end{array}$ \\
\hline Laura & 59 & Lesbian & $\mathrm{F}$ & Not religious but spiritual & Caucasian & $\mathrm{No}$ & -/Employed/- & \\
\hline Lisa & 27 & Gay & 9 & Pagan & Caucasian & No & -/House painter, artist/- & \\
\hline Louise & 44 & Queer & $\mathrm{F}$ & $\begin{array}{l}\text { Intuitive - Ther < apy> } \\
\text { Buddhism }\end{array}$ & Caucasian & No & Middle/-/- & \\
\hline Marcy & 38 & Lesbian & $\mathrm{F}$ & Circled spirituality & Caucasian & - & $-1-/-$ & \\
\hline Mary & $\begin{array}{l}62 \\
\text { (becoming } \\
\text { an elder) }\end{array}$ & Lesbian & Woman & $\begin{array}{l}\text { Jewish mother/goddess } \\
\text { loving/Buddhist/ } \\
\text { Unitarian Universalist }\end{array}$ & $\begin{array}{l}\text { European } \\
\text { American }\end{array}$ & No & $\begin{array}{l}\text { Owner class/retired, } \\
\text { volunteer, community } \\
\text { change agent/HO }\end{array}$ & $\begin{array}{l}\text { Michfest has } \\
\text { changed my life } \\
\text { and will continue } \\
\text { to do so. I am } \\
\text { nurtured here. }\end{array}$ \\
\hline
\end{tabular}


Table A.4 continued Chapter 6: Michigan Womyn's Music Festival

\begin{tabular}{|c|c|c|c|c|c|c|c|c|}
\hline $\begin{array}{l}Z \\
\sum_{3}^{2} \\
0\end{array}$ & ) & 离. & 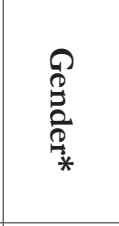 & 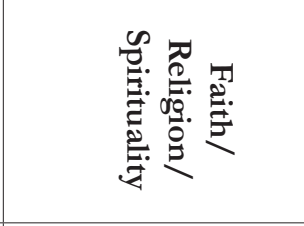 & 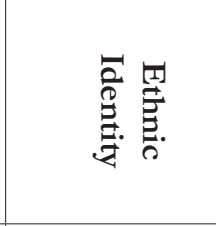 & 导. & 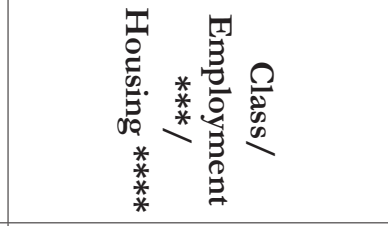 & 蛋 \\
\hline Musawa & 64 & Lesbian & $\begin{array}{l}\text { Womyn } \\
\text { (F) }\end{array}$ & $\begin{array}{l}\text { Earth based womyn's } \\
\text { spirituality }\end{array}$ & Anglo & No & $\begin{array}{l}\text {-/Mother tongue link- } \\
\text { founder employee/ } \\
\text { Womyn's land commune }\end{array}$ & $\begin{array}{l}\text { Yea you - great } \\
\text { work - keep it up }\end{array}$ \\
\hline Patty & 51 & Lesbian & Lesbian & $\begin{array}{l}\text { United church } \\
\text { of Christ, US }\end{array}$ & White & No & Middle/-/- & $\begin{array}{l}\text { Past exp: pilot/ } \\
\text { business owner/ } \\
\text { seminary student }\end{array}$ \\
\hline Roddy & 69 & Lesbian & $\mathrm{F}$ & Unitarian Univ & German & No & $\begin{array}{l}\text {-/retired/with partner } \\
\text { of } 25 \text { years }\end{array}$ & \\
\hline Sally & 69 & $\begin{array}{l}\text { Female } \\
\text { (lesbian) }\end{array}$ & - & Christian & White & No & -/Retired/- & \\
\hline Sandra & 51 & Lesbian & $\mathrm{F}$ & - & Pakeha & No & White middle class/-/- & \\
\hline Sarah & 47 & Lesbian & $\mathrm{F}$ & Christian & $\begin{array}{l}\text { European } \\
\text { American }\end{array}$ & No & Upper middle/Employed/- & \\
\hline Scout & 57-Crone & Lesbian & $\mathrm{F}$ & Earth based & $\begin{array}{l}\text { White gal, part } \\
\text { Cherokee }\end{array}$ & $\begin{array}{l}\text { Stroke/ } \\
\text { collect } \\
\text { disability }\end{array}$ & -/work one day a week/- & $\begin{array}{l}\text { MOTHER } \\
\text { EARTH }\end{array}$ \\
\hline Shane & 28 & - & - & Buddhism & - & Yes & $-1-/-$ & \\
\hline Shari & 53 & Lesbian & - & - & White & Yes & $\begin{array}{l}\text { Middle/Partner } \\
\text { supports me/- }\end{array}$ & $\begin{array}{l}\text { I wish for peace } \\
\text { among all people }\end{array}$ \\
\hline
\end{tabular}


Table A.4 continued Chapter 6: Michigan Womyn's Music Festival

\begin{tabular}{|l|l|l|l|l|l|l|l|}
\hline & & & & & & \\
\end{tabular}


Table A.5 Chapter 7: Findhorn

\begin{tabular}{|c|c|c|c|c|c|c|c|}
\hline Alyson & $20 \mathrm{~s}$ & no label, queer if pushed & $\mathrm{F}$ & white South African & No & non-aligned & community \\
\hline Camilla & $20 \mathrm{~s}$ & Fluid & $\mathrm{F}$ & white Norwegian & No & non-aligned & staff \\
\hline Diana & $50 \mathrm{~s}$ & Lesbian & $\mathrm{F}$ & white UK-English & No & non-aligned & community \\
\hline Hazel & $50 \mathrm{~s}$ & bisexual/lesbian & $\mathrm{F}$ & white Dutch & No & non-aligned & community \\
\hline Heidi & $40 \mathrm{~s}$ & Bisexual & $\mathrm{F}$ & white English & No & non-aligned & staff \\
\hline Holly & $50 \mathrm{~s}$ & Bisexual & $\mathrm{F}$ & white UK-English & No & non-aligned/earth-women's spirituality & community \\
\hline Jason & $30 \mathrm{~s}$ & Gay & M & white UK-English & No & non-aligned & visitor \\
\hline Mike & $40 \mathrm{~s}$ & Gay & $\mathrm{M}$ & white UK-Welsh & No & non-aligned & visitor \\
\hline Niels & $50 \mathrm{~s}$ & Gay & $\mathrm{M}$ & white Danish & No & non-aligned & staff \\
\hline Nigel & $40 \mathrm{~s}$ & Gay & $\mathrm{M}$ & white UK-English & No & Buddhist-Soka-Gakkai & visitor \\
\hline Rebecca & $20 \mathrm{~s}$ & Queer & $\mathrm{F}$ & white UK-Scottish & No & non-aligned & community \\
\hline
\end{tabular}


Table A.6 Chapter 8: Queer Spiritual Seekers

\begin{tabular}{|c|c|c|c|c|c|c|c|c|}
\hline 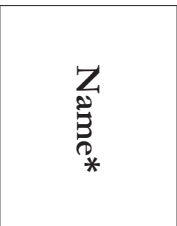 & 家 & 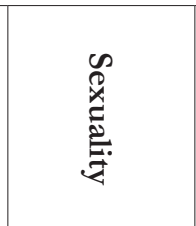 & 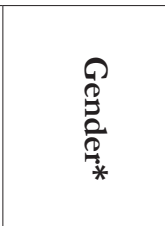 & 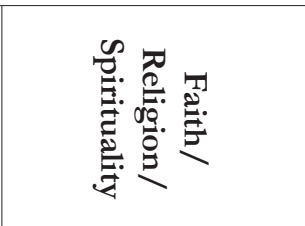 & 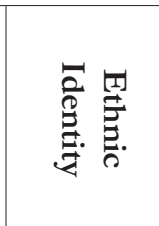 & 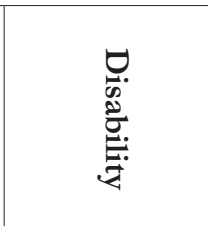 & 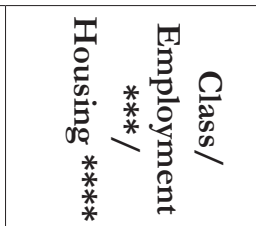 & 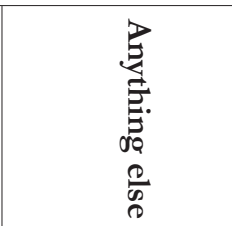 \\
\hline Alice & Late 30's & Lesbian & $\mathrm{F}$ & $\begin{array}{l}\text { Christian/Earth } \\
\text { Based Spirituality }\end{array}$ & Irish & No & $\begin{array}{l}\text {-/FT, business } \\
\text { owner/- }\end{array}$ & \\
\hline Antonia & 32 & Heterosexual & $\begin{array}{l}\text { Woman of } \\
\text { transsexual } \\
\text { experience }\end{array}$ & $\begin{array}{l}\text { My spirituality is in } \\
\text { essence a Roman } \\
\text { Catholic One. In } \\
\text { that, I mean I do not } \\
\text { necessarily agree with } \\
\text { all Church doctrine } \\
\text { but am drawn to the } \\
\text { mystical tradition } \\
\text { within Catholicism, } \\
\text { i.e. St. John of the } \\
\text { Cross, St. Teresa of } \\
\text { Avila, St. Therese } \\
\text { of the Child Jesus }\end{array}$ & $\begin{array}{l}\text { Italian } \\
\text { Welsh, } \\
\text { American }\end{array}$ & No & $\begin{array}{l}\text { Former 'upper- } \\
\text { middle class, } \\
\text { now marginalised } \\
\text { poor person/ } \\
\text { unemployed/- }\end{array}$ & \\
\hline Casey & 21 & Gay & M & $\begin{array}{l}\text { Complicated } \\
\text { interfaithness }\end{array}$ & $\begin{array}{l}\text { White/ } \\
\text { Caucasian }\end{array}$ & $\begin{array}{l}\text { Mild Cerebral } \\
\text { Palsy }\end{array}$ & $\begin{array}{l}\text { Upper-middle/ } \\
\text { student/dorms }\end{array}$ & \\
\hline $\begin{array}{l}\text { Chris, } \\
\text { Paganbearct }\end{array}$ & $\begin{array}{l}39, \\
\text { single, no } \\
\text { children }\end{array}$ & Gay & M & $\begin{array}{l}\text { Pagan and Zen } \\
\text { Buddhist }\end{array}$ & Caucasian & No & $\begin{array}{l}\text { Middle class } \\
\text { I suppose/ } \\
\text { employed FT }\end{array}$ & $\begin{array}{l}\text { My faith, my } \\
\text { gods, my family, } \\
\text { my friends }\end{array}$ \\
\hline
\end{tabular}


Table A.6 continued Chapter 8: Queer Spiritual Seekers

\begin{tabular}{|c|c|c|c|c|c|c|c|c|}
\hline 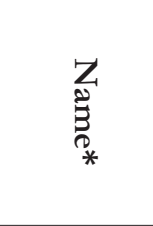 & do & 疍 & 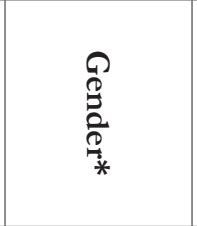 & 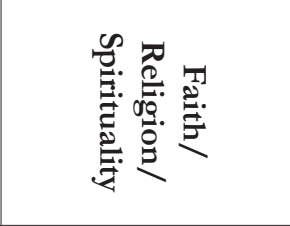 & 四 & 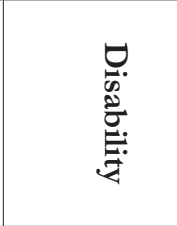 & 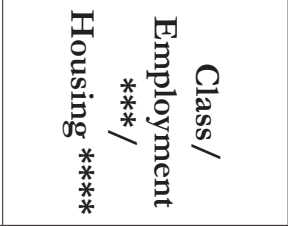 & 裉 \\
\hline Christian & - & Gay & M & $\begin{array}{l}\text { Spiritual but } \\
\text { not religious }\end{array}$ & $\begin{array}{l}\text { Cuban } \\
\text { American }\end{array}$ & - & $-1-1-$ & $\begin{array}{l}\text { Founder of } \\
\text { Q-Spirit }\end{array}$ \\
\hline Heather & 50 & Lesbian & $\mathrm{F}$ & Christian & Mixed & yes & $-/ \mathrm{FT} / \mathrm{HO}$ & \\
\hline Jari & 67 & Gay & M & $\begin{array}{l}\text { Agnostic/Buddhist/ } \\
\text { Integral }\end{array}$ & Czech & HIV/AIDS & -/Retired Prof./HO & \\
\hline $\begin{array}{l}\text { Jubilant } \\
\text { (Ardent } \\
\text { Lilliehook, } \\
\text { Jubi) }\end{array}$ & 47 & $\begin{array}{l}\text { It's } \\
\text { complicated }\end{array}$ & Transwoman & $\begin{array}{l}\text { Zen trained catholic, } \\
\text { although my } \\
\text { theology is Daoist }\end{array}$ & Caucasian & No & -/Student/Condo & $\begin{array}{l}\text { I live very } \\
\text { happily with my } \\
\text { significant other }\end{array}$ \\
\hline Paula & 35 & Lesbian & $\mathrm{F}$ & $\begin{array}{l}\text { Buddhist/Taoist/ } \\
\text { Christian }\end{array}$ & Caucasian & No & -/grad student/- & \\
\hline $\begin{array}{l}\text { Rau, } \\
\text { Luminous } \\
\text { Kanto }\end{array}$ & 44 & Omni & \begin{tabular}{|l|} 
Intersexed \\
physically, \\
androgynous \\
spiritually
\end{tabular} & $\begin{array}{l}\text { Reductionist, } \\
\text { Judaism, Tauism }\end{array}$ & $\begin{array}{l}\text { White } \\
\text { Jewish }\end{array}$ & Yes & -/employed/- & $\begin{array}{l}\text { Demographically- I } \\
\text { am the parent of } \\
\text { a multi-racial child } \\
\text { with a disability }\end{array}$ \\
\hline Rusty & 66 & Bisexual & $\mathrm{F}$ & Pagan/Christian & Scotch-Irish & No & /prof/private home & \\
\hline Simon & 48 & Gay & M & $\begin{array}{l}\text { Broadest Buddhist } \\
\text { based esoteric } \\
\text { spirituality }\end{array}$ & White & No & $\begin{array}{l}\text { Middle/ } \\
\text { freelance } / \mathrm{HO}\end{array}$ & $\begin{array}{l}\text { I am a Reiki } \\
\text { master on an } \\
\text { ascension journey }\end{array}$ \\
\hline
\end{tabular}


Table A.6 continued Chapter 8: Queer Spiritual Seekers

\begin{tabular}{|l|l|l|l|l|l|l|l|}
\hline & & & & & \\
\hline
\end{tabular}





\section{Bibliography}

Anon. 1999. The FWBO-Files. [Online]. Available at: http://fwbo-files.com/ [accessed: 14 July 2008].

Anon. no date. The Pushmepullyou. [Online]. Available at: http://www.geocities. com/geotassie/twoheads.html [accessed: 1 March 2009].

Abraham, I. 2009. 'Out to Get Us': Queer Muslims and the clash of sexual civilisations in Australia. Contemporary Islam, 3(1), 79-97.

Ahmed, S. 2006. Queer Phenomenology: Orientations, Objects, Others. Durham and London: Duke University Press.

The AHRC and ESRC Religion and Society Research Programme. no date. Religion and Society. [Online]. Available at: http://www.religionandsociety.org. uk/ [accessed: 2009].

Ali, K. 2006. Sexual Ethics and Islam: Feminist Reflections on Qur'an, Hadith, and Jurisprudence. Oxford: Oneworld.

Alpert, R. 1997. Like Bread on the Seder Plate: Jewish Lesbians and the Transformation of Tradition. New York: Columbia University Press.

Alpert, R., Elwell, S.L. and Edelson, S. 2001. Lesbian Rabbis: The First Generation. New Brunswick: Rutgers University Press.

Althaus-Reid, M. 2000. Indecent Theology. London: Routledge.

Althaus-Reid, M. 2003. The Queer God. London: Routledge.

Althaus-Reid, M. 2004. From Feminist Theology to Indecent Theology: Readings on Poverty, Sexual Identity and God. London: SCM Press.

Althaus-Reid, M. (ed.) 2006. Liberation, Theology and Sexuality. Aldershot: Ashgate.

Althaus-Reid, M. and Isherwood, L. (eds) 2004. The Sexual Theologian: Essays on Sex, God and Politic. London and New York: T. and T. Clark International. Althaus-Reid, M. and Isherwood, L. 2009. Trans/Formations. London: SCM Press.

Ammerman, N.T. 2007. Everyday Religion: Observing Modern Religious Lives. Oxford: Oxford University Press.

Armour, E.T. and St.Ville, S.M. (eds) 2006. Bodily Citations: Religion and Judith Butler. New York: Columbia University Press.

Asad, T. 2003. Formations of the Secular: Christianity, Islam, Modernity. Stanford: Stanford University Press. 
Aune, K. 2009. Between subordination and sympathy: Evangelical Christians, masculinity and gay sexuality, in Contemporary Christianity and LGBT Sexualities, edited by S.J. Hunt. Aldershot: Ashgate, 39-49.

Aune, K., Sharma, S. and Vincett, G. 2008. Women and Religion in the West: Challenging Secularization. Aldershot: Ashgate.

Austin, J.L. 1962. How to Do Things with Words: The William James Lectures Delivered at Harvard University in 1955. Oxford: Clarendon.

Banerjee, D. and Bell, M.M. 2007. Ecogender: Locating gender in environmental social science. Society and Natural Resources: An International Journal, 20(1), 3-19.

Bardella, C. 2001. Queer spirituality. Social Compass, 48(1), 117-38.

Barrett, B. 2009. Webalizer Quick Help. [online]. Available at: http:/ /www.mrunix. net/webalizer/webalizer_help.html [accessed: 6 March 2009].

Baumann, M. 2001. Global Buddhism: Developmental periods, regional histories and a new analytical perspective. Journal of Global Buddhism, 2, 1-43.

Beck, E.T. (ed.) 1982. Nice Jewish Girls: A Lesbian Anthology. Trumansburg, NY: Crossing Press.

Beck, U., Giddens, A. and Lash, S. 1994. Reflexive Modernization: Politics, Tradition and Aesthetics in the Modern Social Order. Stanford: Stanford University Press.

Beger, N.J. 2004. Tensions in the Struggle for Sexual Minority Rights in Europe: Que(e)rying Political Practices. Manchester: University of Manchester Press.

Bell, D. 1994. In bed with the state: Political geography and sexual politics. Geoforum, 25(4), 445-52.

Bell, D. 1995. Pleasure and danger: The paradoxical spaces of sexual citizenship. Political Geography, 14(2), 139-53.

Bell, D. and Kennedy, B.M. (eds) 2000. The Cybercultures Reader. London: Routledge.

Bellah, R.N., Madsen, R., Sullivan, W.M., Swidler, A. and Tipton, S.M. 1985. Habits of the Heart: Individualism and Commitment in American Life. Berkeley: University of California Press.

Ben-Ze'ev, A. 2004. Love Online: Emotions on the Internet. Cambridge: Cambridge University Press.

Benedikt, M. 1991. Cyberspace: First Steps. Massachusetts: MIT Press.

Berger, P. 1967. The Sacred Canopy: Elements of a Sociological Theory of Religion. New York: Doubleday.

Bergson, H. 1910. Time andFree Will: An Essay on the Immediate Data of Consciousness. London: George Allen and Unwin.

Bergson, H. 1968. The Creative Mind: An Introduction to Metaphysics: Westport: Greenwood.

Berlant, L. 1997. The Queen of America Goes to Washington City: Essays on Sex and Citizenship Durham: Duke University Press. 
Bernauer, J. and Carrette, J. (eds) 2004. Michel Foucault and Theology: The Politics of Religious Experience. Aldershot: Ashgate.

Binnie, J. 2004. The Globalisation of Sexuality. London: Sage.

Bluck, R. 2006. British Buddhism: Teachings, Practice and Development. London: Routledge.

Blunt, A. and Dowling, R. 2006. Home. London: Routledge.

Boellstorff, T. 2008. Coming of Age in Second Life: An Anthropologist Explores The Virtually Human. Princeton: Princeton University Press.

Bohache, T. 2003. Embodiment as incarnation: An incipient queer Christology. Theology and Sexuality, 10(1), 9-29.

Boisvert, D.L. 2005. The spiritual within: Gay male culture as spiritual venue, in Gay Religion, edited by S. Thumma and E.R. Gray. Walnut Creek: AltaMira Press, 351-66.

Boswell, J. 1980. Christianity, Social Tolerance, and Homosexuality. Chicago: Chicago University Press.

Boswell, J. 1994. Same-sex Unions in Premodern Europe. New York: Villard Books. Bouhdiba, A. 1998. Sexuality in Islam. London: Saqi Books.

Bourdieu, P. and Wacquant, L.J.D. 1992. An Invitation to Reflexive Sociology. Cambridge: Polity Press.

Brace, C., Bailey, A.R. and Harvey, D.C. 2006. Religion, place and space: A framework for investigating historical geographies of religious identities and communities. Progress in Human Geography, 30, 28-43.

Brah, A. 1996. Difference, Diversity, Differentiation, in Cartographies of Diaspora: Contesting Identities, edited by A. Brah. London: Routledge, 95-127.

Brent, B. 2006. Mind the Light: Learning to See with Spiritual Eye. Orleans: Paraclete Press.

Broad, W.J. 1992. Clinton to promote high technology, with Gore in charge. The New York Times, 10 November. 1. Available at: http://query.nytimes.com/ gst $/$ fullpage.html?res=9E0CE5DD1130F933A25752C1A964958260.

Brooks, D. 2004. Hooked on heaven lite. The New York Times, 9 March. 25.

Brown, A. 2004. Mentsh: On Being Jewish and Queer. New York: Alyson.

Brown, G. 2009. Thinking beyond homonormativity: Performative explorations of diverse gay economies. Environment and Planning A, 41(6), 1496-1510.

Browne, K. 2004. Genderism and the bathroom problem: (Re)materialising sexed sites, (re)creating sexed bodies. Gender, Place and Culture, 11(3), 331-46.

Browne, K. 2005. Snowball sampling: Using social networks to research nonheterosexual women. International Journal of Social Research Methodology, 8(1), 47-60.

Browne, K. 2006. Challenging 'queer' geographies. Antipode, 38(5), 885-93.

Browne, K. 2007. A Party with politics?: (Re)making LGBTQ Pride spaces in Dublin and Brighton. Social and Cultural Geography, 8(1), 63-87. 
Browne, K. 2008. Selling my queer soul or Can queer research be quantitative? Sociological Research Online, 13(1). [Online]. Available at: http://www. socresonline.org.uk/13/1/11.html.

Browne, K. 2009a. Naked and dirty: Rethinking (not) attending festivals. Journal of Tourism and Cultural Change, 7(2), 115-32.

Browne, K. 2009b. Womyn's separatist spaces: Rethinking spaces of difference and exclusion. Transactions of the Institute of British Geographers, 34(4), 541-56.

Browne, K. and Lim, J. 2008. Bi People: Count Me In Too Additional Findings Report. Brighton: Spectrum and the University of Brighton.

Browne, K., Lim, J. and Brown, G. (eds) 2007. Geographies of Sexualities: Theory, Practice and Politics. Aldershot: Ashgate.

Bruce, S. 1996. Religion in the Modern World, from Cathedrals to Cults. Oxford: Oxford University Press.

Bruce, S. 1998. Good intentions and bad sociology: New Age authenticity and social roles. Journal of Contemporary Religion, 13(1), 23-35.

Bruce, S. 2002. God is Dead: Secularization in the West. Oxford: Blackwell Publishing.

Bryson, M. 2004. When Jill Jacks in: Queer Women and the Net. Feminist Media Studies, 4, 239-54.

Buisson-Fenet, H. 1999. De la dissonance à l'esprit critique: Sur quelques façons d'être clerc et homosexuel. Social Compass, 46(1), 75-84.

Burke, E. 2005. A Philosophical Inquiry into the Origin of Our Ideas of the Sublime and Beautiful. Whitefish, Mont.: Kessinger Publishing.

Butler, J. 1993. Bodies that Matter: On the Discursive Limits of 'Sex'. London: Routledge.

Butler, J. 1997. Excitable Speech: A Politics of the Performative. London: Routledge.

Butler, J. 1999. Gender Trouble: Feminism and the Subversion of Identity. 10th anniversary Edition. London: Routledge.

Byrne, N. 2003. What sex is best for coral reef fish. [Online: Innovations Report]. Available from: http://www.innovations-report.de/html/berichte/biowissen schaften_chemie/bericht-20923.html [accessed: 28 August 2009].

Cabezón, J.I. 1997. Homosexuality and Buddhism, in Queer Dharma: Voices of Gay Buddhists, edited by W. Leyland. San Francisco: Gay Sunshine Press, 29-44.

Caddy, E. 1988. Flight into Freedom. Rockport: Massachusetts Element.

Caddy, P. 1995. In Perfect Timing: Memoirs of a Man for the New Millennium. Forres: Findhorn Press.

Cadge, W. 2005. Lesbian, gay, and bisexual Buddhist practitioners, in Gay Religion, edited by T. Scoot and E.R. Gray. Walnut Creek: Altamira Press, 139-52.

Camp Trans, 2005. Camp Trans: Frequently Asked Questions and Objections [Online]. Available at: http://www.camp-trans.org/trans-inclusion-and-michfest [accessed: 31 August 2007].

Campbell, J.E. 2004. Getting it on Online. Philadelphia: Haworth Press. 
Carrette, J. and King, R. 2005. Selling Spirituality: The Silent Takeover of Religion. New York: Routledge.

Casey, M. 2004. De-dyking queer space(s): Heterosexual female visibility in gay and lesbian spaces. Sexualities, 7(4), 446-61.

Clarke, P.B. 2006. New Religions in Global Perspective. Abingdon, Oxon: Routledge.

Cloke, P. 2003. Country Visions. London: Pearson.

Cloke, P. and Little, J. 1997. Introduction: Other countrysides?, in Contested Conuntryside Cultures: Otherness, Marginalisation and Rurality, edited by P. Cloke and J. Little. London: Routledge, 1-18.

Coleman, E., Colgan, P. and Gooren, L. 1999. Male cross-gender behavior in Myanmar (Burma): A description of the acault, in Que(e)rying Religion: A Critical Anthology, edited by G.D. Comstock and S.E. Henking. New York: Continuum, 287-93.

Comstock, G.D. 1996. Unrepentant, Self-Affirming, Practicing: Lesbian/Bisexual/Gay People within Organized Religion. New York: Continuum.

Comstock, G.D. and Henking, S.E. (eds) 1997. Que(e)rying Religion: A Critical Anthology. New York: Continuum.

Cooke, M. 2007. The Muslimwoman. Contemporary Islam, 1(2), 139-54.

Cooper, W.A. 2001. A Living Faith: An Historical and Comparative Study of Quaker Beliefs. Second Edition. Richmond, Indiana: Friends United Press.

Corless, R. 1998. Coming out in the Sangha: Queer community in American Buddhism, in The Faces of Buddhism in America, edited by C.S. Prebish and K.K. Tanaka. Berkeley: University of California Press, 253-65.

Corless, R. 2004. Towards a queer dharmology of sex. Culture and Religion, 5(2), $229-43$.

Cornwall, S. 2009. 'State of mind' versus 'concrete set of facts': The contrasting of transgender and intersex in Church documents on sexuality. Theology and Sexuality, 15(1), 7-28.

Countryman, W. 2007. Dirt, Greed, and Sex: Sexual Ethics in the New Testament and Their Implications. Minneapolis: Fortress Press.

Cox, A. 2008. Sex Change - Taking It to the Fishes [Online: ION Publications LLC]. Available from: http://www.scientificblogging.com/variety_tap/sex_ change_taking_it_fishes_progress [accessed: 29 October 2008].

Crenshaw, K. 1989. Demarginalizing the intersection of race and sex: A black feminist critique of antidiscrimination doctrine, feminist theory and antiracist politics. University of Chicago Legal Forum, 139-67.

Curb, R. and Manahan, N. (eds) 1985. Lesbian Nuns: Breaking the Silence. Tallahassee, FL.: Naiad Press.

Cvetkovich, A. 2003. An Arcbive of Feelings: Trauma, Sexuality, and Lesbian Public Culture. Durham: Duke University Press. 
Cvetkovich, A. and Wahng, S. 2001. Don't stop the music: Roundtable discussion with workers from the Michigan Womyn's Music Festival. GLQ: Journal of Lesbian and Gay Studies, 7(1), 131-51.

Daly, M. 1978. Gyn/ecology: The Metaphysics of Radical Feminism. Boston: Beacon Press.

Dandelion, P. 1996. A Sociological Analysis of the Theology of Quakers: The Silent Revolution. Lampeter: Edwin Mellen Press.

Dandelion, P. (ed.) 2004. The Creation of Quaker Theory: Inside Perspectives. Aldershot: Ashgate.

Dandelion, P. 2005. The Liturgies of Quakerism. Aldershot: Ashgate.

Dandelion, P. 2007. An Introduction to Quakerism. Cambridge: Cambridge University Press.

Dandelion, P. 2008. The Quakers: A Very Short Introduction. Oxford: Oxford University Press.

Dandelion, P., Gwyn, D., Muers, R., Phillips, B. and Sturm, R.E. 2004. Towards Tragedy/Reclaiming Hope: Literature, Theology and Sociology in Conversation. Aldershot: Ashgate.

Davidson, J., Bondi, L. and Smith, M. (eds) 2005. Emotional Geographies. Aldershot: Ashgate.

Dawkins, R. 2006. The God Delusion. London: Bantam.

Dawson, L. and Cowan, D. (eds) 2004. Religion Online: Finding Faith on the Internet. New York: Routledge.

Deleuze, G. 1988. Bergsonism. New York: Zone Books.

Dillon, M. 1999. Catholic Identity: Balancing Reason, Faith, and Power. Cambridge: Cambridge University Press.

Dillon, M. (ed.) 2003. Handbook of the Sociology of Religion. Cambridge: Cambridge University Press.

Dingwall, E.J. 1962. Very Peculiar People: Portrait Studies in the Queer, the Abnormal and the Uncanny. New York: University Books.

Dinnie, E. 2008. Managing Individuality: An Ethnographic Study of the Findhorn Foundation Community. Unpublished PhD Thesis, University of Aberdeen.

Doctor Dolittle (dir. R. Fleischer, 1998).

Duggan, L. 2002. The new homonormativity: The sexual politics of neoliberalism, in Materializing Democracy: Toward a Revitalized Cultural Politics, edited by R. Castronovo and D.D. Nelson. Durham: Duke University Press, 175-94.

Duggan, L. 2003. The Twilight of Equality: Neoliberalism, Cultural Policy, and the Attack on Democracy. Boston: Beacon Press.

Durkheim, E. 2001. The Elementary Forms of Religious Life. Oxford: Oxford University Press.

Engel, S. 2001. The Unfinished Revolution: Social Movement Theory and the Gay and Lesbian Movement. Cambridge: Cambridge University Press. 
Enke, A. 2007. Finding the Movement: Sexuality, Contested Space, and Feminist Activism. Durham and London: Duke University Press.

Erdem, E., Haritaworn, J. and Tauqir, T. 2008. Queer imperialism: The role of gender and sexuality discourses in the 'War on Terror', in Out of Place: Silences in Queerness/Raciality, edited by E. Miyake and A. Kuntsman. York: Raw Nerve Books, 9-33.

Esposito, J., Hitchcock, S.T., Tutu, D. and Tuto, M. 2004. Geography of Religion: Where God Lives, Where Pilgrims Walk. National Geographic.

Fanthorpe, U.A. and Bailey, R.V. 2007. From Me to You: Love Poems. London: Enitharmon.

Faure, B. 1998. The Red Thread: Buddhist Approaches to Sexuality. Princeton, NJ: Princeton University Press.

Faure, B. 2003. The Power of Denial: Buddhism, Purity and Gender. Princeton, NJ: Princeton University Press.

Feinberg, L. 1997. Transgender Warriors: Making History from Jon of Arc to Rupaul. Boston: Beacon.

The Findhorn Foundation. no date a. The Findhorn Foundation Home Page. [Online]. Available at: http://www.findhorn.org [accessed: 3 May 2008].

The Findhorn Foundation. no date b. What We Do. [Online]. Avaialble at: http://www.findhorn.org/whatwedo/community/nfa.php [accessed: 7 January 2009].

The Findhorn Foundation. no date c. The Findhorn Foundation Courses and Workshops May - October 2008 [Online]. Available at: http://www.findhorn. org/workshops/resources/FFBrochureSummer2008.pdf [accessed: 13 December 2008].

Finding Nemo (dir. A. Stanton, 2003). Flgbtqc, Friends for Lesbian, Gay, Bisexual, Transgender, and Queer Concerns. [Online]. Available at: http://flgbtqc.quaker. org [accessed: 2 December 2008].

Foster, T. 2005. The Souls of Cyberfolk: Posthumanism as Vernacular Theory. Minneapolis: University of Minnesota Press.

Foucault, M. 1979. The History of Sexuality Volume 1: An Introduction. London: Allen Lane.

Foucault, M. 1984a. The History of Sexuality Volume 2: The Use of Pleasure. Harmondsworth: Penguin Books.

Foucault, M. 1984b. What is Enlightenment?. in The Foucault Reader, edited by P.

Rabinow. Harmondsworth: Penguin, 32-50.

Foucault, M. 1986a. Of other spaces. Diacritics, 22-7.

Foucault, M., 1986b. The History of Sexuality Volume 3: The Care of the Self. Harmondsworth: Penguin.

Foucault, M. 1991. Politics and the study of discourse, in The Foucault Effect:

Studies in Governmentality, edited by G. Burchell, C. Gordon and P.M. Miller.

Chicago: University of Chicago Press, 53-72. 
Foucault, M. 1993. About the beginning of the hermeneutics of the self. Political Theory, 21(2), 198-227.

Foucault, M. 1997a. On the genealogy of ethics: An overview of work in progress, in Ethics: Subjectivity and Truth, edited by P. Rabinow. London: Penguin Books, 253-80.

Foucault, M. 1997b. The ethics of the concern for self as a practice of freedom, in Ethics: Subjectivity and Truth, edited by P. Rabinow. New York: New Press, 281-301.

Foucault, M. and Baker, C. 1984. Interview with Michel Foucault. Actes, 45-6 (June), 3-6.

Fowler, M. 2001. Sexual and social scripts and the re-imaginings of community identity. Ethnologies, 23(1), 45-61.

Fox, G. 1975. The Journal of George Fox. London: London Yearly Meeting.

Francis, E., Pratt, M. and Chedgzoy, K. 2002. In a Queer Place: Sexuality and Belonging in British and European Context. Aldershot: Ashgate.

Frankenberg, R. 1997. Living Spirit, Living Practice: Poetics, Politics, Epistemology. Durham: Duke University Press.

Friends Home Service Committee. 1963. Towards a Quaker View of Sex. London: Friends Home Service Committee.

Fuller, R.C. 2001. Spiritual, but not Religious: Understanding Unchurched America. New York: Oxford University Press.

Gallagher, L., Roden, F.S. and Smith, P.J. (eds) 2006. Catholic Figures, Queer Narratives. Basingstoke: Palgrave Macmillan.

Geertz, C. 1973. The Interpretation of Cultures. New York: Basic Books.

Gibson, W. 1984. Neuromancer. New York: Ace Books.

Giffney, N. and Hird, M.J. (eds) 2008. Queering the Non/Human. Aldershot: Ashgate.

Gill, S. 1998. Lesbian and Gay Christian Movement: Campaigning for Justice, Truth and Love. London: Continuum.

Gillman, H. 1988. A Minority of One: A Journey with Friends. London: Quaker Home Service.

Gillman, H. 2003. A Light that Is Shining: An Introduction to the Quakers. Third Edition. London: Quaker Books.

Glaser, C. 1988. Uncommon Calling; A Gay Mean's Struggle to Serve the Church. Louisville, KY: Westminster John Knox.

Goko Media LLC. 2007. MyOutSpirit.com Terms of Service. [Online]. Available at: www.myoutspirit.com —index.php [accessed: 12 December 2008].

Goldberg, A. 2009. Light in the Closet: Torah, Homosexuality, and the Power to Change. Beverly Hills, CA: Red Heifer Press.

Gorman-Murray, A. 2008. Queering the family home: narratives from gay, lesbian and bisexual youth coming out in supportive family homes in Australia. Gender, Place and Culture, 15(1), 31-44. 


\section{BIBLIOGRAPHY}

Gorrell, P.J. 2005. Rite to party: Circuit parties and religious experiences, in Gay Religion, edited by S. Thumma and E.R. Gray. Walnut Creek: AltaMira Press, 313-26.

Goss, R. 2002. Queering Christ: Beyond Jesus Acted Up. Cleveland, OH: Pilgrim Press.

Goss, R. and West, M. 2000. Take Back the Word. Cleveland, OH: The Pilgrim Press.

Gray, E.R. and Thumma, S. 2005. The gospel hour: Liminality, identity, and religion in a gay bar, in Gay Religion, edited by S. Thumma and E.R. Gray. Walnut Creek: AltaMira Press, 285-302.

Gray, M.L. 2009. Out in the Country: Youth, Media, and Queer Visibility in Rural America. New York: New York University Press.

Green, M. and Numrich, P. 2001. Religious Perspectives on Sexuality. Chicago: The Park Ridge Center.

Greenberg, S. 2005. Wrestling with God and Men: Homosexuality in the Jewish Tradition. Wisconsin: University of Wisconsin Press.

Greenham Commemorative Fund Appeal Collective. no date. Greenham Common Women's Peace Camp Commemorative and Historic Site. [Online]. Available at: http://www.greenhamwpc.org.uk/historic.htm [accessed: 13 January 2009].

Gregson, N. and Rose, G. 2000. Taking Butler elsewhere: Performativities, spatialities and subjectivities. Environment and Planning D-Society and Space, 18(4), 433-52.

Gribbon, J. 2009. In Search of the Multiverse. London: Allen Lane.

Gross, M. 2007a. Juif et homosexuel, affiliations identitaires et communalisation. Social Compass, 54(2), 225-38.

Gross, M. 2007b. Les rabbins français et l'nomoparentalité: Discours et attitudes. Archives de Sciences Sociales des Religions, 13, 65-84.

Gross, M. 2008. To be Christian and homosexual: From shame to identitybased claims. Nova Religio, 11(4), 77-101.

Gross, M. and Yip, A.K.T. 2010. Living spirituality and sexuality: A comparison of lesbian, gay, and bisexual Christians in France and Britain. Social Compass, 57(1), 1-17.

Gross, R. 1993. Buddhism after Patriarchy: A Feminist History, Analysis, and Reconstruction of Buddhism. New York: State University of New York Press.

Grosz, E.A. 1999. Becomings: Explorations in Time, Memory, and Futures. London: Cornell University Press.

Grosz, E.A. and Copeland, J. 2005. The Creative Impulse: Elizabeth Grosz (Interview with Elizabeth Grosz with Julie Copeland). [Radio interview]. ABC, 5 June. Available at: http://www.abc.net.au/rn/arts/sunmorn/stories/s1381964. htm.

Grovijahn, J.M. 2008. Godly sex, a queer quest of holiness. Theology and Sexuality, $14(2), 121-42$. 
Guardian Editorial Comment. 2009. In praise of ... The Quakers. The Guardian, 1 August, 32.

Guest, D. 2005. Lesbian Biblical Hermeneutics. London: SCM Press.

Guest, D., Goss, R.E., West, M. and Bohache, T. 2006. The Queer Bible Commentary. London: SCM Press.

Gyatso, J. 2003. One plus one makes three: Buddhist gender, monasticism, and the law of the non-excluded middle. History of Religions, 43(2), 89-115.

Halberstam, J. 2005. In a Queer Time and Place: Transgender Bodies, Subcultural Lives. London: New York University Press.

Halbertal, T.H. and Koren, I. 2006. Between 'being' and 'doing': Conflict and coherence in the identity formation of gay and lesbian orthodox Jews, in Identity and Story: Creating Self in Narrative, edited by D.P. Mcadams, R. Josselson and A. Lieblich. Washington D. C.: American Psychological Association, 37-61.

Hall, D. (ed.) 1997. Lived Religion in America: Towards A History of Practice. Princeton: Princeton University Press.

Hall, R. 1968. The Well of Loneliness. London: Corgi/Jonathan Cape.

Halperin, D. 1995. Saint Foucault: Towards a Gay Hagiography. New York: Oxford University Press.

Hammoud-Beckett, S. 2007. Azima ila hayati - An invitation in to my life: Narrative conversations about sexual identity. International Journal of Narrative Therapy and Community Work, 29(1), 29-39.

Hanway, D.G. 2006. A Theology of Gay and Lesbian Inclusion: Love Letters to the Church. New York: Haworth Press.

Haqq, I.A. 2000. Homosexuality and Islam in America. Journal of Islamic Law and Culture, 5, 87-96.

Harasym, S. 1990. The Post-Colonial Critic: Interviews, Strategies, Dialogues. London: Routledge.

Haritaworn, J. 2007. Queer mixed race? Interrogating homonormativity through Thai interraciality, in Geographies of Sexualities: Theory, Practices and Politics, edited by K. Browne, J. Lim and G. Brown. Aldershot: Ashgate, 101-11.

Harris, S. 2004. The End of Faith: Religion, Terror, and the Future of Reason. New York: W.W. Norton and Co.

Harvey, P. 2000. An Introduction to Buddhist Ethics: Foundations, Values and Issues. Cambridge: Cambridge University Press.

Hasan, T. 2000. Become golden pillars of Kosen-Rufu. World Tribune, 19 May, 11.

Heelas, P. 1996. The New Age Movement: The Celebration of the Self and the Sacralization of Modernity. Oxford: Blackwell.

Heelas, P. 2008. Spiritualities of Life: New Age Romanticism and Consumptive Capitalism. Oxford: Blackwell. 
Heelas, P., Woodhead, L., Seel, B., Szerszynski, B. and Tusting, K. 2004. The Spiritual Revolution: Why Religion Is Giving Way to Spirituality. Oxford: WileyBlackwell.

Hemmings, C. 2002. Bisexual Spaces: A Geography of Sexuality and Gender. London: Routledge.

Henrickson, M., Neville, S., Jordan, C. and Donaghey, S. 2007. Lavender islands:

The New Zealand study. Journal of Homosexuality, 31(4), 57-73.

Herman, T. and Swiss, A. (eds) (2000) The World Wide Web and Cultural Theory. London: Routledge.

Heron, A. (ed.) (1963) Towards A Quaker View of Sex: An Essay by a Group of Friends. London: Friends Home Service Committee.

Herrup, C. 1999. A House in Gross Disorder: Sex, Law, and the 2ndEarl of Castlehaven. Oxford: Oxford University Press.

Hetherington, K. 1998. Expressions of Identity: Space, Performance, Politics. London: SAGE Publications.

Hetherington, K. 2000. New Age Travellers: Vanloads of Uproarious Humanity. London: Cassell.

Hickman, M.J. 1995. Religion, Class and Identity: The State, the Catholic Church and the Education of the Irish in Britain. Aldershot: Avebury.

Hill Collins, P. 2000. Black Feminist Thought: Knowledge, Consciousness, and the Politics of Empowerment. Second Edition. New York: Routledge.

Hill Collins, P. and Andersen, M. (eds) (2007) Race, Class, and Gender: An Anthology. Belmont, CA: Wadsworth.

Himat. Gaymenswellbeing. [Online]. Available at: http://www.gaymenswellbeing. com/groups/himat/ [accessed: 5 April 2009].

Hine, C. 2000. Virtual Ethnography. London: Sage.

Hitchens, C. 2007. God Is Not Great: How Religion Poisons Everything. London: Atlantic.

Holloway, J. 2006. Enchanted spaces: The seance, affect, and geographies of religion. Annals of the Association of American Geographers, 96(1), 182-87.

Holloway, J. and Valins, O. 2002. Editorial: Placing religion and spirituality in geography. Social and Cultural Geography, 3(1), 5-9.

Hoover, S. 2006. Religion in the Media Age. London: Routledge.

Horn, M.J., Piedmont, R.L., Fialkowski, G.M., Wicks, R.J. and Hunt, M.E. 2005. Sexuality and spirituality: The embodied spirituality scale. Theology and Sexuality, 12(1), 81-102.

Hudson, W. and Ricketts, W. 1980. A strategy for the measure of homophobia. Journal of Homosexuality, 5(4), 357-72.

Hume, L. and Mcphillis, K. (eds) 2006. Popular Spiritualities: The Politics of Contemporary Enchantment. Aldershot: Ashgate.

Hunt, S. 2003. Alternative Religions: A Sociological Introduction. Hampshire: Ashgate. 
Hunt, S.J. 2009. Human rights and moral wrongs: The Christian 'gay debate' in the secular sphere, in Contemporary Christianity and LGBT Sexualities, edited by S.J. Hunt. Aldershot: Ashgate, 103-21.

Hunter, N., Joslin, C. and Mcgowan, S. 2004. The Rights of Lesbians, Gay Men, Bisexuals, and Transgender People. Carbondale, IL: Southern Illinois University Press.

Imtoual, A. and Hussein, S. 2009. Challenging the myth of the happy celibate: Muslim women negotiating contemporary relationships. Contemporary Islam, 3(1), 25-39.

Inge, J. 2003. A Christian Theology of Place. Aldershot: Ashgate.

Internet World Stats. 2009. Internet World Stats - Internet and Population Statistics. [Online: Miniwatts Marketing Group]. Available from: http://www. internetworldstats.com [accessed: 2 February 2009].

Ivakhiv, A. 2006. Toward a geography of 'religion': Mapping the distribution of an unstable signifier. Annals of the Association of American Geographers, 96(1), 169-75.

Jackson, P.A. 1998. Male homosexuality and transgenderism in the Thai Buddhist tradition, in Queer Dharma: Voices of Gay Buddhists, edited by W. Leyland. San Francisco: Gay Sunshine Press, 55-89.

Jackson, P.A. 1999. Tolerant but unaccepting: The myth of a Thai 'gay paradise', in Genders and Sexualities in Modern Thailand, edited by P.A. Jackson and N. Cook. Chiang Mai: Silkworm Books, 226-42.

Jackson, P.A. 2000. An explosion of Thai identities: Global queering and reimagining queer theory. Culture, Health and Sexuality, 2(4), 405-24.

Jackson, P.A. 2003. Performative genders, perverse desires: A bio-history of Thailand's same-sex and transgender cultures. Intersections: Gender, History and Culture in the Asian Context [Online], (9). Available at: http://intersections. anu.edu.au/issue9/jackson.html.

Jagose, A. 1996. Queer Theory: An Introduction. Melbourne: University of Melbourne Press.

Jakobsen, J.R. and Pellegrini, A. (eds) (2008) Secularisms. London: Duke University Press.

Jamal, A. 2001. The story of Lot and the Qur'an's perception of the morality of same-sex sexuality. Journal of Homosexuality, 41(1), 1-88.

Jenzen, O. 2007. The Queer Uncanny. eSharp [Online], (9). Available at: http:// www.gla.ac.uk/media/media_41216_en.pdf.

Jenzen, O. 2009. Queering The Fantastic: Dissident Sexuality and Gender in the Works of Jeanette Winterson. Unpublished PhD Thesis. University of Sussex.

Jñanavira. 2003. Homosexuality in the Japanese Buddhist tradition. Western Buddhist Review [Online], 3. Available at: http://www.westernbuddhistreview. com/vol3/homosexuality.html. 


\section{BIBLIOGRAPHY}

Jordan, M. 1998. The Invention of Sodomy in Christian Theology. Chicago: University of Chicago Press.

Jordan, M. 2000. The Silence of Sodomy: Homosexuality and Modern Catholicism. Chicago: University of Chicago Press.

Jordan, M. 2005. Blessing Same-sex Unions: The Perils of Queer Romance and the Confusions of Christian Marriage. Chicago: University of Chicago Press.

Jordan, M. 2006. Authorizing Marriage: Canon, Tradition, and Critique in the Blessing of Same-sex Unions. Princeton: Princeton University Press.

Kant, I. 1987. Critique of Judgment. Cambridge: Hackett.

Keating, T. 1986. Open Mind, Open Heart: The Contemplative Dimension of the Gospel. London: Continuum.

Keenan, M. 2007. Fishers of Men: An Exploration of the Identity Negotiations of Gay Male Anglican Clergy. Unpublished PhD Thesis. Nottingham Trent University.

Keenan, M. 2008. Freedom in chains: Religion as enabler and constraint in the lives of gay male Anglican clergy, in Religion and the Individual, edited by A. Day. Aldershot: Ashgate, 169-82.

Keenan, M. 2009. The gift that dare not speak its name: Exploring the influence of sexuality on the professional performances of gay male Anglican clergy, in Contemporary Christianity and LGBT Sexualities, edited by S.J. Hunt. Aldershot: Ashgate, 23-37.

Kendall, L. 2008. The Michigan Womyn's Music Festival: An Amazon Matrix of Meaning. Baltimore: The Spiral Womyn's Press.

Kennedy, E.L. and Davis, M.D. 1993. Boots of Leather, Slippers of Gold: The History of a Lesbian Community. London: Penguin.

Kennedy, P. 2007. Man-made Monk. Tricycle: The Buddhist Review, (16), 60-65.

Keown, D. 2003. A Dictionary of Buddhism. New York: Oxford University Press.

Khan, B. 1997. Sex Longing and Not Belonging: A Gay Muslim's Quest for Love and Meaning. New York: Floating Lotus.

Khayatt, D. 2002. Toward a queer identity. Sexualities, 5(4), 487-501.

King, C. 2000. A love as fierce as death: Reclaiming the Song of Songs for queer lovers, in Take Back the Word, edited by R. Goss and M. West. Cleveland, OH: The Pilgrim Press, 126-42.

King, R. 1999. Orientalism and Religion: Postcolonial Theory, India and the Mystic East'. London: Routledge.

Kirsch, M.H. 2000. Queer Theory and Social Change. London: Routledge.

Klesse, C. 2007. The Spectre of Promiscuity: Gay Male and Bisexual Non-monogamies and Polyamories. Aldershot: Ashgate.

Koch, T. 2001. A homoerotic approach to scripture. Theology and Sexuality, 7(14), 10-22. 
Kolodny, D.R. 2000. Blessed Bi Spirit: Bisexual People of Faith. New York: Continuum.

Kong, L. 1990. Geography and religion: trends and prospects. Progress in Human Geography, 14(3), 355-71.

Kong, L. 2001. Mapping 'new' geographies of religion: politics and poetics in modernity. Progress in Human Geography, 25(2), 211-33.

Kugle, S.S. 2003. Sexuality, diversity and ethics in the agenda of progressive Muslims, in Progressive Muslims: On Justice, Gender, and Pluralism, edited by $\mathrm{O}$. Safi. Oxford: Oneworld, 190-234.

Kugle, S.S. 2007. Sexual diversity in Islam, in Voice of Islam (Vol. 5), edited by V.J. Cornell, V.G. Henry-Blackemore and O. Safi. Westport, CT: Praeger, 131-68.

Kugle, S.S. 2010. Homosexuality in Islam: Critical Reflection on Gay, Lesbian, and Transgender Muslims. Oxford: Oneworld.

Kuntsman, A. 2007. Belonging through violence: Flaming, erasure, and performativity in queer migrant community, in Queer Online: Media Technology and Sexuality, edited by K. O'Riordan and D. Phillips. New York: Peter Lang, $101-20$.

Larsen, E. 2004. Cyberfaith: How American's pursue religion online, in Religion Online: Finding Faith on the Internet, edited by L. Dawson and D. Cowan. New York: Routledge, 17-22.

Lefebvre, H. 1994. The Production of Space. Oxford: Blackwell.

Lesbian and Gay Christian Movement. 2000. Christian Homophobia. London: LGCM.

The Lesbian and Gay Christian Movement National Resource Centre. 2001. Lesbian and Gay Christians. [Online]. Available at: http://www.lgcm.org.uk/ [accessed: 5 January 2009].

Lewis, K., Kaufman, J., Gonzalez, M., Wimmer, A. and Christakis, N. 2008. Tastes, ties, and times: A new social network data set using Faecebook.com. Social Networks, 30(4), 330-342.

Leyland, W. (ed.) 1997. Queer Dharma: Voices of Gay Buddhists (First Volume). San Francisco: Gay Sunshine Press.

Leyland, W. (ed.) 1999. Queer Dharma: Voices of Gay Buddhists (Second Volume). San Francisco: Gay Sunshine Press.

Lim, J., Brown, G. and Browne, K. 2007. Conclusions and future directions, or our hopes for geographies of sexualities (and queer geographies), in Geographies of Sexualities: Theory, Practices and Politics, edited by K. Browne, J. Lim and G. Brown. Aldershot: Ashgate, 215-24.

Long, R.E. 2004. Men, Homosexuality and the Gods. New York: Haworth Press. Lorde, A. 1984. Sister Outsider: Essays and Speeches. Freedon, CA: The Crossing Press. 


\section{BIBLIOGRAPHY}

Lorde, A. 1994. Uses of the erotic: The erotic as power, in Sexuality and the Sacred: Sources for Theological Reflection, edited by J. Nelson and S. Longfellow. Louisville: John Knox Press, 75-9.

Loughlin, G. (ed.) 2007. Queer Theology: Rethinking the Western Body. Oxford: Blackwell.

Lozada, F. 2000. Identity, in Handbook of Postmodern Biblical Interpretation, edited by A.K.M. Adam. St. Louis, MO: Chalice Press, 113-19.

Lukenbill, B. 1998. Observations of the corporate culture of a gay and lesbian congregation. Journal for the Scientific Study of Religion, 37(3), 440-552.

Lynch, G. 2007. The New Spirituality: An Introduction to Progressive Belief in the Twenty-first Century. London: I.B. Tauris.

Lynch, G. (ed.) (2007) Between Sacred and Profane: Researching Religion and Popular Culture. London: I.B. Tauris.

Lyotard, J.-F. 1994. Lessons on the Analytic of the Sublime: Kant's 'Critique of Judgement'. Stanford: Stanford University Press.

Machacek, D.W. and Wilcox, M.M. 2003. Sexuality and the World's Religions. Oxford: ABC-CLIO.

Machacek, D.W. and Wilcox, M.M. 2008. Introduction: Queering the study of new religious movements. Nova Religio, 11(4), 3-7.

Macknee, C.M. 2002. Profound sexual and spiritual encounters among practicing Christians: A phenomenological analysis. Journal of Psychology and Theology, 30, 234-44.

Macourt, M. 1977. Towards a Theology of Gay Liberation. London: SCM Press.

Mahaffy, K.A. 1996. Cognitive dissonance and its resolution: A study of lesbian Christians. Journal for the Scientific Study of Religion, 35(4), 392-402.

Maher, M.J. 2006. A voice in the wilderness: Gay and lesbian religious groups in the western United States. Journal of Homosexuality, 51(4), 91-117.

Maitreyabandhu. 1998. Coming out into Dharma bliss, in Queer Dharma: Voices of Gay Buddhists, edited by W. Leyland. San Francisco: Gay Sunshine Press, 208-12.

Manji, I. 2003. The Trouble with Islam. New York: Random House.

Marks, J. 2008. Exchanging the Truth for a Lie. London: Courage UK.

Marler, P.L. 2008. Religious change in the West: watch the women, in Women and Religion in the West, edited by K. Aune, S. Sharma and G. Vincett. Aldershot: Ashgate, 23-56.

Martin, D. 2005. On Secularization: Towards a Revised General Theory. Aldershot: Ashgate.

Maslow, A.H. 1943. A Theory of human motivation. Psychological Review, 50, 370-96.

Mayfield, W. 2001. The development of an internalized homonegativity inventory for gay men. Journal of Homosexuality, 41(2), 53-76. 
McCall Tigert, L. 1996. Coming Out While Staying In: Struggles and Celebrations of Lesbians, Gays, and Bisexuals in the Church. Cleveland: United Church Press.

Mcclennen, J.C. 2003. Researching gay and lesbian domestic violence: The journey of a non-LGBT researcher, in Research Methods with Gay, Lesbian, Bisexual and Transgender Populations, edited by M. William and J.I. Martin. New York: Haworth Press, 31-46.

Mccormick, I. (ed.) 1997. Secret Sexualities: A Sourcebook of 17th and 18th Century Writing. London: Routledge.

Mcfadyen, A. 2000. Bound to Sin. Cambridge: Cambridge University Press.

Mcguire, M. 2008. Lived Religion: Faith and Practice in Everyday Life. Oxford: Oxford University Press.

Mcintosh, M. 1993. Queer theory and the war of the sexes, in Activating Theory: Lesbian, Gay, Bisexual Politics, edited by J. Bristow and A.R. Wilson. London Lawrence and Wishart, 32-52.

Mckim, D. 2001. The Westminster Handbook To Reformed Theology. Louisville, Westminster: John Knox Press.

Mclean, K. 2008. Coming out, again: Boundaries, identities and spaces of belonging. Australian Geographer, 39(3), 303-313.

Meezan, W. and Martin, J.I. 2003. Exploring current themes in research in gay, lesbian, bisexual and transgender populations, in Research Methods with Gay, Lesbian, Bisexual and Transgender Populations, edited by M. William and J.I. Martin. New York: Haworth Press, 1-14.

Mellor, P.A. and Shilling, C.,1997. Re-forming the Body: Religion, Community and Modernity. London: Sage.

Metcalf, W.J. 2004. Community Living. Forres: Findhorn Press.

Minwalla, O., Rosser, B., Feldman, J. and Varga, C. 2005. Identity experience amongst progressive, gay Muslims in North America: A qualitative study within Al-Fatiha. Culture, Health and Sexuality, 7(2), 113-28.

Moehring, J.L. 1972. Communication Systems of a Goby-Shrimp Symbiosis. University of Hawaii.

Mollenkott, V.R. 2007. Omnigender: A Trans-religious Approach. Cleveland: Pilgrim Press.

Mollenkott, V.R. and Sheridan, V. 2003. Transgender Journeys. Cleveland: Pilgrim Press.

Moon, D. 2004. God, Sex, and Politics: Homosexuality and Everyday Theologies. Chicago: University of Chicago Press.

Moore, S. 2001. God's Beauty Parlour and Other Queer Spaces in and Around the Bible. Stanford: University of Stanford Press.

Morin, K.M. and Guelke, J.K. (eds) 2007. Women, Religion and Space: Global Perspectives on Gender and Faith. Syracuse, NY: Syracuse University Press.

Morris, B.J. 1993. Celebrating Jewish identity at festivals. Hot Wire, (January), 38. 
Morris, B.J. 1998. Ingathering the tribe. Off Our Backs, 28(4), 10-11.

Morris, B.J. 1999. Eden Built by Eves: The Culture of Women's Music Festivals. Los Angeles: Alyson.

Morris, B.J. 2005. Valuing womyn-only spaces. Feminist Studies, 31(3), 619-30.

Mrozik, S. 2002. The value of human differences: South Asian Buddhist contributions toward an embodied virtue theory. Journal of Buddhist Ethics, (9), 1-33.

Mrozik, S. 2006. Materializations of virtue: Buddhist discourses on bodies, in Bodily Citations: Religion and Judith Butler, edited by E.T. Armour and S.M. St. Ville. Chichester: Columbia University Press, 15-47.

Munt, S. R. 1998. Butch/Femme: Inside Lesbian Gender. London: Cassell.

Munt, S.R. 2007. Queer Attachments: The Cultural Politics of Shame. Aldershot: Ashgate.

Munt, S.R., Bassett, E.H. and O’Riordan, K. 2002. Virtually belonging: Risk, connectivity and coming out on-line. International Journal of Sexuality and Gender Studies, 7(2-3), 125-37.

Nahas, O. 2004. Yoesuf: An Islamic idea with Dutch quality. Journal of Gay and Lesbian Social Services, 16(1), 53-64.

Nash, C. J. 2005. Contesting Identity: Politics of gays and lesbians in Toronto in the 1970s. Gender, Place and Culture, 12(1), 113-35.

Nash, C.J. 2007. Material Entanglements: Queer Geographies and Trans Experience and Embodiment. [Conference paper]. Association of American Geographers Conference, San Francisco, April 2007.

Naz Project. 2000. Emerging Sexualities: Ten Testimonies. London: N. Project.

Neitz, M.J. 2000. Queering the dragonfest: Changing sexualities in a postpatriarchal religion. Sociology of Religion, 61(4), 369-91.

Nelson, J.B. 1992. Body Theology. Louisville, KY: Westminster John Knox Press.

Nelson, R. 2004. The Shrimp-Goby Chronicles [Online]. Available at: http://www. explorebiodiversity.com/Hawaii/Shrimp-goby/general/index.htm[accessed: 28 August 2008].

Nightingale, A. 2006. The nature of gender: Work, gender, and environment. Environment and Planning D: Society and Space, 24(2), 165-85.

NPL. No date. Naz Project London. [Online]. Available at: http://www.naz.org. uk [accessed: 3 March 2009].

Nussbaum, M.C. 2004. Hiding from Humanity: Disgust, Shame, and the Law. Princeton: Princeton University Press.

Office for National Statistics. 2001. Focus on Religion: Geographic Distribution - Minority Religions Mainly in London. [Online]. Acailable at: http://www. statistics.gov.uk/cci/nugget.asp?id=956 [accessed: 28 November 2007].

O'Leary, T. 2002. Foucault and the Art of Ethics. London: Continuum.

O'Brien, J. 2004. Wrestling the angel of contradiction: Queer Christian identities. Culture and Religion, 5(2), 179-202. 
O'Riordan, K. and Phillips, D. (eds) 2007. Queer Online: Media Technology and Sexuality. London: Peter Lang.

Olson, C. 1992. The Hermaphrodite in early Buddhism. Buddhist Studies Review, 9(1), 2-4.

Oppenheim, J. 1985. The Other World: Spiritualism and Psychical Research in England, 1850-1914. Cambridge: Cambridge University Press.

Orsi, R. 2002. The Madonna of 115th Street: Faith and Community in Italian Harlem, 1880-1950. New Haven: Yale University Press.

Oswin, N. 2005. Towards radical geographies of complicit queer futures. ACME: An International E-Journal for Critical Geographers, 3(2), 79-86.

Oswin, N. 2008. Critical geographies and the uses of sexuality: Deconstructing queer space. Progress in Human Geography, 32(1), 89-103.

Park, C. 2004. Religion and geography, in Routledge Companion to the Study of Religion, edited by J. Hinnells. London: Routledge, 439-55.

Pearson, J. (ed.) 2002. Belief Beyond Boundaries: Wicca, Celtic Spiritualities and the New Age. Aldershot: Ashgate in association with The Open University.

Peletz, M.G. 2006. Transgenderism and gender pluralism in southeast Asia since early modern times. Current Anthropology, 47(2), 309-40.

Peperzak, A.T. 1997. Beyond: The Philosophy of Emmanuel Levinas. Evanston, IL.: Northwestern University Press.

Perecman, E. and Curran, S.R. (eds) 2006. A Handbook for Social Science: Field Research: Essays and Bibliographic Sources on Research Design and Methods. London: SAGE.

Peterson, T.V. 2005. Gay men's spiritual experience in the leather community, in Gay Religion, edited by S. Thumma and E.R. Gray. Walnut Creek: AltaMira Press, 337-50.

The Pew Forum on Religion and Public Life. 2008. The Pew Forum on Religion and Public Life U.S. Religious Landscape Survey.[Online]. Available at: http:// religions.pewforum.org [accessed: 23 October 2008].

Phillips, R. 2005. Conservative Christians Identity and Same-sex Orientation: The Case of Gay Mormons. New York: Peter Lang.

Plummer, K. 2003. Intimate Citizenship: Private Decisions and Public Dialogues. Seattle: University of Washington Press.

Podmore, J. A. 2001. Lesbians in the crowd: Gender, sexuality and visibility along Montreal's Boul St-Laurent. Gender, Place and Culture, 8(4), 333-55.

Prosser, J. 1998. Second Skin: The Body Narrative of Transsexuality. New York: Columbia University.

Puar, J. 2007. Terrorist Assemblages: Homonationalism in Queer Times. Durham: Duke University Press.

Quackenbush, J. Transjubilant. [Online]. Available at: http://transjubilant. blogspot.com [accessed: 20 October 2008]. 


\section{BIBLIOGRAPHY}

The Quaker Lesbian and Gay Fellowship. 2003. QLGF Homepage. [Online]. Available at: http://www.qlgf.org.uk/quakers.htm [accessed: 28 October 2008].

Ramji, H. 2007. Dynamics of religion and gender amongst young British Muslims. Sociology, 41(6), 1171-89.

Rau, R. Rivflections. [Online]. Available at: http://rivflections.blogspot.com [accessed: 2 October 2008].

The Religious Society of Friends (Quakers) in Britain. 2008. Quakers in Britain [Online]. Available at: http:/ / www.quakerweek.org.uk/ [accessed: 28 October 2008].

Rice, A.N. 1999. The Physiology of Sex-Change in Coral Reef Fish. [Online: Department of Biology, Davidson College, NC]. Available at: http:// www.bio.davidson.edu/Courses/anphys/1999/Rice/Rice.htm [accessed: 6 September 2008].

Richardson, D. 1998. Sexuality and citizenship. Sociology, 32(1), 83-100.

Richardson, D. 2000a. Constructing sexual citizenship: Theorizing sexual rights. Critical Social Policy, 20(1), 105-35.

Richardson, D. 2000b. Rethinking Sexuality. London: Sage.

Riddell, C. 1991. The Findhorn Community, Creating a Human Identity for the 21st Century. Forres: Findhorn Press.

Robinson, G. 2008. In the Eye of the Storm. Norwich: Canterbury Press.

Roden, F. 2009. Jewish/Christian/Queer: Crossroads and Identities. Aldershot: Ashgate.

Roderick, T., McCammon, S.L., Long, T.E. and Allred, L.J. 1998. Behavioral aspects of homonegativity. Journal of Homosexuality, 36(1), 79-88.

Rodriguez,E.M. and Ouellette, S.C. 2000. Gay andlesbianChristians:Homosexual and religious identity integration in the members and participants of a gaypositive church. Journal for the Scientific Study of Religion, 39(3), 333-47.

Roof, W.C. 2001. Spiritual Marketplace: Baby Boomers and the Remaking of American Religion. Princeton: Princeton University Press.

Rose, G. 1999. Performing space, in Human Geography Today, edited by D. Massey, J. Allen and P. Sarre. Cambridge: Polity Press, 257-59.

Rose, N. 1999a. Governing the Soul: The Shaping of the Private Self. Second Edition. London: Free Association Books.

Rose, N. 1999b. Inventing Our Selves: Psychology, Power, and Personhood. Cambridge: Cambridge University Press.

Roseneil, S. 2000. Common Women, Uncommon Practices: The Queer Feminisms of Greenham. London: Cassell.

Rouhani, F. 2007. Religion, identity, and activism among transnational queer Muslims, in Geographies of Sexualities: Theory, Practices and Politics, edited by G. Brown, K. Browne and J. Lim. Aldershot: Ashgate, 169-80. 
Rowbotham, S. 2008. Edward Carpenter: A Life of Liberty and Love. London: Verso.

Royle, N. 2003. The Uncanny. London and New York: Routledge.

Rudy, K. 1997. Sex and the Church: Gender, Homosexuality, and the Transformation of Christian Ethics. Boston: Beacon Press.

Ruttenberg, D. 2009. The Passionate Torah: Sex and Judaism. New York: New York University Press.

Safra Project. 2001. SAFRA Project. [Online]. Available at: http://www. safraproject.org/ [accessed: 2009].

Safra Project. 2003. Initial Findings: Identifying the Difficulties Experienced by Muslim LBT Women in Accessing Social and Legal Services. London: S. Project.

Salaam Canada. Salaam, Queer Muslim Community. [Online]. Available at: http:// www.salaamcanada.org [accessed: 20 February 2009].

Salzman, T.A. and Lawler, M.G. 2008. The Sexual Person: Toward a Renewed Catholic Anthropology. Washington, DC: Georgetown University Press.

Samuel, B. 2002. Quaker Food?. [Online]. Available at: http://www.quakerinfo. com/quakfood.shtml [accessed: 13 February 2009].

Sangharakshita. 1990. The individual and the world today, in New Currents in Western Buddhism: The Inner Meaning of the Friends of the Western Buddhist Order, edited by Sangharakshita Glasgow: Windhorse Publications, 16-39.

Sangharakshita. 1995. Peace is a Fire. Second Edition. Birmingham: Windhorse. Sangharakshita. 2000. A Buddhist view of current world problems, in What Is the Sangha? The Nature of Spiritual Community, edited by Sangharakshita. Birmingham: Windhorse Publications, 235-42.

Schad, J. 2004. Queer Fish: Christian Unreason from Darwin to Derrida. Brighton: Sussex Academic Press.

Schalow, P.G. 1998. The legend of Kukai and the tradition of male love in Japanese Buddhism, in Queer Dharma: Voices of Gay Buddhists, edited by W. Leyland. San Francisco: Gay Sunshine Press, 91-106.

Schalow, P.G. 1998. Spiritual dimensions of male beauty in Japanese Buddhism, in Qeer Dharma: Voices of Gay Buddhists, edited by W. Leyland. San Francisco: Gay Sunshine Press, 107-24.

Schmidt, L. 2005. Restless Souls: The Making of American Spirituality from Emerson to Oprah. San Francisco: Harper Collins.

Schnoor, R.F. 2006. Being gay and Jewish: Negotiating intersecting identities. Sociology of Religion, 67(1), 43-60.

Seidman, S. (ed.) (1996) Queer Theory/Sociology. Cambridge, Mass.: Blackwell. Sen, A. 2006. Identity and Violence: The Illusion of Destiny. London: Allen Lane. Shannahan, D.S. 2009. Sexual ethics, marriage, and sexual autonomy: the landscapes for Muslimat and lesbian, gay, bisexual, and transgendered Muslims. Contemporary Islam, 3(1), 59-78. 
Sheridan, V. 2001. Crossing Over: Liberating the Transgendered Christians. Cleveland: Pilgrim Press.

Sherkat, D.E. 2002. Sexuality and religious commitment in the United States: An empirical examination. Journal for the Scientific Study of Religion, 41(2), 313-23.

Shneiderman, B. 1998. Treemaps for Space-constrained Visualization of Hierarchies. [Online: Maryland USA, Department of Computer Science]. Available at: http://www.cs.umd.edu/hcil/treemap-history/ [accessed: 10 December 2008].

Shokeid, M. 1995. A Gay Synagogue in New York. New York: Columbia University Press.

Siraj, A. 2006. On being homosexual and Muslim: Conflicts and challenges, in Islamic Masculinities, edited by L. Ouzgane. London: Zed Books, 202-16.

Siraj, A. 2009. The construction of the homosexual 'Other' by British Muslim heterosexuals. Contemporary Islam, 3(1), 41-57.

Skeggs, B. 2004. Class, Self, Culture. London: Routledge.

Smith, S. 2007. Buddhism and Same-Sex Love. [Conference paper]. Faith, Homophobia and Human Rights: Securing Legal Protection and Managing Conflicts, London.

Smith, S. 2008. Buddhism, Diversity and 'Race': Multiculturalism and Western Convert Buddhist Movements in East London - A Qualitative Study. London: Goldsmiths', University of London.

Speyer, A. no date. Riding the Metrospiritual Wave. [Online]. Available at: http:// www.beliefnet.com/story/177/story_17799.html [accessed: 26 November 2008].

Sreedhar, S. and Hand, M. 2006. The ethics of exclusion: Gender and politics at the Michigan Womyn's Music Festival, in Trans/Forming Feminisms: Trans Feminist Voices Speak Out, edited by K. Scott-Dixon. Toronto: Sumach Press, 161-69.

Starhawk. 1989. Feminist, earth based spirituality and eco-feminism, in Healing the Wounds: The Promise of Ecofeminism, edited by J. Plant. London: Green Print, 174-85.

Steere, D.V. (ed.) 1984. Quaker Spirituality: Selected Writings. Mahwah, N.J.: Paulist Press.

Stone, J.I. 2003. Nichiren's activist heirs: Sōka Gakkai, Risshō Kosekai, Nipponzan Myōhōji, in Action Dharma: New Studies in Engaged Buddhism, edited by C. Queen, C. Prebish and D. Keown. London: Routledge Curzon, 63-94. Stone, K. 2001a. Homosexuality and the Bible or queer reading? A response to Martti Nissinen. Theology and Sexuality, 7(14), 107-118.

Stone, K. 2001b. Queer Commentary and the Hebrew Bible. Sheffield: Sheffield Academic Press.

Stuart, E. 1992. Dare to Speak Love's Name. London: Hamish Hamilton. 
Stuart, E. 1995. Just Good Friends: Towards a Lesbian and Gay Theology of Relationships. London: Mowbray.

Stuart, E. 2003. Gay and Lesbian Theologies: Repetitions with Critical Difference. Aldershot: Ashgate.

Stuart, E., Braunston, A., Mcmahon, J. and Morrison, T. 1997. Religion is a Queer Thing. London: Cassell.

Subhuti. 1988. Buddhism for Today: A Portrait of a new Buddhist Movement. Glasgow: Windhorse Publications.

Subhuti. 1994. Sangharakshita: A New Voice in the Buddhist Tradition. Birmingham: Windhorse Publications.

Subhuti. 1995. Women, Men and Angels: An Inquiry Concerning the Relative Spiritual Aptitudes of Men and Women. Birmingham: Windhorse Publications.

Sullivan, N. 2003. A Critical Introduction to Queer Theory. Edinburgh: Edinburgh University Press.

Sutcliffe, S. 1995. The authority of the self in New Age religiosity: The example of the Findhorn Community. Diskus, 3(2), 23-42.

Sutcliffe, S. 2003a. Category formation and history of 'New Age'. Culture and Religion, 4(1), 5-29.

Sutcliffe, S. 2003b. Children of the New Age: A History of Spiritual Practices. London: Routledge.

Sweasey, P. 1997. From Queer to Eternity: Spirituality in the Lives of Lesbian, Gay and Bisexual People. London: Cassell.

Sweet, M.J. and Zwilling, L. 1993. The first medicalization: The taxonomy and etiology of queerness in classical Indian medicine. Journal of the History of Sexuality, 3(4), 590-607.

Tacey, D. 2004. The Spirituality Revolution: The Emergence of Contemporary Spirituality. London: Routledge.

Tanis, J. 2003. Trans-gendered: Theology, Ministry and Communities of Faith. Cleveland: The Pilgrim Press.

Taylor, C. 1991. The Ethics of Authenticity. Cambridge, MA.: Harvard University Press.

Taylor, C. 2007. A Secular Age. London: The Belknap Press of Harvard University Press.

Thatcher, A. 1993. Liberating Sex: Christian Sexual Theology. London: SPCK.

Thatcher, A. 1999. Marriage after Modernity: Christian Marriage in Postmodern Times. Sheffield: Sheffield Academic Press.

Thatcher, A. 2003. Norms, rules and steadfast love: Towards an inclusive theology of intimacy. Theology and Sexuality, 9(2), 230-41.

Thatcher, A. 2008. The Savage Text: The Use and Abuse of the Bible. Chichester: John Wiley and Sons. 
Thierry, S. 2005. Une Nuée de Témoins: Expériences de Vie et de Foi de Chrétien/ne/s Lesbiennes, Gays, Transgenres et de Leurs Proches. Montpellier: Edition Croix Arc en Ciel.

Thumma, S. 1991. Negotiating a religious identity: The case of the gay evangelical. Sociological Analysis, 52(4), 333-47.

Timoth, D.J. and Olsen, D.H. 2006. Tourism, Religion and Spiritual Journeys. London: Routledge.

Toft, A. 2009a. Bisexual Christians: The life-stories of a marginalised community, in Contemporary Christianity and LGBT Sexualities, edited by S.J. Hunt. Aldershot: Ashgate, 67-85.

Toft, A. 2009b. Negotiating identity: The life-narratives of bisexual Christians, in Narrative, Memory and Identities, edited by D. Robinson, P. Fisher, T. Yeadon-Lee, S.J. Robinson and P. Woodcock. Huddersfield: University of Huddersfield Press, 127-35.

Trzebiatowska, M. 2009. Common pathways, different lives: The 'coming out' narratives of Catholic nuns and lesbians in Poland, in Contemporary Christianity and LGBT Sexualities, edited by S.J. Hunt. Aldershot: Ashgate, 51-65.

Turner, B.S. 2007. Managing religions: State responses to religious diversity. Contemporary Islam, 1(2), 123-37.

Turner, T.C., Smith, M.A., Fisher, D. and Welser, H.T. 2005. Picturing usenet: Mapping computer-mediated collective action. Journal of Computer-Mediated Communication[Online], 10(4). Available at: http://jcmc.indiana.edu/vol10/ issue 4/turner.html.

Ulanah. 1995. Healing through my own eyes, in Talking Black: Lesbians of African and Asian Descent Speak Out, edited by V. Mason-John. London: Cassell, 126-39.

Usui, A. 2003. The role of women, in Global Citizens: The Soka Gakkai Movement in the World, edited by D. Machacek and B. Wilson. Oxford: Oxford University Press, 153-204.

Vahanian, G. 1961. The Death of God: The Culture of Our Post-Christian Era. New York: Braziller.

Valentine, D. 2007. Imagining Transgender: An Ethnography of a Category. London: Duke University Press.

Valentine, G. 1993. Negotiating and managing multiple sexual identities: Lesbian time management strategies. Transactions of the Institute of British Geographers, 18(2), 237-48.

Valentine, G. 1996. (Re)negotiating the 'Heterosexual Street': Lesbian productions of space, in Body Space: Destabilising Geographies of Gender and Sexualities, edited by N. Duncan. London: Routledge, 146-55.

Van Dyke, A. 1992. The Search for a Woman-Centred Spirituality. New York: New York University Press. 
Vidal-Ortiz, S. 2008. 'The Puerto Rican way is more tolerant': Constructions and uses of 'homophobia' among Santeria practitioners across ethno-racial and national identification. Sexualities, 11(4), 476-95.

Vincett, G., Sharma, S. and Aune, K. 2008. Introduction: Women, religion and secularization: One size does not fit all, in Women and Religion in the West: Challenging Secularization, edited by K. Aune, S. Sharma and G. Vincett. Aldershot: Ashgate, 1-19.

Wakeford, N. 1997. Cyberqueer, in Lesbian and Gay Studies: A Critical Introduction, edited by A. Medhurst and S.R. Munt. London: Cassell, 20-38.

Walker, A. 1994. The Kingdom Within: A Guide to the Spiritual Work of the Findhorn Community. Forres: Findhorn Press.

Wallis, R. 1984. The Elementary Forms of the New Religious Life. London: Routledge and Kegan Paul.

Walton, G. 2006. 'Fag church': Men who integrate gay and Christian identities. Journal of Homosexuality, 51(2), 1-17.

Warner, M. 1999. The Trouble with Normal: Sex, Politics, and the Ethics of Queer Life. New York: The Free Press.

Waterhouse, H. 1997. Buddhism in Bath: Adaptation and Authority. Leeds: Department of Theology and Religious Studies, Community Religions Project, University of Leeds.

Waterhouse, H. 1999. Who says so? Legitimacy and authenticity in British Buddhism. Scottish Journal of Religious Studies, 20(1), 19-36.

Weeks, J. 2000. Making Sexual History. Cambridge: Polity.

Weeks, J. 2007. The World We Have Won. London: Routledge.

Weening, H. 1995. Meeting the Spirit: An Introduction to Quaker Beliefs and Practices. [Online]. Available at: http://www.fwccemes.org/quakers/meeting-the-spirit [accessed: 1 November 2008].

Welch, C. 2007. Spirituality and social change at Greenham Common Peace Camp. Journal for Faith, Spirituality and Social Change, 1(1), 50-67.

Wertheim, M. 1999. The Pearly Gates of Cyberspace: A History of Space from Dante to the Internet. New York: W.W. Norton.

Wertheim, M. 1999. The Pearly Gates of Cyberspace: A History of Space from Dante to the Internet. New York: W. W. Norton and Company.

West, W. 2000. Psychotherapy and Spirituality: Crossing the Line between Therapy and Religion. London: SAGE.

White, D. and White, O.K. 2004. Queer Christian confessions: Spiritual autobiographies of gay Christians. Culture and Religion, 5(2), 203-17.

Wilchins, R.A. 1997. Read my Lips: Sexual Subversion and the End of Gender. Ithaca, NY: Firebrand Books.

Wilcox, M.M. 2001. Of markets and missions: The early history of the Metropolitan Community Church. Religion and American Culture, 11(1), 83108. 
Wilcox, M.M. 2002. When Sheila's a lesbian: Religious individualism among Lesbian, Gay, Bisexual, and Transgender Christians. Sociology of Religion, 63(4), 497-513.

Wilcox, M.M. 2003. Coming Out In Christianity: Religion, Identity, and Community. Bloomington: Indiana University Press.

Wilcox, M.M. 2005. A religion of one's own: Gender and LGBT religiosities, in Gay Religion, edited by S. Thumma and E.R. Gray. Walnut Creek: AltaMira Press, 203-20.

Wilcox, M.M. 2006. Outlaws or in-laws? Queer theory, LGBT studies, and religious studies. Journal of Homosexuality, 52(1-2), 73-100.

Wilcox, M.M. 2009. Queer Women and Religious Individualism. Bloomington, IN: Indiana University Press.

Wuthnow, R. 2000. After Heaven: Spirituality in America Since the 1950s. Berkeley: University of California Press.

The Yearly Meeting of the Religious Society of Friends (Quakers) in Britain. 1994. Quaker Faith and Practice: The Book of Dicipline of the Yearly Meeting of the Religious Society of Friends (Quakers) in Britain. Third Edition. London. Available at: http://qfp.quakerweb.org.uk Yip, A.K.T. 1996a. Gay Christians and their participation in the gay subculture. Deviant Behavior, 17(3), 297-318.

Yip, A.K.T. 1996b. Gay Christian couples and blessing ceremonies. Theology and Sexuality, 2(4), 100-117.

Yip, A.K.T. 1997a. Attacking the attacker: Gay Christians talk back. British Journal of Sociology, 48(1), 113-27.

Yip, A.K.T. 1997b. Dare to differ: Lesbian and gay Catholics' assessment of official Catholic positions on sexuality. Sociology of Religion, 58(2), 165-80.

Yip, A.K.T. 1997c. Gay Male Christian Couples: Life Stories. Westport, CT: Praeger.

Yip, A.K.T. 1997d. Gay male Christian couples and sexual exclusivity. Sociology, 31(2), 289-306.

Yip, A.K.T. 1998. Gay Christians and their perceptions of the Christians community in relation to their sexuality. Theology and Sexuality, 8(2), 40-51.

Yip, A.K.T. 1999a. The politics of counter-rejection: Gay Christians and the Church. Journal of Homosexuality, 37(2), 47-63.

Yip, A.K.T. 1999b. Listening to lived experiences: The way forward in the debate on homosexuality, in Sociology, Theology and the Curriculum, edited by L.J. Francis. London: Cassell, 187-96.

Yip, A.K.T. 2000. Leaving the church to keep my faith: The lived experiences of non-heterosexual Christians, in Joining and Leaving Religion: Research Perspectives, edited by L.J. Francis and Y.J. Katz. Leominster: Gracewing, 129-46.

Yip, A.K.T. 2002. The persistence of faith among non-heterosexual Christians: Evidence for the neosecularization thesis of religious transformation. Journal for the Scientific Study of Religion, 41(2), 199-212. 
Yip, A.K.T. 2003a. The self as the basis of religious faith: Spirituality of gay, lesbian, and bisexual Christians, in Predicting Religion: Mainstream and Margins in the West, edited by G. Davie, L. Woodhead and P. Heelas. London: Ashgate, 135-46.

Yip, A.K.T. 2003b. Spirituality and sexuality: The religious beliefs of nonheterosexual Christians in Great Britain. Theology and Sexuality, 9(2), 137-54.

Yip, A.K.T. 2004a. Embracing Allah and sexuality? South Asian non-heterosexual Muslims in Britain, in South Asians in the Diaspora, edited by P. Kumar and K. Jacobsen. Leiden: EJ Brill, 294-310.

Yip, A.K.T.2004b. Negotiating space with family and kin in identity construction: The narratives of British non-heterosexual Muslims. The Sociological Review, 52(3), 336-50.

Yip, A.K.T. 2004c. Same-sex marriage: Contrasting perspectives among lesbian, gay, and bisexual Christians. Feminism and Psychology, 14(1), 173-80.

Yip, A.K.T. 2005a. Queering religious texts: An exploration of British nonheterosexual Christians' and Muslims' strategy of constructing sexualityaffirming hermeneutics. Sociology, 39(1), 47-65.

Yip, A.K.T. 2005b. Religion and the politics of spirituality/sexuality: Reflections on researching British lesbian, gay, and bisexual Christians and Muslims. Fieldwork in Religion, 1(3), 271-89.

Yip, A.K.T. 2006. Liens familiaux: Réflexions sur les experiences vécues de LGB musulmans britanniques, in Homoparentalités: Approches Scientifiques et Politiques, edited by A. Cadoret, M. Gross, C. Mécary and B. Perreau. Paris: Presses Universitaires de France, 75-86.

Yip, A.K.T. 2007. Changing religion, changing faith: Reflections on the transformative strategies of lesbian, gay, and bisexual Christians and Muslims. Journal of Faith, Spirituality and Social Change [Online], 1. Available at: http:// www.fsscnference.org.uk/journal/1-1.htm.

Yip, A.K.T. 2008a. The quest for intimate/sexual citizenship: Lived experiences of lesbian and bisexual Muslim women. Contemporary Islam, 2(2), 103-29.

Yip, A.K.T. 2008b. Researching lesbian, gay, and bisexual Christians and Muslims: Some thematic reflections. Sociological Research Online [Online], 13(1). Available at: http://www.soresonline.org.uk/13/1/5.html

Yip, A.K.T. (ed.) 2009a. Special issue: Islam and sexuality. Contemporary Islam, 3(1).

Yip, A.K.T. 2009b. Islam and sexuality: Orthodoxy and contestations. Contemporary Islam, 3(1), 1-5.

Yip, A.K.T. and Keenan, M. 2004. By name united, by sex divided: A brief analysis of the current crisis facing the Anglican Communion. Sociological Research Online [Online], 9(1). Available at: http://www.soresonline.org. uk/9/1/yip.html 


\section{BIBLIOGRAPHY}

Yip, A.K.T. and Keenan, M. 2009. Transgendering Christianity: Gender-variant Christians as visionaries, in Contemporary Christianity and LGBT Sexualities, edited by S.J. Hunt. Aldershot: Ashgate, 87-101.

Zickmund, S. 2000. Approaching the radical Other: The discursive culture of cyberhate, in The Cybercultures Reader, edited by D. Bell and B.M. Kennedy. London: Routledge, 237-53.

Zournazi, M. 2002. Hope: New Pbilosophies for Change. London: Lawrence and Wishart.

Zwilling, L. 1998. Avoidance and exclusion: Same-sex sexuality in Indian Buddhism, in Queer Dharma: Voices of Gay Buddhists, edited by W. Leyland. San Francisco: Gay Sunshine Press, 45-54. 



\section{Index}

Abraham, I 48

Abrahamic religions 11, 125, 171, 233, 243

agnosticism 16, 29

Christian agnostic 227 Al-Masjid al-haram, the 103 Althaus-Reid, M 219

American Psychological Association, the (APA) 77, 78

Anthony, Susan B 52

anti-Semitism 41, 161, 167

atheism see also secularism 9, 16, 224

Bergson, Henri 21, 22, 25

Bible, the 37, 41, 47, 63, 180, see also The Old Testament

and heterosexuality 37

bisexuality 1, 3, 38, 39, 45, 63, 65, 130, 133, 137, 179, 194, 197, 201

biphobia 235, 237

exclusion of bisexual women from lesbian groups 195

Bitch (artist) 146

blogs 199, 218, 226

Broadhead, George 231

Browne, Kath 20, 32, 45, 49, 227, 234

Bryson, M 230

Buddhism 1, 27, 32, 38, 46, 81, 100, $111-14,115,131,134,137$, $138,155,217,237$

Buddhahood 116, 120, 134, 137

Buddhanature 116, 120, 137

Buddhist ethics 118-19, 127-8 and celibacy 111

Community of Interbeing $\mathrm{UK}$, the (CoI) 131-2

Friends of the Western Buddhist

Order, the (FWBO) 114-15, 123, 127-30, 132, 133, 135,

136, 137 see also WBO

homosexuality in Buddhist

scriptures 112-13

LGBTQI Buddhists 113-14, 115, 124-5, 132, 137-8

Network of Buddhist Organisations, the 114

Nichiren Buddhism 114, 117, 119, 122, 125, 127

Pali Canon, the 113

queering of Buddhism 138

sangha 111, 125, 128, 129, 132,

133

Sōka Gakekai International - United

Kingdom, the (SGI-UK) 114,

115, 117, 120, 126-27, 134-35

see also Nichiren Buddhism

Three Jewels, the 128

Tibetan Buddhism 112, 114, 118, 121,130

UK Buddhist scene 114

Western Buddhist Order, the (WBO)

114 n 4, 115, 116, 118, 120,

$128,129,133,134$ see also

FWBO

Zen Buddhism 114, 131, 214

Burke, Edmund 6

Butler, Judith 22 
Cabezón, J.I 112

Caddy, Peter and Eileen 171

Canada 84 n 6, 96, 117, 214

capitalism 8, 16, 77, 200

and selfhood as a practice of

freedom 10, 16

late capitalism 16, 192

Carpenter, Edward 14

Celibacy 111, 125, 229

Christian church, the 44, 120,163, 165, 166, 179, 237, 239

Metropolitan community church, the 46

Christian Quakers see Quakers

Christianity 36-40, 45, 123, 159, 238, 243

Catholicism 13, 14, 15, 60, 163, 215-16

discursive linking of sodomitical practices to

Roman Catholicism 15

eroticisation of Catholicism 15

Sedevacantist Catholicism 219

Christian martyrdom 14

Christian normativity 164

Jesus 39, 41, 120, 163, 164, 209, 216

LGBTQI Christians 43, 45-6, 47, 108

Lesbian and Gay Christian

Movement, the 43, 108

LGBTQI Christian support networks 44

at Michfest 163-66

Post-Christian 9, 11, 54, 204

Protestant 51, 53, 76, 77, 197

state Christianity 11, 244

decline of state Christianity 11

Civil Partnerships Act, the 127

class 2, 48, 64-6, 89, 95, 116, 137,

138, 222, 236, 242 see also

social justice middle class/petit-bourgeoisie 56, 58, 64, 66-7, 73, 74, 77, 81, 107, $115,125,137,138,174,190$, 197

bourgeoisification 77-8

working class 58, 66

Cognitive Behavioural Therapy

(CBT) 213

coming out 3, 17, 86-7, 90, 163-4, 182-3, 192, 202, 218, 224, 227 computer mediated communication see also the internet 226 consumerism 16, 17, 74

Corless, R 111, 112, 116

Cox, Ashley 5

cultural capital 192

cultural geography 2, 58

Dalai Lama, the 130 see also Tibetan Buddhism

Declaration for the Universal

Decriminalisation of

Homosexuality, the 231

Deleuze, Gilles 20, 21, 25, 26

digital embodiment 226 see also

Second Life

digital technology 200, 224, 227

Dinnie, Elizabeth 32, 176, 177, 181, 234

divine, the 31 n 22, 40, 41, 47, 93, 98, 99-100, 147, 183, 206, 207-10, 211, 213, 215-16, 230

Duggan, Lisa 17

Durkheim, Emile 204

Erdem, E 230

ethics 7, 17, 32, 40, 41-2, 47, 57, 76, $112,113,117-19,132,148$

Feldman, Maxine 146

feminism 12, 58, 108, 135, 137, 140, $156,189,242$ 
eco-feminism 13, 151

feminist separatism 12, 13, 139, 141

feminist spiritualities 150, 163 evangelical radical lesbian feminism 163

lesbian feminism 3, 12, 147, 156, 163

Findhorn Foundation, the 1, 27, 32, $154,169,170-74,176,178$, 184, 185, 193, 197, 207, 236, 237

campus in Forres 171

campuses in Moray 171

Diva 187

experience week 174-5, 177-8, 186-7, 189, 190-91, 192, 194

FAGS, The (Findhorn Gay Men's Society) 187

heterosexualisation of Findhorn space 181,196

lesbian and gay spaces at

Findhorn 175, 182, 185-96

absence of a formal LGBTQI organisation within the community 176

New Findhorn Association, the 172,173 relationships and sexual arrangements in the Findhorn community 174-6, 196

resident population 172

Foucault, Michel 11, 17

Fox, George 52, 78, 79

Fry, Elizabeth 52

FWBO, the see Buddhism

Gay Pride see Pride

gay priests 19, 42

Gergen, Kenneth 74

Giddens, Anthony 10 n 9, 74

Glastonbury 140 globalisation 113

Great Britain 12, 26, 51, 52, 68, 77, $81,83,84,107,108,114,125$, 127, 131, 138, 163, 201, 204, 229, 238

Green Movement, the 12 see also ecofeminism

Greenham Common peace camp, the 12-13

Greenham women 13

Grosz, Elizabeth 20, 21

Gwyn, Douglas 74, 75

Hadith, the 82

Haj 103

Hall, Radclyffe 14, 15

Harrison, Rex 24

Harvey, P 112

Hebrew 159, 161

feminine Hebrew 161

Heelas, P 10, 11

Herman, Thomas 203

heteronormativity $22,23,36,38,39$, $42,45,46,49,73,82,86,91$, $92,113,127,129,130,132$, 136, 188, 230, 235, 236, 237, 240, 244

heterosexism 36, 45, 89, 147 see also homonegativity

Hine, Christine 202

HIV/AIDS 73, 113, 186, 187, 192

Hobbs, J.P 3, 4

holy ordinary, the 213

homonegativity $37,45-6,48,49,92$, 238 see also heterosexism and homophobia

homonormativity 17, 107, 117, 219, 230, 235, 236

homophobia 18, 19, 37 n 3, 44, 63, $66,73,95,141,147,187,191$, 202, 216, 219, 230, 231, 237, 240 see also homonegativity 
homosexuality $14,15,36,37,38,41$, $42,45,47,60,62,63,74,82$, 87, 112-13, 129, 130, 32, 138, $155,183,200,239$

as a manifestation of Western society $82-3$

Hoover, Stuart 203

human rights $36,43,44,49,96,130$, 231

identity politics 3, 36, 108 queering of sexual and gender definitions 237

Ikeda, Daisaku 126, 134, 135 individualism 9, 75, 77, 192, 203 religious individualism 42, 47, 204

Integral Life Practice 212, 214 intellectual capital 89

Internet, the 1, 28, 57, 129, 200, 2012, 205, 212, 216, 217, 218, 219, 224, 226, 227 see also online worlds and virtual worlds anonymity of 218 as democratising 222 as inherently spiritual 203 queer spiritual internet practices

213, 230

religion and the internet 202-4 as research tool 218 social networking sites 199, 205 n

4, 227

Facebook 205, 215

Gaia 205, 217

MyOutSpirit 205, 217, 227

White Crane, the 227 intersectionality $2,83,109,181$ intersex 1, 3, 12, 45, 137, 167, 170, 207, 220, 224, 227, 235 see also monogenderism intimacy 23, 26, 38, 39, 40, 90
Islam 27, 32, 36, 38, 46, 48, 81-3, 92, 94, 95, 97, 99, 100, 102, 109, $123,181,238$ Allah 82, 83, 85, 87, 90, 94, 101, 103, 109

and the censuring of homosexuality 82 Islamic practice of ijtihad 42,90 Islamophobia 48, 238 A Jibad for Love 82 LGBTQI Muslims 19, 48, 82, 83, $86,88,90,91,92,96,108,109$, 176

LGBTQI Muslim communities 83

Mosque, the 94, 101-5, 238 Muslim LGBTQI support networks 105, 107, 108 Imaan 84, 96, 105, 107, 108 Naz Project, the 84, 95, 105 Safra Project, the 84, 105 the Prophet Mohammad 39 'queering' of Islamic religious texts 90

Ivakhiv, A 238

Jackson, P.A 113

Jamal, A 82

James, Patrick 30, 32

Jenzen, Olu 23, 32

Judaism 36, 38, 46, 139, 152, 159, 179, 220

Bat/Bar Mitzvahs 160

Jewish ritual 159, 161

Jewish womyn 147, 159, 161-2

Jewishness 152, 159, 160, 162, 163

Reconstructionist Judaism 220

Shabbat, the 159-62

Torah study 162, 220-222 Judeo-Christian traditions 178 Jumma 104 
Kant, Immanuel 6, 7, 20

karma 112, 113, 119

kathoey 113 see also pandaka

Keating, Father Thomas 214, 215

Kendall, L 140, 141, 163

Khalid, Amna 32, 83, 84, 85, 176, 234

Kong, L 238

Ladies of Llangollen, the 13

Plas Newydd 13

Lasch, Christopher 74

Lefebvre, Henri 2

lesbian/lesbian women $3,12,14,15$, 19, 35, 36, 44, 47, 57, 58, 61, $66,89,90,93,97,115,123-4$, 129, 130, 133, 137, 139, 142, $148,153,155,156,161,163$, 164, 167, 174-5, 177, 179, 181-2, 187, 188, 191, 195, 234 see also lesbian feminism

lesbian feminist separatism 12 , 139 see also Michfest womynborn womyn policy

lesbian sexuality 141, 175 lesbianism 112, 130, 153

lesbians as a tribe $145,147,149$ tension between lesbian

communities and Christianity 165-6

lesbian and gay believers 44, 45

Levinas, Emmanuel 26

LGB/LGBTQI visibility 35, 105, 130, 161, 185, 189, 194, 196, 197

\section{LGBTQI}

identities 16, 91, 107, 111, 115, 116, 117, 123, 137, 218, 219

politics $17,19,35,46,65,66,72$, 78,196

rights $16,81,95,96$ liberalism 16, 17, 42, 60, 66, 76, 77, 81, 191 see also Quaker liberalism

Lorde, A 93

Lotus Sütra, the 125

Lynch, Gordon 204, 229

Lyotard, Jean-François 7

Machacek, D.W 185

Maclean, Dorothy 171

Marler, P.L 239

marginalisation 23, 92, 93, 125, 129, 130, 137, 138, 161, 167, 229, 236, 237, 240, 243

multiple marginal identities 85,88 , 89,109

marriage 40, 47, 77 n 13, 82, 108, $118,127,132,160$

marriage of convenience 87-8

Maslow, A.H 7

meditation $21,54,81,118,123,124$, 151, 158, 172, 174, 186, 207, 212, 215

Michfest 139-41, 144, 147, 149, 151, $153,156,158,159,161,163$, 164, 166, 167, 237

altars at Michfest 147, 149, 150, 158

candlelight concert 146-7

Dianic spiritualities at Michfest 139, 140, 146, 163

Elders at Michfest 144, 145

Michigan Magic 149, 156-8

as sacred $140,151-2$

the Shabbat, at Michfest 159-60, 162

spectacle spiritualities at Michfest 145-9

Twilight Zone 156

womyn-born womyn policy 139

n 2, 141, 144 see also feminist separatism 
Michigan Womyn's Music Festival see Michfest

Moehring, Lynn 5

Mollenkott, V.R 38

monogamy 39, 89, 118-19, 129

monosexism 235

monogenderism 235 see also

transphobia and intersex

Morris, Bonnie 159, 161

Mott, Lucretia 52

Mrozik, S 112

multi-faith 29, 30

Munday, Philip 5

Munt, Sally R. 32, 35, 231, 234, 237, 240

Murphy, Eddie 24

Muslim 1, 18, 29, 81-2, 85, 86, 89, $92,95,96,100,102,103,107$, 143, 180, 231 see also Islam

Muslim culture 86

Muslim women 99, 108

mysticism 51, 74, 100, 197, 206

nationalism 43, 113

Nayler, James 52

Nelson, Rob 5

New Age Spiritualities 11, 100, 169, 170, 174, 178, 182, 183, 190, 191, 197

Course on Miracles, the 100

New Age individualism 191, 192

New Age normativity 192

and selfhood 179

New Religious Movements 141, 185, 196

Nietzsche, Friedrich 9

Nightingale, A 151

non-aligned faith activities 1

at Michfest 140, 165

Dianic spiritualities see Michfest

Wicca 13, 140, 143, 163, 165, 203 non-aligned spirituality curious, the 199, 205, 213, 215, 216, 230 see also spiritual but not religious

Old Testament, the 39, 161

Ten Commandments, the 54 online worlds 29, 205, 218, 225 see also Second Life and virtual worlds

ordinary transcendence 156, 206, 211, 241 see also extra/ordinary spiritualities

paganism 19, 143, 154, 163, 165, 166, 218, 220

Gaia (earth) 13

Neo-Paganism 13, 14, 29

pandaka 113 see also kathoey

patriarchy/patriarchal norms 9, 13, 78, 140, 147, 148, 161, 162, 163, 164 see also the Old

Testament

performativity 2

Pew research Foundation, the 214 pilgrimage $8,103,141$

political activism 3. 76, 192, 194, 201, 237

political left, the 17, 204, 229

popular culture 74, 202, 203, 204

praying $94,95,98,99,101,102,103$, 105,215

Pride 8, 67-8, 69, 72, 117

in Brighton and Hove 67, 68

in London 105

Pride marches 67

privacy $58,59,60,189,226$

ideologies of privacy 196

sexuality as private 50,175

privatisation of sexual

practices 185

Puar, J 42, 43

pushmi-pullyu, the 24 
Quakers 1, 13, 27, 51-6, 60, 63, 72, 77,237

Britain yearly Meeting, the 53

Friends Homosexual Fellowship, the 63

Friends for Lesbian, Gay, Bisexual, Transgender and Queer Concerns, US, the 56

LGBTQI Quakers 56, 58, 63, 67, 71,73

Quaker Bisexual Group, the 63

Quaker discipline 73

Quaker Faith and Practice 53, 62

Quaker Lesbian and Gay

Fellowship, the 56, 63

Quaker liberalism 64, 66, 74, 75

Quaker manners 63-7

Quaker testimonies 55-6

Quaker tolerance 53, 60, 63, 67

Quaker wedding ceremonies for same-sex couples (UK) 77

Quaker Witness 55, 77 n 13

Quaker worship/the Meeting for Worship 54-6, 73, 75

Quakerism 52, 63, 64, 65, 66, 68, 69, 74, 76, 77

and selfhood 72, 73, 77

Religious Society of Friends, the see Quakers

Towards a Quaker View of Sex 60, 62-3

queer $1 \mathrm{n} 2,19,21,25,138,167,191$, $229,233-7$

as a theoretical term $23,58,132$,

201, 234

queer scholarship 166, 202

as an umbrella term $176 \mathrm{n}$ 4, 201

Queer Spiritual Spaces website, the

$28,29,205$

quest culture 203

Qur'an, the 37, 82, 89 racism 41, 48, 66, 238

Rainbow Bridge, the 190

religion 8-12, 16, 27, 43, 203

geographies of religion 233, 240, 241, 243, 244

and the internet 202-4

intolerance of religion 42

lived religion 201, 213

religious practice $10,124,159$, 161, 167, 200, 207, 214, $215,224,230$

mainstream religion 15, 32, 181 as opposed to spirituality 9, 136 organised religions $35,36,81,82$, 111,155

religious communities $35,36,38$, $39,42,43,45,46,237$

religious idealism 14 religious institutions 200, 203, 237, 238, 239, 240, 243, 244 religious orthodoxy 44, 49, 74, 99, 107, 109

religious surfers 203, 216

religious texts $36,37,39-42,47$, $82,89,90,131$

scriptural studies 36, 42.45

Religion and Society programme, the 18,26 n 21

religiosity $35 \mathrm{n}$ 1, 47, 49, 76, 230, 237

Religious Society of Friends, the see

Quakers

Revolutionary Wisdom 209-10, 217 ritual 7, 76, 97, 98, 100, 101, 103, $122,123,139,140,145,146$, $147,148,149,150,154,157$, 166, 167, 169, 173, 174, 178

healing 144-5, 146

Jewish 159, 161

of silence $66,72,76$

water 146

romanticism 11, 13, 17

Rowbotham, Sheila 14 
Royle, Nicholas 22, 25

rural, the 194, 196, 197

protestant, presbyterian rurality 197

rural Scotland 174, 185, 189, 190, 196

Ruskin, John 14

S\&M/BDSM 156, 185

sacred, the 9,12,139,152,153,163, 211, 239, 241

sacred ground 147, 151

sacred ordinary, the 149, 150, 157

Sangharakshita 127, 128, 129, 136

Scotland 1, 27, 169, 171, 174, 185, 189, 190, 196

SCUBA diving 4, 7, 26

Second Life 29, 30, 58, 201, 205, 220, 222, 227 see also virtual worlds and online worlds use of an avatar in Second Life

31 n 22, 207, 224, 226 see also

digital embodiment

sects $15,53,175$

secularism see also atheism 8, 9, 16,

17,44

secularisation 10, 136, 241 self

New Age selfhood 179

Quaker selfhood 72, 73, 77

self-help 200

self-sacrifice 16, 101

self-spirituality see New Age

subjectivization thesis 10

turn to self 10

sex $15,40,85,89,91,95,97,118$, 123, 124, 130, 131, 132, 153, 154, 155, 156, 184, 185, 197, 212, 218, 220, 230

Buddhism as sex-negative 111 sex for the purpose of 'soulunion' 14 sex and spirituality 14, 40, 97, 153, 164, 167, 183 sex as ritual 154, 167

sexual conservatism 190

sexual morality $63,77,170,180$, 184

sexual difference $35,43,44,49,63$, $64,81,82,151,192,231,234$, 236, 237

sexual diversity $14,15,16,35$

sexual freedoms 179, 185, 190

and New Age 179, 190

sexual identities $85,117,123,125$, 129, 179-80, 181, 185, 234, 235, 236

sexual liberalism 35

sexual minorities 95, 105

non-hegemonic sexualities 174 , 176

sexual orientation $77,85,91-2,96$, 105, 108, 116, 117, 123, 214

same-sex relationships $3,38,41$, $60,127,174,175,191$

sexual theology $36,40,90$

shame 15, 16, 42, 43, 45, 56, 93

Shari'ah, the 82, 89

Smith, Sharon 32, 114, 115, 137, 234

social justice 46, 49, 52, 64, 95, 103, 109 see also class

social networking sites 199, 205 n 4, 227 see also Facebook

sociologists of religion 11, 18

Song of Songs, the 39

soul, the 99, 105, 180, 182, 196

space 2, 240

cyberspace 26,203

as duration 21-2

as dynamic and interactive 2, 8

everyday spaces 241

festival spaces 140, 145, 161, 162

heteronormative spaces 45

internal space 55,121 
LGBTQI spaces 104, 123

online spaces 218

personalised space 104

queer spiritual spaces 20-6, 27,

43, 78, 138, 231

queer spiritual spaces as

capricious 20

queer spiritual spaces and the sodomitical sublime 8

queer spiritual spaces online 205

religious spaces $43,46,49,105$, 163, 241

sacred spaces 7, 153, 232, 239,

240, 241

female sacral space 13,144

patriarchal sacred spaces 9

spiritual spaces $1-2,7,32,43,46$,

101-5, 120-23, 136, 148, 236,

$240,242,245$

virtual space 29, 205, 226, 240 see

also online spaces

spatial theory 2

spiritual

everyday space as spiritual 241

spiritual cosmopolitanism 217 , 229

spiritual exploration 174, 218, 219

spiritual life 7, 128, 193, 214

spiritual but not religious 199 ,

200,230

spiritual seekers 10, 27, 205, 235, 237

spiritual spaces $1-2,7,32,43,46$, 101-5, 120-23, 136, 148, 236, $240,242,245$

use of spaces to achieve spiritual

connections 242

spirituality

Aboriginal spiritualities 13

dyke spiritualities 166 earth-based spiritualities 150, 151, 199

and the erotic 183-4

and the 'everyday' 178

extra/ordinary spiritualities 159 see also ordinary transcendence goddess spiritualities 146, 150, 154, 163

LGBTQI religiosity/spirituality 36, 45, 49 see also queer spiritualities

and multiple alignments 214 , 229

and research focus on homosexuality 36

spirituality within LGBTQI community spaces 48

Native American spiritualities 13, 144, 146, 217

personal spirituality 103, 169 queer spiritualities 12-20, 23, 25, $35,237,238,243$

sex as part of spirituality 14,40 , $97,153,164,167,183$

spectacle spirituality 145-9, 165

spiritualities of life see New Age

Stewart, Potter 10

story of Lot, the 37, 82, 89, 90

Strachey, Lytton 14

string theory 22

sublime, the 3, 6, 7, 32

the sodomitical sublime $6-8$

Sufism 99, 100

supernatural, the $8,24,98$

Sutcliffe, S 169, 170

Swiss, Andrew 203

Tacey, David 11

Tatchell, Peter 77

Taoism 220

Thailand 113

Thatcher, A 41 
theology 3, 36, 40-41, 45, 74, 90 see also sexual theology heteronormative theology 39 theological capital 36, 40, 44, 46, 89

Thich, Nhat Hanh 131, 132

trans people $3,12,38,45,83,99$, $125,130,135,137,138,141$, $167,201,207,212,215,225$, 226, 227, 235

transgenderism 38, 113, 224

transphobia 107, 202, 219, 237 see also monogenderism

Trekki, Ali Abdussalam 231

uncanny, the $7,17,21,22,23,25,26$

Unitarian Universalism 3, 57

United States, the 12, 26, 52, 56, 58, $71,108,127,161,164,201$, 204, 214

US Religious Landscape Survey, the 214

Usui, A 126

Vahanian, Gabriel 9
Van Dyke, A 147, 150, 163

'Venus in the Cloister; or, the Nun in her Smock' 15

Vinaya, the 112

virtual believers 27

virtual ethnography 202

virtual worlds 205, 226, 240 see also the internet, online worlds and Second Life

Waterhouse, H 131

WBO, the see Buddhism

Welch, Christina 13

Wertheim, Margaret 203

White, Heather 32, 56, 156, 207, 211, $212,214,218,219,224,227$, 234

Wilcox, M.M 47, 139, 163, 166, 167, $185,237,243$

Wolfenden report, the 61

Womanhood 147

womyn $139 \mathrm{n} 1,167$

Yip, Andrew K.T 18, 32, 44, 48, 81, $84,232,238$ n 5 